\title{
DEVELOPING NEW AND OPTIMIZING CURRENT TEST METHODS TO EVALUATE SULPHIDE-BEARING AGGREGATE
}

\author{
by \\ Mona El-Mosallamy, \\ M.Sc., Cairo University, 2013 \\ BSc, Cairo University, 2008
}

\author{
A dissertation \\ presented to Ryerson University \\ in partial fulfillment of the \\ requirements for the degree of \\ Doctor of Philosophy \\ in the program of \\ Civil Engineering
}

Toronto, Ontario, Canada, 2019

C Mona El-Mosallamy, 2019 


\section{Declaration of Authorship}

I hereby declare that I am the sole author of this dissertation. This is a true copy of the dissertation, including any required final revisions, as accepted by my examiners.

I authorize Ryerson University to lend this dissertation to other institutions or individuals for the purpose of scholarly research.

I further authorize Ryerson University to reproduce this dissertation by photocopying or by other means, in total or in part, at the request of other institutions or individuals for the purpose of scholarly research.

I understand that my dissertation may be made electronically available to the public. 


\begin{abstract}
DEVELOPING NEW AND OPTIMIZING CURRENT TEST METHODS TO EVALUATE SULPHIDE-BEARING AGGREGATE

Doctor of Philosophy

2019

Mona El-Mosallamy

Civil Engineering

Ryerson University
\end{abstract}

This research focuses on testing the applicability on aggregates from Ontario of a testing protocol to evaluate the potential oxidation of sulphide-bearing aggregates, optimizing the protocol test methods, and develop new tests based on the obtained results. The protocol comprises of three sequential tests: Total sulphur content, Oxygen Consumption Test and Oxidation Mortar Bar Test. For the oxygen consumption test, using processing equipment with cast iron media, was found to contaminate the samples and produce high consumption. Moreover, controlling the tested aggregate gradation produces higher consumption and more consistent results than using a fine aggregate sample $(<150 \mu \mathrm{m})$ without controlling the minimum size. The oxidation consumption test showed lower expansion values for carbonate aggregates compared to aggregates with high silicate content. Exposing siliceous aggregate, whether alkali-silica reactive or not, to the high $\mathrm{pH}$ from the oxidizing solution and the high temperature produces high expansion regardless of the oxidizable sulphide content. As such, 
new expansion criteria are suggested which takes into consideration the silicate content of the aggregates. The dissertation proposes, based on testing twenty-six aggregates, modifications to: the oxygen consumption test; the expansion criteria of the mortar bar test; and proposes a new oxidation mortar bar test to avoid the limitation of the applicability of the original mortar bar test on siliceous aggregates. In the new testing program, different testing regimes were investigated using different oxidizing agents and environmental conditions that can promote oxidation of sulphide-bearing aggregates, without the promotion of other chemical reactions (Alkali silica reaction products or Friedel's' salt). Out of the various investigated tested regimes, two testing procedures showed promising results and recommended for further development and use. Bleach and lime water are used in these tests as the oxidizing agents; however, mortar bars in both regimes are stored at lower temperature compared to that of the original test in the protocol. Based on the expansion results, new expansion criteria are suggested that can detect if the aggregate contains oxidizable sulphides. 


\section{Dedication}

This thesis is dedicated to my parents, without pour, love, and endless support $\otimes$ wouldn't have been able to complete this work. 


\section{Acknowledgments}

First and foremost, I would like to express my sincere gratitude and appreciation to my supervisor Professor Medhat Shehata for his guidance, motivation, patience, and support during my study. Working with Prof. Shehata was a great privilege as I gained tremendous technical knowledge and experience from him through his mentorship. I certainly wouldn't have been able to continue this work without his input and motivation.

I would also like to express my sincere gratitude to MTO Staff for their support in carrying out the activities of this project. Specifically, the support of Carole Ann McDonald for her technical support with the geological formation of aggregates and Ms. Hannah Schell for her valuable comments and in the area of concrete testing and test development.

I would also like to thank Professor Ahmed El-Rabbany for his support during his appointment as Graduate Program Director in the Civil Engineering Department that continued even after the end of his appointment. A special thank you goes to Dr. Bassili Guirgues, who I owe a great share of gratitude for training me when I first joined the lab.

I would like to thank all of the technical staff in the civil engineering department at Ryerson University for their assistance, especially Robin Luong and Dominic Valle for being continuously available and supportive and Min Yao, who passed away last year, and it is never the same without him, may God bless his soul. I would like to extend a special thanks to all my colleagues in the Concrete Materials Lab. 
A special thank you goes out to my dear parents and siblings, Aliaa, Abdallah and Qotb, who have unconditionally supported and loved me, for always believing in me, for pushing me to succeed and for always being there when I needed them.

To my friends Bailasan, Sarah Salem, Somaia, Heba, Noura, Ghadeer, Sara Elzomar, Sara Anis, Samah, Mai, Aya, Toka, Mohammed, Abselsattar, Ayman and Mahmoud, thank you for your exceptional support and thoughtfulness, I have always considered you more like a second family to me during my stay in Toronto. 


\section{Table of contents}

Declaration of Authorship ...........................................................

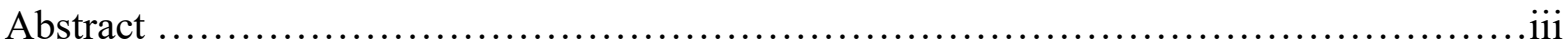

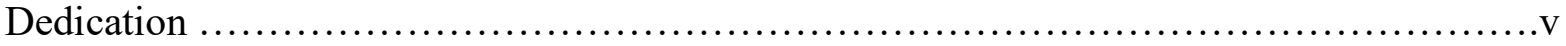

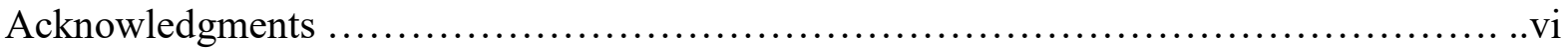

List of tables ........................................................................

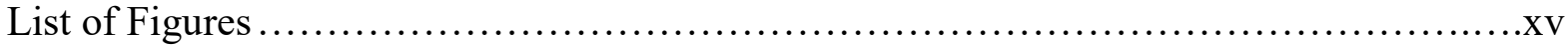

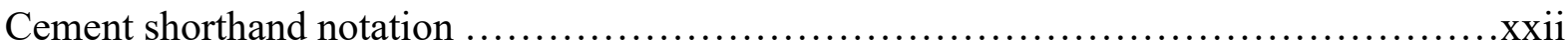

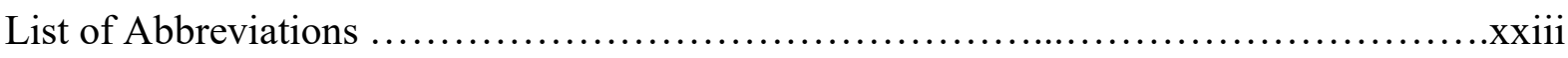

\section{Chapter 1: Introduction and Thesis Outline}

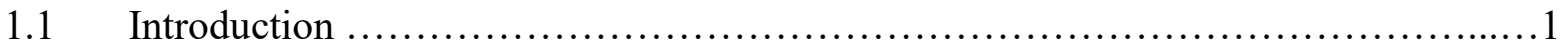

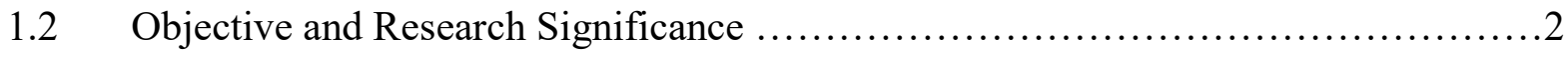

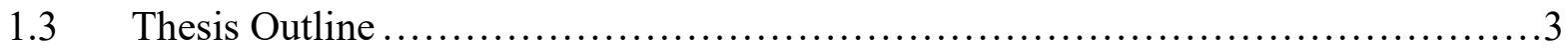

\section{Chapter 2: Literature Review}

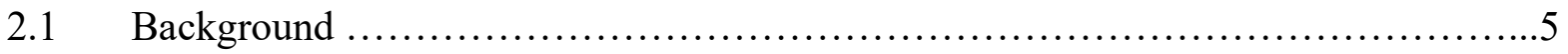

2.2 Mechanism and Phases Associated with Sulphate Attack .........................8

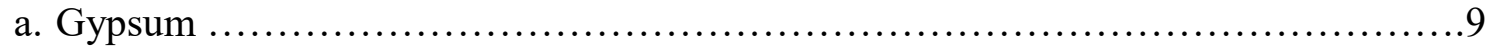

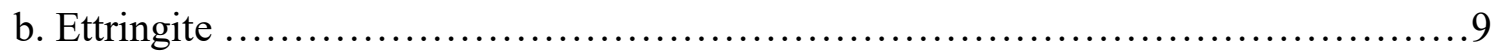

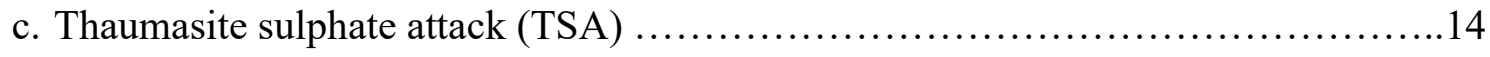

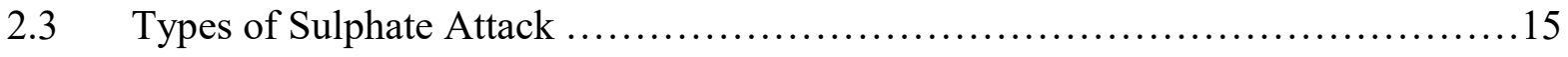

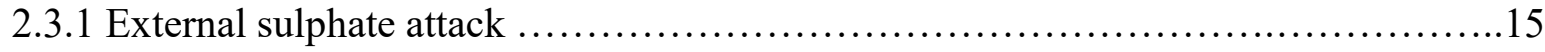

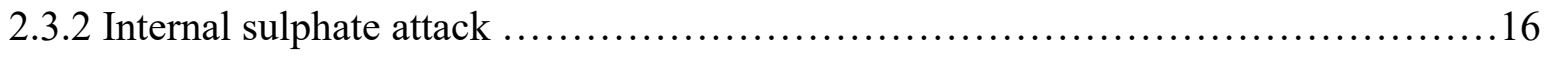

2.3.2.1 Calcium sulphate ..................................................... 17

2.3.2.2 Oxidation of sulphide-bearing aggregate ..................................17 
2.3.2.3 Iron sulphide minerals

2.4 Mitigation of Internal Sulphate Attack Using Supplementary Cementing Materials..21

2.5 Evaluation of Sulphide-bearing Aggregates ..................................29

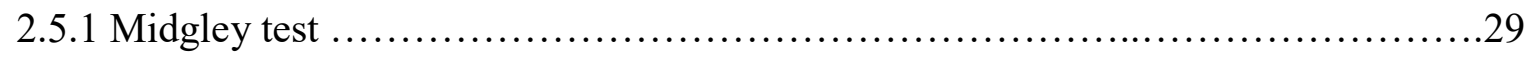

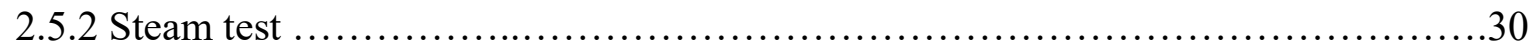

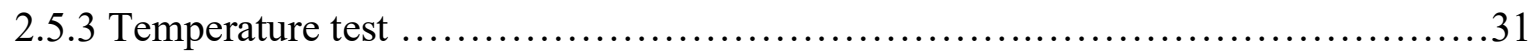

2.5.4 Petrographic identification of sulfide-bearing aggregates ........................ 31

2.5.5 Testing protocol for evaluation of sulphide-bearing aggregate susceptibility to

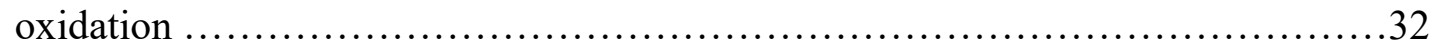

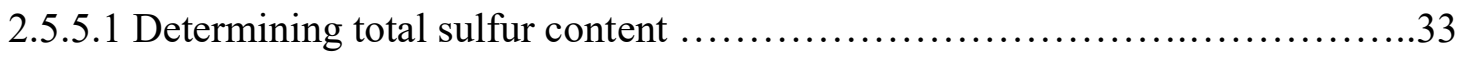

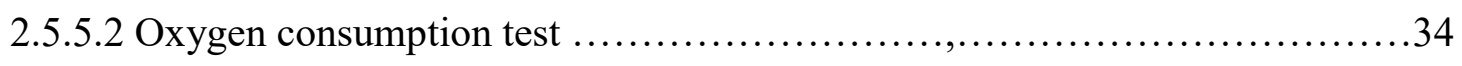

2.5.5.3 Oxidation of mortar bar test ...................................... 38

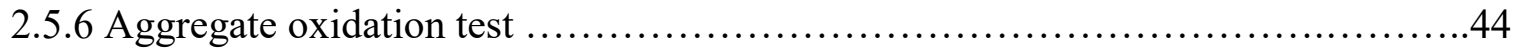

\section{Chapter 3: Experimental Investigation}

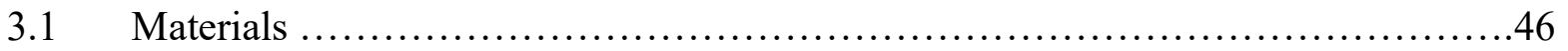

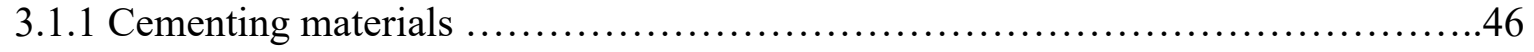

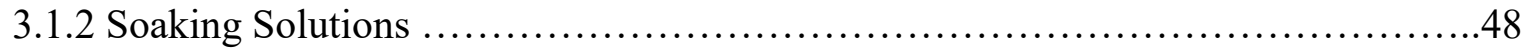

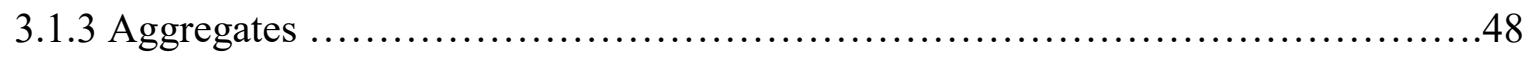

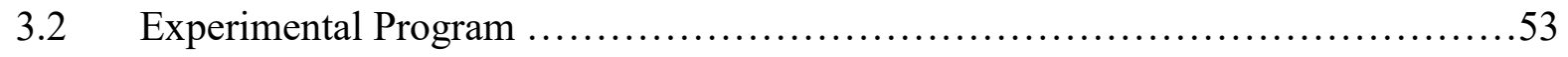

3.2.1 Protocol applicability to different aggregates.................................

3.2.1.1 Oxygen consumption test (OCT) and test optimization ...................53

3.2.1.2 Oxidation mortar bar test (OMBT) ............................... 57

3.2.2 Alkali-silica reaction (ASR) accelerated mortar bar test ......................60

3.2.3 Development of new oxidation mortar bar test (OMBT) .....................60

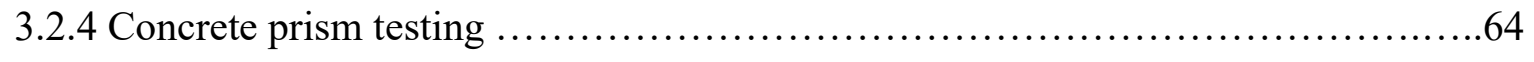




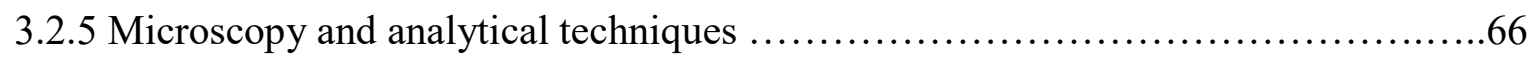

3.2.5.1 Microstructural examination ........................................66

3.2.5.2 Differential Thermal Analysis (DTA) .................................67

\section{Chapter 4: Applicability and Optimization of Oxygen Consumption Test (OCT)}

$4.1 \quad$ Oxygen Consumption Test (OCT) Optimization ..............................68

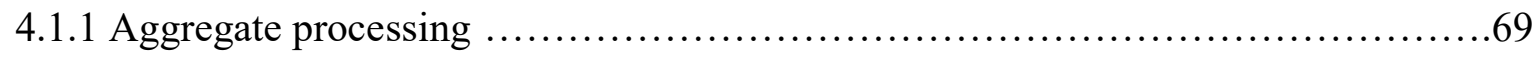

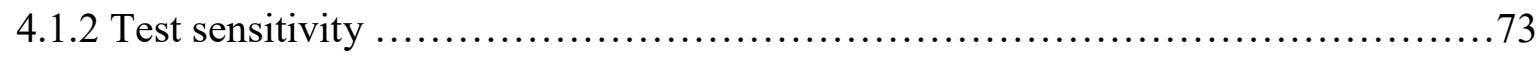

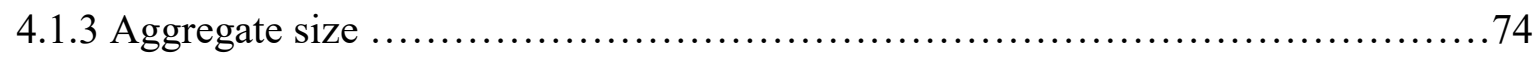

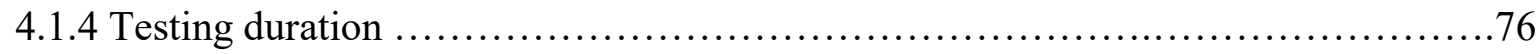

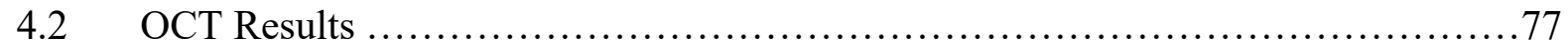

4.3 Use of Jaw Crusher with Manganese Plates for Aggregate Processing ................81

4.4 Applying OCT to Aggregates of Controlled Total Sulphur Content ..................86

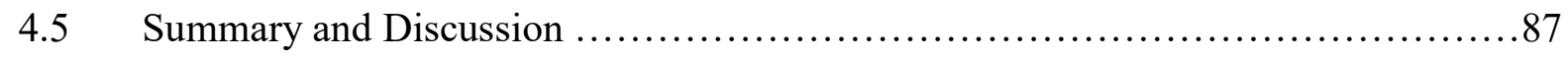

Chapter 5: Applicability of Oxidation Mortar Bar Test (OMBT)

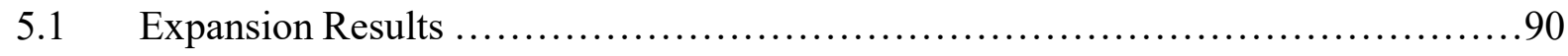

5.2 Investigating the Ability of the (OMBT) to Evaluate the Oxidation Potential of

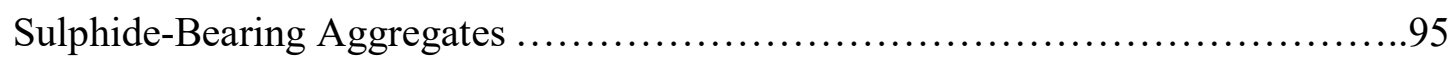

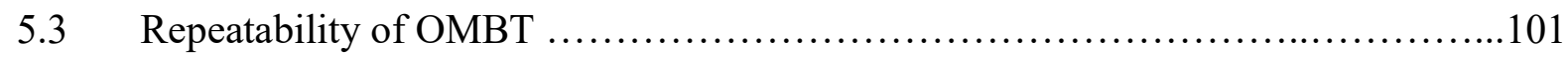

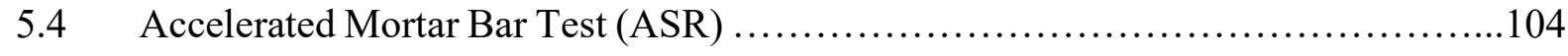

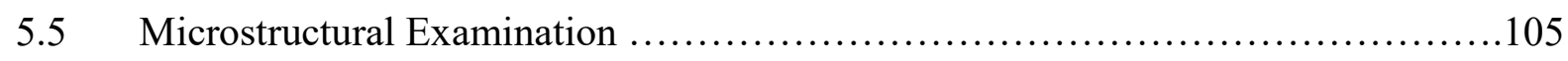

5.6 Application of OMBT on Aggregates with Controlled Total Sulphur Content........114

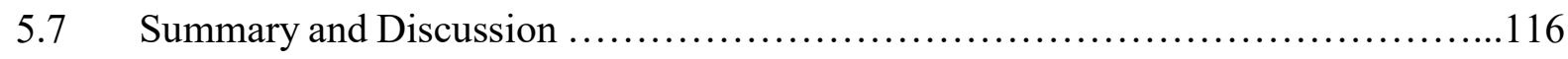

Chapter 6: Development of New Expansion Test for Evaluation of Oxidation Potential of Sulphide-Bearing Aggregate 
6.1. Oxidation Mortar Bar Test

6.1.1 Using sodium hypochlorite $(\mathrm{NaClO})$ to promote oxidation

120

6.1.1.1 Effect of lower storage temperature in Phase I $\left(21-23^{\circ} \mathrm{C} / 80 \% \mathrm{RH}\right)$ on the expansion of the mortar bars (Exposure B-1)

6.1.1.2 Effect of higher storage temperature in Phase II $\left(21-23^{\circ} \mathrm{C} / 100 \% \mathrm{RH}\right)$ on the expansion of mortar bars (Exposure B-2)

6.1.2 Using calcium hypochlorite $(\mathrm{Ca}(\mathrm{ClO}) 2)$ as soaking solution to promote oxidation

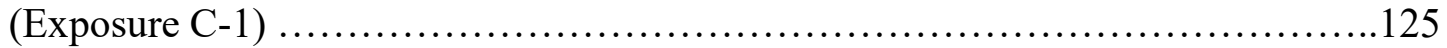

6.1.3 Using saturated lime soaking solution to promote oxidation ...................129

6.1.3.1 Soaking mortar bars for three hours .............................. 129

6.1.3.2 Soaking mortar bars for 48 hours (Exposure L-3, L-4 and L-5) ...........137

6.1.3.3 Effect of supplementary cementing materials ..........................141

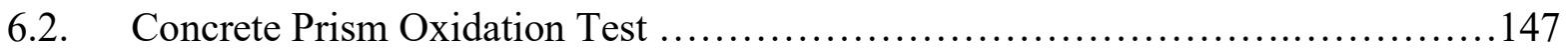

6.2.1 Samples soaked in bleach (sodium hypochlorite $6 \%$ ) ......................... 147

6.2.1.1 Samples stored at $80^{\circ} \mathrm{C} / 80 \% \mathrm{RH}$ and $5^{\circ} \mathrm{C} / 100 \% \mathrm{RH}$ in Phase I and Phase II, respectively (Exposure PB-1) ...................................... 147

6.2.1.2 Samples stored at $60^{\circ} \mathrm{C} / 80 \% \mathrm{RH}$, then $23^{\circ} \mathrm{C} / 50 \% \mathrm{RH}$, and then $5^{\circ} \mathrm{C} / 100 \% \mathrm{RH}$ in Phase I, Phase II and Phase III, respectively (Exposure PB-2) .................149

6.2.1.3 Samples stored at $60^{\circ} \mathrm{C} / 80 \% \mathrm{RH}$, then $23^{\circ} \mathrm{C} / 50 \% \mathrm{RH}$, and then $5^{\circ} \mathrm{C} / 100 \% \mathrm{RH}$ in Phase I, Phase II and Phase III, respectively (Exposure PB-3) ............... 150

6.2.2 Samples soaked in saturated lime solution (LW), Exposure PL-1 ............. 151

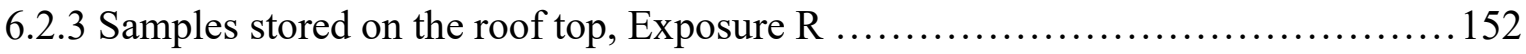

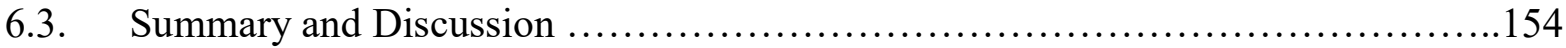

\section{Chapter 7: Summary and Conclusions}

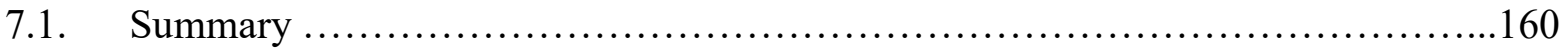




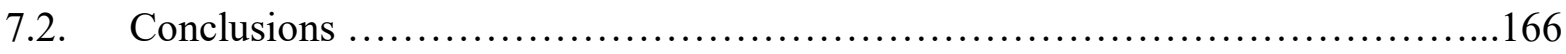

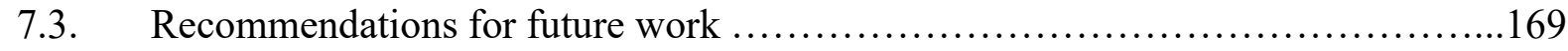

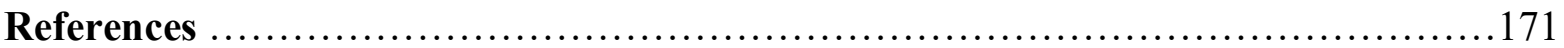




\section{List of tables}

Table 2.1. Time to Cracking for Metakaolin Concrete Prisms Subject to Sulphate (Al-Akhras, 2006) 25

Table 2.2. Effect of degree of saturation and air volume on oxygen consumption (Rodrigues, Duchesne, and Fournier, 2016b)

Table 2.3. Effect of ground material thickness on oxygen consumption (Rodrigues, Duchesne, \& Fournier, 2016b) .36

Table 2.4. Effect of aggregate size on oxygen consumption (Rodrigues, Duchesne, \& Fournier, 2016b) 36

Table 2.5. Results of oxygen consumption test (Rodrigues, Duchesne, \& Fournier, 2016b)..37

Table 3.1. Chemical composition of the Portland cement and SCMs (mass \%) determined using XRF .46

Table 3.2. Composition of the (GU) Portland cement

Table 3.3. Chemical analyses and abrasion resistance of the aggregates .51

Table 3.4. Gradation of the tested samples .56

Table 3.5. Details of testing exposures for mortar bars

Table 3.6. Details of testing exposures for concrete prisms .65

Table 4.1. Results of oxygen consumption test processed by jaw crusher with cast iron plates and by disk pulverizer with ceramic plates 78

Table 4.2. Results of oxygen consumption test for aggregates crushed with cast iron and manganese plates .82

Table 4.3. Oxygen consumption after 3 hours in samples with controlled total sulphide content

Table 5.1. Results of mortar bars oxidation test .93

Table 5.2. Statistical analysis for Phase II expansion for the repeated OMBT 103

Table 5.3. Expansion of mortar bars with controlled total sulphide content 114 
Table 5.4. Ratio between the expansion of Phase II and Phase II of mortar bars 118

Table 6.1. Ratio between the expansion of Phase II and Phase II of mortar bars 155

Table 7.1. Expansion criteria for the developed new tests 165 


\section{List of Figures}

Figure 2.1. Map cracking in concrete foundations and deck slabs (Rodrigues et al., 2012) .....8

Figure 2.2. Deteriorations in concrete foundations (Rodrigues et al., 2012) .................8

Figure 2.3. Ettringite crystals with thicknesses ranging between 2 and $200 \mu \mathrm{m}$ (Stark \& Bollmann, 2000) .......................................................... 11

Figure 2.4. EM-element analysis for Si-Ettringite (Lukas, 1976) .........................12

Figure 2.5. Effect of curing temperature on expansion, from (Fu et al., 1997) .................13

Figure 2.6. Mass gain of mortar bars with time after soaking for 30 hours (Guirguis et al., 2018)

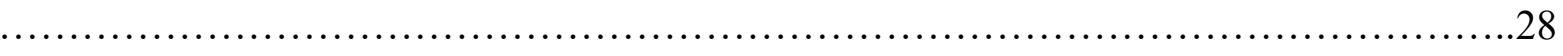

Figure 2.7. Penetration of soaking solution into the samples after different times of exposure (Guirguis et al., 2018) . 29

Figure 2.8. Reflected polarized light views of iron sulfide minerals included in the anorthositic

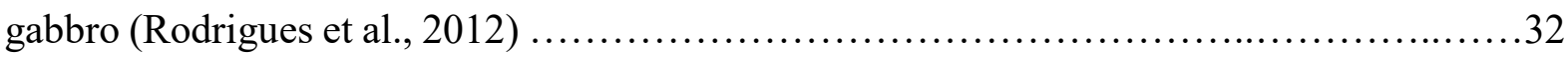

Figure 2.9. Expansion of mortar bars in Phase I: Bars are soaked three hours in bleach (6\%) twice per week and stored at $80^{\circ} \mathrm{C} / 80 \% \mathrm{RH}$. Phase II: Bars are soaked three hours in bleach (6\%) twice per week and stored at $4{ }^{\circ} \mathrm{C} / 100 \%$ RH (Rodrigues, Duchesne, Fournier, et al., 2016)

Figure 2.10. Expansion in control and aggregates with total sulphur $<0.05 \%$ (Guirguis, 2017)

Figure 2.11. Evidence of ASR gel inside an air void in mortar bars containing: (a) C2 aggregate

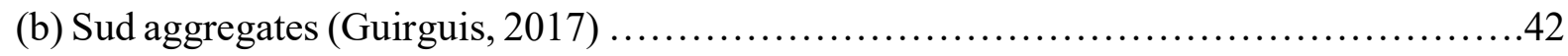

Figure 2.12. Expansion in samples with various sulphide contents (Guirguis, 2017) .........43

Figure 2.13. Effect of aggregate composition on expansion due to DEF (Grattan-Bellew et al.,

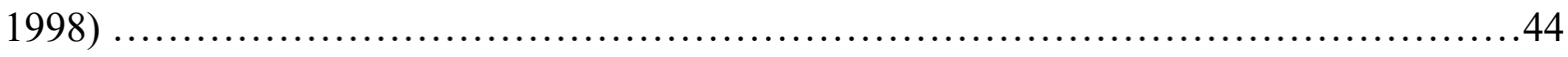

Figure 2.14. Change in colour of sodium hypochlorite solution (Guirguis, 2017) ...........45

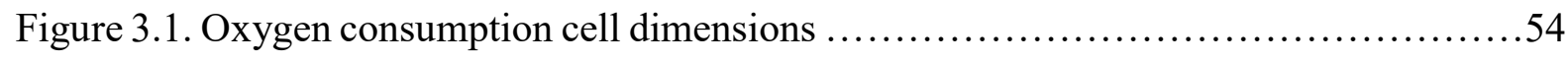


Figure 3.2. OCT set-up showing sealed plexiglass cells with $100-\mathrm{mm}$ crushed aggregates .....55

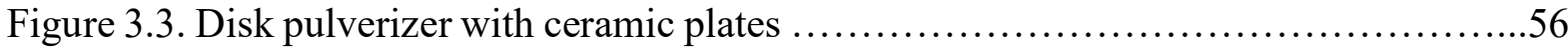

Figure 3.4. Mortar bars length measurements ....................................58

Figure 4.1. Oxygen consumption for samples crushed by disk pulverizer with cast iron plates . .70

Figure 4.2. Rust in aggregate crushed by disk pulverizer with iron plates to a size of (600 $\mu \mathrm{m}$ to $300 \mu \mathrm{m})$

Figure 4.3. Oxygen consumption for sand A crushed by the micro-deval abrasion machine and disk pulverizer with cast iron plates and a sample with crushed with the micro-deval with $5 \%$ iron powder

Figure 4.4. Oxygen consumption for samples crushed by disk pulverizer with ceramic plate 72

Figure 4.5. Oxygen consumption for samples crushed by the micro-deval abrasion machine, containing the indicated sulphide-bearing aggregate percentages $\ldots \ldots \ldots \ldots \ldots \ldots \ldots \ldots \ldots . \ldots \ldots$

Figure 4.6. Oxygen consumption after 3 hours for tested samples with different gradations 75

Figure 4.7. Effect of grinding size in the OCT (3-hour test duration) .76

Figure 4.8. Oxygen consumption after a 16-hour test duration for some of the tested aggregates: a) carbonate, b) aggregates with silicates, and c) sulphide-bearing aggregates .77

Figure 4.9. Oxygen consumption test results for silicate (1051) and carbonate (1032) aggregates with the same total sulphur content

Figure 4.10. Oxygen consumption test for aggregates crushed with cast iron and manganese plates

Figure 4.11. Oxygen consumption in carbonate aggregates processed with cast iron-plated and manganese-plated jaw crusher 84

Figure 4.12. Oxygen consumption for non-carbonate aggregates prepared with cast iron-plated and manganese-plate jaw crusher .... 
Figure 4.13 Oxygen consumption test results for aggregates crushed with cast iron and manganese jaw crusher plates 89

Figure 5.1. Expansion of mortar bars with blends of $\mathrm{C} 1$ and Ore with and without placing the samples for three hours in the fume hood (FH) after soaking . .92

Figure 5.2. Expansion of mortar bars with washed and unwashed MSK .92

Figure 5.3. Expansion of mortar bars with carbonate aggregates, with the number in the legend box representing the total sulphur of the aggregate

Figure 5.4. Tested mortar bars with carbonate aggregates after 26 weeks of subjecting them to the exposure condition

Figure 5.5. Expansion of mortar bars cast with non-carbonate aggregates

Figure 5.6. Tested mortar bars with aggregates with high silicate content after 26 weeks of exposure

Figure 5.7. Repeatability of oxidation mortar bar test (OMBT) for aggregates with different composition subjected to the same exposure condition 103

Figure 5.8. Expansion of ASR mortar bars tested for 28 days 105

Figure 5.9. Friedel's salt with traces of silica appears in aggregate 1030. SEM-EDS obtained the BSE image and spectra, respectively 106

Figure 5.10. Sodium chloride appears in carbonate aggregate 1029 107

Figure 5.11. Friedel's salt appears in aggregate 1046 with high silicate content 107

Figure 5.12. Un-oxidized iron sulphides in the carbonate aggregate 1029

Figure 5.13. ASR gel around the aggregate in mortar bars with the carbonate aggregate 1029 110

Figure 5.14. Un-oxidized iron sulphides in the sulphide-bearing aggregate 1052; the light grey areas show the composition of the aggregate

Figure 5.15. Un-oxidized iron sulphides in another site in the sulphide-bearing aggregate 1052 
Figure 5.16. SEM and EDS images for mortar, with aggregate 1052 showing a mix of Friedel's salt with traces of ettringite 112

Figure 5.17. Deteriorated paste of mortar bar with aggregate 1046 showing presence of ASR gel

Figure 5.18. Deteriorated paste of mortar bar with aggregate 1049 showing presence of ASR gel

Figure 5.19. Expansion of mortar bars with controlled total sulphide content

Figure 5.20. Expansion of mortar bars with controlled total sulphide content

Figure 6.1. Expansion of mortar bars stored at room temperature $\left(21-23^{\circ} \mathrm{C} / 80 \% \mathrm{RH}\right)$ for 13 weeks in Phase I

Figure 6.2. SEM-EDS analysis of mortar bar with 1052 soaked in bleach in Phase I ...... 123

Figure 6.3. Expansion of mortar bars soaked in bleach and stored at room temperature (21$\left.23^{\circ} \mathrm{C} / 100 \% \mathrm{RH}\right)$ in Phase II

Figure 6.4. Comparison between the expansions of samples soaked in bleach and stored at 21$23{ }^{\circ} \mathrm{C} / 100 \% \mathrm{RH}$ and $5^{\circ} \mathrm{C} / 100 \% \mathrm{RH}$ in Phase II; the solid color represents expansion in Phase I, while the hatched area represents expansion in Phase II 124

Figure 6.5. Expansion of mortar bars soaked in calcium hypochlorite and stored at $80^{\circ} \mathrm{C} / 80 \% \mathrm{RH}$ and $5^{\circ} \mathrm{C} / 100 \% \mathrm{RH}$ in Phase I and Phase II respectively 126

Figure 6.6. Comparison between the expansions of mortar bars soaked in calcium hypochlorite and those soaked in sodium hypochlorite and stored at $80^{\circ} \mathrm{C} / 80 \% \mathrm{RH}$ and $5^{\circ} \mathrm{C} / 100 \% \mathrm{RH}$ in Phase I and Phase II respectively

Figure 6.7. SEM-EDS analysis for mortar bar with aggregate 1049 and high silicate content soaked for three hours in calcium hypochlorite showing the presence of Friedel's salt. ...

Figure 6.8. DTA analysis for mortar bar with high silicate content 1049 soaked in calcium hypochlorite 128 
Figure 6.9. Expansion of mortar bars with MSK and 1046 soaked for three hours in lime water at $80^{\circ} \mathrm{C} / 80 \% \mathrm{RH}$ and $5^{\circ} \mathrm{C} / 100 \% \quad \mathrm{RH}$ in Phase $\mathrm{I}$ and Phase II, respectively

Figure 6.10. Comparison between the expansion of mortar bars soaked in lime-water and mortar bars soaked in bleach both stored at $80^{\circ} \mathrm{C} / 80 \% \mathrm{RH}$ in Phase I and $5^{\circ} \mathrm{C} / 100 \% \mathrm{RH}$ in Phase II.

Figure 6.11. Expansion of mortar bars soaked in lime water for three hours and stored at $40^{\circ} \mathrm{C} / 70 \% \mathrm{RH}$ and $5^{\circ} \mathrm{C} / 100 \% \mathrm{RH}$ in Phase I and Phase II, respectively 132 Figure 6.12. Comparison between expansions of mortar bars soaked in lime water and stored at $40^{\circ} \mathrm{C} / 70 \% \mathrm{RH}$ in Phase I and mortar bars soaked in bleach and stored at $80^{\circ} \mathrm{C} / 80 \% \mathrm{RH}$ in Phase I, .133

Figure 6.13. Expansion of mortar bars with 100\% Ore stored at different conditions in Phase II 134

Figure 6.14. Expansion of mortar bars with MSK stored at different conditions in Phase II 134

Figure 6.15. SEM analysis showing the presence of ettringite and Thaumasite mixture for mortar bar with $50 \%$ Ore soaked in lime water for three hours and stored at $40^{\circ} \mathrm{C} / 70 \mathrm{RH}$ in Phase I and at $5^{\circ} \mathrm{C} / 100$ in Phase II 136 Figure 6.16. SEM analysis showing the presence of ettringite and Thaumasite mixture for mortar bar with MSK soaked in lime water for three hours and stored at $40^{\circ} \mathrm{C} / 70 \mathrm{RH}$ in Phase

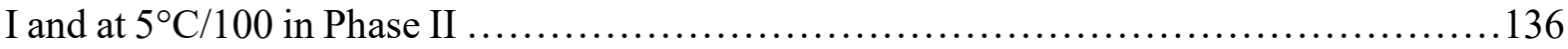

Figure 6.17. DTA for MSK soaked in lime water for three hours and stored at $40^{\circ} \mathrm{C} / 70 \mathrm{RH}$ in Phase I and at $5^{\circ} \mathrm{C} / 100$ in Phase II

Figure 6.18 Expansion of MSK soaked 2-days in lime water and stored $40^{\circ} \mathrm{C} / 70 \% \mathrm{RH}$ and $5^{\circ} \mathrm{C} / 100 \% \mathrm{RH}$ in Phase I and Phase II, respectively. 138

Figure 6.19. Expansion of mortar bars incorporating 50\% Ore soaked2-days in lime water and stored at $40^{\circ} \mathrm{C} / 70 \% \mathrm{RH}$ and $5^{\circ} \mathrm{C} / 100 \% \mathrm{RH}$ in Phase I and Phase II, respectively..... 
Figure 6.20. Expansion of mortar bars with control carbonate and silicate aggregates soaked for two days in lime water and stored at $40^{\circ} \mathrm{C} / 70 \% \mathrm{RH}$ and $5^{\circ} \mathrm{C} / 100 \% \mathrm{RH}$ in Phase I and Phase II, respectively.

Figure 6.21. Expansion of mortar bars soaked in lime water for two days and stored at $40^{\circ} \mathrm{C} / 70 \% \mathrm{RH}$ and $5^{\circ} \mathrm{C} / 100 \% \mathrm{RH}$ in Phase I and Phase II, respectively 140

Figure 6.22. Expansion of mortar bars soaked in lime water for two days compared with those soaked for three hours, with the solid color representing expansions in Phase I and the hatched area representing expansions in Phase II

Figure 6.23. Effect of SCM on Ore sample soaked for three hours in lime water and stored at $40{ }^{\circ} \mathrm{C} / 70 \%$ and at $5^{\circ} \mathrm{C} / 100 \%$ for 26 weeks

Figure 6.24. Effect of SCM on sample with 50\% Ore soaked for three hours in lime water and stored at $40{ }^{\circ} \mathrm{C} / 70 \%$ and at $5^{\circ} \mathrm{C} / 100 \%$ for 26 weeks

Figure 6.25. Effect of SCM on sample with MSK soaked for three hours in lime water and stored at $40^{\circ} \mathrm{C} / 70 \%$ and $5^{\circ} \mathrm{C} / 100 \%$ for 26 weeks

Figure 6.26. Expansions of mortar bars soaked in lime water for 2days with aggregates a) $50 \%$ Ore and b) MSK

Figure 6.27. SEM analysis of mortar bar with 50\% Ore and GU-PC soaked in lime water for three hours and stored at $40^{\circ} \mathrm{C} / 70 \% \mathrm{RH}$ for 26 weeks showing the hydrated and un-hydrated cement 144

Figure 6.28. SEM analysis for mortar bar with $50 \%$ Ore and GU+25\% FA soaked for three hours in lime water and stored at $40^{\circ} \mathrm{C} / 70 \% \mathrm{RH}$ for 26 weeks showing the hydrated and unhydrated cement 144

Figure 6.29. SEM for MSK incorporating GU-PC+10\% MK soaked for three hours in lime water and stored at $40^{\circ} \mathrm{C} / 70 \% \mathrm{RH}$, showing the presence of monosulphoaluminate and ettringite 146

Figure 6.30. DTA for mortar bars incorporating MSK aggregate with GU-PC, GU+25\% FA and $\mathrm{GU}+10 \% \mathrm{MK}$ soaked for three hours in lime water and stored at $40{ }^{\circ} \mathrm{C} / 70 \% \mathrm{RH}$ 146 
Figure 6.31. Expansion of concrete prisms soaked in bleach for eight hours and stored at $80^{\circ} \mathrm{C} / 80 \% \mathrm{RH}$ and $5^{\circ} \mathrm{C} / 100 \% \mathrm{RH}$ in Phase I and Phase II, respectively ................... 148

Figure 6.32. Deterioration and rust in concrete prisms with MSK ....................... 148

Figure 6.33. Deterioration and pop-outs in concrete prisms with aggregate 1046 .........149

Figure 6.34. Expansion of concrete prisms soaked in bleach for two days and stored at $60^{\circ} \mathrm{C} / 80 \% \mathrm{RH}$, then $23^{\circ} \mathrm{C} / 50 \% \mathrm{RH}$, and then $5^{\circ} \mathrm{C} / 100 \% \mathrm{RH}$ in Phase I, Phase II and Phase III,

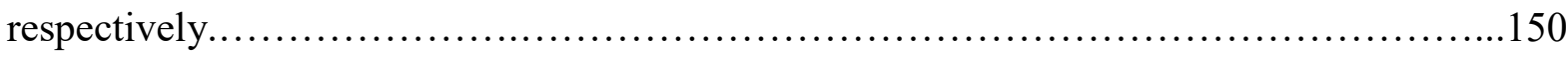

Figure 6.35. Expansion of concrete prisms soaked in bleach for two days and stored at $60^{\circ} \mathrm{C} / 80 \% \mathrm{RH}$, then $23^{\circ} \mathrm{C} / 50 \% \mathrm{RH}$, and then $5^{\circ} \mathrm{C} / 100 \% \mathrm{RH}$ in Phase I, Phase II and Phase III, respectively

Figure 6.36. Expansion of concrete prisms soaked in lime water for eight hours and stored at $80^{\circ} \mathrm{C} / 80 \% \mathrm{RH}$ and $5^{\circ} \mathrm{C} / 100 \% \mathrm{RH}$ in Phase I and Phase II, respectively ................... 152

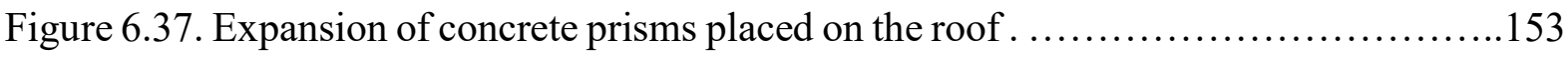

Figure 6.38. Expansion of mortar bars with 50\% Ore soaked in lime water for three hours or

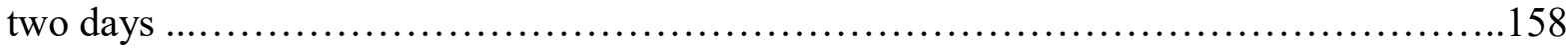

Figure 6.39. Expansion of mortar bars with MSK soaked in lime water for three hours or two

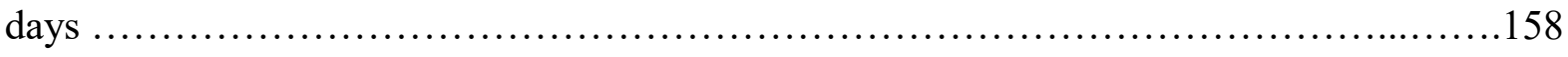

Figure 6.40. Total expansion of mortar bars soaked in lime water for three hours and stored at $40^{\circ} \mathrm{C} / 70 \% \mathrm{RH}$ and $5^{\circ} \mathrm{C} / 100 \% \mathrm{RH}$ in Phase I and Phase II, respectively 159

Figure 7.1. Modified protocol for evaluation of sulphide-bearing aggregate 162 


\section{Cement shorthand notation}

$$
\begin{aligned}
& \mathrm{C}=\mathrm{CaO} \\
& \mathrm{S}=\mathrm{SiO}_{2} \\
& \mathrm{H}=\mathrm{H}_{2} \mathrm{O} \\
& \mathrm{A}=\mathrm{Al}_{2} \mathrm{O}_{3} \\
& \mathrm{~F}=\mathrm{Fe}_{2} \mathrm{O}_{3} \\
& \mathrm{~S}=\mathrm{SO}_{3} \\
& \mathrm{C}=\mathrm{CO}_{2} \\
& \mathrm{~N}=\mathrm{Na}_{2} \mathrm{O} \\
& \mathrm{K}=\mathrm{K}_{2} \mathrm{O} \\
& \mathrm{CH}=\mathrm{Ca}_{2}\left(\mathrm{OH}_{2}\right. \\
& \mathrm{CSH} 2=\mathrm{CaSO}_{4} .2 \mathrm{H}_{2} \mathrm{O} \\
& \mathrm{CC}=\mathrm{CaCO}_{3} \\
& \mathrm{CSH}=\mathrm{C}_{3} \mathrm{~S}_{2} \mathrm{H}_{8}
\end{aligned}
$$




\section{List of Abbreviations}

OCT $=$ Oxygen Consumption Test

OMBT $=$ Oxidation Mortar Bar test

$\mathrm{CA}=$ Calcium Aluminate Hydrate

C-S-H = Calcium Silicate Hydrate

$\mathrm{F}=$ Friedel's Salt

$\mathrm{E}=$ Ettringite

$\mathrm{MS}=$ Monosulphoaluminate

GU-PC $=$ General Use Portland Cement

FA = Fly Ash

$\mathrm{SG}=$ Slag

$\mathrm{M}=$ Metakaolin

ISF $=$ Internal Sulphate Attack

ASR $=$ Alkali Silica Reaction 


\section{Chapter 1}

\section{Introduction and Thesis Outline}

\subsection{Introduction}

The oxidation of sulphide phases in some aggregates was found to cause deterioration in concrete elements (Belgeri \& Siegel, 1998; Dougherty \& Barsotti, 1972; Bassili Guirguis, 2017; Hawkins \& Pinches, 1992; Rodrigues et al., 2012). In most of these cases, the coarse aggregate used to produce the concrete contained various proportions of sulphide minerals. The deteriorations and expansions were attributed to the production of sulfuric acid followed by gypsum, leading to internal sulphate attack.

Sulphate ions can readily migrate into the nearest cracks, react with the tricalcium aluminate phase of the hydrated cement paste or mono-sulphoaluminate, and re-crystallize in the form of ettringite. These ions can also, at low-temperature conditions, attack the C-S-H matrix in the cement paste to form thaumasite. Formation of these materials, which large in volume, results in a number of problems, including significant loss of strength, spalling, pop-outs, hairline cracks, and concrete expansion.

The rapid deterioration of concrete foundations occurred in more than 400 residential houses in the Trois-Rivières area of Quebec, Canada, only within four years after construction. The deterioration appeared in the form of map cracking, yellowish coloration, and open cracks at the corners of the affected foundations, often close to the source of humidity such as drainage paths. Cracks and deteriorations were observed around and through the aggregate particles and the cement paste, with some disintegration. The aggregate material in all the tested samples was intrusive igneous rock, containing various proportions of sulphide minerals, mostly pyrite and pyrrhotite. 
To evaluate the rate and amount of the consumed oxygen by sulphide-bearing aggregates and the deleterious behaviour resulting from using these aggregates in concrete, some researchers developed screening tests to evaluate sulphide-bearing aggregates (Seaton, 1948; Midgley, 1958; Rodrigues et al., 2016; Guirguis \& Shehata, 2017). The main objective of the present research is to study and optimize the testing protocol developed by Rodrigues et al. (2016) and adopted by Annex P of CSA 23.1-19. The thesis also proposed new tests based on limitation of the tests in the original protocol.

\subsection{Objective and Research Significance}

The aim of this research is to determine the applicability of Rodrigues et al.'s (2016) testing protocol (included in the 2019 CSA 23.1 as Annex P) to aggregates of different compositions as well as blends of aggregates with controlled total sulphur content. The testing protocol is comprised of three stages:

1) determining the total sulphur content (which was done in separate labs and was not studied here in this research);

2) testing aggregates for oxygen consumption caused by iron sulphides oxidation (OCT); and

3) measuring the expansion of mortar bars in the oxidation mortar bar test (OMBT).

Details of these test methods are presented in Chapter 3. The study is carried out in an attempt to understand both the applicability and the limitations of the testing protocol and to find ways to address those limitations. The research results are used to propose modifications to the aggregate processing and acceptance criteria for the OCT and OMBT in order to enhance their efficacy and 
applicability. Also, in an attempt to improve the testing protocol, a new oxidation mortar bar test is proposed to avoid the limitations of the original test.

\subsection{Thesis Outline}

The thesis chapters are organized as follows:

- Chapter 1: Outlines the problem definition and objective of the research and includes details of the thesis outline.

- Chapter 2: Covers the literature pertaining to the oxidation of sulphide-bearing aggregates and sulphate attack with a thorough review of topics related to the research program. The body of this chapter contains an overview of:

$>$ Mechanism and phases associated with sulphate attack.

$>$ Different types of sulphate attack (external and internal).

$>$ Sulphide-bearing aggregate as a source of internal sulphate attack and concrete deterioration

$>$ Using of supplementary cementing materials $(\mathrm{SCM})$ to mitigate sulphate attack in concrete.

$>$ Screening tests for the evaluation of susceptibility of sulphide-bearing aggregates to oxidation.

- Chapter 3: Describes the properties of the materials used in this research program and discusses the experimental methodology carried out at various phases. 
- Chapter 4: Provides details of the oxygen consumption test (OCT) in terms of aggregate applicability, optimization of test methods, sample size, and proposed limit.

- Chapter 5: Provides details of the oxidation mortar bar test (OMBT) in terms of applicability and limitations and suggests some ways to address the limitations. The chapter also proposes expansion criteria that work for all types of aggregates.

- Chapter 6: Discusses results from a new expansion of the mortar bar test designed to avoid the limitations of the original test, along with results of concrete prisms testing.

- Chapter 7: Presents discussions and conclusions based on all results obtained in the research program. 


\section{Chapter 2 \\ Literature Review}

\subsection{Background}

Until the early 1990s, internal sulphate attack was not identified as an issue in concrete structures (Skalny, 2004). Design standards established limits on the sulphate content of cement for structures subjected to sulphate environment, which resulted in the development of sulphateresistant cement to be used in sulphate-rich external environments (Skalny, Marchand, \& Odler, 2003). During the past decades, the increasing demand for developing accelerated early concrete strength led the manufacturers to produce cement of higher reactivity with higher amounts of alite and $\mathrm{C}_{3} \mathrm{~A}$, higher Blaine surface area, increased amounts of sulphates, and more efficient concrete processing in mixing and curing.

Units made of this Portland cement and subjected to heat treatment during production have shown durability failure from deleterious internal reactions. Such reactions arise from the release of sulphates from the gypsum in the Portland cement or from the oxidation of iron sulphides existing in aggregate (Grabowski, Czarnecki, Gillott, Duggan, \& Scott, 1992). Sulphate ions can readily migrate into the nearest cracks, react with the tricalcium aluminate phase of the hydrated cement. paste or mono-sulphoaluminate, and re-crystallize in the form of high molar volume ettringite. These ions can also, in low temperature, attack the C-S-H matrix in the cement paste to form thaumasite. Formation of these materials, which occupy several times the volume of the original sulphides, can result in significant loss of strength properties, as well as spalling, pop-outs, hairline cracks (etching), and concrete expansion.

Few studies have addressed the potential concrete deterioration caused by using sulphide-bearing aggregate in construction. Various concrete deteriorations were recorded around the world 
resulting from the presence of in-situ pyrite that was being used as the soil under concrete foundations. However, an exact determination of swell pressures or a time-rate of expansion is rarely possible for a specific formation or site due to natural variations in pyrite mineralization within a stratigraphic unit (Byerly, 1990).

In 1995, the concrete used in some buildings and public works in Maresme, a region near Barcelona, Spain, during the period 1970-1972, underwent considerable degradation due to the development of fissures. Several authors mentioned that all of the affected concretes contained aggregates from the Mont Palau quarry, which have a high content of iron sulphides, mainly pyrrhotite (Chinchón, Ayora, Aguado, \& Guirado, 1995). It was also mentioned that the analytical approach used in measuring for sulphide in the aggregates underestimated the sulphide content.

A study was carried out by Chinchón et al. (1995) on the same aggregate from Mont Palau, Spain, to obtain a relationship between the mineralogy of the aggregate and the mineralogy of the weathering products. The aggregate consisted mainly of limestone (about $70 \%$ ) and a minor percentage of black shale (25\%). The limestone consisted of recrystallized calcite $(92 \%)$ and dolomite $(8 \%)$, while the shales consisted of quartz, feldspar, muscovite and organic matter. The aggregate contained both pyrrhotite and pyrite in the black shells. Oxidation of these minerals produced ferrihydrite, gypsum, halotrichite, pickeringite, melanterite, and laurnontite.

Recently, deteriorations were recorded in the foundation walls of more than 900 residential houses in the Trois-Rivieres region of Quebec, Canada. The concrete foundations rapidly deteriorated and severely cracked within the first three to five years after construction due to the oxidation of sulphide-bearing aggregates (Rodrigues et al., 2012; Duchesne \& Fournier, 2013; Rodrigues et al., 2016; Guirguis, 2017). The deterioration appeared in the form of map cracking, yellowish 
coloration, and open cracks, mostly at the corners of the foundation and often next to drainage elements.

A large number of concrete samples were investigated using different petrographic tools. Cracks and deteriorations were observed around and through the aggregate particles and the cement paste, and some particles completely disintegrated. The aggregate material in all the tested samples was igneous rock, containing various proportions of unstable sulphide minerals comprising mostly pyrite and pyrrhotite. The sulfuric acid generated through the oxidation of these sulphides reacted with the solids of the cement paste - particularly with the calcium hydroxide $\left(\mathrm{Ca}(\mathrm{OH})_{2}\right)$ - to form gypsum. As shown in Figure 2.1 and 2.2, the concrete deterioration was in the form of a network of cracks known as map cracking, especially in the concrete foundation's deck slabs.

According to the National Association of Home Builders in Washington, U.S, sulphate attack can decrease the expected useful life of concrete from approximately 150 years to 15 years or less (Simonds \& Epstein, 2002). The primary objective of this study is to investigate the applicability of the protocol developed by Rodrigues, Duchesne, Fournier, et al. (2016) on aggregate from Ontario, and to modify the protocol according to the results. Studying the effect of supplementary cementing materials on the oxidation of sulphide-bearing aggregates is also an objective. 

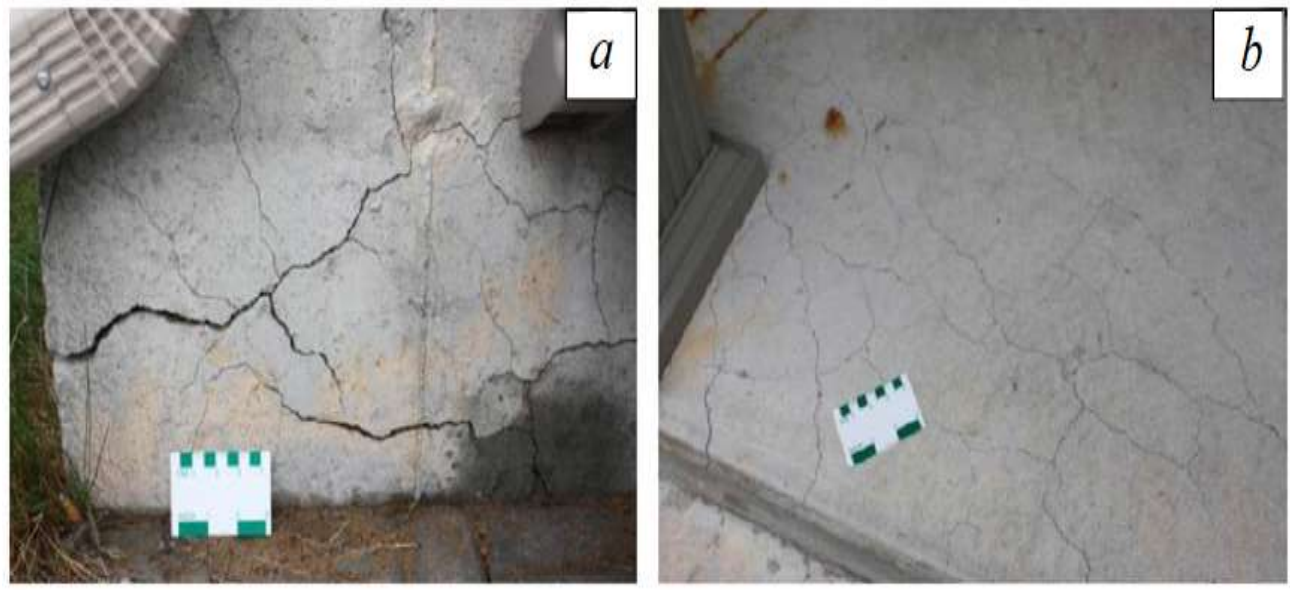

Figure 2.1. Map cracking in concrete foundations and deck slabs (Rodrigues et al., 2012)

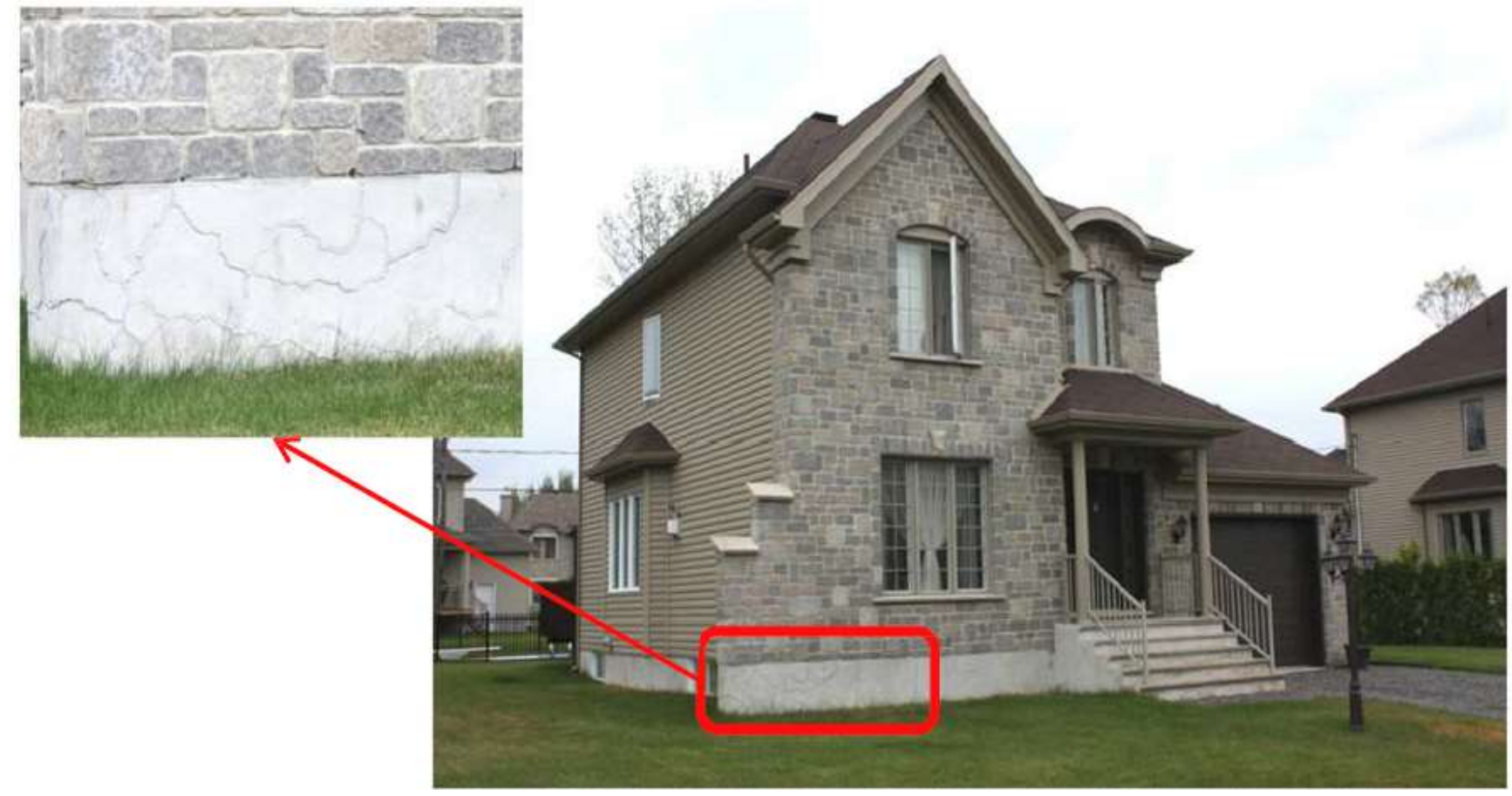

Figure 2.2. Deteriorations in concrete foundations (Rodrigues et al., 2012)

\subsection{Mechanism and Phases Associated with Sulphate Attack}

When an external source of sulphides penetrate or internal source present in the concrete, sulphate ions may be released and react with the hydration products of cement. The reaction between calcium hydroxide $\left(\mathrm{Ca}(\mathrm{OH})_{2}\right)$ and the sulphate ions forms calcium sulphate hydrate (gypsum), 
which subsequently reacts with tri-calcium aluminate $\left(\mathrm{C}_{3} \mathrm{~A}\right)$, through the formation of monosulphoaluminate, to form ettringite. The formation of Ettringite can then provide a nucleation site for thaumasite formation at a lower temperature $\left(<5^{\circ} \mathrm{C}\right)$ and in the presence of carbon dioxide and a high concentration of sulphate ions.

\section{a. Gypsum}

Gypsum formation results primarily from the reaction between sulphate ions and calcium hydroxide $\left(\mathrm{Ca}\left(\mathrm{OH}_{2}\right)\right.$, a by-product of Portland cement hydration. The question of whether or not gypsum formation leads to expansion is controversial. Some theories support while others contradict the expansive behaviour of gypsum. There is also a question as to whether or not it may cause disruptive deleterious expansion when it forms (Bonen \& Cohen, 1992; Herrero, Artieda, \& Hudnall, 2009; Nielsen, 1966; Tian \& Cohen, 2000).

It is commonly known that gypsum formation has a softening effect that causes loss of both mass and strength (Cohen \& Mather, 1991; Hansen, 1963, 1966; Mather, 1997). Additionally, some theories suggest that tensile stresses during gypsum formation may also play a role in the expansion and subsequent cracking (Bonen \& Cohen, 1992; P. Mehta, 1992; Nielsen, 1966).

\section{b. Ettringite}

Ettringite forms as a hydration product from a reaction between the tricalcium aluminate and soluble sulphates in Portland cement. It usually forms in the initial stages of hydration and is essential for controlling flash setting, increasing early strength, and reducing shrinkage (Ramlochan, 2003). Ettringite formation at this stage is called primary ettringite formation, where it is dispersed uniformly and discretely throughout the cement paste at a submicroscopic level (less than a micrometre in cross-section) (Kosmatka, Kerkhoff, \& Panarese, 2002). Kuzel (1996) 
raised some doubts concerning the stability of ettringite at longer ages. According to his investigation, ettringite has a relatively short life-time as an ephemeral constituent of hydrated OPC, but its amount decreases and eventually vanishes after a year or more.

Glasser (2002) studied the stability of ettringite, concluding that ettringite is stable within the $\mathrm{CaO}-\mathrm{Al}_{2} \mathrm{O}_{3}-\mathrm{SO}_{3}-\mathrm{H}_{2} \mathrm{O}$ system in temperatures up to its decomposition point at $114^{\circ} \mathrm{C}$. Exposure of concrete elements to high heat during curing or excessive exposure to sulphates from internal or external sources (soil, water, gypsum or aggregate) that can attack the calcium aluminate hydrate can result in the formation of expansive forms of ettringite. Stark and Bollmann (2000) investigated the crystal structure of ettringite in hardened concrete with a scanning electron microscope (SEM). Under high vacuum, ettringite crystals often consisted of many parallel slender crystals with a thickness ranging between 2 and $200 \mu \mathrm{m}$, lying close to one another. Figure 2.3 illustrates these crystals.
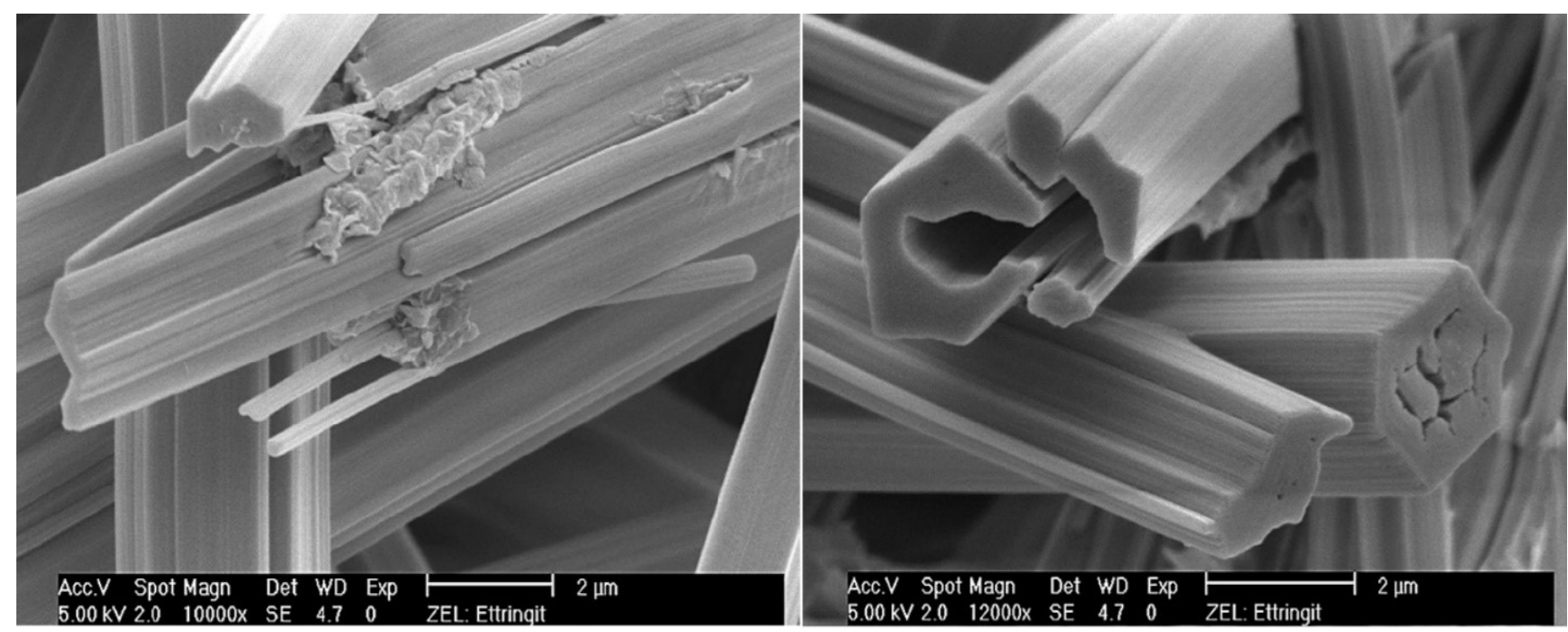

Figure 2.3. Ettringite crystals with thicknesses ranging between 2 and $200 \mu \mathrm{m}$ (Stark \& Bollmann, 2000) 
Local changes in the amount of substance in the Afm phases (which have higher specific density, particularly the formation of ettringite from denser precursors) may produce expansion that can generate stresses within concrete (Glasser, 2002). The amount of expansion depends on mass gain and mass loss from leaching. When the concrete is immersed in flowing or aggressive water, the mass loss can be significant, as the factors that affect the expansion potential are often specific to particular exposure environments and also depend on the nature of the concrete material e.g., its permeability.

Moreover, investigations have shown that ettringite phases can occur in a variety of forms because ettringite crystals exhibit a changing composition in all components. According to Lukas (1976), in addition to the main ettringite components $\left(\mathrm{CaO}, \mathrm{Al}_{2} \mathrm{O}_{3}, \mathrm{SO}_{3}\right)$, silicon oxides $\left(\mathrm{SiO}_{2}\right)$ was found to be included as a proxy for $\mathrm{Al}_{2} \mathrm{O}_{3}$ producing Si-ettringite (Figure 2.4). Jones (1938) reported the replacement of $\mathrm{Al}_{2} \mathrm{O}_{3}$ with iron oxides $\left(\mathrm{Fe}_{2} \mathrm{O}_{3}\right)$

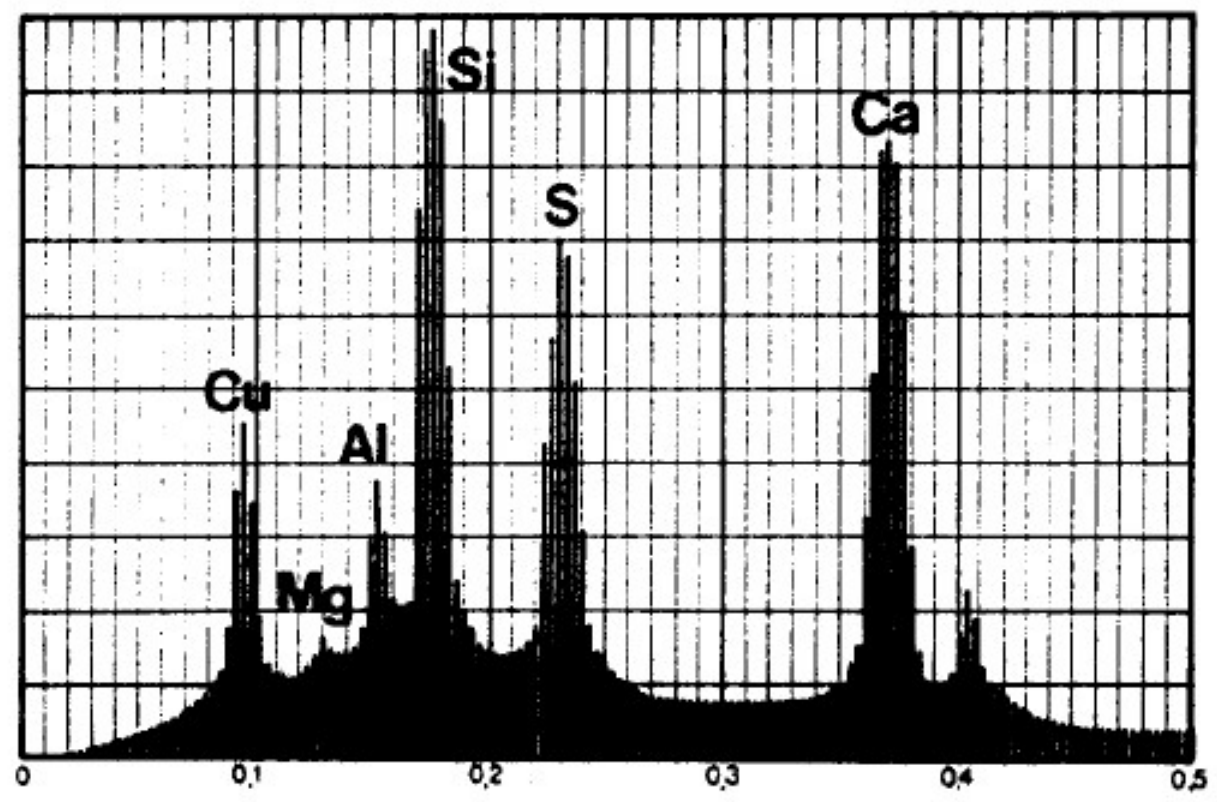

Figure 2.4. EM-element analysis for Si-Ettringite (Lukas, 1976) 
Ettringite in a $\mathrm{CaO}, \mathrm{Al}_{2} \mathrm{O}_{3}, \mathrm{SO}_{3}, \mathrm{H}_{2} \mathrm{O}$ system has an $\mathrm{Al}: \mathrm{Ca}$ ratio of 0.33 and an $\mathrm{S}$ : Ca ratio of 0.5 , whereas monosulphoaluminate has an $\mathrm{Al}$ : Ca ratio of 0.5 and an $\mathrm{S}$ : Ca ratio of 0.25 . In some cases, these ratios were not achieved, but researchers considered the product as ettringite or monosulphoaluminate where $\mathrm{Si}, \mathrm{CO}_{3}, \mathrm{OH}^{-}$or $\mathrm{Fe}$ were considered proxies for aluminum or sulphur (Lukas, 1976; Diamond \& Lachowski, 1983; Kuzel, 1996; Glasser, 2002)

\section{i. Delayed ettringite formation}

Delayed ettringite formation refers to late-stage ettringite formation after setting and hardening of the cement paste accompanied by the development of high pressure and may cause cracking and deterioration of the concrete element. In normal cases, when the normal formation of ettringite is delayed or reformed at later ages in the hardened concrete, this may be accompanied by deleterious expansion.

Heat curing is commonly used in the production of pre-cast concrete elements to increase the rate of hydration and accelerate early-age strength development. As explained by Fu, Ding, and Beaudoin (1997), when concrete elements are exposed to excessive temperature during early stages of curing $\left(>70^{\circ} \mathrm{C}\right)$ as a result of heat curing or self-heating or both, the sulphate in cement systems could be bound in the C-S-H gel structure to form a new phase called "phase X". The CS-H gel adsorbs sulphate resulting in a relatively quick disappearance of the gypsum phase in CS-H- gypsum mixtures. C-S-H gel (i.e., adsorbed sulphate at a high temperature) releases the sulphate more slowly than the gel that has adsorbed sulphate at a normal temperature. This slower release of sulphate from an internal sulphate source (i.e., phase X) causes DEF.

Fu et al. (1997) investigated the effect of curing temperature on the expansion of cement mortars. In all the samples that were cured at $80^{\circ} \mathrm{C}$ and $90^{\circ} \mathrm{C}$, expansions developed within 90 days. Moreover, as shown in Figure 2.5, the rise in curing temperature resulted in a significantly 
increased expansion of the mortars. In other words, curing at high-temperature results in a high concentration of sulphate in the pore fluid, and hence a significant amount of sulphate incorporated in the calcium silicate hydrate (C-S-H). With exposure to moisture at ambient temperature, the sulphate is released from the C-S-H, leading to the formation of ettringite in the hardened material (Ramlochan, 2003).

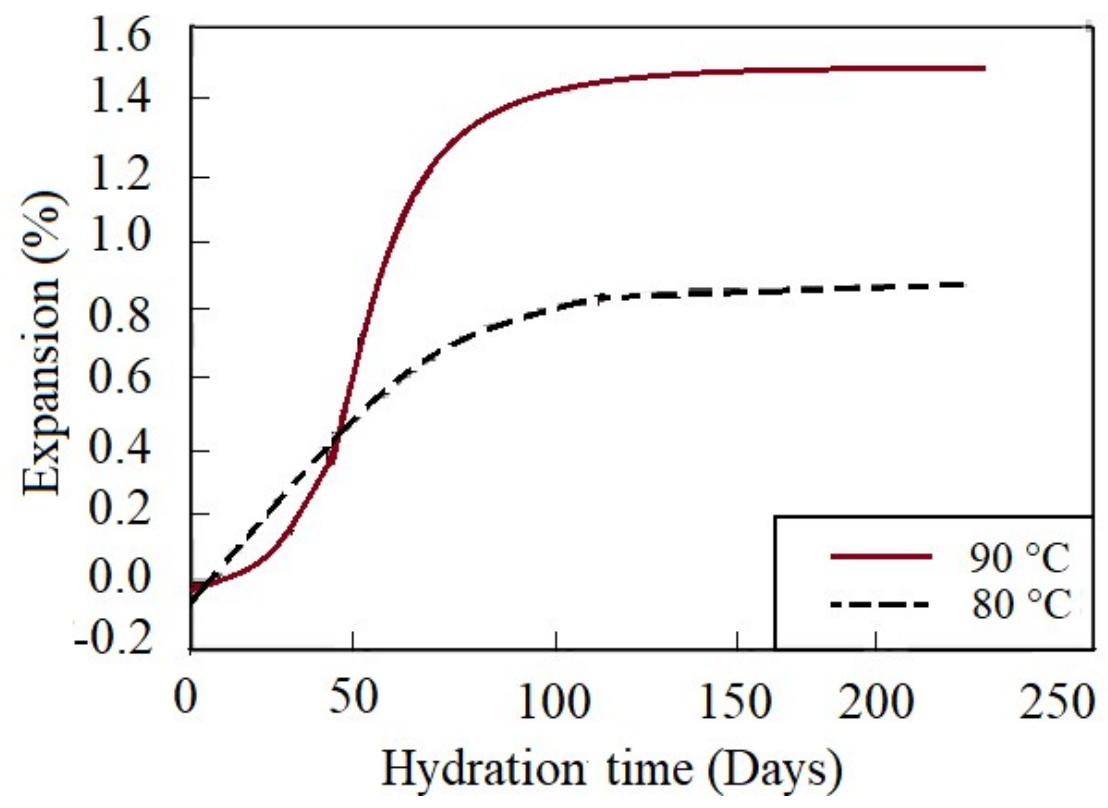

Figure 2.5. Effect of curing temperature on expansion (Fu et al., 1997)

\section{ii. Secondary ettringite formation}

Collepardi (1999), studied the mechanism of secondary ettringite formation and summarized that the damage caused by SEF is based on a chain of three essential elements: (a) micro-cracking, (b) exposure to water or saturated air, and (c) late sulphate release.

Sulphate ions from calcium sulphate can readily migrate into the nearest cracks, react with the tricalcium aluminate phase of the hydrated cement paste or mono-sulphoaluminate, and recrystallize in the form of high molar volume ettringite (Casanova, Aguado, \& Agullo, 1997a), as shown in following reactions: 
$3\left(\mathrm{CaSO}_{4} \cdot 2 \mathrm{H}_{2} \mathrm{O}\right)+\mathrm{C}_{3} \mathrm{~A}+26 \mathrm{H}_{2} \mathrm{O} \rightarrow \mathrm{C}_{3} \mathrm{~A} \cdot 3 \mathrm{CaSo}_{4} \cdot \mathrm{H}_{32}$ (ettringite)

Eq. (2.1)

$2 \mathrm{CSH}_{2}+\mathrm{C}_{4} \mathrm{ASH}_{12}$ (monosulphoaluminate) $+16 \mathrm{H}_{2} \mathrm{O} \rightarrow \mathrm{C}_{6} \mathrm{AS}_{3} \cdot \mathrm{H}_{32}$ (ettringite) $\quad$ Eq. (2.2)

\section{c. Thaumasite sulphate attack (TSA)}

There is a significant difference between Thaumasite formation (TF) and Thaumasite sulphate attack (TSA). If the thaumasite forms within the voids and cracks without any signs of deterioration to the structure, it is called thaumasite formation (TF). This is not considered problematic to concrete. On the other hand, TSA is the reaction product associated with severe sulphate attack. It can cause deterioration in the concrete by the formation of expansive material, resulting in a volume increase. It can also attack the C-S-H matrix in the cement paste, converting it to mush (Brown, 2002).

Thaumasite is a calcium carbonate-silicate sulphate hydrate with the following formula (Bensted, 2003): $\mathrm{Ca}_{6}\left[\mathrm{Si}(\mathrm{OH})_{6}\right]_{2}\left(\mathrm{CO}_{3}\right)_{2}\left(\mathrm{SO}_{4}\right)_{2} \cdot 24 \mathrm{H}_{2} \mathrm{O}$ or $\mathrm{CaSiO}_{3} \cdot \mathrm{CaCO}_{3} \cdot \mathrm{CaSO}_{4} \cdot 15 \mathrm{H}_{2} \mathrm{O}$. Formation of Thaumasite requires the transportation of $\mathrm{Ca}^{+2}, \mathrm{CO}_{3}^{-2}, \mathrm{SO}_{4}^{-2}$ ions and sufficient moisture through the hardened cement (Kakali, Tsivilis, Skaropoulou, Sharp, \& Swamy, 2003) as well as the presence of sulphates and carbonates. Carbonates may be present in concrete due either to carbonation from surrounding air or to cement fillers such as limestone (Shi, Wang, \& Behnood, 2012).

Thaumasite formation favours low temperatures compared to ettringite; $5^{\circ} \mathrm{C}$ is thought to be the optimal temperature to promote thaumasite sulphate attack TSA (Collepardi, 1999). Moreover, Thaumasite deterioration is often more severe than that caused by ettringite, as it attacks silicate, which occurs in a high percentage in Portland cement; it also occurs more rapidly (Shi et al., 2012). 
Kakali et al. (2003) investigated the effect of temperature and lime content on thaumasite formation by exposing mortars to sulphate solution at $5^{\circ} \mathrm{C}$ and $23^{\circ} \mathrm{C}$ with different lime content. Samples stored in $5^{\circ} \mathrm{C}$ showed deterioration after eight months, while deterioration took longer for samples stored at $23^{\circ} \mathrm{C}$. It was also noticed that damage due to sulphate attack was more severe with higher salt content. Although it is commonly agreed that thaumasite formation is favourable at low temperature $\left(<5^{\circ} \mathrm{C}\right)$, it was also reported at a higher temperature close to room temperature (Macphee \& Diamond, 2003).

Köhler, Heinz, \& Urbonas (2006) investigated the effect of the ettringite on the formation of thaumasite. As thaumasite was detected in samples where ettringite formation was recorded, the authors suggested that Thaumasite starts at the surface of ettringite and uses the ettringite as heterogeneous nucleation due to the structural similarities of these minerals. This is then followed by the growth of Thaumasite at lower layers. This theory was also reaffirmed in the work of Crammond (2003), where it was concluded that thaumasite uses ettringite for its initial nucleation.

\subsection{Types of Sulphate Attack}

\subsubsection{External sulphate attack}

The term external sulphate attack (ESA) refers to the occurrence of a sulphate attack caused by the presence of an external source of sulphate in the environment surrounding the concrete. These sources may include but are not limited to, sulphate salts in groundwater surrounding concrete foundations or sulphate salts in water. Salts in their solid states do not attack concrete, but when present in solution, they can react with hydrated cement paste (Neville, 1963).

Common sulphates that have a deleterious effect on concrete are sodium, potassium, magnesium, and calcium sulphate, all of which occur in soil or groundwater. Soluble sulphates can react with 
calcium hydroxide and produce gypsum and acids, which may cause complete leaching of calcium hydroxide (Neville, 1963), these reactions create high internal pressure to damage the cement paste, causing severe deterioration of the concrete (Kosmatka et al., 2002).

\subsubsection{Internal sulphate attack}

The term internal sulphate attack (ISA) refers to the occurrence of sulphate attack due to the presence of a source of sulphate in the concrete. Concrete damage caused by internal sulphate attack is often the result of the presence of sulphate ions sources either from added natural waters or gypsum used for the concrete mix (Casanova, Aguado, \& Agullo, 1997b). Evidence of this type of attack is most likely to appear in concrete members subjected to open-air and drying/wetting cycles (Fu et al., 1997), depending on cement composition and mix proportioning (Casanova et al., 1997b).

Sources of ISA could be sulphate-rich aggregate or excess of gypsum in the cement. Three critical conditions were reported in (Fu et al., 1997) to have a significant effect on internal sulphate attack:

(i) Portland cement composition, i.e., the content of $\mathrm{C}_{3} \mathrm{~A}$ and $\mathrm{SO}_{3}$; (ii) curing temperatures; and (iii) exposure to a moist environment.

Rapid deterioration of concrete elements has been recorded around the world (Penner, Eden, \& Grattan-Bellew, 1972; Dougherty \& Barsotti, 1972a; Hawkins \& Pinches, 1992; Belgeri \& Siegel, 1998a; Rodrigues et al., 2012; Bassili Guirguis, 2017). In most of these cases, the coarse aggregate used to produce the concrete contained various proportions of sulphide minerals. These deteriorations were attributed to the oxidation of sulphide minerals that were thought to have caused the swelling and cracking of the affected concrete elements. 


\subsubsection{Calcium sulphate}

Calcium sulphate $\left(\mathrm{CaSO}_{4}\right)$ is added to the clinker during the manufacture of cement to regulate the initial setting time to prevent flash setting. However, it is considered one of the primary sources of internal sulphate attack in concrete. The reaction between calcium sulphate and tri-calcium aluminate $\left(\mathrm{C}_{3} \mathrm{~A}\right)$ in fresh concrete results in the formation of ettringite (primary ettringite formation). This reaction has no deleterious effects on concrete, as it takes place prior to the hardening of the concrete. Nevertheless, if this reaction continued after the hardening, it would produce delayed ettringite due to the slow release of sulphates from the calcium sulphate. This would then cause internal stress in the concrete, resulting in damage to the concrete elements $(\mathrm{Xu}$, Wang, \& Zhang, 2012).

\subsubsection{Oxidation of sulphide-bearing aggregate}

A significant source of internal sulphate attack is the oxidation of iron sulphide minerals, mainly pyrrhotite. These minerals are unstable upon exposure to oxygen and air. Furthermore, this type of attack is usually followed by the formation of secondary ettringite and thaumasite formation, materials which are considered responsible for the swelling and cracking of the concrete (Ramos, Rodrigues, Fournier, \& Duchesne, 2016).

The stability of elemental sulphur is a significant issue in the field of civil construction. Moreover, the presence of iron sulphides in aggregates has recently become recognized as a problem in concrete durability. The degree of oxidation leads to the identification of the potential for future problems, such as expansion caused by sulphate attack or sulfuric acid production.

Sulphide problems have occurred in materials containing even a very small percentage of sulphide. In fact, about $0.1 \%$ of sulphide minerals can result in the production of harmful oxidation 
products such as sulphates, in the form of sulfuric acid $\left(\mathrm{H}_{2} \mathrm{SO}_{4}\right)$ and aluminum sulphates, when oxidized (Nordstorm \& Alpers, 1999). The products of sulphide oxidation reactions are much less dense than the original sulphide and therefore occupy more volume than the initial sulphide product. These products can occupy up to eight times the volume of the original sulphide mineral (Dougherty \& Barsotti, 1972a). As a direct result, concrete expansion and degradation may take place. Hence, sulphide minerals are generally of the greatest concern in engineering systems.

Oxidation also increases with higher alkalinity level (Hawkins \& Pinches, 1992). According to (Casanova et al., 1997b), sulphides will be unstable at $\mathrm{pH}$ values $>10$, and the speed of oxidation is very high under $\mathrm{pH}$ between 12.5 and 13.7. They also indicated that for $\mathrm{pH}$ levels between 7.5 and 8.5, the sulphide oxidation rate is independent of the alkalinity and is mainly controlled by oxygen availability and grain size.

\subsubsection{Iron sulphide minerals}

Sulphide minerals are reactive when exposed to air and humidity, forming mainly as a combination of the element sulphur and various kinds of metals, such as iron (Guirguis, 2017).

Pyrite $\left(\mathrm{FeS}_{2}\right)$ and pyrrhotite $(\mathrm{Fe} 1-\mathrm{xS}(\mathrm{x}=0$ to $\mathrm{x}=0.2))$ are the most common and easily oxidized sulphide minerals linking sulphide with iron. These minerals are often found in sedimentary rocks, such as shale and ore deposits (Bryant, 2003). Humidity and the rate of the curing temperature affects the rate of oxidation, with high temperatures accelerating oxidation processes (Hawkins \& Pinches, 1992).

\section{a. Pyrite $\left(\mathrm{FeS}_{2}\right)$}

Pyrite, known as fool's gold, is an iron sulphide mineral that produces sulfuric acid when oxidized. Pyrite oxidation by $\mathrm{O}_{2}$ and water produces ferrous iron ( $\mathrm{Fe}^{+2}$, reduced iron), sulphates $\left(\mathrm{SO}_{4}^{-2}\right)$, and 
acid $\left(\mathrm{H}^{+}\right)$(Skousen, Sexstone, \& Ziemkiewicz, 2000), as shown in Eq. (2.3). Oxidation of ferrous iron produces ferric iron $(\mathrm{Fe}+3)$, as given in Eq. (2.4), while ferric iron can be hydrolyzed to produce ferric hydroxide $\left(\mathrm{Fe}(\mathrm{OH})_{3}\right)$ and acidity, as expressed in Eq. (2.5).

$\mathrm{FeS}_{2}+7 / 2 \mathrm{O}_{2}+\mathrm{H}_{2} \mathrm{O} \rightarrow \mathrm{Fe}^{+2}+2 \mathrm{SO}_{4}{ }^{-2}+2 \mathrm{H}^{+}$

$\mathrm{Fe}^{+2}+1 / 4 \mathrm{O}_{2}+\mathrm{H}+\rightarrow \mathrm{Fe}^{+3}+1 / 2 \mathrm{H}_{2} \mathrm{O}$

$\mathrm{Fe}^{+3}+3 \mathrm{H}_{2} \mathrm{O} \rightarrow \mathrm{Fe}(\mathrm{OH})_{3}+3 \mathrm{H}^{+}$

After oxidation, sulphides release sulphuric acids that react with the calcium hydroxide, causing sulphate attack. Acids dissolve the hydration components of the cement that holds the concrete together (Chinchón et al., 1995). The sulfuric acid can attack the calcium hydroxide or the calcium silicate hydrate, releasing calcium ions to form gypsum, as expressed in Eqs. (2.6) and (2.7) (Monteny et al., 2000).

$\mathrm{Ca}(\mathrm{OH})_{2}+\mathrm{H}_{2} \mathrm{SO}_{4} \rightarrow \mathrm{CaSO}_{4} \cdot 2 \mathrm{H}_{2} \mathrm{O}$

$\mathrm{CaO} \cdot \mathrm{SiO}_{2} \cdot 2 \mathrm{H}_{2} \mathrm{O}+\mathrm{H}_{2} \mathrm{SO}_{4} \rightarrow \mathrm{CaSO}_{4}+\mathrm{Si}(\mathrm{OH})_{4}+\mathrm{H}_{2} \mathrm{O}$

This reaction results in the formation of gypsum that occupies several times the volume of the original sulphides (Orndorff, 2001) and results in significant loss of strength properties, spalling, pop-outs, hairline cracks (etching), and concrete expansion/heave (Skalny et al., 2003).

Sulphate ions from calcium sulphate can readily migrate into the nearest cracks, react with the tricalcium aluminate phase of the hydrated cement paste or mono-sulphoaluminate, and recrystallize in the form of high molar volume ettringite (Casanova et al., 1997b), as indicated in following reactions: 
$3\left(\mathrm{CaSO}_{4} \cdot 2 \mathrm{H}_{2} \mathrm{O}\right)+\mathrm{C}_{3} \mathrm{~A}+26 \mathrm{H}_{2} \mathrm{O} \rightarrow \mathrm{C} 3 \mathrm{~A} \cdot 3 \mathrm{CaSO}_{4} \cdot \mathrm{H}_{32}$ (ettringite)

Eq. (2.8)

$2 \mathrm{CSH}_{2}+\mathrm{C}_{4} \mathrm{ASH}_{12}$ (monosulphoaluminate) $+16 \mathrm{H}_{2} \mathrm{O} \rightarrow \mathrm{C}_{6} \mathrm{AS}_{3} \cdot \mathrm{H}_{32}$ (ettringite) Eq. (2.9)

\section{b. Pyrrhotite (Fe1-xS)}

Pyrrhotite minerals are considered the second most dominant minerals in sulphur-rich aggregate after pyrite. They can be found in sulphide-bearing aggregates in many places around the world, especially Canada, Russia, Australia, and China. Pyrrhotites were found on most of the problematic aggregates that were susceptible to oxidation around the world (Belgeri \& Siegel, 1998; Dougherty \& Barsotti, 1972; Hawkins \& Pinches, 1997; Rodrigues et al., 2016).

When pyrrhotite is exposed to open air and moisture conditions over a long period of time, it develops widespread surface oxidation, which may lead to the formation of a thin overlying layer of ferric oxide/hydroxide (C. F. Jones, LeCount, Smart, \& White, 1992). Thus, pyrrhotite minerals are very harmful to concrete. According to Chinchón-Payá, Aguado, and Chinchón (2012), degradation of pyrrhotite takes place much faster than the degradation of pyrite. When aggregates containing pyrrhotite and pyrite minerals were soaked in a water solution with a constant oxygen flow for almost two months, Pyrrhotite generated a larger amount of $\mathrm{SO}_{42}$ - and $\mathrm{Fe}_{2}$ than pyrite grains. This behaviour can be explained by the study conducted by Belzile, Chen, Cai, and Li (2004), who found that the specific surface (crystal structure) of crystalline pyrrhotite is two to ten times larger than crystalline pyrite. Moreover, Craig and Vokes (1993) reported that the Vickers hardness number (VHN) of pyrrhotite is between 230 and 318, compared to the VHN of pyrite being between 1505-1620. This measurement indicates that pyrrhotite is much weaker than pyrite, the latter which can stand far more deformations. 


\subsection{Mitigation of Internal Sulphate Attack Using Supplementary Cementing Materials}

The durability of concrete paste when subjected to a sulphate environment, whether internal or external, was related to the $\mathrm{C}_{3} \mathrm{~A}$ content (Wedding \& Dunstan, 1980). Cement with lower tricalcium aluminate content generally exhibits higher sulphate resistance. According to the ASTM standards for Portland cement (ASTM C150, 2018), in sulphate-resistant cement, the $\mathrm{C}_{3} \mathrm{~A}$ content should not exceed 5 to $8 \%$.

The incorporation of supplementary cementitious materials such as blast-furnace slag, fly ash, and metakaolin in the cement industry as a partial replacement of Portland cement was found to enhance the resistance to sulphate attack by slowing down the formation of Thaumasite (Wedding \& Dunstan, 1980). The enhanced concrete durability is not yet confirmed as resulting from decreasing the concrete permeability and enhancing the pore structure within the concrete, or from binding between sulphide and supplementary cementing materials that can reduce the reaction between sulfuric acid and calcium hydroxide.

Ramlochan (2003) investigated the expansive behaviour of heat-cured Portland cement mortars and concretes containing pozzolans such as silica fume, slag, metakaolin, and fly ash. He found that, in general, using any amount of supplementary cementing materials into the mixture reduced the long-term expansion and slowed the rate of expansion. The use of supplementary cementing materials to resist external sulphate attack is recommended in CSA A 3001, Table 9, sub-clause 3 (Hooton, Nokken, \& Thomas, 2007), to obtain moderate or highly sulphate-resistant blended hydraulic cement. This blend includes minimum 40\% slag, minimum 25\% Fly Ash Class F, 15\% Metakaolin, 5\% Type SF Silica Fume $+25 \%$ slag, or 5\% Type SF Silica Fume $+20 \%$ Fly Ash Class F. 


\section{- Fly ash}

Fly ash is produced from burning coal (usually used in power plants). There are different types of fly ashes; some increase the sulphate resistance of concrete, while others increase the susceptibility of concrete to deterioration in a sulphate environment (Tikalsky, 1993).

High calcium fly ash (HCFA) with calcium content $>20 \%$ was reported to have low sulphate resistance (Tikalsky, 1992, 1993; Thomas, Shehata, Shashiprakash, Hopkins, \& Cail, 1999). Shehata, Adhikari and Radomski (2008) studied the effects of HCFA on the sulphate resistance of mortar bars subjected to sodium sulphate. The study aimed to enhance the resistance of HCFA to sulphate attack by using HCFA with silica fume (SF) and GUPC, and by introducing gypsum to HCFA to optimize the ratio of the reactive aluminate phase to sulphur content. The results indicated that high-calcium fly ash has the lowest resistance to sulphate attack. Blending high calcium fly ash with an optimum amount of gypsum or 5\% silica fume (SF) increased the resistance to sulphate attack, with better resistance with silica fume. The small amounts of silica fume reduced the calcium hydroxide $(\mathrm{CH})$ and resulted in a more stable calcium aluminosilicate and finer pore structure. Blending high calcium fly ash with gypsum also sustained the early formation of stable ettringite rather than monosulphate.

The ratio of the reactive alumina to sulphate in the cement-fly ash blend likewise has a significant effect on concrete sulphate resistance (Mehta, 1986). A high ratio enhances the formation of monosulphate and calcium aluminate hydrate, which will convert to ettringite in the presence of sulphate.

This low resistance of HCFA to sulphate attack may be attributed to the reactive calcium aluminosilicate glass in HCFA, as well as cementitious crystalline compounds of calcium such as $\mathrm{C}_{3} \mathrm{~A}, \mathrm{C}_{4} \mathrm{~A}_{3} \mathrm{~S}, \mathrm{CS}$, and $\mathrm{CaO}$, which produce more sulphate-susceptible calcium aluminate hydrate 
(C-A-H) during hydration (P. K. Mehta, 1986; Tikalsky, 1992; Freeman \& Carrasquillo, 1995; Thomas et al., 1999). On the other hand, low calcium fly ash (LCFA) was found to improve the sulphate resistance of GU-PC. This improvement is attributed to the delayed ettringite formation and the pozzolanic reaction that reduces $\mathrm{CH}$ in mortars and, consequently, gypsum formation (Irassar \& Batic, 1989).

\section{- Blast furnace slag}

Blast furnace slag (GGBFS) is one of the by-products from an iron blast furnace that can be used as supplementary cementing material after being ground down into very fine particles. Researchers have found that the use of slag as an SCM can increase the durability of concrete and play an effective role in decreasing sulphate-induced damage (Ramlochan, 2003; Binici \& Aksoğan, 2006; Topçu \& Bilir, 2007).

The enhanced resistivity of GGBFS to sulphate attack is attributed to its low permeability and enhanced pore structure within the concrete. Ramlochan (2003) studied the dimensional stability of mortar bars and concrete prisms containing various levels of pozzolans and slag that were subjected to high curing temperatures of $60,70,80$, or $95^{\circ} \mathrm{C}$ for around 12 hours. The samples were then exposed to moisture at ambient temperature and monitored for periods of up to 4 years. In samples without pozzolans, no expansion was recorded at $60^{\circ} \mathrm{C}$, but at higher temperatures $\left(\sim 95^{\circ} \mathrm{C}\right)$, expansion reached $3.0 \%$.

Mortars made with $25 \%$ and $35 \%$ blast furnace slag expanded considerably less $(<0.02 \%$ expansion) when heat cured at $95^{\circ} \mathrm{C}$ after more than 3.5 years of storage. However, there was some long-term expansion with $25 \% \operatorname{slag}\left(0.2 \%\right.$ after three years) when heat cured at $95^{\circ} \mathrm{C}$, though not with $35 \%$ slag. Samples with only $10 \%$ slag expanded by more than $1.0 \%$ after only one year. 


\section{- Metakaolin (MK)}

Metakaolin (MK) is a common term used for calcined kaolin, which is composed of relatively pure alumino-silicate clay with very low alkali content (Transportation Research Board, 2013). Recently, metakaolin has been used as a supplementary cementation material that has been found to produce high strength concrete with improved durability (Al-Akhras, 2006). It has a commercial product of high purity with a mean particle size of $5.1 \mu \mathrm{m}$ (Kakali et al., 2003) and has proven effective in reducing thaumasite-type sulphate attack in concrete containing limestone filler (Smallwood, Wild, \& Morgan, 2003).

Al-Akhras (2006) tested concrete prisms with different levels of metakaolin and water/cementing material ratios. The researcher observed that cracks of plain and MK concrete specimens due to sulphate attack started first at the corners of the concrete specimens and then propagated across the surface of the specimens. Table 2.1 shows the time to cracking for the twelve tested samples. As can be seen, the greater the metakaolin replacement, the longer the time for cracks to appear. The table also illustrates that high-pressure steam curing (autoclave curing) and a lower w/c ratio increase the cracking time.

Specimens with 10 to $15 \%$ MK replacement showed excellent durability to sulphate attack, with maximum sulphate expansion values occurring after 18 months of sulphate exposure. Expansions after 18 months for samples with only Portland cement were $0.40 \%$ and $0.45 \%$ for a w/cementation ratio of 0.5 and 0.6 , respectively. When using $15 \% \mathrm{MK}$, these expansions decreased to $0.10 \%$ and $0.07 \%$, respectively, for concrete with the same w/cementation. The improved behaviour of the MK concrete was likely due to the following reasons:

- A reduction in the total amount of tricalcium aluminate hydrate in the cement paste matrix by the replacement of a portion of Portland cement with MK. 
- Less gypsum formation due to the pozzolanic reaction between the MK and calcium hydroxide released during the hydration of cement, which consumes part of the calcium hydroxide.

- Formation of secondary C-S-H by the pozzolanic reaction. Although less dense than the primary C-S-H gel, it is effective in filling and segmenting large capillary pores, thus reducing the total permeability of concrete.

Table 2.1. Time to Cracking for Metakaolin Concrete Prisms Subject to Sulphate (Al-Akhras, 2006)

\begin{tabular}{ccccc}
\cline { 2 - 5 } W/C & \multicolumn{4}{c}{ Time to Cracking (Days) } \\
\cline { 2 - 5 } & $0 \%$ & $5 \%$ & $10 \%$ & $15 \%$ \\
\hline \hline 0.5 (Moist curing) & 180 & 240 & 300 & 360 \\
\hline 0.5 (Autoclave curing) & 300 & 500 & No crack & No crack \\
\hline 0.6 (Moist curing) & 150 & 200 & 260 & 310 \\
\hline \hline
\end{tabular}

It was also concluded that autoclave curing of concrete using high-pressure steam produces tricalcium aluminate hydrates that are more stable in the presence of sulphate ions than those formed in the moist cured concrete specimens (A. Neville, 2004). Moreover, autoclave curing causes a greater reduction in pore volume than does moist curing, resulting in decreased permeability and thereby preventing sulphate ions from intruding into autoclaved concrete.

Kakali et al. (2003) studied the effect of adding a secondary mineral on the sulphate resistance of limestone cement mortars. Ordinary Portland cement was replaced 10 to $50 \%$ by mass (depending on the mineral) with fly ash, blast furnace slag, natural pozzolans, and metakaolin. Deterioration started on the mortars with only Portland cement and natural pozzolans after only eight and seven months, respectively. Samples with fly ash started to deteriorate after eleven months, while no 
deterioration appeared on traced samples with blast furnace slag or metakaolin. This behaviour was attributed to the lower permeability and pore refinement of the composite cement.

In the deteriorated mortars, XRD revealed the formation of mainly thaumasite, gypsum and brucite with small amounts of ettringite. Moreover, as no calcium hydroxide was detected in the degradation product, it was concluded that it was all consumed by the brucite.

The compressive strength at 28 days was also recorded for mortars with different supplementary cementing materials. Metakaolin and blast furnace slag led to an increase in compressive strength. Fly ash, on the other hand, did not affect the strength, and the addition of natural pozzolans actually caused a reduction in strength. After nine months of exposure to a sulphate solution, the strength of mortars with natural pozzolans had dropped $34 \%$ from the 28 -day strength, while ordinary mortars had dropped $18 \%$ and fly ash mortars $9 \%$. No reduction was measured in mortars with metakaolin or blast furnace slag.

Ramlochan (2003) investigated the effect of using $8 \%$ metakaolin in mortar bars subjected to heat curing. No significant expansion was observed with any of the heat-cured mortars. In general, long-term expansions were $0.03 \%$ with all of the cement investigated after as long as four years of storage in limewater. For samples with $25 \%$ slag, $25 \%$ fly ash and $8 \%$ metakaolin, mortar retardation in the early hydration (especially in the alite phase) was recorded but with more dense paste and much less visible porosity than the Portland cement mortar.

At 90 days, in mortars with $8 \%$ metakaolin, $25 \%$ blast furnace slag, or $25 \%$ fly ash (both Class $\mathrm{F}$ and Class C), numerous clusters of ettringite were detected in all of the voids. The clusters were more significant than those found in the $8 \%$ silica fume specimen at this age and were similar in size to those found in the $95^{\circ} \mathrm{C}$ Portland cement mortar. After 500-1350 days, no significant 
expansion or cracking in any of the mortars was recorded. All of the air voids were filled with ettringite, along with some calcium hydroxide.

The study indicated that the effectiveness of pozzolans to control expansion is higher with materials that contained a significant amount of reactive alumina. This was concluded as the expansive behaviour of mortars with $8 \%$ metakaolin was considerably less than mortars with $8 \%$ silica fume. Nevertheless, both metakaolin and silica fume are capable of producing a denser, less porous past, consume portlandite, and promote the formation of supplemental C-S-H, which will be beneficial in reducing expansion.

Guirguis et al. (2018) investigated the effects of different cementing blends with supplementary cementitious materials ( $\mathrm{SCM}$ ) on the damage due to oxidation of iron sulphide-bearing aggregates. The test was applied on maskimo, a sulphide-bearing aggregate deemed responsible for the deterioration of structural elements in several earlier studies (e.g., Guirguis \& Shehata, 2017; Rodrigues, Duchesne, \& Fournier, 2016b; Rodrigues et al., 2015, 2012), and two control aggregates with no sulphide contents.

Different cementitious material blends were used: a general use Portland cement (GU-PC); low heat of hydration Portland cement (LH-PC), and high-sulphate resisting Portland cement (HSFPC) with about $8 \%$ silica fume. Also, three types of SCMs were used as partial replacement of the GU-PC: $25 \%$ low-calcium fly ash (FA), 30\% slag (S) and 10\% metakaolin (MK). As shown in Figure 2.6, most of the mass gain was achieved within the first three hours for all samples. The same test was repeated using $20 \% \mathrm{CaCl}_{2}$ solution to investigate the penetration depth of the solution with time. As Figure 2.7 illustrates, the concentration of chloride ions within the samples changes with time without a significant alteration in the mass gain of the bars, especially in samples with SCMs. 
According to the authors, this behaviour may be explained by the more refined pore structure of the samples, particularly with SCM, where they remain at relative humidity higher than $80 \%$ or close to saturation while in the oven. Hence, the solution penetrates the outer part of the sample cross-section and the ions continue to diffuse within the water-saturated cores of the samples.

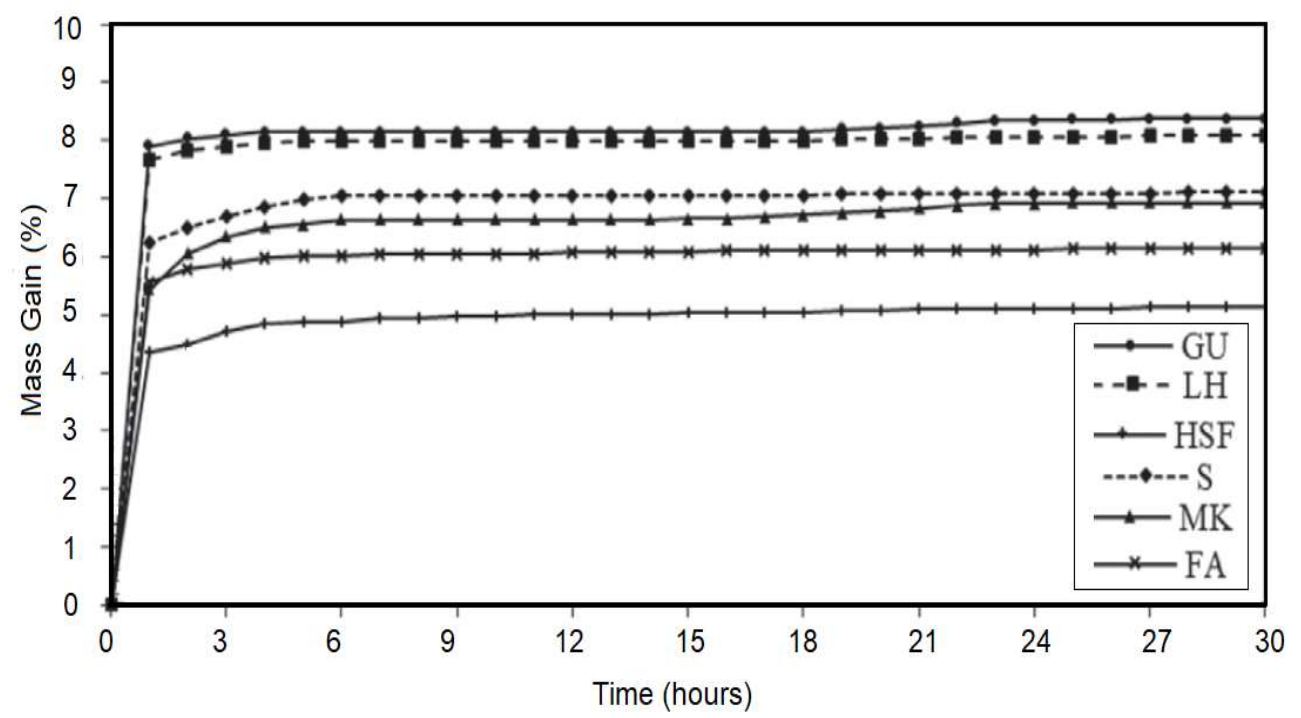

Figure 2.6. The mass gain of mortar bars with time after soaking for 30 hours (Guirguis et al., 2018) 


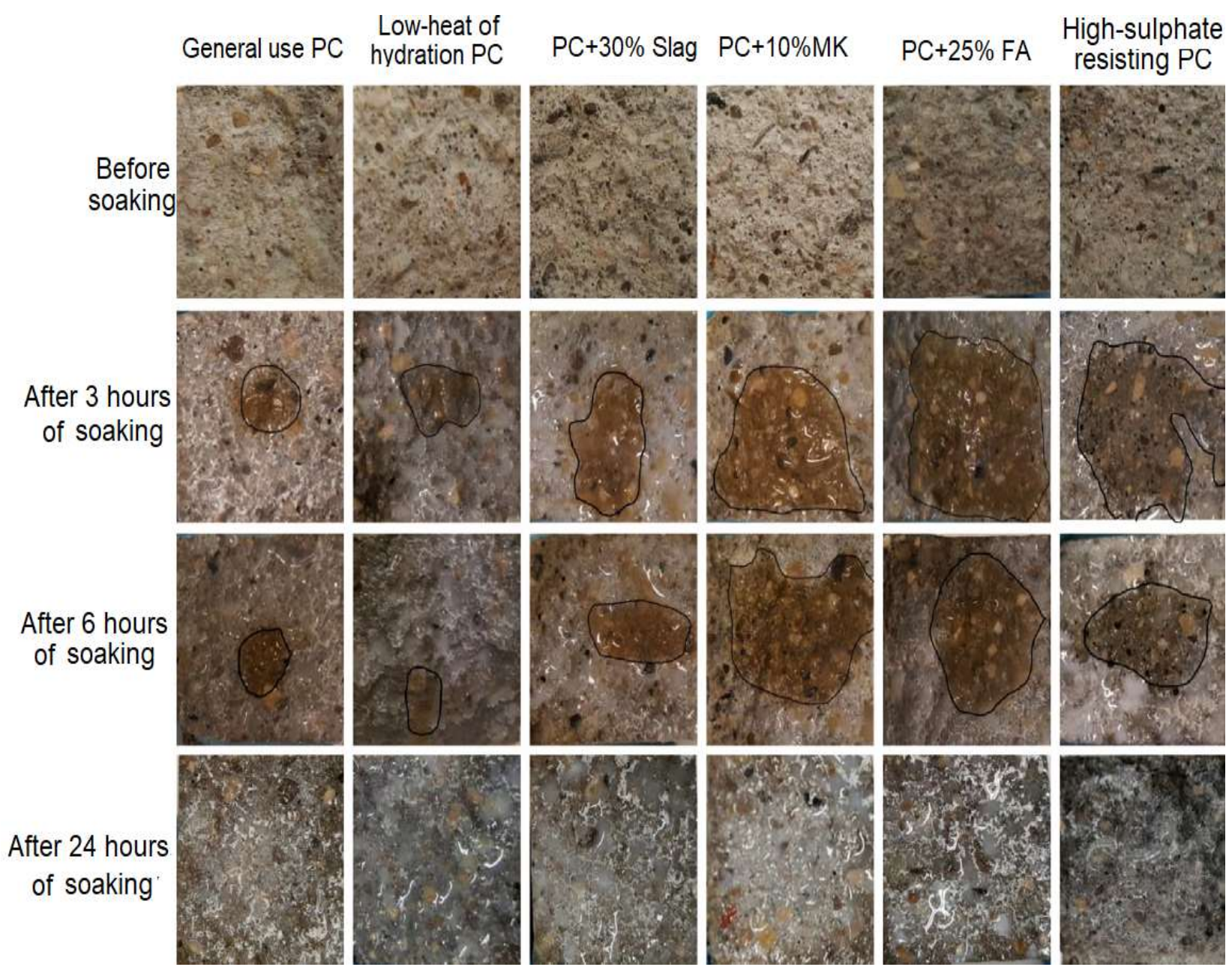

Figure 2.7. Penetration of soaking solution into the samples after different times of exposure (Guirguis et al., 2018)

\subsection{Evaluation of Sulphide-bearing Aggregates}

\subsubsection{Midgley test}

Midgley (1958) developed a rapid qualitative test for the evaluation of susceptibility of iron sulphide bearing aggregates to oxidation. The procedure involved immersing the aggregate in a saturated lime water solution. If blue-green ferrous sulphides form within 30 minutes and turn into brown when exposed to air, this indicates the presence of potential deleterious material or the potential reactivity of the aggregates. 
The Midgley test was modified in the work of Ramos et al. (2016), as it was unable to detect the potential oxidation of the aggregate that was responsible for the severe deterioration in the concrete foundation in Trois-Rivières, Quebec. The modifications included using hydrogen peroxide and sodium hypochlorite solutions as oxidizing agents instead of the lime-water solution. However, with these modifications, the test failed to assess the oxidation potential of some of the sulphide-bearing aggregates.

\subsubsection{Steam test}

A steam test was developed by Seaton (1948) to detect the impurities in cinder aggregates. The procedure involves placing three representative samples of the crushed aggregate in a foldable white filter paper foldable as superimposed layers in a cheesecloth bag. The bag is then saturated with water and exposed to steam at $100^{\circ} \mathrm{C}$ for a minimum of 16 hours. After removing the bag from the steam bath, the aggregates are carefully removed from the papers and the papers are thoroughly washed with clean tap water and dried in an oven at 94 to $105^{\circ} \mathrm{C}$. The quantity and intensity of the characteristic stains on the papers can be then used to evaluate the tendency of the aggregate to develop Class 2 pop-outs. Hence, Seaton (1948) established a stain index as a graduated scale of classification based on visual examination of the filter papers.

Although the steam test was adopted in ASTM specifications (C641) for iron-staining materials in lightweight concrete, it was unable to detect the potential oxidation of the aggregate that was responsible for the severe deterioration in the concrete foundation in Trois-Rivières, Quebec, Canada (Ramos et al., 2016). This led to the subsequent development of two chemical tests based on the Midgley test and the steam test used in ASTM C641. These tests will be discussed in the following section. 


\subsubsection{Temperature test}

The temperature test was developed by Ramos et al. (2016) to overcome the issues identified in the Midgley test and ASTM 641 for evaluating sulphide-bearing aggregates. The temperature test involves soaking $10.0 \mathrm{~g}$ of aggregate crushed to $<150 \mu \mathrm{m}$ in $100 \mathrm{~mL}$ of $6 \%$ bleach in a homemade calorimeter. The test is run at controlled room temperature at $23^{\circ} \mathrm{C}$. The reaction temperature is then monitored, and an increase in the temperature until stabilization is an indication of the aggregate oxidation. The results indicate that this test can distinguish between sulphide-bearing aggregates and control aggregates.

\subsubsection{Petrographic identification of sulphide-bearing aggregates}

The petrographic analysis was carried out in the work of Rodrigues et al. (2012) on some concrete samples from the foundations of buildings that were subjected to deterioration in the TroisRivières area, Quebec. The examination showed that the concretes were all made with the same coarse aggregate containing iron-sulphide minerals. The aggregate used to produce the concrete housing foundations is a norite or a hypersthene's gabbro, containing various proportions of sulphide minerals, including pyrite, pyrrhotite, pentlandite and chalcopyrite.

The results indicated that the sulphide mineral content in the aggregate varied significantly, with some particles containing more than $50 \%$ of sulphide minerals. However, in most cases, it was lower than 5 to $10 \%$ by volume. As Figure 2.8 a illustrates, pyrite and pyrrhotite are associated with each other and well-disseminated into silicate minerals. Figures $2.8 \mathrm{~b}, \mathrm{c}$ and $\mathrm{d}$ show a pentlandite intergrowth in pyrrhotite, where it is often oriented perpendicular to the cracks as a feature of the exsolved pentlandite. 

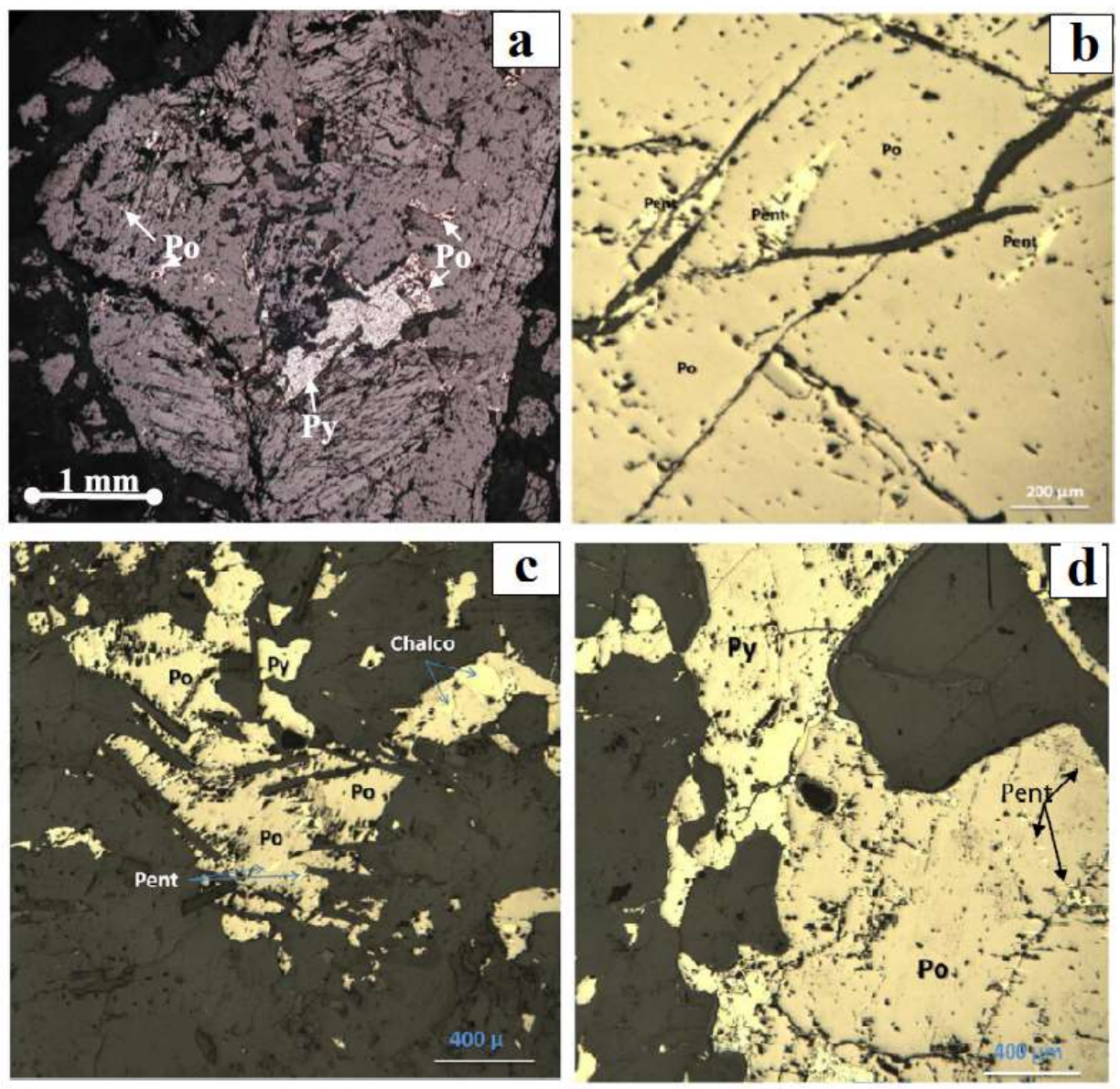

Figure 2.8. Reflected polarized light views of iron sulphide minerals included in the anorthositic gabbro. (Py = pyrite; $\mathrm{Po}=$ pyrrhotite; Pent: pentlandite; Chalco: chalcopyrite) (Rodrigues et al., 2012)

\subsubsection{Testing protocol for evaluation of sulphide-bearing aggregate susceptibility to oxidation}

In order to evaluate the rate and amount of oxygen consumed by sulphide-bearing aggregates and the deleterious behaviour resulting from using these aggregates in concrete, Rodrigues, Duchesne, Fournier et al. (2016) developed a protocol for evaluating the susceptibility of sulphide-bearing aggregate to oxidation. This protocol, which has since been adopted as an Annex in the CSA A23.1, 2019, comprises of three stages: 
i. Determining the total sulphur content of the aggregate where the aggregate would be considered acceptable for use in concrete if the total sulphur content were $\leq 0.10 \%$. After further studies, this limit was relaxed to $0.15 \%$ as per Annex P of (CSA A23.1, 2019). Aggregates with a total sulphur content $>1.0 \%$ are considered not suitable for use in concrete.

ii. Samples not meeting the lower limit for total sulphur (i.e., total sulphur $>0.15$ but $<1.0 \%$ ) are tested for oxygen consumption and considered to pass the test if the consumption is $\leq 5 \%$ after 3 hours. The limit was reduced to 4\% in Annex P in the 2019 edition of (CSA A23.1, 2019).

iii. Samples not meeting the limit of the oxygen consumption test are tested using the oxidation mortar bar test (OMBT) (Rodrigues et al., 2015; Rodrigues, Duchesne, Fournier, et al., 2016). This test is comprised of two phases. If the expansion in Phase $\mathrm{I}\left(80^{\circ} \mathrm{C}\right.$ and $80 \% \mathrm{RH}$ for 90 days) is lower than $0.10 \%$, the sample should be transferred to Phase $\mathrm{II}\left(5^{\circ} \mathrm{C}\right.$ and $\left.100 \% \mathrm{RH}\right)$ for another 90 days. If at the end of the second 90 days, the expansion of the sample becomes stable, the aggregate is considered suitable for use in concrete. If not, the aggregate is deemed not suitable for use in concrete. Aggregates that show expansion $>0.10 \%$ in the first 90 -day period are considered not suitable for use in concrete. In this case, the aggregate should be investigated, as the expansion could be a result of alkali-silica reactivation (ASR).

In the 2019 edition of (CSA A23.1, 2019), the expansion limit was modified to considering the aggregate suitable for use in concrete if the expansion between 90 and 180 days was $\leq 0.10 \%$. If the expansion limit is not met, the aggregate is deemed not suitable for use in concrete.

\subsubsection{Determining total sulphur content}

This test was explained and used in Rodrigues, Duchesne, Fournier, et al.'s (2016) study as the first step in the testing protocol for the evaluation of sulphide-bearing aggregates. The test 
involved testing a representative sample of 0.3 to $1.0 \mathrm{~g}$ in a carbon/sulphur analyzer induction furnace, where the sample is melted in a pure oxygen atmosphere, causing sulphur to react to form sulphur dioxide $\left(\mathrm{SO}_{2}\right)$. The $\mathrm{SO}_{2}$ content is determined by infrared absorption, from which the total sulphur content $\left(\mathrm{S}_{\mathrm{T}}\right)(\%$ by mass) is calculated.

\subsubsection{Oxygen consumption test}

Oxidation tests help identify the expansion rate and predict future issues. Elberling et al. (1994) developed a series of column experiments to determine sulphide oxidation rates in mine tailings. This test was adopted and used by Rodrigues, Duchesne, and Fournier (2016) to evaluate the potentially deleterious effects of sulphide-bearing aggregates for use in concrete. The oxygen consumption test (OCT) was adopted by Rodrigues, Duchesne, and Fournier (2016b) for measuring the oxygen consumption of a compacted aggregate layer 100-mm thick and consisting

of crushed aggregates in cells made of Plexiglas columns. For aggregate processing, a jaw-crusher was used, followed by a roller crusher until the entire sample passed the $1.18 \mathrm{~mm}$ sieve. Then, a rod mill was used until the sample passed the $150 \mu \mathrm{m}$ sieve with no limitations on the smallest aggregate size.

The plexiglass columns have an internal diameter of $141.7 \mathrm{~mm}$ and a height of $200 \mathrm{~mm}$. They are sealed during testing with a Plexiglas cap in their upper part with a gasket of $3 \mathrm{~mm}$ in thickness. This is to avoid any leaks or entry of oxygen into the system and to allow a headspace above the ground aggregate. A galvanic-cell type oxygen sensor (Apogee SO-100 \& 200 series) was inserted through the Plexiglas cap and connected to a four-channel quad-volt data logger (OM-CPIFC200). 
Tests were conducted at atmospheric pressure and room temperature $\left(22^{\circ} \mathrm{C}\right)$ and the oxygen consumption was measured in the cell for 3.5-hour (30 minutes for probes stabilization in addition to 3 hours of effective oxygen consumption measurements). To obtain the most reliable testing conditions, a series of experiments were carried out to identify the optimum degree of saturation, aggregate size, compacted material thickness, and air volume.

For particle size, three aggregate sizes were tested: mortar bar size fractions (i.e., $5 \mathrm{~mm}$ to 150 $\mu \mathrm{m})$, particle size less than $1.18 \mathrm{~mm}$, and particle size less than $150 \mu \mathrm{m}$. The test was carried out with two degrees of saturation of $40 \%$ and $60 \%$. The last testing series was to find the optimum compacted aggregate thickness where three thicknesses were tested $(25,50$ and $100 \mathrm{~mm})$.

In terms of investigating the optimum degree of saturation and headspace, the test was applied on sulphide-bearing aggregate (MSK) from Quebec, with a total sulphur content of $0.93 \%$. The ground material thickness used in this test was fixed to $50 \mathrm{~mm}$. As shown in Table 2.2, a $60 \%$ degree of saturation prevents the oxygen from reacting with the ground aggregate. Also, the greater the headspace, the more oxygen is available for oxidation.

Table 2.2. Effect of degree of saturation and air volume on oxygen consumption (Rodrigues, Duchesne, \& Fournier, 2016b)

\begin{tabular}{ccc}
\hline \hline $\begin{array}{c}\text { Degree of } \\
\text { Saturation }\end{array}$ & Headspace & $\begin{array}{c}\mathrm{O}_{2} \text { Consumption } \\
\left.\text { (moles } / \mathrm{m}^{2} / \mathrm{yr}\right)\end{array}$ \\
\hline \hline $40 \%$ & $50 \mathrm{~mm}$ & 83 \\
\cline { 2 - 3 } & $100 \mathrm{~mm}$ & 126 \\
\hline $60 \%$ & $50 \mathrm{~mm}$ & 8 \\
\cline { 2 - 3 } & $100 \mathrm{~mm}$ & -1 \\
\hline \hline
\end{tabular}


The test was also applied on the same aggregate to test the effect of ground material thickness on the oxidation. The degree of saturation and headspace was fixed to $40 \%$ and $10 \mathrm{~cm}$, respectively. As shown in Table 2.3, the greater the amount of available materials, the higher the oxygen consumption.

Table 2.3. Effect of ground material thickness on oxygen consumption (Rodrigues, Duchesne, \& Fournier, 2016b)

\begin{tabular}{cc}
\hline $\begin{array}{c}\text { Ground Aggregate } \\
\text { Thickness }\end{array}$ & $\begin{array}{c}\mathrm{O}_{2} \text { Consumption } \\
\left.\text { (moles } / \mathrm{m}^{2} / \mathrm{yr}\right)\end{array}$ \\
\hline \hline $25 \mathrm{~mm}$ & 58 \\
\hline $50 \mathrm{~mm}$ & 126 \\
\hline $100 \mathrm{~mm}$ & 289 \\
\hline \hline
\end{tabular}

The last test parameter to optimize was the ground material size. As mentioned earlier, three fraction sizes were tested: mortar bar size fractions (i.e., $5 \mathrm{~mm}$ to $150 \mu \mathrm{m}$ ), particle size less than $1.18 \mathrm{~mm}$, and particle size less than $150 \mu \mathrm{m}$. Table 2.4 shows the results of applying the test on (MSK) with a $40 \%$ degree of saturation, $100 \mathrm{~mm}$ headspace, and $100 \mathrm{~mm}$ ground material thickness. As shown in the table, the oxygen consumption increases with finer grinding size because of the more exposed surface area of aggregate to oxidation.

Table 2.4. Effect of aggregate size on oxygen consumption (Rodrigues, Duchesne, \& Fournier, 2016b)

\begin{tabular}{cc}
\hline \hline $\begin{array}{c}\text { Crushed } \\
\text { Aggregate Size }\end{array}$ & $\begin{array}{c}\mathrm{O}_{2} \text { Consumption } \\
\left(\text { moles } / \mathrm{m}^{2} / \mathrm{yr}\right)\end{array}$ \\
\hline \hline Mortar bar size & 41 \\
\hline$<1.18$ & 156 \\
\hline$<150 \mu \mathrm{m}$ & 267 \\
\hline \hline
\end{tabular}


The obtained results show that the optimized test parameters were a $40 \%$ degree of saturation, a $100 \mathrm{~mm}$ of compacted ground material with a $100 \mathrm{~mm}$ headspace, and a maximum particle size of $150 \mu \mathrm{m}$ with no limit on the minimum size. After the test optimization, the test was applied to six sulphide-bearing aggregates, which were mainly silicates. To test the control aggregate behaviour, the test was also applied to three aggregates with no or very limited sulphide contents. Two of these aggregates are carbonate aggregates, and the other is anorthosite (igneous). Table 2.5 shows the results of the OCT on two samples from each aggregate and the total sulphur content of each sample.

Table 2.5. Results of oxygen consumption test (Rodrigues, Duchesne, \& Fournier, 2016b)

\begin{tabular}{|c|c|c|c|c|c|}
\hline \multirow{2}{*}{\multicolumn{2}{|c|}{ Aggregate }} & \multicolumn{2}{|c|}{$\begin{array}{l}\text { Total Sulphur } \\
\left(\mathrm{S}_{\mathrm{t}}\right)(\%)\end{array}$} & \multicolumn{2}{|c|}{$\begin{array}{c}\mathrm{O}_{2} \text { Consumption } \\
(\%)\end{array}$} \\
\hline & & 1 & 2 & 1 & 2 \\
\hline \multirow{6}{*}{$\begin{array}{c}\text { Sulphide- } \\
\text { bearing } \\
\text { aggregate }\end{array}$} & SDBR & 13.86 & 14.46 & 57 & 55.5 \\
\hline & MSK & 0.99 & 1.11 & 21.7 & 21.4 \\
\hline & SBR & 0.87 & 0.75 & 10.7 & 10.8 \\
\hline & PHS & 0.32 & 0.29 & 6.2 & 6.2 \\
\hline & GGP & 0.25 & 0.24 & 5.4 & 6.0 \\
\hline & WS & 0.07 & 0.07 & 8.2 & 8.2 \\
\hline \multirow{3}{*}{$\begin{array}{c}\text { Control } \\
\text { aggregates }\end{array}$} & DLS & 0.12 & 0.19 & 3.0 & 0.2 \\
\hline & PKA & 0.06 & 0.04 & 2.6 & 2.8 \\
\hline & HPL & 0.02 & 0.02 & 1.7 & 0.2 \\
\hline
\end{tabular}




\subsubsection{Oxidation of mortar bar test}

The expansion mortar bar test, adopted by Rodrigues et al. (2015), comprised of two stages. The first stage aims at reproducing the oxidation reaction of iron sulphides in the aggregate by soaking the samples twice a week for three hours in sodium hypochlorite solution $(6 \%$ bleach at room temperature) and storing the sample the remaining time in $80^{\circ} \mathrm{C}$ and $80 \%$ humidity. The second stage aims at promoting the thaumasite formation by soaking the samples twice a week for three hours in a sodium hypochlorite solution $(6 \%$ bleach at room temperature) and storing the sample the remaining time in $5^{\circ} \mathrm{C}$ and $100 \%$ humidity.

Mortar bars were prepared using an aggregate gradation similar to the gradation used in the accelerated mortar bar test (CSA A23.2-25A, 2014): $5.00 \mathrm{~mm}$ to $150 \mu \mathrm{m}$ with a water-to-cement ratio $(\mathrm{w} / \mathrm{c})$ of 0.65 . The following test conditions were followed:

\section{a. Phase I: week 1 to week 13:}

1. Samples were placed in bleach for three hours.

2. Lengths were measured for the wet samples at room temperature.

3. Samples were placed 3.5 days in the oven at $80^{\circ} \mathrm{C}$ and $80 \%$ relative humidity.

\section{b. Phase II, week 14 to week 26:}

1. Samples were placed in bleach for three hours.

2. Lengths were measured for the wet samples at room temperature.

3. Samples were placed 3.5 days in the fridge at $5^{\circ} \mathrm{C}$ and $100 \%$ relative humidity.

If the expansion of Phase I exceeded $0.1 \%$, expansion of Phase II should be monitored. For aggregates to be accepted for use in concrete, expansion in Phase II should be $\leq 0.1 \%$. 
Figure 2.9 shows the expansions of mortar bars subjected to the exposure explained earlier. The results show expansions of MSK, the sulphide-bearing aggregate that was considered responsible for the deterioration of concrete structures in Quebec (Rodrigues et al., 2012). SW is a mica schist aggregate from Switzerland. This aggregate was used in the construction of a concrete dam in 1970 which started to show signs of expansion in 1980 (Schmidt, Leemann, Gallucci, \& Scrivener, 2011). Two control aggregates with no sulphide content are Spratt, a control aggregate but known for alkali-silica reactivity, and PKA, a limestone aggregate.

The figure shows that the PKA showed very small expansion during the 26 weeks of testing. For the sulphide-bearing aggregate (MSK), the expansion of mortar bars increased at a high rate in Phase II, passing the $0.1 \%$ limit, while for the ASR reactive aggregate (SPRATT), the expansion in Phase II was $<0.1 \%$. The figure also shows the expansion of MSK with the same exposure tested by Guirguis et al. (2018). The expansion at the end of Phase II was less $(\approx 0.09 \%)$ than the expansion found by Rodrigues, Duchesne, Fournier, et al. (2016), which may indicate that the test is sensitive and may not give the same repeatability results. 


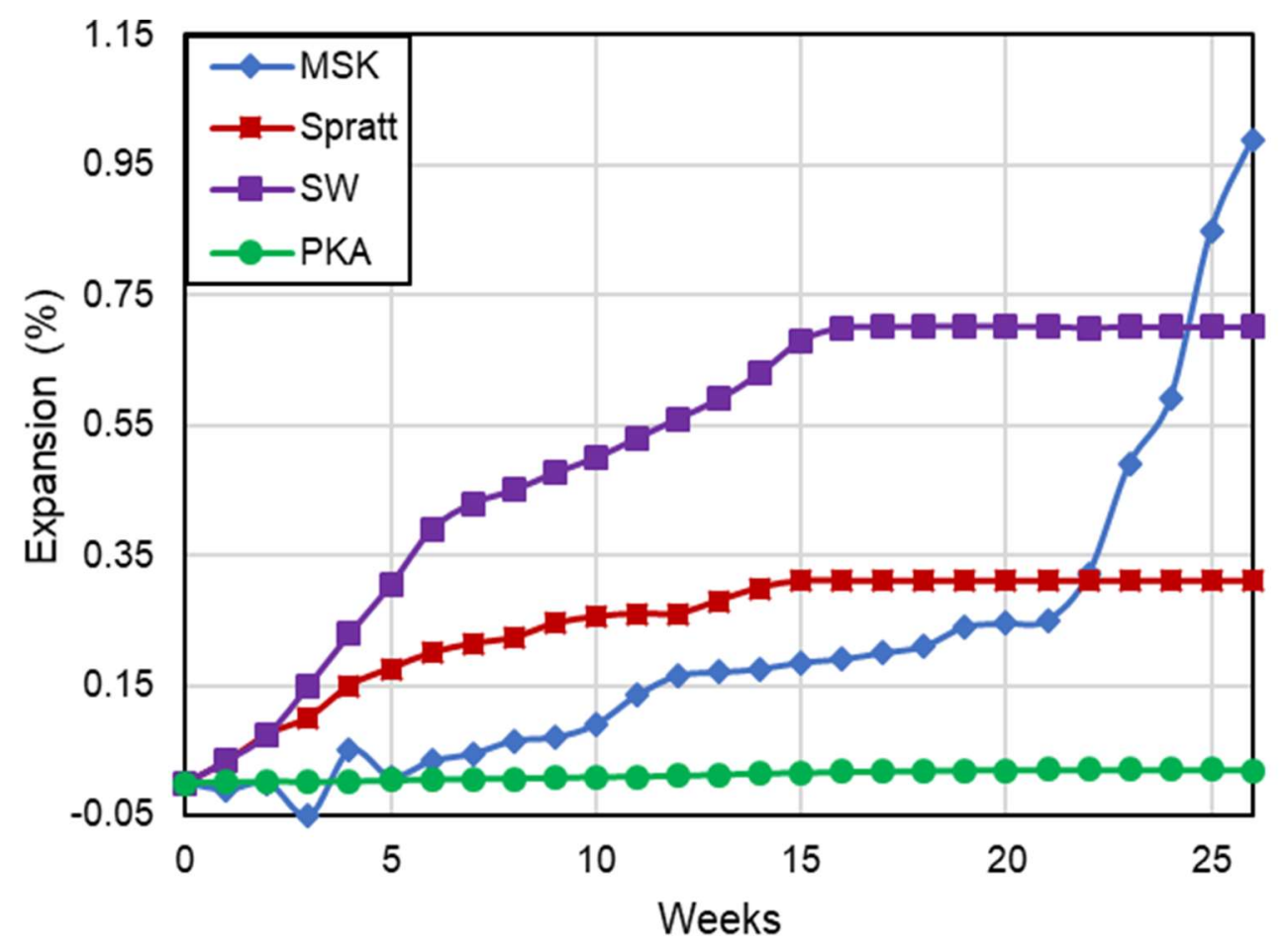

Figure 2.9. Expansion of mortar bars in Phase I: Bars are soaked three hours in bleach (6\%) twice per week and stored at $80^{\circ} \mathrm{C} / 80 \%$ RH. Phase II: Bars are soaked three hours in bleach (6\%) twice per week and stored at $4{ }^{\circ} \mathrm{C} / 100 \%$ RH (After Rodrigues, Duchesne, Fournier, et al., 2016)

Guirguis (2017) applied the oxidation mortar bar test on nine aggregates (four non-sulphide bearing aggregates and five sulphide bearing aggregates). Some of these aggregates (MSK and Pka) were tested by Rodrigues et al. (2015).

The four non-sulphide aggregates are C1, C2, PKA and Sud, which are silicate aggregates. Sud is known to be alkali-silica reactive. Figure 2.10 shows the expansion of the three aggregates, where the test was repeated for $\mathrm{C} 1, \mathrm{C} 2$, and PKA to confirm the results. As illustrated, the samples show the expansion in the first stage of the test (i.e., the first 13 weeks) with no significant expansion in the second 13 weeks when stored at $5^{\circ} \mathrm{C}$ at $100 \%$ relative humidity. 


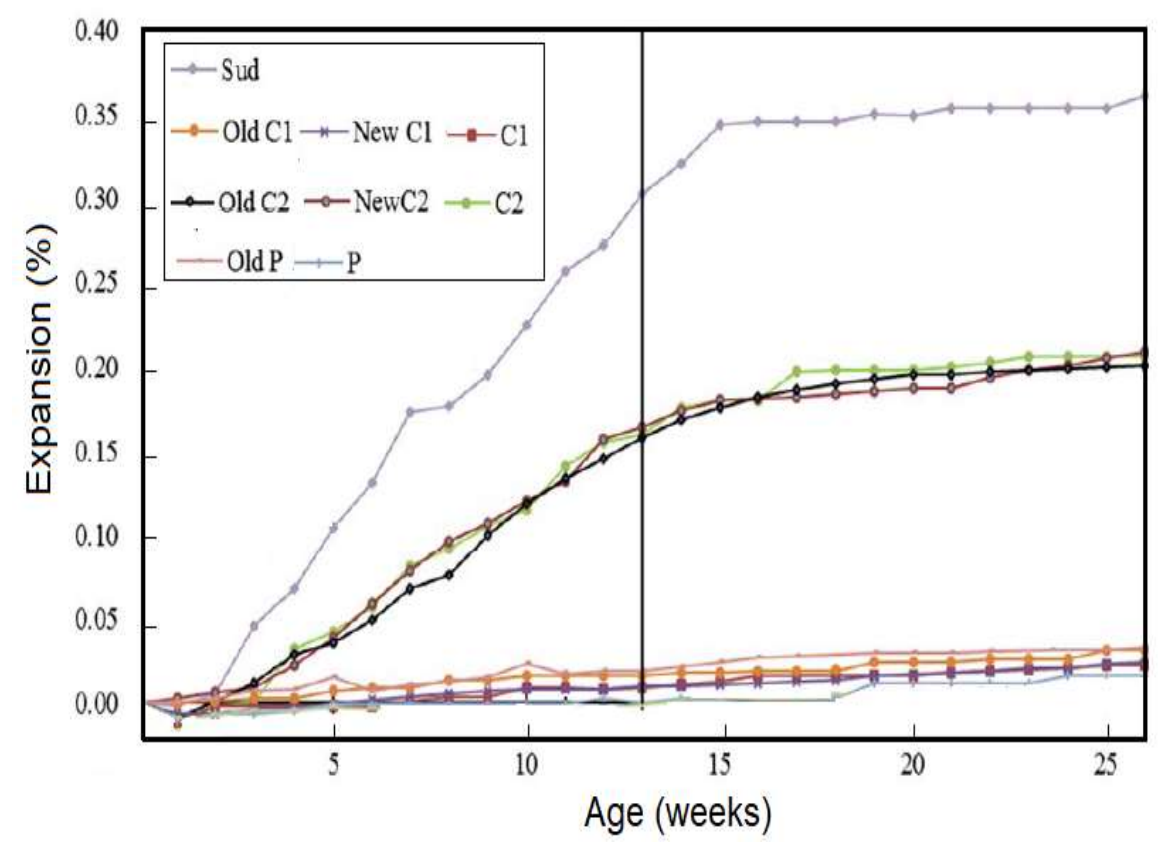

Figure 2.10. Expansion in control and aggregates with total sulphur $<0.05 \%$ (Guirguis, 2017)

The high expansion in the first stage of the test was observed for most of the silicate aggregates in the work of Guirguis (2017) and Rodrigues et al. (2015). Figure 2.11 indicates the X-ray mappings for mortar bars with C2 and Sud aggregates with high silicate content (Guirguis, 2017) after exposure to sodium hypochlorite solution (bleach). The mapping shows the concentration of silicon, sodium and calcium, giving evidence of silica gel in the mortar bar.

This behaviour was attributed to the dissolution of the silica ions because of the exposure to high heat and sodium hypochlorite solution. Guirguis (2017) reaffirmed this theory by analyzing the oxidizing solution for some of the aggregates at 40 and $80^{\circ} \mathrm{C}$. From the analysis shown in Figure 2.12, the expansions of $\mathrm{C} 2$ and Sud aggregates is proportional to the amount of dissolved silica. Also, the amount of silica ion is low for both control aggregates $\mathrm{C} 1$ and PKA, as they have limited silica content and thus accordingly low expansion. 


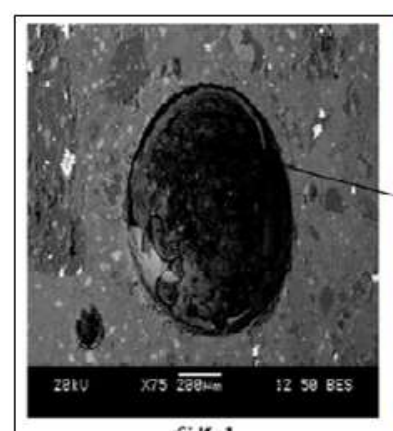

Si Kal
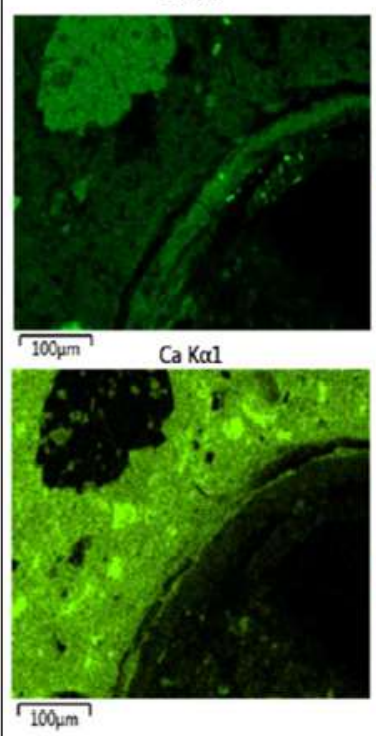

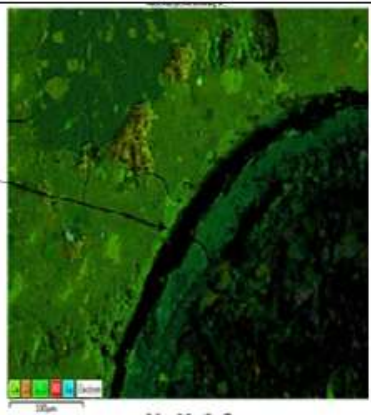

$\mathrm{NaKa1} 2$

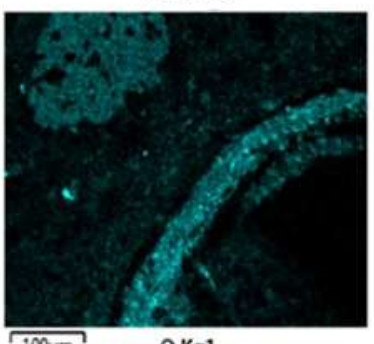

$100 \mathrm{~mm} \quad 0 \mathrm{Kal}$

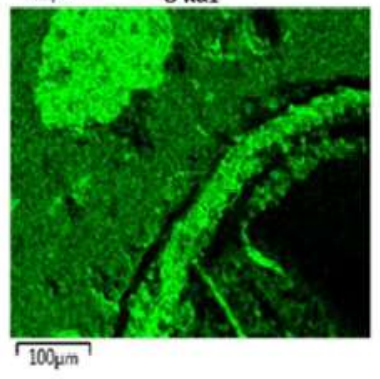

(a)

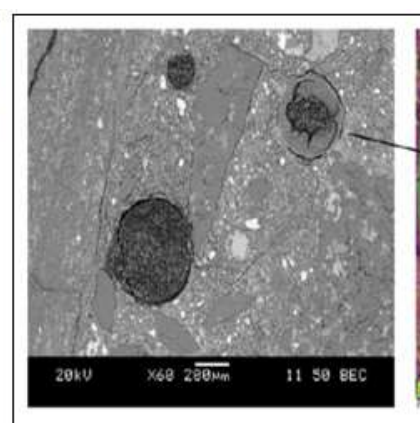

Si Kal

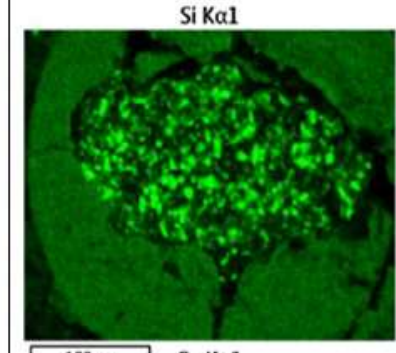

$\mathrm{Ca} \mathrm{Ka} 1$

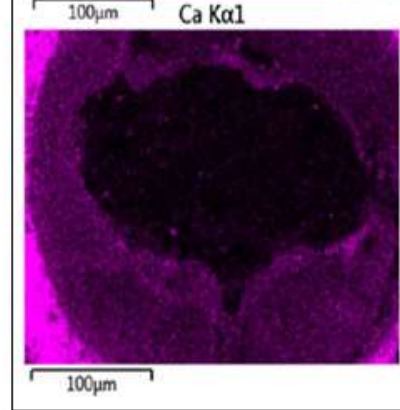

(b)

Figure 2.11. Evidence of ASR gel inside an air void in mortar bars containing: (a) C2 aggregate (b) Sud aggregates (Guirguis, 2017)

When aggregates with higher sulphide contents $(>0.5 \%)$ were tested as Figure 2.12 illustrates, higher expansion was observed in the first stage (i.e., first 13 weeks); this higher expansion is thought to be due to the oxidation process. Also, the expansion during the second stage (i.e., second 13 weeks) is likely due to thaumasite formation, as thaumasite favourably forms at temperatures of about $5^{\circ} \mathrm{C}$, as previously confirmed.

The same behaviour of silicate aggregates was observed when mortar bar samples with quartz and limestone aggregates were cured at high temperature (Heinz \& Ludwig, 1987; Grattan-Bellew, 
Beaudoin, \& Vallée, 1998; Lawrence, 1999). Limestone aggregates were reported to give lower expansions compared to mortars or concretes with quartz aggregate.

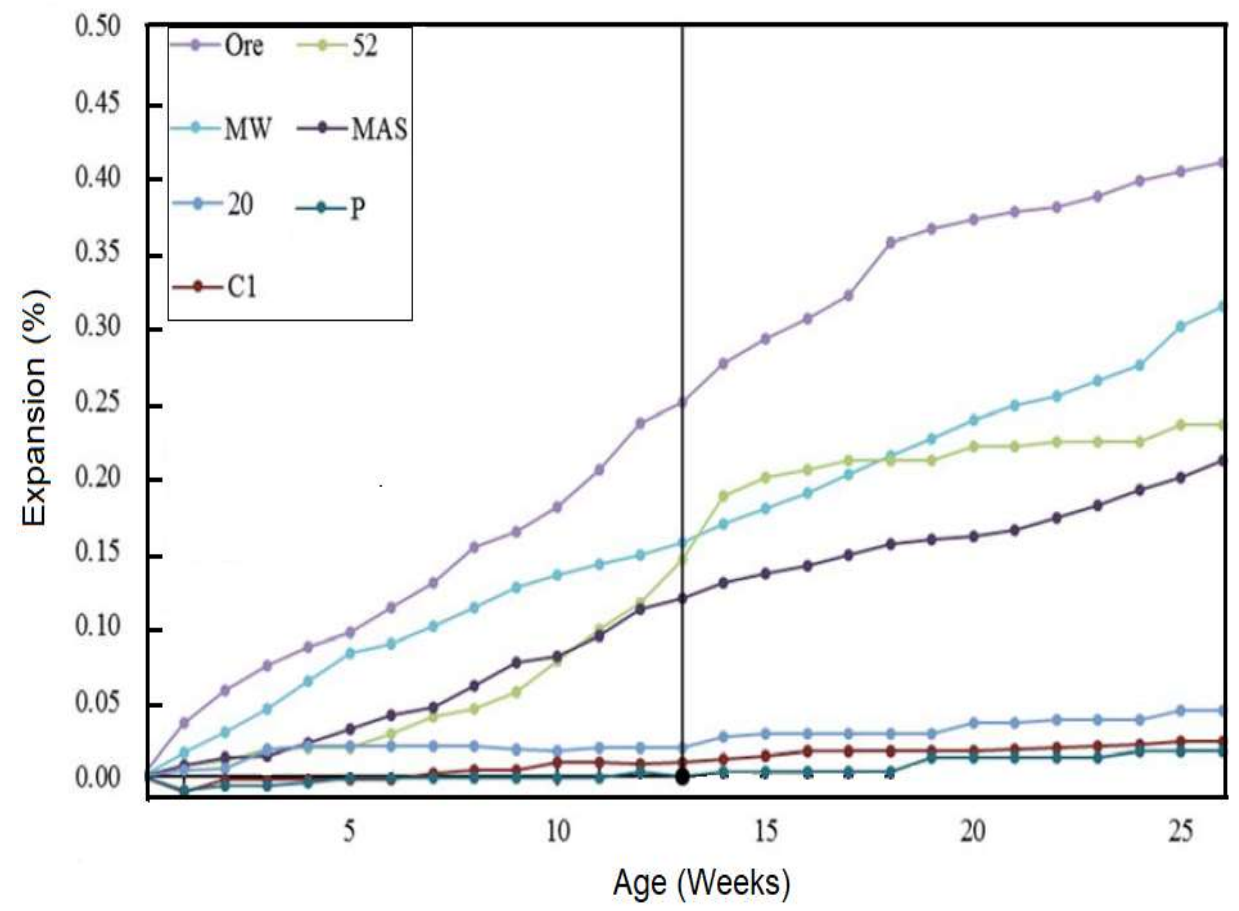

Figure 2.12. Expansion in samples with various sulphide contents (Guirguis, 2017)

Grattan-Bellew et al. (1998), observed the rate of expansion of mortar containing six different rock/mineral types. As illustrated in Figure 2.13, expansion greater than $0.1 \%$ at 56 days was only observed in the mortar containing quartz aggregate. 


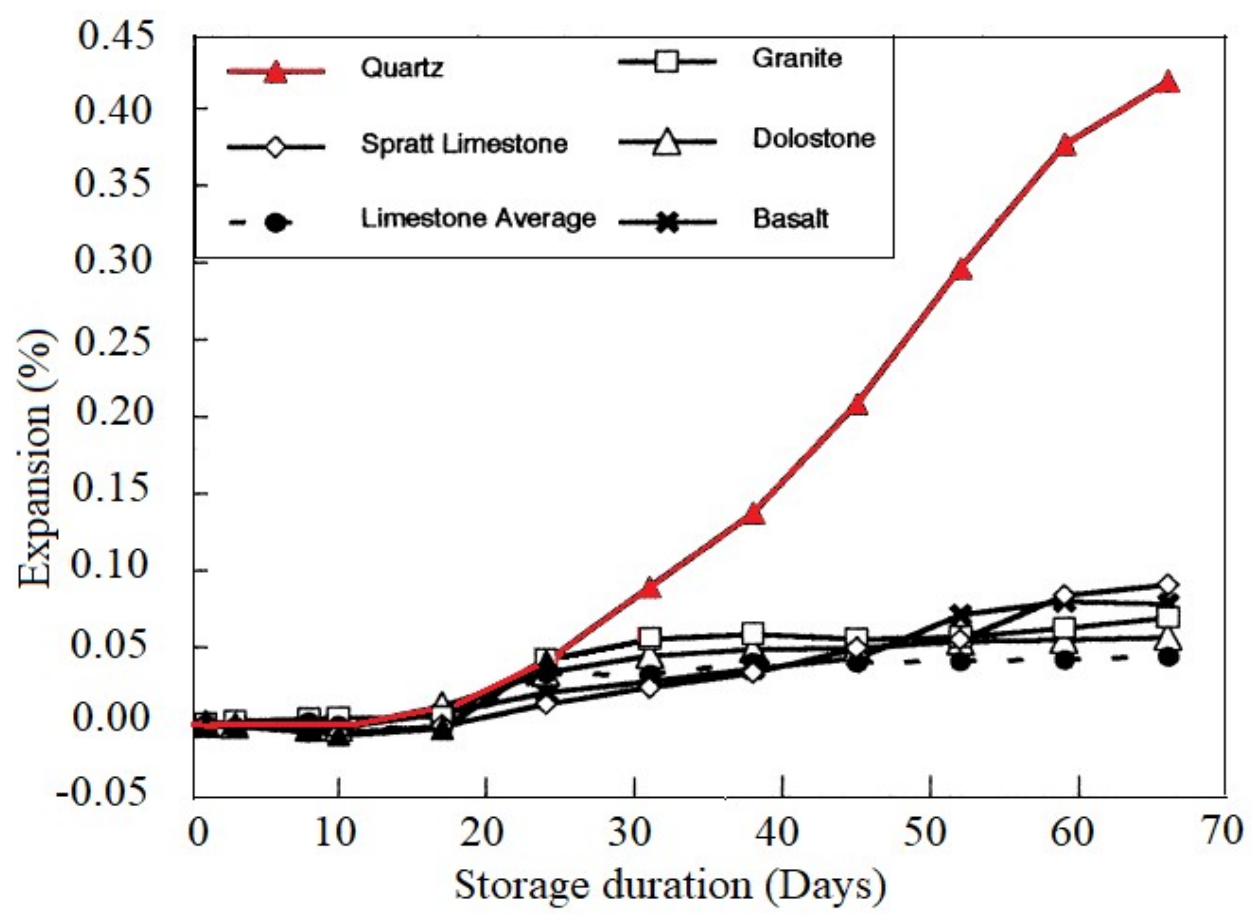

Figure 2.13. Effect of aggregate composition on expansion due to DEF (Grattan-Bellew et al., 1998)

Sylla (1988) explained the difference in expansion between limestone and silicate aggregates by the difference in the thermal expansion coefficients of the aggregates. For limestone aggregates, the thermal expansion coefficient is more similar to that of the cement paste, which results in less thermal stress during heat curing. In the case of silicate aggregates, Grattan-Bellew et al. (1998) observed that expansion was greatest with aggregates that had a thermal coefficient of expansion greater than about $10 \times 16^{-61} \mathrm{C}$. The results of these studies may explain the expansion of silicate aggregates when stored at $80^{\circ} \mathrm{C} / 80 \%$ humidity in the work of Guirguis et al. (2018) and Rodrigues et al. (2015)

\subsubsection{Aggregate oxidation test}

This test is not in the testing protocol but is likely to be impeded at the first step of the protocol. Guirguis and Shehata (2017) and Guirguis (2017) developed a quick screening test for coarse 
aggregates to assess their susceptibility to oxidation that may cause damage when used in concrete due to the oxidation of sulphide phases. The screening test involves soaking $100 \mathrm{~g}$ from the processed aggregates (recommended size is a fraction passing $2.36 \mathrm{~mm}$ and retained on $1.18 \mathrm{~mm}$ ) in the oxidizing agent ( $6 \%$ sodium hypochlorite-household bleach). In this test, the aggregate sample is submerged for five days in bleach and then washed over a $600 \mu \mathrm{m}$ sieve and dried in an oven at $80^{\circ} \mathrm{C}$ for two days. After drying the sample, the mass loss is recorded after each cycle of one week.

Aggregates with limited or no known oxidizable iron-sulphides showed a mass loss of $<1.0 \%$ after one week. On the other hand, aggregates containing oxidizable iron-sulphides showed a mass loss higher than 3.5\% and changes in the colour of the test solution. Guirguis and Shehata (2017) proposed that if the mass loss after the first cycle is less than $0.5 \%$ and there is no considerable change in the colour of the soaking solution (Figure 2.14), the aggregates are considered acceptable for use in concrete.

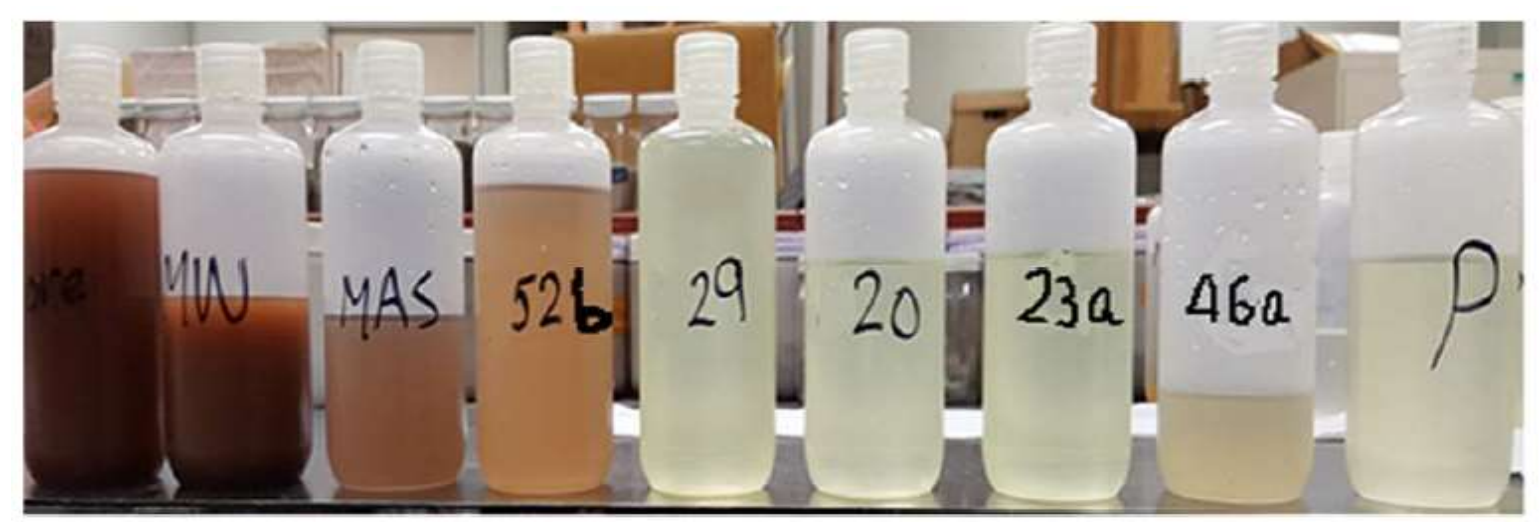

Figure 2.14. Change in colour of sodium hypochlorite solution (Guirguis, 2017) 


\section{Chapter 3}

\section{Materials and Experimental Procedure}

\subsection{Materials}

The materials used in this study include cementing materials (Portland cement and supplementary cementing materials), various soaking solutions for aggregate oxidation, and aggregates with different composition and sulphur contents.

\subsubsection{Cementing materials}

A general use (GU) Portland cement (PC) from the province of Ontario, Canada, and three types of supplementary cementing materials (SCMs) were used as partial replacements for the GUPortland cement. The SCMs were used at levels of 25\% for FA, 30\% for slag, and 10\% for MK. The chemical compositions of the cementing materials are listed in Table 3.1 and Table 3.2, as determined by X-ray fluorescence (XRF)

Table 3.1. Chemical composition of the Portland cement and SCMs (mass \%) determined using $\mathrm{XRF}$

\begin{tabular}{c|cccc}
\hline \hline Material & PC-GU & FA & $\mathrm{S}$ & $\mathrm{MK}$ \\
\hline \hline LOI $\left(1000^{\circ} \mathrm{C}\right)(\%)$ & 2.8 & - & 0.91 & - \\
LOI $\left(750^{\circ} \mathrm{C}\right)(\%)$ & -- & 2.78 & 1.86 & 1.82 \\
Blain $\left(\mathrm{m}^{2} / \mathrm{kg}\right)$ & 402 & -- & 639.7 & -- \\
\hline \hline $\mathrm{SiO}_{2}(\%)$ & 19.4 & 47.36 & 35.97 & 63.10 \\
$\mathrm{Al}_{2} \mathrm{O}_{3}(\%)$ & 5.0 & 23.86 & 8.75 & 30.69 \\
$\mathrm{Fe}_{2} \mathrm{O}_{3}(\%)$ & 3.13 & 17.40 & 0.38 & 1.22 \\
\hline \hline
\end{tabular}




\begin{tabular}{c||cccc}
\hline \hline Material & PC-GU & FA & S & MK \\
\hline \hline $\mathrm{CaO}(\%)$ & 61.7 & 3.67 & 37.34 & 0.36 \\
$\mathrm{MgO}(\%)$ & 2.4 & 1.00 & 11.23 & 0.50 \\
$\mathrm{SO}_{3}(\%)$ & 3.56 & 0.40 & 3.11 & 0.05 \\
$\mathrm{~K}_{2} \mathrm{O}(\%)$ & 1.12 & 1.84 & 0.57 & 1.77 \\
$\mathrm{Na}_{2} \mathrm{O}(\%)$ & 0.23 & 0.65 & 0.17 & 0.16 \\
\hline \hline
\end{tabular}

Table 3.2. Phase Composition of the (GU) Portland cement

\begin{tabular}{c||c}
\hline \hline Phase & Amount (\%) \\
\hline \hline $\mathrm{C}_{3} \mathrm{~S}$ & 49 \\
$\mathrm{C}_{2} \mathrm{~S}$ & 17 \\
$\mathrm{C}_{3} \mathrm{~A}$ & 8 \\
$\mathrm{C}_{4} \mathrm{AF}$ & 9 \\
\hline \hline
\end{tabular}




\subsubsection{Soaking Solutions}

\section{a. Sodium hypochlorite}

Sodium hypochlorite $(\mathrm{NaOCl})$ was used as an oxidizing agent to promote the oxidation of the sulphide-bearing aggregates. This solution is household bleach (6\%) with a specific gravity of 1.1 and a $\mathrm{pH}$ of 12.2 .

\section{b. Calcium hypochlorite}

Calcium hypochlorite $\left(\mathrm{Ca}(\mathrm{ClO})_{2}\right)$ was used as another oxidizing agent to promote the oxidation of the sulphide-bearing aggregates. This solution was prepared by mixing $(6 \%)$ of calcium hypochlorite powder by mass with water.

\section{c. Saturated lime solution}

Lime solution was used as a soaking solution to raise humidity inside mortar samples and promote the oxidation of the sulphide-bearing aggregates. The solution was prepared by mixing $6 \%$ of hydrated lime with water, with a recorded $\mathrm{pH}$ of 12.39 .

\subsubsection{Aggregates}

The aggregates used in this study were divided into three categories according to their composition and total sulphur contents, as follows:

- Category (1): Materials with high total sulphur content $(>0.50 \%)$ and known to have sulphides that can cause damage to concrete. These materials are sulphide ore (ORE) and the coarse aggregates maskimo (MSK) and 1052.

- Category (2C): Materials like carbonate aggregates with low total sulphur content and with no known issues related to oxidation of sulphide minerals. 
- Category (2S): Materials like non-carbonate aggregates with low total sulphur content and no known issues related to oxidation of sulphide minerals.

Twenty-one coarse aggregates from Ontario of known total sulphur content and known to have no issues related to sulphide were investigated. Some of these aggregates are not concrete aggregates for reasons other than potential oxidation of sulphide phases. Three more materials which are known to have oxidizable sulphide and three control aggregates were tested. The materials with oxidizable sulphide are:

- Sulphide ore (ORE) contains pyrite, pyrrhotite, pentlandite, and chalcopyrite minerals. ORE is derived from the Sudbury (Ontario) area from mine waste rocks. It has a total sulphur content of $14 \%$ and is used in this study as a control source of total sulphur at $5 \%, 10 \%, 20 \%, 50 \%$ and $100 \%$ by mass of the total aggregate, with the remainder being a control aggregate with no sulphides (aggregates C1, Sand A or Sand B).

- Maskimo (MSK) is a sulphide-bearing aggregate from Quebec that consists mainly of pyrrhotite minerals. This aggregate is considered responsible for the severe deterioration in the concrete foundations in Trois-Rivières, as detailed in the previous chapter (Rodrigues et al., 2012; Rodrigues, Duchesne, \& Fournier, 2015; Rodrigues, Duchesne, Fournier, et al., 2016; Rodrigues, Duchesne, \& Fournier, 2016a; B Guirguis \& Shehata, 2017; B Guirguis et al., 2018).

- Aggregate 1052 is from Ontario. It contains oxidizable sulphide minerals with a mineralogical composition that contains quartz-biotite schist. Aggregate 1052 has never been used in concrete. The petrographic examination of this aggregate demonstrated the presence of 
oxidizable sulphide minerals that occur as discrete, isolated particles or nuggets, unlike the maskimo aggregate, where sulphide minerals occur in a disseminated state.

- The concrete aggregate $(\mathrm{C} 1)$ is a crushed quarried limestone that has an excellent history as a non-reactive aggregate. It is used in concrete in Toronto, Ontario.

- Sand A is concrete sand that has a long history of satisfactory performance. It is used in commercial concrete in southern Ontario. This sand is produced in the Caledon area, near Toronto.

- Sand B is concrete sand from Wakefield, Quebec.

Table 3.3 shows the total sulphur and main mineralogical, chemical, and abrasion resistance of the tested aggregates. 
Table 3.3. Chemical analyses and abrasion resistance of the aggregates

\begin{tabular}{|c|c|c|c|c|c|c|c|c|c|c|c|c|c|c|c|c|}
\hline $\begin{array}{l}\text { Cat- } \\
\text { egory }\end{array}$ & $\begin{array}{l}\text { Aggre- } \\
\text { gate }\end{array}$ & Rock Type & $\begin{array}{l}\text { Main Mineral } \\
\text { Constituents }\end{array}$ & $\begin{array}{c}\text { Micro- } \\
\text { Deval } \\
\text { Abrasion } \\
\end{array}$ & $\begin{array}{c}\text { Iron- } \\
\text { Sulphur } \\
\text { Minerals }\end{array}$ & $\begin{array}{c}\text { Total } \\
\text { Sulphur } \\
\mathrm{S}_{\mathrm{t}}(\%) \\
\end{array}$ & $\begin{array}{l}\mathrm{SiO}_{2} \\
(\%)\end{array}$ & $\begin{array}{l}\mathrm{CO}_{2} \\
(\%)\end{array}$ & $\begin{array}{l}\mathrm{Fe}_{2} \mathrm{O} \\
3(\%)\end{array}$ & $\begin{array}{l}\mathrm{Al}_{2} \mathrm{O} \\
3(\%)\end{array}$ & $\begin{array}{l}\mathrm{TiO}_{2} \\
(\%)\end{array}$ & $\begin{array}{c}\mathrm{CaO} \\
(\%)\end{array}$ & $\begin{array}{l}\text { MgO } \\
(\%)\end{array}$ & $\begin{array}{c}\mathrm{Na}_{2} \mathrm{O}+ \\
\mathrm{K}_{2} \mathrm{O} \\
(\%) \\
\end{array}$ & $\begin{array}{l}\text { LOI } \\
(\%)\end{array}$ & $\begin{array}{l}\text { Total } \\
(\%)\end{array}$ \\
\hline \multirow{3}{*}{1} & ORE & Mine waste & $\begin{array}{c}\text { Plagioclase, pyroxenes, } \\
\text { biotite, epidote and apatite }\end{array}$ & -- & $\begin{array}{c}\text { Pyrrhotite } \\
\text { Pyrite } \\
\text { Chalcopyrite } \\
\text { Pentlandite } \\
\end{array}$ & 14.00 & 33.09 & 0.13 & 39.40 & 8.53 & 0.73 & 4.20 & 3.05 & 2.39 & 5.26 & 100 \\
\hline & MSK & Gabbro & $\begin{array}{l}\text { Plagioclase, biotite, } \\
\text { pyroxenes and quartz }\end{array}$ & 8.5 & $\begin{array}{c}\text { Pyrrhotite } \\
\text { Pyrite } \\
\text { Chalcopyrite } \\
\text { Pentlandite } \\
\end{array}$ & 0.930 & 50.58 & 0.71 & 8.1 & 19.36 & 0.53 & 8.84 & 6.85 & 3.79 & 1.87 & 100.3 \\
\hline & 1052 & $\begin{array}{c}\begin{array}{c}\text { Quartz-feldspar-mica } \\
\text { schist }\end{array} \\
\end{array}$ & Quartz-biotite schist & 7.6 & $\begin{array}{l}\text { Pyrrhotite } \\
\text { Pyrite }\end{array}$ & 0.543 & 66.51 & 0.304 & 4.29 & 15.78 & 0.32 & 2.61 & 1.67 & 6.81 & 1.20 & 99.44 \\
\hline \multirow{11}{*}{$2 \mathrm{C}$} & $\mathrm{C} 1$ & Limestone & Carbonate & 9.2 & -- & 0.090 & 1.88 & 46.1 & 0.37 & 0.44 & 0.02 & 29.9 & 20.60 & 0.22 & 46.10 & 100.29 \\
\hline & 1020 & Gasport dolostone & Carbonate & 11.0 & $\begin{array}{l}\text { Gypsum } \\
\text { Pyrite }\end{array}$ & 0.151 & 2.25 & 43.22 & 0.79 & 0.32 & 0.03 & 29.85 & 20.00 & 0.06 & 45.31 & 98.76 \\
\hline & 1022 & $\begin{array}{c}\text { Limestone, dolomitic } \\
\text { limestone, minor shale }\end{array}$ & Carbonate & 10.6 & -- & 0.038 & 2.11 & 39.93 & 0.25 & 0.59 & 0.03 & 54.21 & 0.79 & 0.17 & 42.66 & 100.84 \\
\hline & 1025 & $\begin{array}{c}\text { Limestone, dolomitic } \\
\text { limestone, shale }\end{array}$ & Carbonate & 14.3 & -- & 0.046 & 1.73 & 40.92 & 0.22 & 0.37 & 0.02 & 54.75 & 0.72 & 0.09 & 42.97 & 100.91 \\
\hline & 1027 & Dolostone & Carbonate & 8.7 & -- & 0.161 & 5.31 & 42.36 & 0.91 & 0.93 & 0.05 & 28.25 & 19.42 & 0.37 & 43.64 & 98.67 \\
\hline & 1029 & $\begin{array}{l}\text { Oxford formation } \\
\text { (Dolostone) }\end{array}$ & Carbonate & 10.9 & Pyrite & 0.303 & 14.05 & 35.18 & 1.06 & 1.74 & 0.08 & 27.52 & 15.1 & 1.22 & 37.72 & 98.67 \\
\hline & 1030 & $\begin{array}{l}\text { Oxford formation } \\
\text { (Dolostone) }\end{array}$ & Carbonate & 6.9 & -- & 0.017 & 6.82 & 39.58 & 0.53 & 1.31 & 0.05 & 28.90 & 18.41 & 0.74 & 42.94 & 99.82 \\
\hline & 1031 & $\begin{array}{c}\text { Limestone and } \\
\text { dolomitic limestone }\end{array}$ & Carbonate & 13.0 & -- & 0.059 & 3.53 & 40.60 & 0.35 & 0.85 & 0.04 & 52.25 & 1.38 & 0.29 & 41.78 & 100.49 \\
\hline & 1032 & $\begin{array}{c}\text { Limestone and } \\
\text { dolomitic limestone }\end{array}$ & Carbonate & 13.7 & -- & 0.009 & 1.57 & 30.85 & 0.20 & 0.4 & 0.02 & 54.75 & 0.62 & 0.09 & 43.27 & 100.96 \\
\hline & 1033 & Limestone & Carbonate & 14.8 & -- & 0.025 & 2.03 & 41.01 & 0.39 & 0.43 & 0.03 & 53.33 & 1.3 & 0.13 & 42.58 & 100.32 \\
\hline & 1050 & $\begin{array}{c}\text { Limestone and } \\
\text { dolomitic limestone }\end{array}$ & Carbonate & 10.6 & -- & 0.058 & 2.24 & 41.59 & 0.28 & 0.53 & 0.02 & 0.86 & 0.67 & 0.14 & 42.31 & 100.73 \\
\hline
\end{tabular}




\begin{tabular}{|c|c|c|c|c|c|c|c|c|c|c|c|c|c|c|c|c|}
\hline $\begin{array}{l}\text { Cat- } \\
\text { egory }\end{array}$ & $\begin{array}{l}\text { Aggre- } \\
\text { gate }\end{array}$ & Rock Type & $\begin{array}{l}\text { Main Mineral } \\
\text { Constituents }\end{array}$ & \begin{tabular}{c||} 
Micro- \\
Deval \\
Abrasion \\
\end{tabular} & $\begin{array}{c}\text { Iron- } \\
\text { Sulphur } \\
\text { Minerals }\end{array}$ & $\begin{array}{c}\text { Total } \\
\text { Sulphur } \\
\mathrm{S}_{\mathrm{t}}(\%) \\
\end{array}$ & $\begin{array}{l}\mathrm{SiO}_{2} \\
(\%)\end{array}$ & $\begin{array}{l}\mathrm{CO}_{2} \\
(\%)\end{array}$ & $\begin{array}{l}\mathrm{Fe}_{2} \mathrm{O} \\
3(\%)\end{array}$ & $\begin{array}{l}\mathrm{Al}_{2} \mathrm{O} \\
3(\%)\end{array}$ & $\begin{array}{l}\mathrm{TiO}_{2} \\
(\%)\end{array}$ & $\begin{array}{c}\mathrm{CaO} \\
(\%)\end{array}$ & $\begin{array}{l}\text { MgO } \\
(\%)\end{array}$ & $\begin{array}{c}\mathrm{Na} 2 \mathrm{O}+ \\
\mathrm{K}_{2} \mathrm{O} \\
(\%) \\
\end{array}$ & $\begin{array}{l}\text { LOI } \\
(\%)\end{array}$ & $\begin{array}{c}\text { Total } \\
(\%)\end{array}$ \\
\hline \multirow{13}{*}{$2 \mathrm{~S}$} & 1043 & $\begin{array}{c}\text { Mafic to intermediate } \\
\text { gneiss }\end{array}$ & Silicate & 11.9 & Pyrite & 0.112 & 58.39 & 0.16 & 6.94 & 17.44 & 0.94 & 5.61 & 2.4 & 6.26 & 0.48 & 98.95 \\
\hline & 1044 & Gabbro & Silicate & 8.8 & $\begin{array}{c}\text { Pyrrhotite } \\
\text { Pyrite }\end{array}$ & 0.151 & 51.27 & 1.13 & 12.54 & 14.87 & 2.25 & 6.52 & 3.0 & 5.39 & 1.35 & 98.47 \\
\hline & 1045 & $\begin{array}{c}\text { Coarse-grained pink } \\
\text { granite }\end{array}$ & Silicate & 5.7 & -- & 0.045 & 61.90 & 0.41 & 4.27 & 17.24 & 0.74 & 2.47 & 1.04 & 10.04 & 0.72 & 99.02 \\
\hline & 1046 & Metabasalt & $\begin{array}{l}\text { Actinolite, plagioclase, } \\
\text { chlorite, epidote, trace } \\
\text { calcite and trace sulphide }\end{array}$ & 6.8 & -- & 0.027 & 49.09 & 1.30 & 14.24 & 13.91 & 2.12 & 8.12 & 4.7 & 4.42 & 2.94 & 100.05 \\
\hline & 1047 & $\begin{array}{c}\text { Granite to granodiorite } \\
\text { gneiss }\end{array}$ & Silicate & 4.9 & -- & 0.014 & 70.77 & 0.15 & 3.18 & 14.3 & 0.39 & 2.07 & 0.8 & 7.22 & 0.56 & 99.51 \\
\hline & 1048 & $\begin{array}{l}\text { Nipissing diabase } \\
\text { (gabbro) }\end{array}$ & Silicate & 3.7 & -- & 0.039 & 51.89 & 0.21 & 10.36 & 16.87 & 0.75 & 9.69 & 6.13 & 3.28 & 1.07 & 100.28 \\
\hline & 1049 & $\begin{array}{l}\text { Quartzite with mafic } \\
\text { dike }\end{array}$ & Silicate & 3.4 & -- & 0.024 & 93.57 & 0.36 & 0.61 & 3.01 & 0.18 & 0.40 & 0.35 & 0.84 & 0.88 & 99.86 \\
\hline & 1051 & $\begin{array}{l}\text { Granite to granite } \\
\text { gneiss }\end{array}$ & Silicate & 4.8 & -- & 0.009 & 73.88 & 0.23 & 2.40 & 13.07 & 0.27 & 5.61 & 0.4 & 8.18 & 0.63 & 99.81 \\
\hline & 1056 & Siliceous gravel & Silicate & 10.0 & -- & 0.010 & 68.91 & 0.06 & 3.83 & 14.41 & 0.52 & 1.48 & 1.32 & 8.12 & 0.98 & 99.88 \\
\hline & 1058 & Siliceous gravel & Silicate & 10.2 & -- & 0.025 & 67.07 & 0.29 & 4.08 & 14.72 & 0.58 & 2.79 & 1.28 & 7.48 & 0.71 & 99.07 \\
\hline & $\mathrm{P}$ & Anorthosite & $\begin{array}{l}\text { Plagioclase, hornblende } \\
\text { and biotite }\end{array}$ & 10.8 & -- & 0.05 & 51.72 & 0.82 & 4.7 & 24.03 & 1.21 & 9.49 & 2.12 & 5.76 & 0.95 & 100.4 \\
\hline & $\begin{array}{c}\text { Sand } \\
\mathrm{A}\end{array}$ & Quartz & Silicate & -- & -- & 0.04 & 56.44 & 22.7 & 4.24 & 8.34 & 0.59 & 11.71 & 1.80 & 4.00 & 10.07 & 97.51 \\
\hline & Sand B & Quartz-feldspar & Silicate & -- & -- & $<0.01$ & 69.5 & 0.05 & 4.32 & 11.9 & 0.50 & 4.64 & 1.88 & 5.55 & 1.34 & 99.9 \\
\hline
\end{tabular}




\subsection{Experimental Program}

The experimental program in this study is divided into two parts. The first part aims at testing the applicability of the testing protocol devolved by Rodrigues et al. (2016) to aggregates of different composition and blends of aggregates with controlled total sulphur content. This part is carried out in an attempt to understand the applicability and the limitation of the testing protocol and ways to optimize the test and address the limitations.

The second part aims at improving the testing protocol and developing a new oxidation mortar bar test (OMBT) for evaluating the susceptibility of sulphide-bearing aggregate to oxidation

\subsubsection{Protocol applicability to different aggregates}

\subsubsection{Oxygen consumption test (OCT) and test optimization}

In this part, the test configuration of the oxygen consumption test is adopted from (Rodrigues, Duchesne, \& Fournier, 2016a; Rodrigues, Duchesne, Fournier, et al., 2016). The cells are made of Plexiglass columns that are sealed with a Plexiglass cap in their upper part, allowing a headspace above the ground material. Each cell has a $200 \mathrm{~mm}$ height and an internal diameter of $141.7 \mathrm{~mm}$ (Figure 3.1). During the experiment, the columns were sealed using a gasket of $3 \mathrm{~mm}$ thick to avoid any leaks or entry of oxygen into the system.

Oxygen consumption was monitored for 3.5 hours (which includes the first 30 minutes for oxygen sensor probe stabilization), as originally proposed by (Rodrigues, Duchesne, \& Fournier, 2016b), and extended to 16.0 hours, in addition to the 30 minutes for the oxygen sensor probe stabilization. The ground aggregate was tested at $40 \%$ degree of saturation, and a $100 \mathrm{~mm}$ headspace was left at the top of the cell. A galvanic-cell type oxygen sensor (Apogee SO-100 \& 200 series) was inserted through the Plexiglass cap and connected to a four-channel Quad-Volt data Logger (OM- 
CP-IFC200), as shown in Figure 3.2. This part in the research examines the factors that affect the test results, including the aggregate method of processing and the tested aggregate size.

In terms of the test acceptance criterion, aggregates are considered to pass the test if the oxygen consumption is $\leq 5 \%$ after 3 hours. This limit was reduced to 4\% in Annex P in the 2019 edition of CSA A23.1.

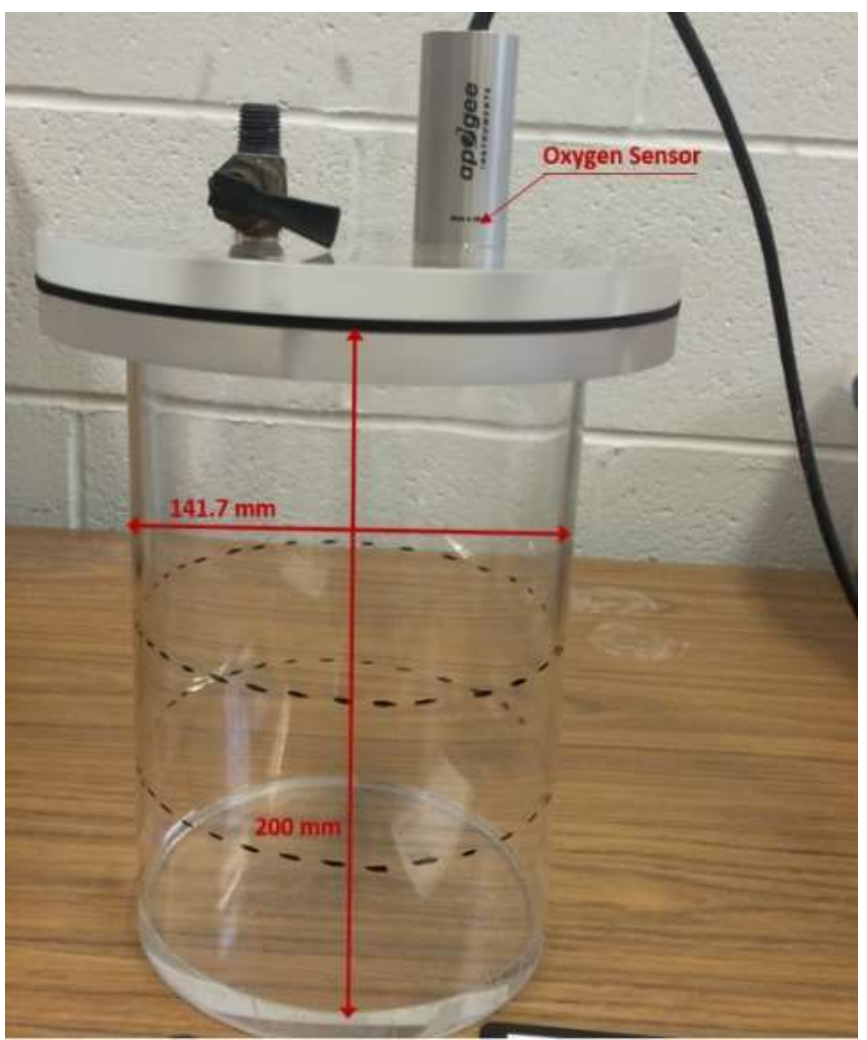

Figure 3.1. Oxygen consumption cell dimensions 


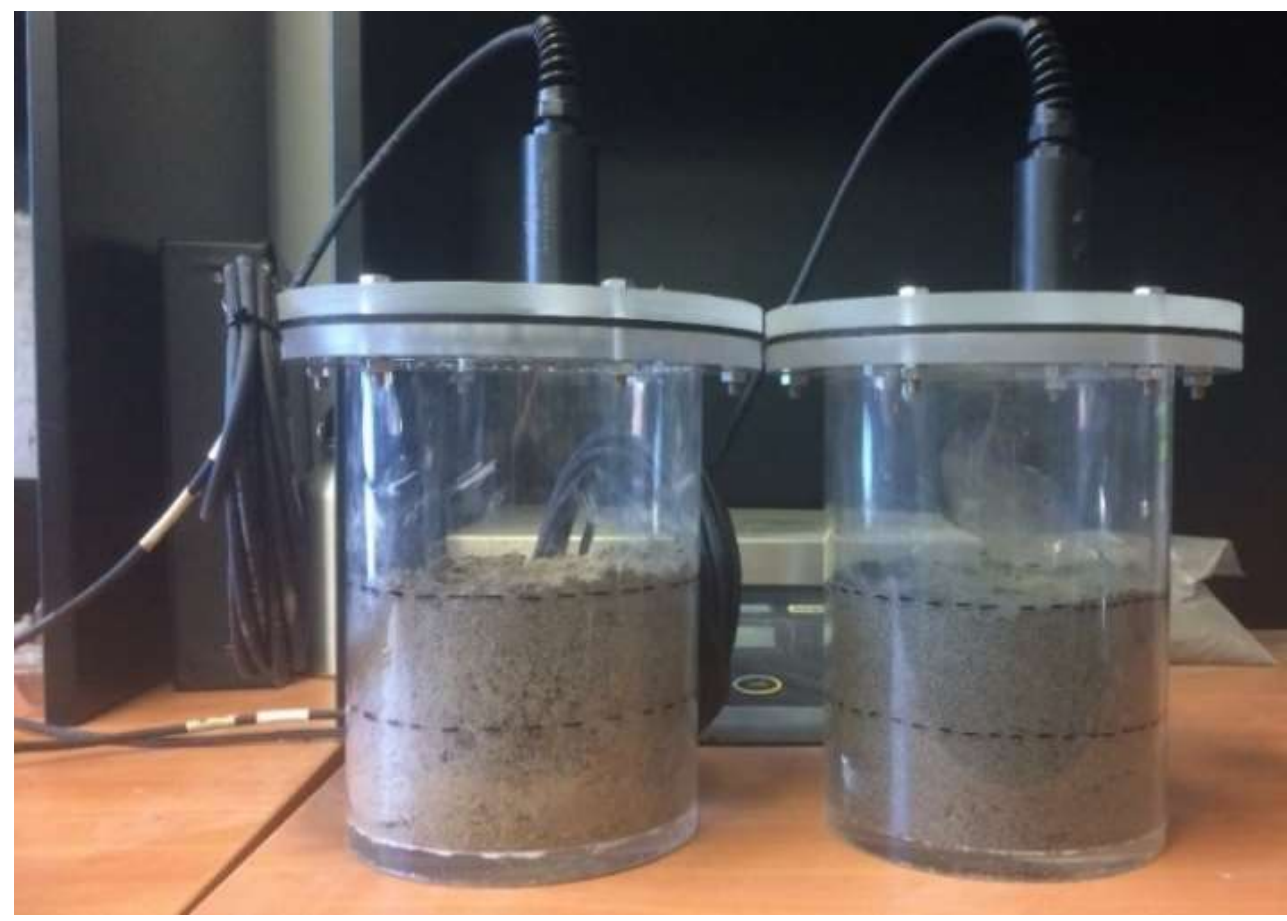

Figure 3.2. OCT set-up showing sealed plexiglass cells with 100-mm crushed aggregates

\section{a. Aggregate processing optimization}

For aggregate processing, four methods of processing were used to avoid aggregate contamination, as follows:

1. Jaw crusher with cast iron plates, followed by disk pulverizer with cast iron plates.

2. Jaw crusher with cast iron plates, followed by grinding mill with stainless steel balls (microdeval apparatus).

3. Jaw crusher with cast iron plates, followed by disk pulverizer with ceramic plates (Figure 3.3).

4. Jaw crusher with manganese plates, followed by disk pulverizer with ceramic plates.

In all cases, the aggregate samples were initially crushed in the jaw crusher until the whole sample passed sieve \#16 (1.18 mm). The samples were then introduced to the secondary mode of crushing until reaching the required size. Although the micro-deval apparatus may not produce 
representative samples, it is used here with a non-sulphide aggregate sample to examine the effects of utilizing a disk pulverizer with iron plates.

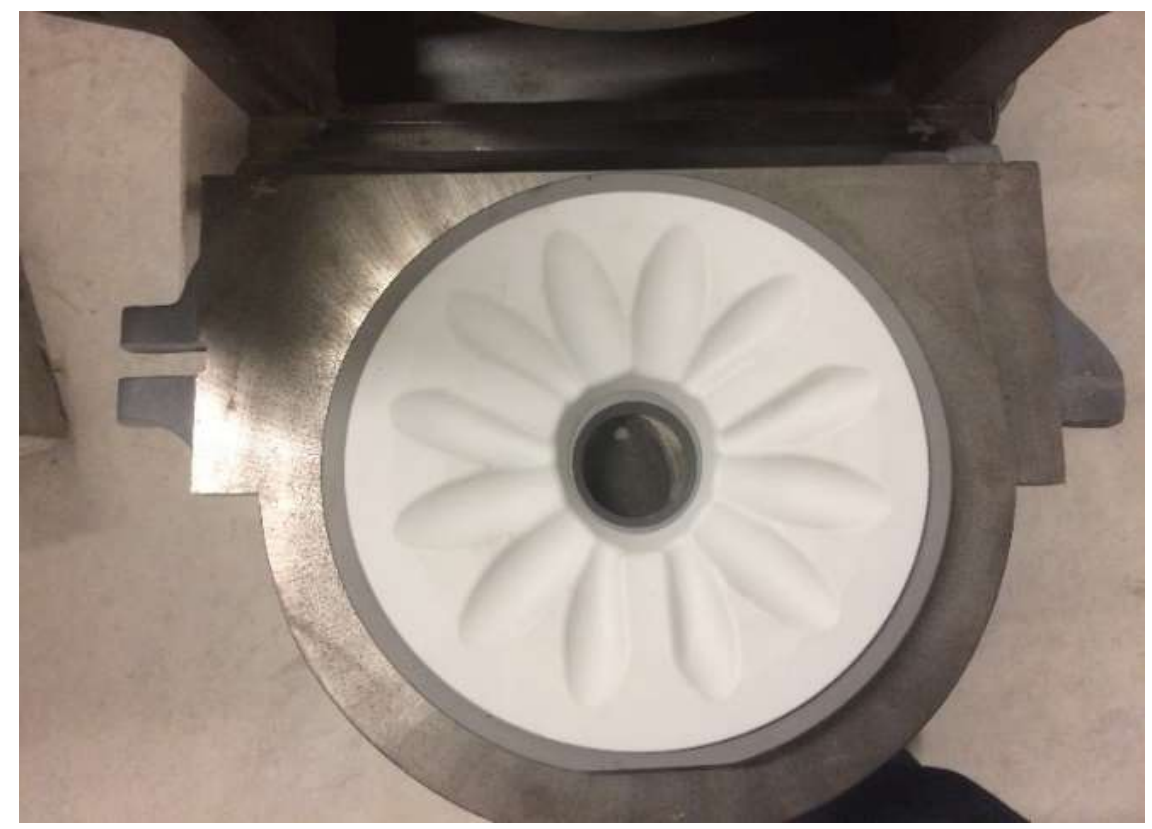

Figure 3.3. Disk pulverizer with ceramic plates

\section{b. Aggregate size optimization}

To test the effect of grinding size, the aggregates were tested in two gradations, as shown in Table

3.4. These sample gradations and proportions were chosen in an attempt to have control on the tested gradation, especially the fine fraction.

Table 3.4. Gradation of the tested samples

\begin{tabular}{ccccc}
\hline & \multicolumn{5}{c}{ Sieve Size } \\
\cline { 2 - 5 } Gradation \# & $\begin{array}{c}600 \mu \mathrm{m}- \\
300 \mu \mathrm{m}\end{array}$ & $\begin{array}{c}300 \mu \mathrm{m}-150 \\
\mu \mathrm{m}\end{array}$ & $\begin{array}{c}150 \mu \mathrm{m}- \\
75 \mu \mathrm{m}\end{array}$ & $<150 \mu \mathrm{m}$ \\
\hline 1 & $50 \%$ & $50 \%$ & -- & -- \\
\hline 2 & -- & $50 \%$ & $50 \%$ & -- \\
\hline 3 & -- & -- & -- & $100 \%$ \\
\hline
\end{tabular}




\section{c. Test capacity to measure different levels of oxidation}

To examine the sensitivity (ability to detect different levels of oxidizable sulphide) of the test to detect different levels of sulphide in aggregates, mixtures of Sand (A) and different percentages of sulphide ore aggregate (ORE) were tested. The samples were first processed in the jaw crusher and then introduced in the micro-deval abrasion machine for eight hours until a size passing 150 $\mu \mathrm{m}$ and retaining $75 \mu \mathrm{m}$ was reached. The tested samples were:

- Sand A: $100 \%$ sand

- Sand A+ 1\% ORE: Sand A containing 1\% crushed sulphide ore aggregate

- Sand A+ 2\% ORE: Sand A containing 2\% crushed sulphide ore aggregate

- Sand A+ 5\% ORE: Sand A containing 5\% crushed sulphide ore aggregate

- Sand A+ 10\% ORE: Sand A containing 10\% crushed sulphide ore aggregate

In addition to the previous samples, a Sand (A) sample with 5\% iron powder collected from the machine shop at Ryerson University, Toronto, was tested to investigate the effect of iron impurities on the oxygen consumption.

\subsubsection{Oxidation mortar bar test (OMBT)}

This test was carried out following the oxidation mortar bar test in the protocol proposed in (Rodrigues et al., 2015; Rodrigues, Duchesne, Fournier, et al., 2016). Mortar bar samples were tested in a manner that promotes the oxidation of sulphide-bearing aggregate and subsequent internal sulphate attack. Each tested set comprised of three specimens $25 \times 25$ x $285 \mathrm{~mm}(1.0 \times$ $1.0 \times 11.2 \mathrm{in}$ ), equipped with a titanium gauge stud at each end for measurements. Titanium studs are used when sodium hypochlorite is utilized as an oxidizing solution to avoid metal degradation. 
Length measurements were taken weekly (Figure 3.4) using a length comparator as per ASTM C490/C490M (2017).

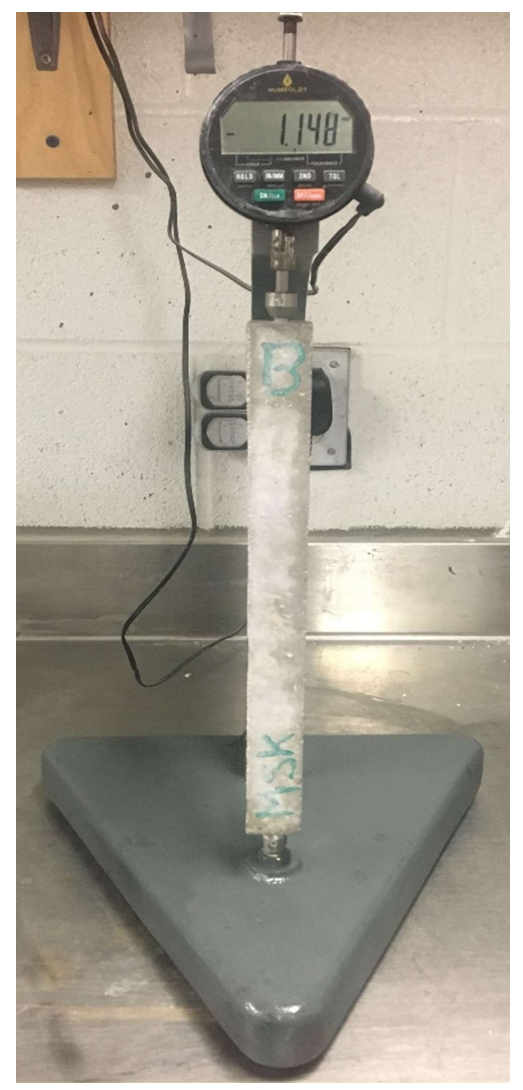

Figure 3.4. Mortar bars length measurements

Mortar bars were prepared using an aggregate gradation similar to the gradation used in the alkalisilica reaction (ASR) accelerated mortar bar test CSA A23.2-25A (2014): $5.00 \mathrm{~mm}$ to $150 \mu \mathrm{m}$ (Sieve \#4 to \#100). Mixture properties remained constant for all tests, with a water-to-cement ratio (w/c) of 0.65 , rather than the 0.47 used in the ASR testing. The test consisted of two phases, as follows:

(a) Phase I: up to week 13 or 90 days, involving soaking the samples in an oxidizing agent (sodium hypochlorite or bleach) for 3 hours, followed by placing the samples for 3.5 days in the oven at $80^{\circ} \mathrm{C}$ and $80 \%$ relative humidity. 
(b) Phase II: from week 14 to week 26 (another 90 days), involving placing the samples in bleach for 3 hours, followed by placing them for 3.5 days in a fridge at $5^{\circ} \mathrm{C}$ over water to achive $100 \%$ relative humidity.

Length measurements in both phases were taken at room temperature after the samples were soaked in bleach in a saturated surface dry condition. In the original testing protocol, the samples were placed under the fume hood for 3 hours following the 3 hours of soaking to reach the required $80 \%$ relative humidity in a shorter period. Guirguis (2017) investigated the effect of leaving the mortar bars in the fume hood prior to placing them in the oven at $80^{\circ} \mathrm{C} / 80 \% \mathrm{RH}$, and it was found that more expansion was achieved when mortar bars are placed in the oven without placing them for 3 hours in the fume hood.

This behaviour was investigated again in this study, as will be presented in Chapter 6 . As the expansion behaviour was similar to that found by Guirguis (2017), the test was applied the same way (as will be presented in Chapter 5), with samples being placed at $80^{\circ} \mathrm{C} / 80 \% \mathrm{RH}$ without placing them for 3 hours in the fume hood.

In terms of the acceptance criteria, in the protocol developed by (Rodrigues, Duchesne, Fournier, et al., 2016) the aggregate is considered suitable for use in concrete if the expansion in Phase I $\left(80^{\circ} \mathrm{C}\right.$ and $80 \% \mathrm{RH}$ for 90 days) is lower than $0.10 \%$. If it is, the sample should be transferred to Phase II ( $4^{\circ} \mathrm{C}$ and $\left.100 \% \mathrm{RH}\right)$ for another 90 days. If at the end of the second 90 days the expansion of the sample becomes stable, the aggregate is considered suitable for use in concrete. If not, the aggregate is deemed not suitable for use in concrete. Aggregates that showed expansion $>0.10 \%$ within the first 90-day period are considered not suitable for use in concrete. In this case, the aggregates should be investigated, as the expansion could be the result of alkali-silica reactivation 
(ASR).

This test was adopted as an Annex in the 2019 edition of CSA A23.1, but with different acceptance criterion (i.e., the aggregate is deemed suitable for concrete if the expansion which occurs between 90 and 180 days is $\leq 0.10 \%$ ). If the mortar bar expansion does not meet the expansion limit, the aggregate is considered not suitable for use in concrete.

\subsubsection{Alkali-silica reaction (ASR) accelerated mortar bar test}

This test was carried out as per CSA A23.2-25A (2014), with an extended period of 28 days. The test was applied to some of the non-carbonate aggregates that had high expansion in the oxidation mortar bar test. Mortar bars were prepared using an aggregate gradation of $5.00 \mathrm{~mm}$ to $150 \mu \mathrm{m}$ (Sieve \#4 to \#100) and a (w/c) ratio of 0.47 . Samples were immersed in 1-N sodium hydroxide solution and stored in the oven at $80^{\circ} \mathrm{C}$. Each tested set comprised three specimens of $25 \times 25 \times$ $285 \mathrm{~mm}$. Length expansion measurements were taken using a length comparator, as per ASTM C490/C490M (2017), at 1, 7, 14 and 28 days.

\subsubsection{Development of new oxidation mortar bar test (OMBT)}

In order to develop an oxidation mortar bar test (OMBT) capable of evaluating the expansion potential of mortar bars with sulphide-bearing aggregates, different testing regimes were investigated with various exposure conditions.

\section{a. Testing details}

All of the samples used in this testing regime consisted of three specimens $(25 \times 25 \times 285 \mathrm{~mm})$ equipped with a gauge stud at each end for measurements. Length measurements were taken weekly using a length comparator as per ASTM C490/C490M (2017). Sand-size aggregates were 
used of gradations similar to those used in the ASR accelerated mortar bar test CSA A23.2-25A (2014): $5.00 \mathrm{~mm}$ to $150 \mu \mathrm{m}$ (Sieve \#4 to \#100).

In Phase I, the mortar bar samples were exposed to cycles that promote sulphide oxidation, while in Phase II, they were exposed to conditions that promote thaumasite formation. Mixture properties remained constant for all tests, with 1-part Portland cement (PC) or cementing materials to 3 parts aggregates. A water-to-cement ratio (w/c) of 0.65 was used, rather than the 0.47 used in the ASR testing to represent the damaged residential concrete in the Québec case. After casting, the samples were cured for two days after demolding in a standard curing room at a relative humidity $(\mathrm{RH})>95 \%$ and a temperature of $23{ }^{\circ} \mathrm{C}$.

After curing, the samples were then moved from the curing room and immediately placed in the soaking solution for the designated period of exposure. After soaking, the samples were stored for the remaining time in the exposure temperature and humidity. The assigned temperature and humidity, depending on the exposure condition, were achieved by one or more of the following methods:

(i) storing the samples in a conventional oven in a sealed container over a supersaturated solution of $\mathrm{NaCl}$ at a temperature of $80^{\circ} \mathrm{C}$, to produce a relative humidity of $80 \%$.

(ii) storing the samples in a humidity chamber that controls the temperature and humidity, or

(iii) storing the samples in a conventional refrigerator at a temperature of $5^{\circ} \mathrm{C}$ in a sealed container above water to achieve $100 \%$ humidity.

After the storing period, the samples were allowed to reach room temperature for half an hour before being soaked again for the next cycle. Length change measurements were taken only 
once per week following the soaking period when the mortar bars were in a saturated surface dry condition.

\section{b. Exposure details}

Testing exposure covers the effect of i) using different soaking solutions, such as bleach, calcium hypochlorite and lime water, and ii) storage temperature and humidity in both Phase I and Phase

II. Table 3.5 shows the details of the investigated testing program.

Table 3.5. Details of testing exposures for mortar bars

\begin{tabular}{|c|c|c|c|c|}
\hline \multirow{2}{*}{ ID* } & \multicolumn{2}{|c|}{ Soaking Condition } & \multicolumn{2}{|c|}{ Storing Details } \\
\hline & Solution & Duration & Phase I & Phase II \\
\hline B-1 & \multirow{2}{*}{ Bleach } & $\begin{array}{l}3 \text { hrs, two } \\
\text { cycles/week }\end{array}$ & $\begin{array}{l}\text { Samples stored at } 23^{\circ} \mathrm{C} / 80 \% \\
\text { humidity for } 3.5 \text { days for } 13 \\
\text { weeks }\end{array}$ & $\begin{array}{l}\text { Samples stored at } 5^{\circ} \mathrm{C} / 100 \% \\
\text { humidity for } 3.5 \text { days for } 13 \\
\text { weeks }\end{array}$ \\
\hline B-2 & & $\begin{array}{c}3 \mathrm{hrs,} \text { two } \\
\text { cycles/week }\end{array}$ & $\begin{array}{c}\text { Samples stored at } \\
80^{\circ} \mathrm{C} / 100 \% \text { humidity for } 3.5 \\
\text { days for } 22 \text { weeks }\end{array}$ & $\begin{array}{c}\text { Samples stored at } 23^{\circ} \mathrm{C} / 100 \% \\
\text { humidity for } 3.5 \text { days for } 22 \\
\text { weeks }\end{array}$ \\
\hline C-1 & $\begin{array}{l}\text { Calcium } \\
\text { Hypochlorite } \\
\left(\mathrm{Ca}(\mathrm{ClO})_{2}\right)\end{array}$ & $\begin{array}{l}3 \text { hrs, two } \\
\text { cycles/week }\end{array}$ & $\begin{array}{l}\text { Samples stored at } 80^{\circ} \mathrm{C} / 80 \% \\
\text { humidity for } 3.5 \text { days for } 13 \\
\text { weeks }\end{array}$ & $\begin{array}{l}\text { Samples stored at } 5^{\circ} \mathrm{C} / 100 \% \\
\text { humidity for } 3.5 \text { days for } 13 \\
\text { weeks }\end{array}$ \\
\hline L-1 & $\begin{array}{c}\text { Saturated } \\
\text { lime solution }\end{array}$ & $\begin{array}{c}\text { 3hrs, two } \\
\text { cycles/week }\end{array}$ & $\begin{array}{l}\text { Samples stored at } 80^{\circ} \mathrm{C} / 80 \% \\
\text { humidity for } 3.5 \text { days for } 13 \\
\text { weeks }\end{array}$ & $\begin{array}{l}\text { Samples stored at } 5^{\circ} \mathrm{C} / 100 \% \\
\text { humidity for } 3.5 \text { days for } 13 \\
\text { weeks }\end{array}$ \\
\hline
\end{tabular}




\begin{tabular}{|c|c|c|c|c|}
\hline \multirow{2}{*}{ ID* } & \multicolumn{2}{|c|}{ Soaking Condition } & \multicolumn{2}{|c|}{ Storing Details } \\
\hline & Solution & Duration & Phase I & Phase II \\
\hline L-2 & & $\begin{array}{c}3 \mathrm{hrs} \text {, two } \\
\text { cycles/week }\end{array}$ & $\begin{array}{l}\text { Samples stored at } 80^{\circ} \mathrm{C} / 80 \% \\
\text { humidity for } 3.5 \text { days for } 13 \\
\text { weeks }\end{array}$ & $\begin{array}{c}\text { Samples stored at } 23^{\circ} \mathrm{C} / 100 \% \\
\text { humidity for } 3.5 \text { days for } 13 \\
\text { weeks }\end{array}$ \\
\hline L-3 & & $\begin{array}{c}3 \mathrm{hrs} \text {, two } \\
\text { cycles/week }\end{array}$ & $\begin{array}{l}\text { Samples stored at } 40^{\circ} \mathrm{C} / 70 \% \\
\text { humidity for } 3.5 \text { days for } 13 \\
\text { weeks }\end{array}$ & $\begin{array}{c}\text { Samples stored at } 5^{\circ} \mathrm{C} / 100 \% \\
\text { humidity for } 3.5 \text { days for } 13 \\
\text { weeks }\end{array}$ \\
\hline L-4 & & $\begin{array}{c}3 \mathrm{hrs} \text {, two } \\
\text { cycles/week }\end{array}$ & $\begin{array}{l}\text { Samples stored at } 40^{\circ} \mathrm{C} / 70 \% \\
\text { humidity for } 3.5 \text { days for } 13 \\
\text { weeks }\end{array}$ & $\begin{array}{c}\text { Samples stored at } 23^{\circ} \mathrm{C} / 100 \% \\
\text { humidity for } 3.5 \text { days for } 13 \\
\text { weeks }\end{array}$ \\
\hline L-5 & & $\begin{array}{c}3 \mathrm{hrs}, \text { two } \\
\text { cycles/week }\end{array}$ & $\begin{array}{l}\text { Samples stored at } 40^{\circ} \mathrm{C} / 70 \% \\
\text { humidity for } 3.5 \text { days for } 13 \\
\text { weeks }\end{array}$ & $\begin{array}{c}\text { Samples stored at } 40^{\circ} \mathrm{C} / 70 \% \\
\text { humidity for } 3.5 \text { days for } 13 \\
\text { weeks }\end{array}$ \\
\hline L-6 & & 2 days/week & $\begin{array}{l}\text { Samples stored at } 40^{\circ} \mathrm{C} / 70 \% \\
\text { humidity for five days for } \\
13 \text { weeks }\end{array}$ & $\begin{array}{c}\text { Samples stored at } 40^{\circ} \mathrm{C} / 70 \% \\
\text { humidity for five days for } 13 \\
\text { weeks }\end{array}$ \\
\hline L-7 & & 2 days/week & $\begin{array}{l}\text { Samples stored at } 40^{\circ} \mathrm{C} / 70 \% \\
\text { humidity for five days for } \\
13 \text { weeks }\end{array}$ & $\begin{array}{c}\text { Samples stored at } 23^{\circ} \mathrm{C} / 100 \% \\
\text { humidity for five days for } 13 \\
\text { weeks }\end{array}$ \\
\hline L-8 & & 2 days/week & $\begin{array}{l}\text { Samples stored at } 40^{\circ} \mathrm{C} / 70 \% \\
\text { humidity for five days for } \\
13 \text { weeks }\end{array}$ & $\begin{array}{c}\text { Samples stored at } 5^{\circ} \mathrm{C} / 100 \% \\
\text { humidity for five days for } 13 \\
\text { weeks }\end{array}$ \\
\hline is & soa & each, $C=$ & les soaked in calcium hy & lorite, and $\mathrm{L}=$ Samples soake \\
\hline
\end{tabular}




\subsubsection{Concrete prism testing}

Testing using concrete prisms was investigated to examine the capacity of the test in the evaluation of the expansion potential of sulphide-bearing aggregates. Different testing regimes were designed that included a range of exposure conditions. Concrete testing incorporates coarse aggregates without any crushing, which is thought to be more representative of concrete used in the field.

\section{a. Testing details}

All of the samples used in this testing regime consisted of three specimens $(76 \mathrm{~mm} \times 76 \mathrm{~mm} \times$ $285 \mathrm{~mm}$ ) equipped with a gauge stud in each end for measurements. Length measurements were taken weekly using a length comparator as per ASTM C490/C490M (2017). Samples were prepared as per ASTM C. 192 (2010).

For Phase I, the concrete prism samples were exposed to cycles that promote sulphide oxidation, whereas, for Phase II, they were exposed to conditions that promote ettringite/thaumasite formation. Mixture properties remained constant for all testing, with a water-to-cement ratio (w/c) of 0.65 to represent residential concrete. After casting and demolding, the samples were cured for one week in a standard curing room at a relative humidity $>95 \%$ and a temperature of $23^{\circ} \mathrm{C}$.

After curing, the samples were then moved from the curing room immediately placed in the soaking solution for the designated period of exposure. After soaking, the samples were stored for the remaining time in the exposure temperature and humidity. The assigned temperature and humidity, depending on the exposure condition, were achieved by either storing the sample in a conventional oven in a sealed container over a supersaturated solution of $\mathrm{NaCl}$, storing the samples in a humidity chamber that controls the temperature and humidity, or storing the samples in conventional refrigerator in a sealed container above water to achieve $100 \%$ humidity. Some 
samples were stored immediately after curing in the open air to test the effect of exposure to weather conditions.

After the storing period, the samples were allowed to reach room temperature for half an hour before being soaked again for the next cycle. Length change measurements were taken only once per week following the soaking period, while the mortar bars were in a saturated surface dry condition.

\section{b. Exposure details}

Table 3.6 shows the details of the investigated testing program for concrete prisms.

Table 3.6. Details of testing exposures for concrete Prisms

\begin{tabular}{|c|c|c|c|c|c|}
\hline \multirow{2}{*}{$\begin{array}{c}\text { Sample } \\
\text { ID* }\end{array}$} & \multicolumn{2}{|c|}{ Soaking Condition } & \multicolumn{3}{|c|}{ Storing Details } \\
\hline & Solution & Duration & Phase I & Phase II & Phase III \\
\hline PB-1 & & $\begin{array}{c}8 \text { hrs, two } \\
\text { cycles } \\
\text { /week }\end{array}$ & $\begin{array}{l}\text { Samples stored at } \\
80^{\circ} \mathrm{C} / 80 \% \text { humidity } \\
\text { for } 3.5 \text { days for } 17 \\
\text { weeks }\end{array}$ & $\begin{array}{l}\text { Samples stored at } \\
\qquad 5^{\circ} \mathrm{C} / 100 \% \\
\text { humidity for } 3.5 \\
\text { days for } 13 \text { weeks }\end{array}$ & Roof Top \\
\hline PB-2 & Bleach & $\begin{array}{l}\text { One day } \\
\text { /week }\end{array}$ & $\begin{array}{l}\text { Samples stored at } \\
60^{\circ} \mathrm{C} / 80 \% \text { humidity } \\
\text { for four days and in } \\
23^{\circ} \mathrm{C} / 50 \% \text { humidity } \\
\text { for two days for eight } \\
\text { weeks }\end{array}$ & $\begin{array}{l}\text { Samples stored at } \\
223^{\circ} \mathrm{C} / 50 \% \\
\text { humidity for eight } \\
\text { weeks }\end{array}$ & $\begin{array}{l}\text { Samples stored } \\
\text { in } 5^{\circ} \mathrm{C} / 100 \% \\
\text { humidity for six } \\
\text { days for } 20 \\
\text { weeks }\end{array}$ \\
\hline PB-3 & & $\begin{array}{l}\text { One day } \\
\text { /week }\end{array}$ & $\begin{array}{l}\text { Samples stored at } \\
60^{\circ} \mathrm{c} / 80 \% \text { humidity }\end{array}$ & $\begin{array}{l}\text { Samples stored at } \\
23^{\circ} \mathrm{C} / 50 \%\end{array}$ & $\begin{array}{l}\text { Samples stored } \\
\text { in } 23^{\circ} \mathrm{C} / 100 \%\end{array}$ \\
\hline
\end{tabular}




\begin{tabular}{|c|c|c|c|c|c|}
\hline \multirow{2}{*}{$\begin{array}{c}\text { Sample } \\
\text { ID* }\end{array}$} & \multicolumn{2}{|c|}{ Soaking Condition } & \multicolumn{3}{|c|}{ Storing Details } \\
\hline & Solution & Duration & Phase I & Phase II & Phase III \\
\hline & & & $\begin{array}{l}\text { for four days and in } \\
23^{\circ} \mathrm{C} / 50 \% \text { humidity } \\
\text { for two days for eight } \\
\text { weeks }\end{array}$ & $\begin{array}{c}\text { humidity for eight } \\
\text { weeks }\end{array}$ & $\begin{array}{c}\text { humidity for six } \\
\text { days for } 20 \\
\text { weeks }\end{array}$ \\
\hline PL-1 & $\begin{array}{l}\text { Saturated } \\
\text { lime } \\
\text { solution }\end{array}$ & $\begin{array}{c}8 \text { hrs, two } \\
\text { cycles } \\
\text { /week }\end{array}$ & $\begin{array}{l}\text { Samples stored in } \\
80^{\circ} \mathrm{C} / 80 \% \text { humidity } \\
\text { for at days for } 17 \\
\text { weeks }\end{array}$ & $\begin{array}{l}\text { Samples stored at } \\
\qquad 5^{\circ} \mathrm{C} / 100 \% \\
\text { humidity for } 3.5 \\
\text { days for } 13 \text { weeks }\end{array}$ & NA \\
\hline $\mathrm{R}$ & NA & NA & Samples stored in oper & -air conditions & \\
\hline
\end{tabular}

${ }^{*} \mathrm{~B}=$ samples soaked in bleach, $\mathrm{L}=$ Samples soaked in lime water, $\mathrm{R}=$ Samples stored on the roof

\subsubsection{Microscopy and analytical techniques}

\subsubsection{Microstructural examination}

Samples from the OMBT containing different aggregates were prepared for scanning electron microscopy (SEM) and energy dispersive spectroscopy (EDS) examination after the end of testing (after 26 weeks). Mortar bars were cut, dried under vacuum, impregnated with epoxy, and polished with a diamond grade of $0.3 \mu \mathrm{m}$. The polished specimens were sputtered with carbon using the Edwards Vacuum Coating System Model \#306A. Polished sections were studied in a JEOL JSM6380 LV (SEM) operated at $20 \mathrm{kV}$ in backscattered electron imaging mode (BSE). 
The test was used here to investigate the expansion mechanism of mortars and what are the developed phases in mortar bars containing aggregate with high sulphate content aggregates and control aggregates. Scanning Electron Microscopy (SEM) is petrography method which uses high energy electrons to produce various signals at the surface of a sample. These signals reveal information such as the orientation, location and composition of crystalline structures, and overall amount and composition of the chemical compounds existing within the specimen (Swapp, 2012)

\subsubsection{Differential Thermal Analysis (DTA)}

Differential Thermal Analysis (DTA) was carried out on crushed mortar samples containing sulphide-bearing aggregates and PC, PC/FA, PC/SL and PC/MK and aggregate with high silicate content 1049. The test was used to investigate the developed phases at the end of testing. The samples were run through a temperature range from $30^{\circ} \mathrm{C}$ to $700^{\circ} \mathrm{C}$ with a heating rate of 10 $\mathrm{deg} / \mathrm{min}$ under grade 5.0 nitrogen to produce heat energy flow curves. For sample preparation, samples were ground to pass sieve $80 \mu \mathrm{m}$ and stored in an environment free of carbon dioxide and humidity until testing. 


\section{Chapter 4}

\section{Applicability and Optimization of Oxygen Consumption Test (OCT)}

As introduced in chapter 3, the oxygen consumption test adopted by Rodrigues et al. $(2012 ; 2016)$ employs a sealed plexiglass cylinder to test oxygen consumption. The set-up is shown in Figure 3.2. The test is conducted at atmospheric pressure and at room temperature $\left(21^{\circ} \mathrm{C}-23^{\circ} \mathrm{C}\right)$, applying a $40 \%$ degree of saturation. A crushed aggregate sample $(100 \mathrm{~mm}$, with a maximum particle size of $150 \mu \mathrm{m})$ is tested over a 3.5-hour duration. Note that the first 30 minutes of the test is used for probe stabilization and to exclude the typical minor consumption that takes place within the first 30 minutes

for any aggregate. Aggregates are considered to pass the test if the consumption is $\leq 5 \%$ after 3 hours. This limit was reduced to 4\% in Annex P in the 2019 edition of CSA A23.1.

This chapter aims at testing different aggregates to check the applicability of the test to a wide range of aggregate and to optimize the test procedures. The optimization was mainly related to aggregate processing techniques, aggregate size, and test sensitivity in measuring the oxidation of iron sulphides. The oxygen consumption was monitored for 3.5 hours, as proposed initially by Rodrigues, Duchesne, \& Fournier (2016), and extended to 16.5 hours (which includes the first 30 minutes for oxygen sensor probe stabilization) to investigate if a longer duration provides more reliable results.

\subsection{Oxygen Consumption Test (OCT) Optimization}

The main objective of this section is to optimize the OCT to get the most reliable testing parameters in terms of i) aggregate processing methods, ii) test sensitivity to measure the oxygen consumption, iii) tested aggregate size, and iv) test duration. 


\subsubsection{Aggregate processing}

The effect of using different aggregate processing techniques was investigated in this part of the research. Four processing procedures were used, as mentioned earlier in the experiment details in Chapter 3. Changing the processing method enabled us to avoid contamination that can affect the results of oxygen consumption. The techniques used, according to the order of usage, were:

a. Jaw crusher with cast iron plates, followed by disk pulverizer with cast iron plates.

b. Jaw crusher with cast iron plates, followed by grinding mill with stainless steel balls (microdeval apparatus).

c. Jaw crusher with cast iron plates, followed by disk pulverizer with ceramic plates (Figure $3.3)$.

d. Jaw crusher with manganese plates, followed by disk pulverizer with ceramic plates.

Initially, the control aggregates $\mathrm{P}$ and $\mathrm{C} 1$ were prepared using the commercially available jaw crusher and disk pulverizer, both with cast iron plates. The oxygen consumption test results for these aggregates are shown in Figure 4.1. Aggregate $\mathrm{P}$ is anorthosite, with a total sulphur content of 0.04$0.06(\%)$, and $\mathrm{C} 1$ is a concrete aggregate, with a total sulphur content of $\mathrm{S}_{\mathrm{t}}=0.09-0.19(\%)$. As the figure illustrates, both aggregates had high oxygen consumption. It is interesting to report that when aggregate $\mathrm{P}$ was processed using the same method but with a coarser size (between $600 \mu \mathrm{m}$ and 300 $\mu \mathrm{m}$ ), it showed very high consumption (about 94\%), despite the anticipated lower oxidation associated with larger particle size. When the same sample $(600 \mu \mathrm{m}$ to $300 \mu \mathrm{m})$ was left in the cell for two days, rust appeared in the aggregate, as shown in Figure 4.2. 


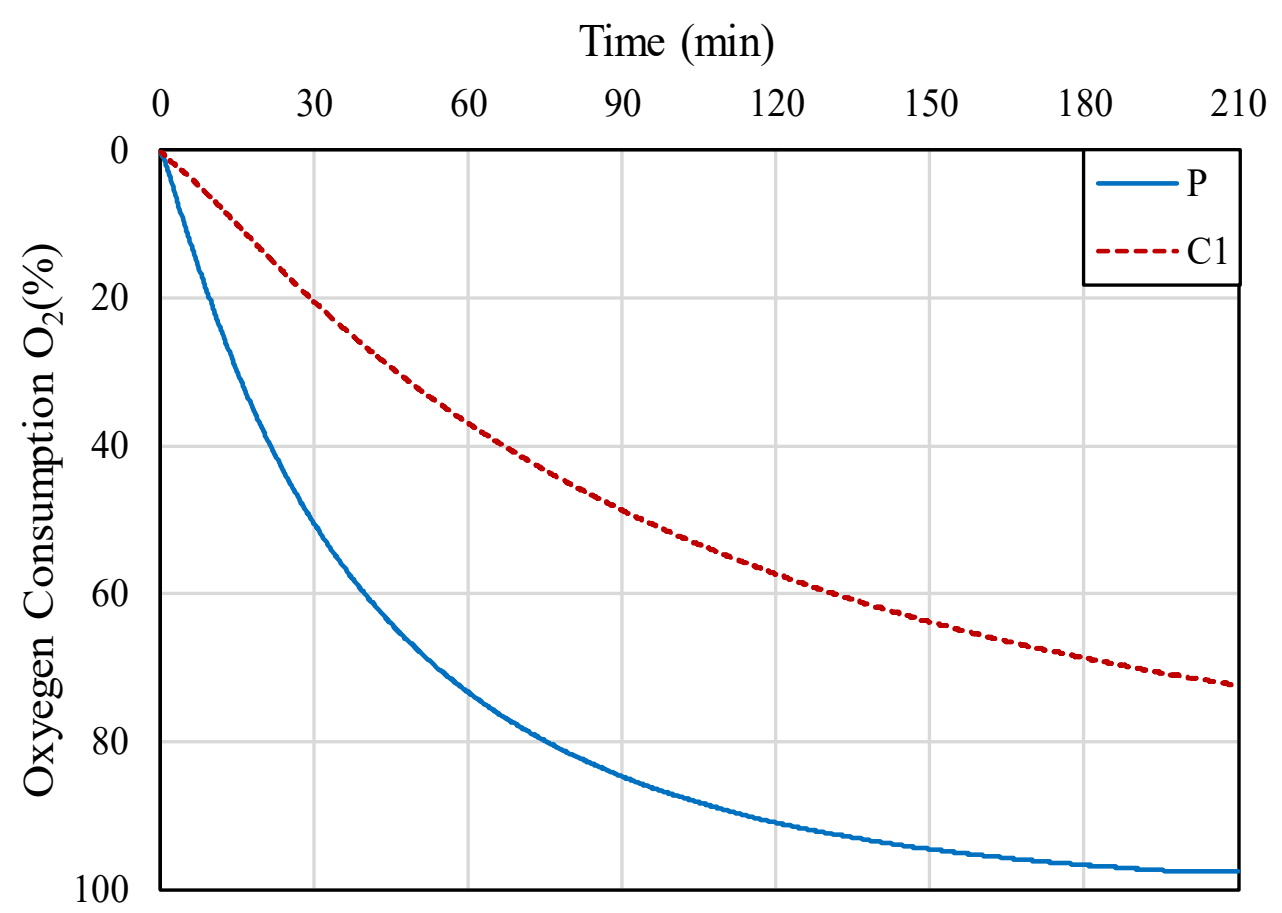

Figure 4.1. Oxygen consumption for samples crushed by disk pulverizer with cast iron plates

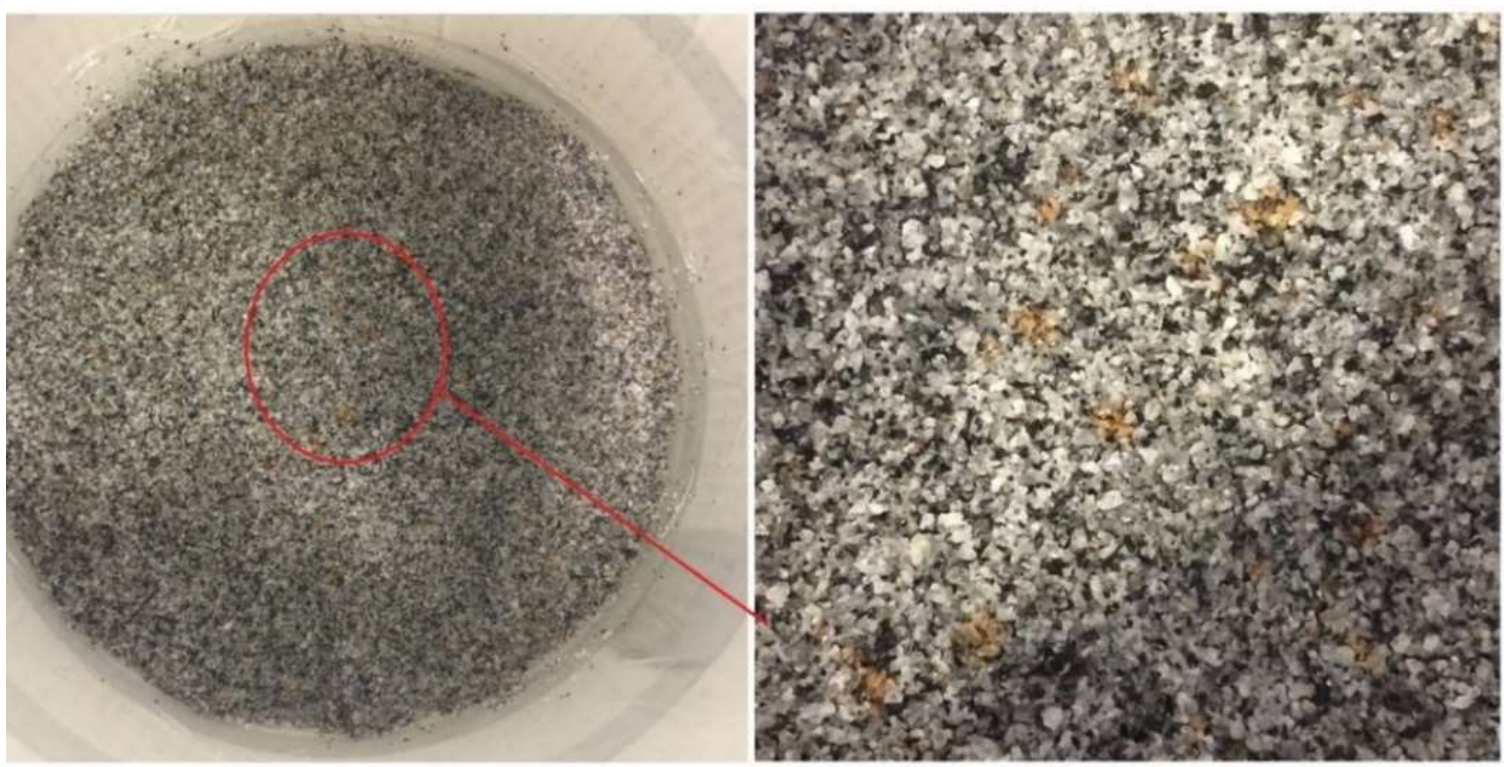

Figure 4.2. Rust in aggregate crushed by disk pulverizer with iron plates to a size of (600 $\mu \mathrm{m}$ to 300 $\mu \mathrm{m})$ 
For more evaluation of this behaviour, sand $\mathrm{A}\left(\mathrm{S}_{\mathrm{t}}=0.04 \%\right)$ was processed in the disk pulverizer with cast iron plates. Another sample was crushed by the micro-deval abrasion machine for comparison. A third sample was prepared by mixing the sand processed by the micro-deval with $5 \%$ by mass of iron powder. The results of these tests are shown in Figure 4.3. As can be seen, the first sample has high oxygen consumption, while the sample crushed in the micro-deval has very little consumption (1.1\%). A $5 \%$ by mass iron powder added to the sand crushed in the micro-deval show high oxygen consumption that is close to the measured consumption of the sand crushed in the disk pulverizer.

These results indicate that the measured oxygen consumption in the samples tested and presented in Figure 4.1 was not the result of sulphide oxidation. Instead, the consumption is believed to be due to the inclusion of iron impurities within the sample either from the iron plates of the disc pulverizer or through intentionally adding the iron powder.

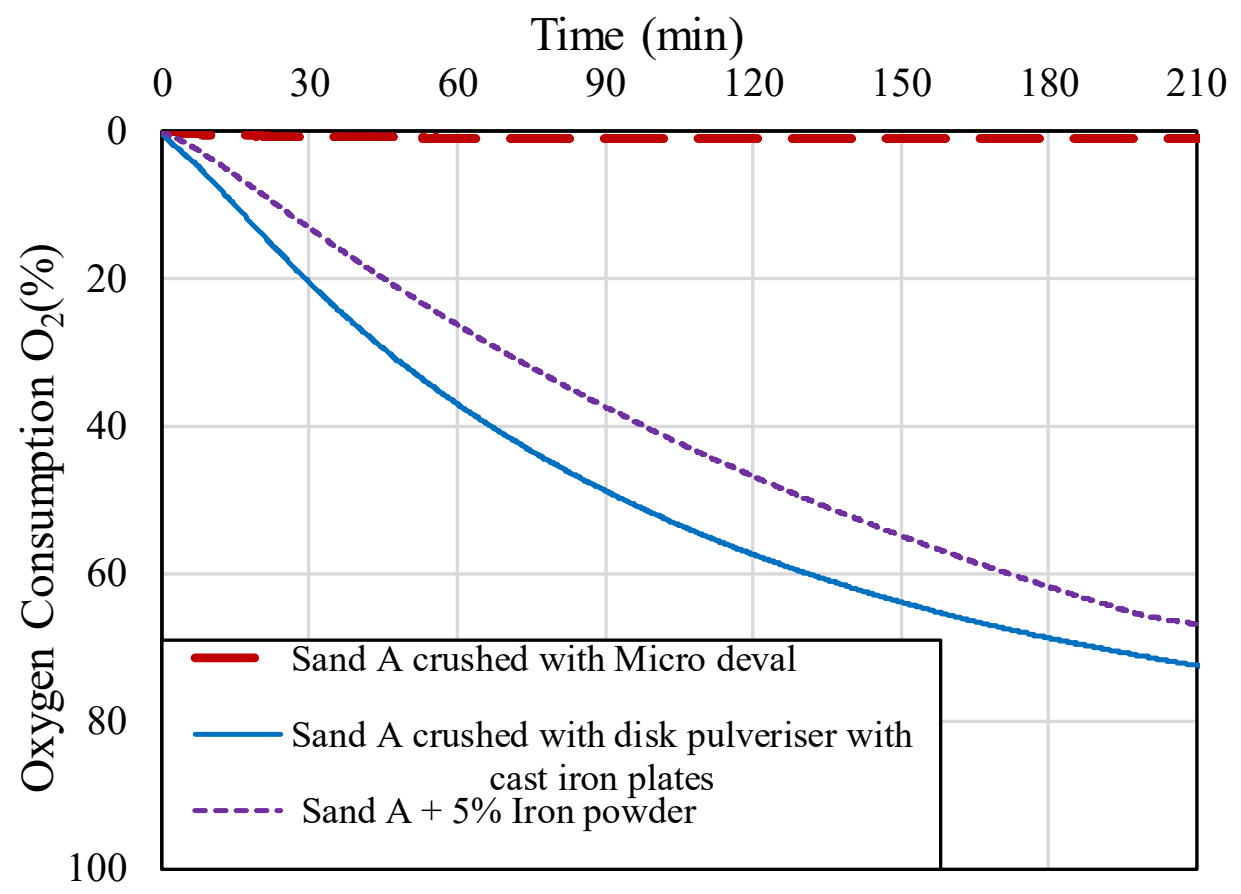

Figure 4.3. Oxygen consumption for sand A crushed by the micro-deval abrasion machine and disk pulverizer with cast iron plates and a sample with crushed with the micro-deval with $5 \%$ iron powder 
Based on the obtained results, and to avoid the effect of the abraded iron from using the disk pulverizer in grinding the aggregate, the cast iron plates were replaced with ceramic plates. After crushing the sample in the jaw crusher with cast iron plates until being able to pass through sieve \#16 $(1.18 \mathrm{~mm})$, the samples were introduced to the disk pulverizer with ceramic plates.

Figure 4.4 shows the oxygen consumption for three aggregate samples crushed using the ceramic plates (sand A, C1 and MSK) to particle size ( $300 \mu \mathrm{m}$ to $75 \mu \mathrm{m})$. Sand A is a fine aggregate and C1 is a coarse aggregate, but both are concrete aggregates that have an excellent record in concrete with very minimal sulphur content. These aggregates (sand A and C1) showed consumptions of $2 \%$ and $5 \%$ after $3: 30$ and $2 \%$ and $7 \%$ after $16: 30$ hours, respectively (including 30 minutes for probe stabilization). The third sample (MSK), which contains total sulphur between 0.73 and $1.28 \%$, showed consumption of about $28 \%$ and $65 \%$ after $3: 30$ and $16: 30$ hours, respectively (minus the negligible consumption which occurred within the first 30 minutes).

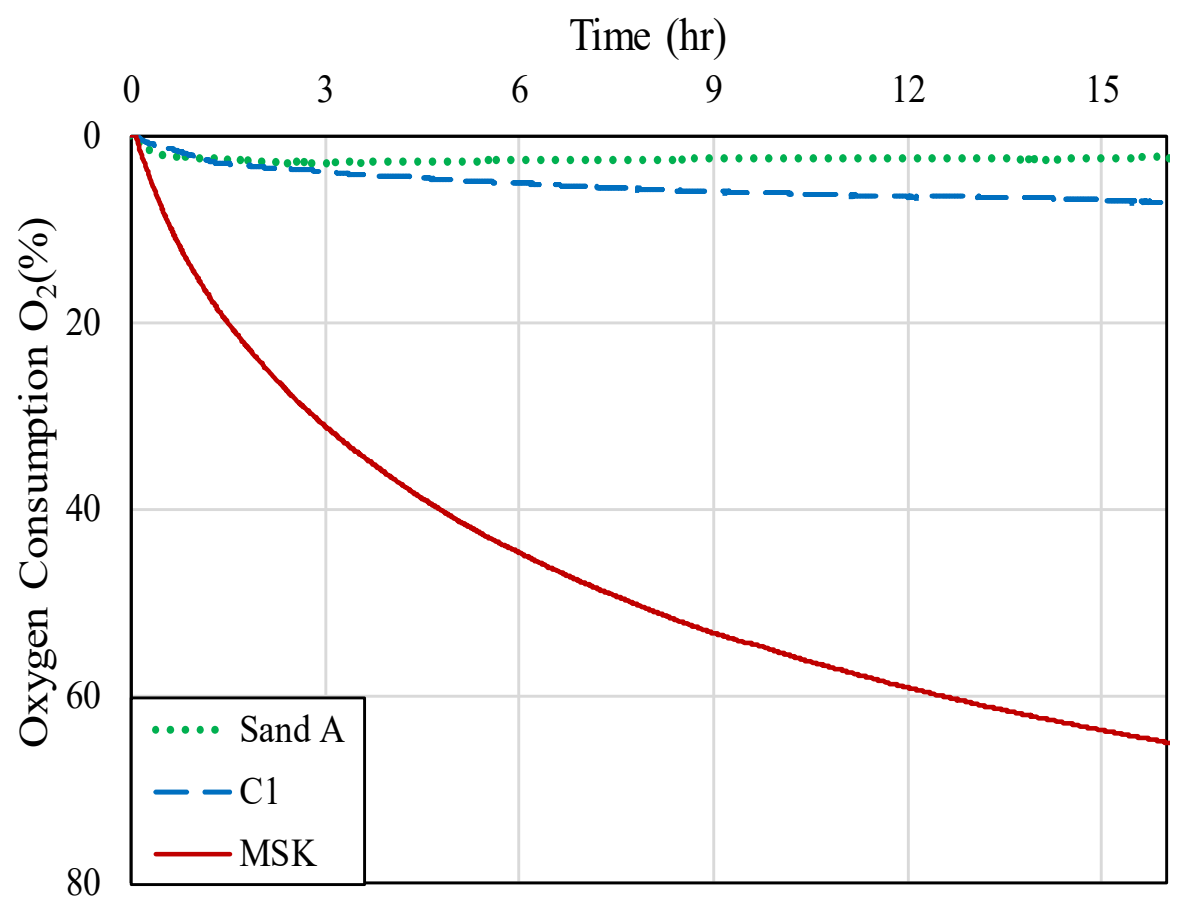

Figure 4.4. Oxygen consumption for samples crushed by disk pulverizer with ceramic plate 


\subsubsection{Test capacity to evaluate aggregate with different sulphide levels}

After obtaining results with less contamination (from processing the aggregate with the jaw crusher with cast iron plates and the disk pulverizer with ceramic plates), the ability of the test to measure the oxygen consumption for materials with different sulphur contents is tested.

In order to evaluate the testability to measure the oxidation of iron sulphides, sand A was tested with different sulphide ore (Ore) contents. The sand sample was crushed in the micro-deval abrasion machine, while the (Ore) sample was introduced first to the jaw crusher with cast iron plates until the sample reached $1.18 \mathrm{~mm}$, then the sample was processed in the micro-deval until the samples reached a size of $150 \mu \mathrm{m}$ to $75 \mu \mathrm{m}$. As Figure 4.5 illustrates, the oxygen consumption for sand A was about $1 \%$. This percentage increased to $7 \% \mathrm{O}_{2}$ when using $1 \%$ of Ore, and about $30 \% \mathrm{O}_{2}$ when mixed with $10 \%$ of Ore during the 3.5 -hour test period.

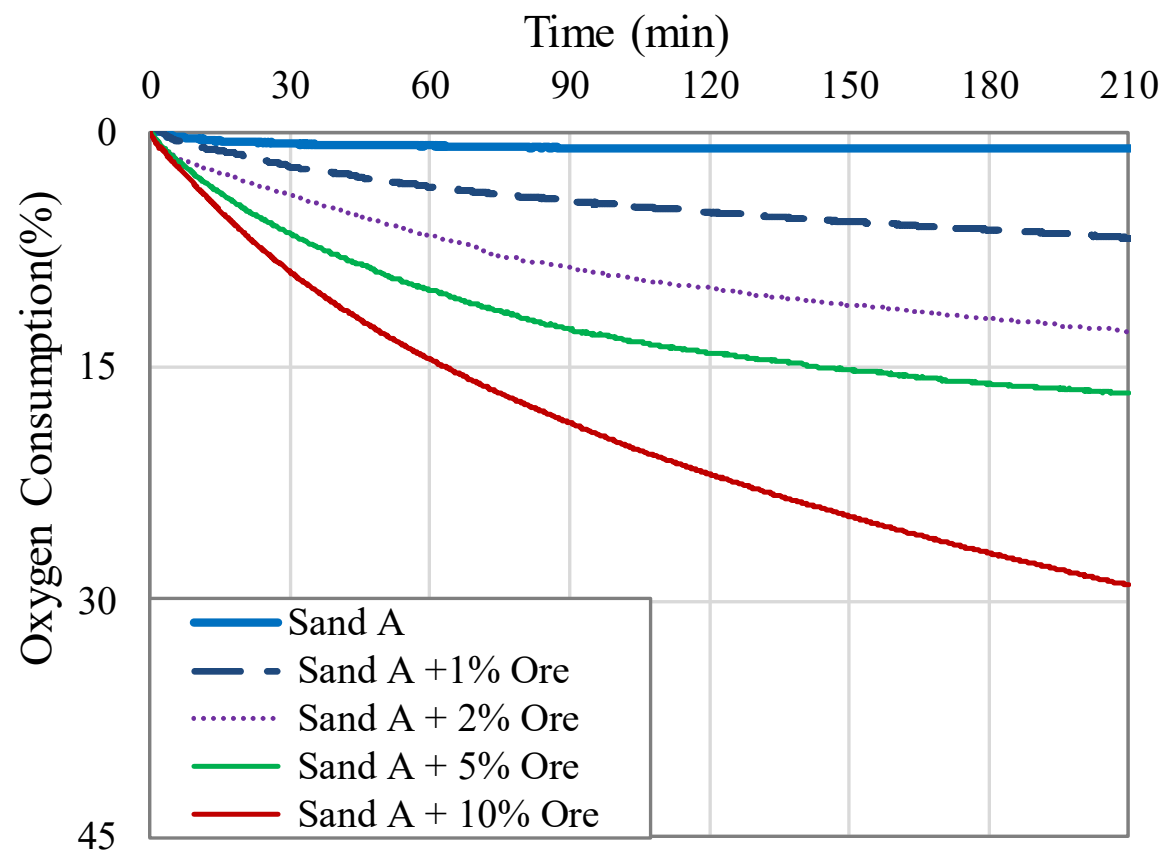

Figure 4.5. Oxygen consumption for samples crushed by the micro-deval abrasion machine, containing the indicated sulphide-bearing aggregate percentages 


\subsubsection{Aggregate size}

The ultimate goal of this subsection, using the previously optimized test parameters, is to obtain the aggregate size that provides more reliable and consistent results. In the testing protocol developed by Rodrigues et al. (2016), the tested aggregate size was $<150 \mu \mathrm{m}$, without controlling the minimum aggregate size. To optimize the tested aggregate size, three different aggregate gradations were tested.

The oxygen consumption test was applied to two aggregates with three gradations - the gradation suggested by (Rodrigues, Duchesne, \& Fournier, 2016) and two new gradations. The aggregates MSK and C1 were crushed into the sizes: i) $<150 \mu \mathrm{m}$ as proposed by Rodrigues et al. (2016), ii) 300 $\mu \mathrm{m}$ to $75 \mu \mathrm{m}$, and iii) $600 \mu \mathrm{m}$ to $150 \mu \mathrm{m}$.

The results of the consumption (3-hour test duration) are shown in Figure 4.6. As illustrated in the figure, the oxygen consumption for samples tested with the same size suggested by (Rodrigues, Duchesne, \& Fournier, 2016) is slightly lower than the oxygen consumption obtained from samples crushed to $300 \mu \mathrm{m}$ to $75 \mu \mathrm{m}$. Although the difference may not be significant, it is thought that controlling the minimum grain size of the sample will provide more consistency in the obtained results. Based on this assumption, two sizes were compared for other aggregates $-600 \mu \mathrm{m}$ to 300 $\mu \mathrm{m}$, and $300 \mu \mathrm{m}$ to $75 \mu \mathrm{m}$ - to determine the size that produces the highest consumption. The results are presented in Figure 4.7. It should also be stated that when tested at Laval University, the OCT consumption for MSK passing $150 \mu \mathrm{m}$ was $21.4 \%$ compared to $19.23 \%$ obtained at Ryerson, suggesting good repeatability for this test. 


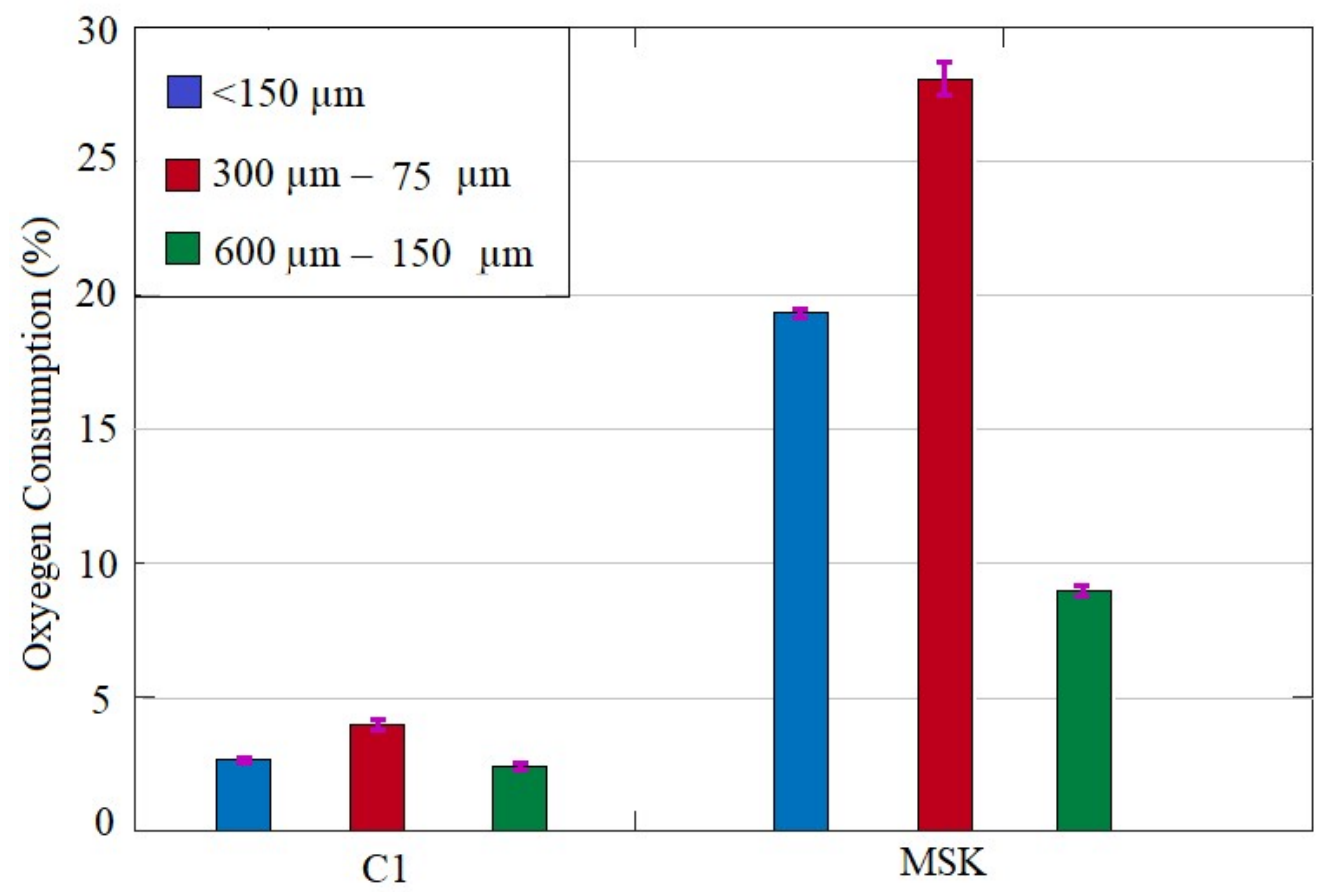

Figure 4.6. Oxygen consumption after 3 hours for tested samples with different gradations, the histogram bars represent the mean value, while the error bars represent test\#1 and test\#2 Figure 4.7 shows the results of the oxygen consumption test after 3 hours of testing. As shown, various aggregates were processed to the two gradations: i) from 300 to $150 \mu \mathrm{m}$ and from 150 to 75 $\mu \mathrm{m}$, at a ratio of $1: 1$; and ii) from 600 to $300 \mu \mathrm{m}$ and 300 to $150 \mu \mathrm{m}$, at a ratio of 1:1. Processing the aggregate to larger particle size $(600 \mu \mathrm{m}$ to $150 \mu \mathrm{m})$ resulted in less oxygen consumption. The higher consumption, in the case of the smaller grinding size, is likely attributable to the increase of the surface area of iron sulphide. Hence, a large surface is exposed to moisture and oxygen. 


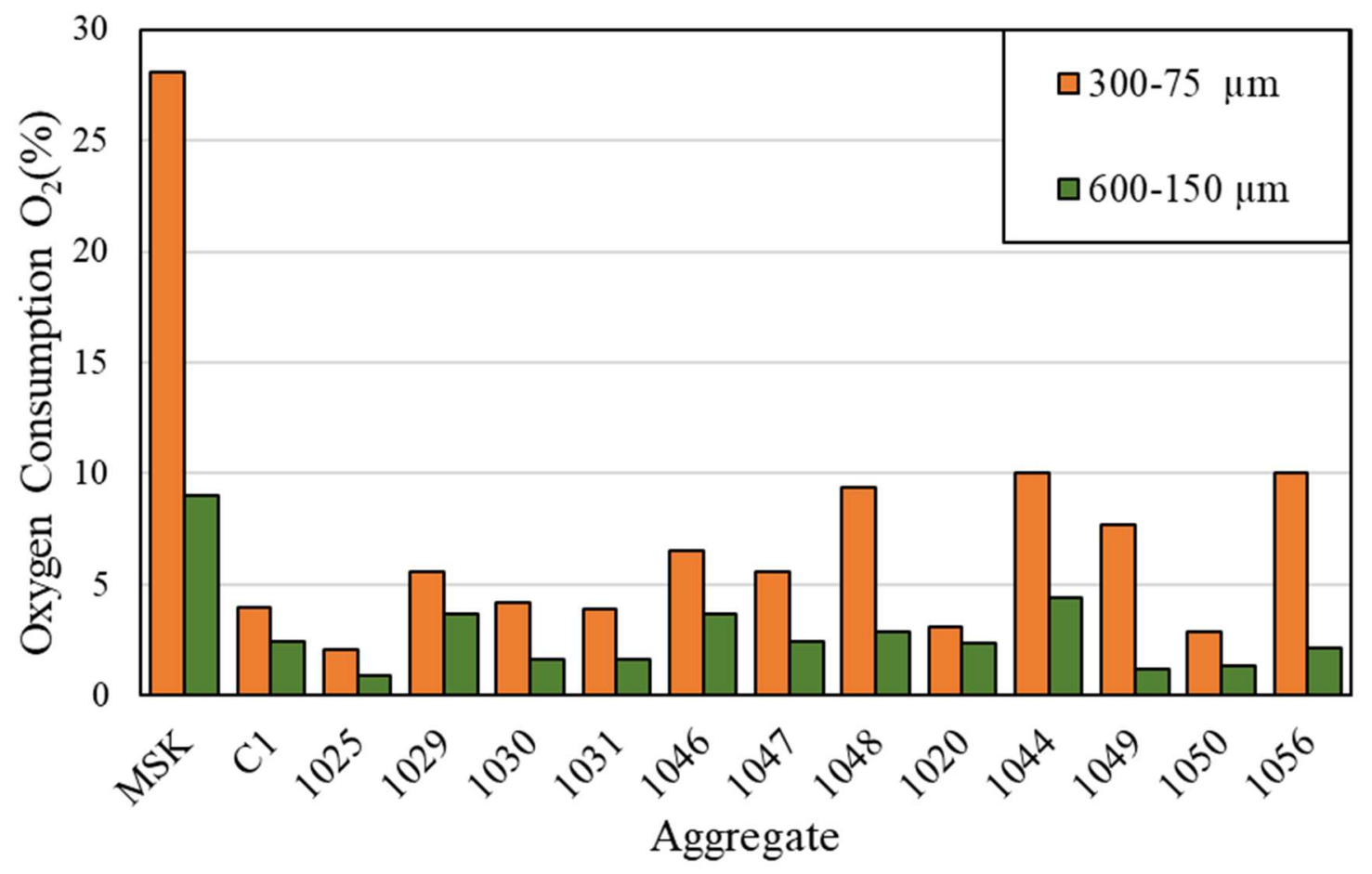

Figure 4.7. Effect of grinding size in the OCT (3-hour test duration)

\subsubsection{Testing duration}

To investigate whether measuring oxygen consumption for a longer period would give more reliable results, the test duration was extended to 16 hours. Figure 4.8 (a to c) demonstrates the level and shape of oxygen consumption for some of the carbonates, silicate and sulphide-bearing aggregates after extending the test duration for 16 hours.

As the figure illustrates, the consumption continued with longer testing duration. This behaviour is further analyzed in subsection 4.3. 


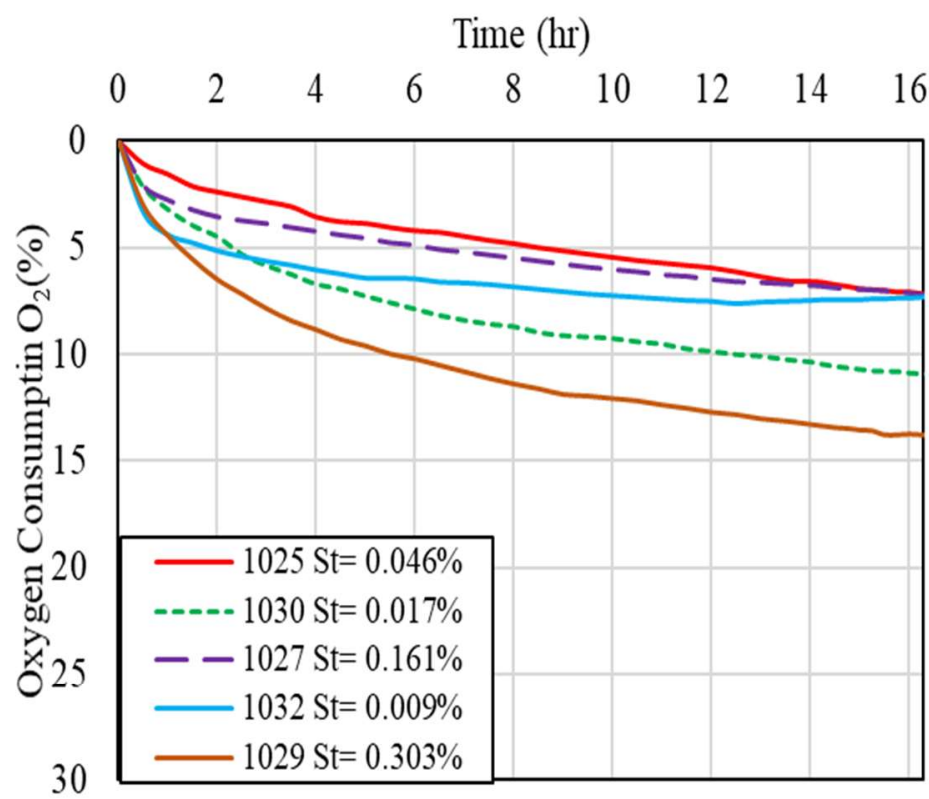

(a) Carbonate aggregates (Cat 2C)
Time (hr)

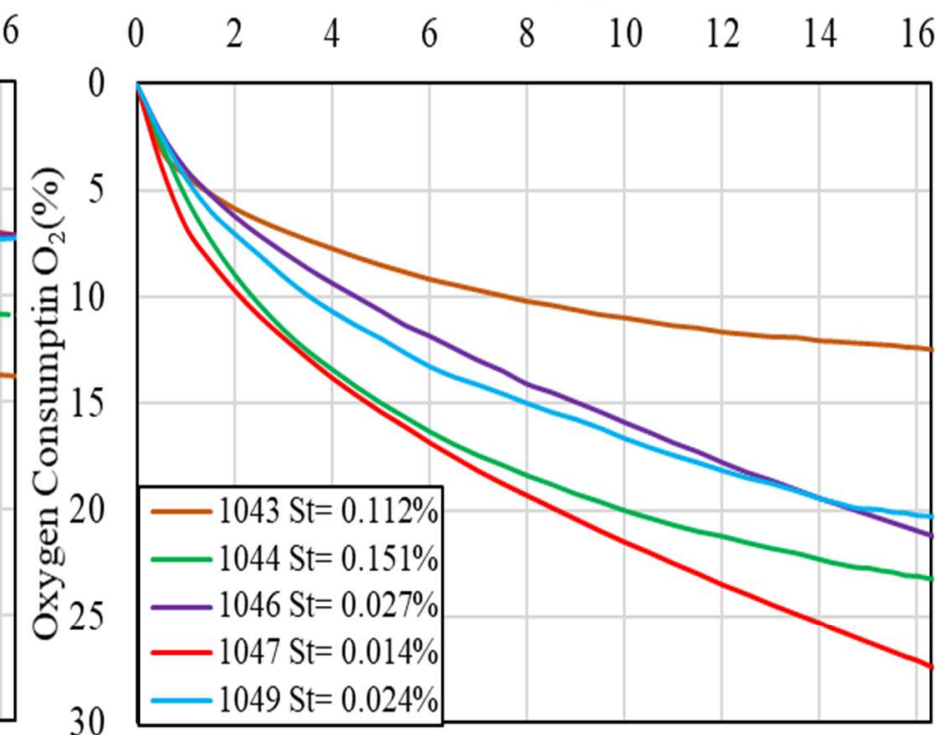

(b) Aggregates with silicates (Cat 2S)

Time (hr)

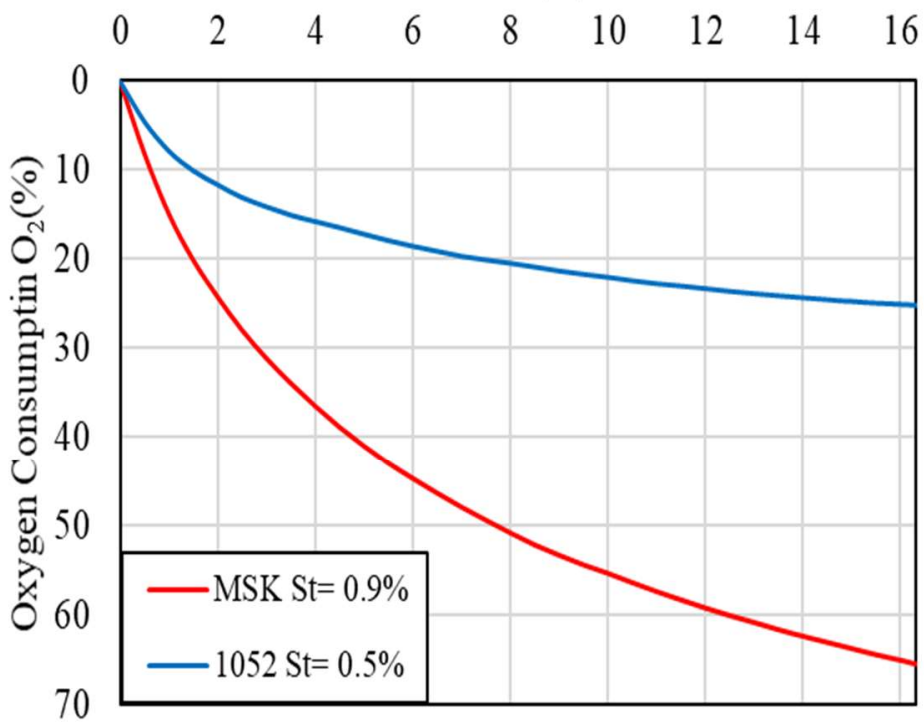

(c) Sulphide-bearing aggregates (Cat 1)

Figure 4.8. Oxygen consumption after a 16-hour test duration for some of the tested aggregates: a) carbonate, b) aggregates with silicates, and c) sulphide-bearing aggregates

\subsection{OCT Results}

Based on the obtained optimization results for all aggregates tested in this section, the aggregate was processed initially with the jaw crusher with cast iron plates until sized to $1.18 \mathrm{~mm}$, after which it 
was introduced to the disc pulverizer with ceramic plates until reaching the required size. The selected size for testing in OCT was from 300 to $75 \mu \mathrm{m}$ (300 to $150 \mu \mathrm{m}$ and from 150 to $75 \mu \mathrm{m}$, at a ratio of 1:1). Table 4.1 summarizes the oxygen consumption test results.

Table 4.1. Results of oxygen consumption test processed by jaw crusher with cast iron plates and by disk pulverizer with ceramic plates

$\mathrm{O}_{2} \%$ Consumption

\begin{tabular}{|c|c|c|c|c|c|c|}
\hline Category & Aggregate & Rock Type & $\begin{array}{c}\text { Dominant } \\
\text { Composition }\end{array}$ & $S_{t}(\%)$ & 3:00 hrs & 16:00 hrs \\
\hline \multirow{2}{*}{1} & MSK & Igneous & Quartz-feldspar-mica & $\begin{array}{c}0.73- \\
1.28\end{array}$ & 28.05 & 62.52 \\
\hline & 1052 & Metamorphic & Silicate & 0.543 & 11.03 & 21.71 \\
\hline \multirow{11}{*}{$2 \mathrm{C}$} & $\mathrm{C} 1$ & Sedimentary & Carbonate & 0.04 & 2.86 & 6.06 \\
\hline & 1020 & Sedimentary & Carbonate & 0.151 & 3.07 & 8.61 \\
\hline & 1022 & Sedimentary & Carbonate & 0.038 & 2.70 & 8.44 \\
\hline & 1025 & Sedimentary & Carbonate & 0.046 & 1.95 & 6.24 \\
\hline & 1027 & Sedimentary & Carbonate & 0.161 & 2.02 & 5.36 \\
\hline & 1029 & Sedimentary & Carbonate & 0.303 & 5.60 & 11.11 \\
\hline & 1030 & Sedimentary & Carbonate & 0.017 & 4.21 & 8.98 \\
\hline & 1031 & Sedimentary & Carbonate & 0.059 & 3.88 & 7.89 \\
\hline & 1032 & Sedimentary & Carbonate & 0.009 & 2.57 & 4.16 \\
\hline & 1033 & Sedimentary & Carbonate & 0.025 & 4.56 & 9.34 \\
\hline & 1050 & Sedimentary & Carbonate & 0.058 & 2.91 & 5.96 \\
\hline
\end{tabular}


$\mathrm{O}_{2} \%$ Consumption

\begin{tabular}{|c|c|c|c|c|c|c|}
\hline Category & Aggregate & Rock Type & $\begin{array}{c}\text { Dominant } \\
\text { Composition }\end{array}$ & $S_{t}(\%)$ & 3:00 hrs & 16:00 hrs \\
\hline \multirow{9}{*}{$2 \mathrm{~S}$} & 1043 & Igneous & Silicate & 0.112 & 4.36 & 9.74 \\
\hline & 1044 & Igneous & Silicate & 0.151 & 10.02 & 21.09 \\
\hline & 1045 & Igneous & Silicate & 0.045 & 12.59 & 35.17 \\
\hline & 1046 & Metamorphic & Silicate & 0.027 & 6.49 & 19.48 \\
\hline & & & & & & \\
\hline & 1047 & Igneous & Silicate & 0.014 & 5.61 & 17.15 \\
\hline & 1048 & Igneous & Silicate & 0.039 & 9.39 & 24.64 \\
\hline & 1049 & Metamorphic & Silicate & 0.024 & 7.69 & 18.41 \\
\hline & 1051 & Igneous & Silicate & 0.009 & 6.46 & 18.01 \\
\hline
\end{tabular}

The oxygen consumption for aggregates crushed using the disc pulverizer with ceramic plates indicated that the highest values of oxygen consumption were obtained for the aggregates with the highest total sulphur content (MSK with 0.73-1.28).

Most of the aggregates in category $2 \mathrm{C}$ and $2 \mathrm{~S}$ are known to have very low total sulphur content, as shown in Table 3.3. Also, these aggregates are not known to have sulphides, and it is anticipated that the aggregates in this category would pass the oxygen consumption test. As the table indicates, the oxygen consumption for most of the $2 \mathrm{C}$ aggregates (carbonate) was $\leq 4 \%$, which is the proposed limit by Annex P of CSA A23.1. It should be noted that this recommended limit was based on testing aggregate size passing $150 \mu \mathrm{m}$ (Sieve \#100), not the size used in the present research after optimization (300 $\mu \mathrm{m}$ to $75 \mu \mathrm{m}$ ), where the coarser size produces higher oxygen consumption. 
The only exception for the carbonate aggregates is aggregate 1029 , which has relatively high total sulphur and may contain a low level of sulphide minerals based on its geological formation. The total sulphur $\left(\mathrm{S}_{\mathrm{t}}\right)$ content of aggregate 1029 is $0.30 \%$; when tested for oxygen consumption, the consumption was $5.6 \%$ after 3 hours, which means it failed the test and should be tested for the third stage of the protocol (OMBT). All the other carbonate aggregates passed the test limit.

In the case of the tested non-carbonate aggregates (Category 2S), which have low total sulphur content and an excellent in-service history, the aggregates showed higher than expected oxygen consumption. This consumption was not related to the total sulphur in the aggregates. The difference between the behaviour of carbonate versus aggregate with silicate is illustrated in Figure 4.9, which shows the results for aggregates \#1032 (Category C2) and \#1051 (Category S2).

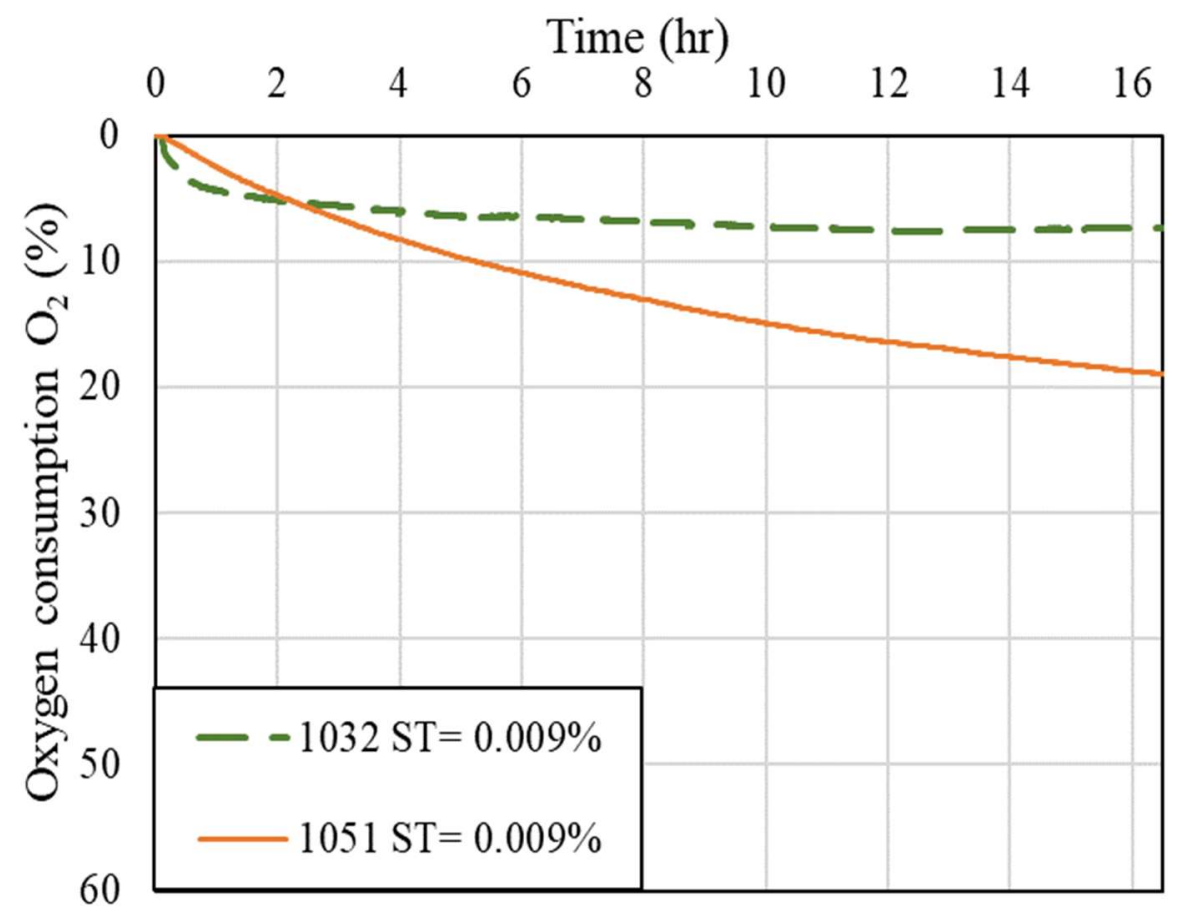

Figure 4.9. Oxygen consumption test results for silicate (1051) and carbonate (1032) aggregates with the same total sulphur content 
Both aggregates have similarly negligible total sulphur contents of $0.009 \%$. Aggregate \#1032 is limestone-carbonate with a silicate content of $1.57 \%$, while aggregate $\# 1051$ is granite with a silica content of $73.88 \%$. After 16.5 hours of testing (subtracting the consumption for the first 30 minutes for probe stabilization), aggregate $\# 1051$ recorded an oxygen consumption of $18.01 \%$ compared to $4.16 \%$ for aggregate $\# 1032$. The micro-deval abrasion resistance was $13.7 \%$ and $4.8 \%$ for aggregates 1032 and 1051, respectively. In other words, aggregate 1051 has high abrasion resistance compared to 1032 , which may be causing contamination of the aggregate with iron traces from the cast-iron plates of the jaw crusher (not the pulverizer ceramic plates, which are used to grind aggregates to the final fractions). It was then thought that the high oxygen consumption of these samples might be attributed to contamination of the aggregates from abrading the cast iron plates of the jaw crusher. This led to replacing the cast iron jaw crusher plates with manganese-based plates as discussed in the coming subsection.

\subsection{Use of Jaw Crusher with Manganese Plates for Aggregate Processing}

The cast-iron plates of the jaw crusher used previously were replaced with manganese plates that are known to have higher abrasion resistance to reduce the effect of contamination from eroded iron. Selected samples of carbonate and non-carbonate aggregates (aggregates with silicates) were crushed and re-tested for oxygen consumption using the manganese plates. The results of the consumption are shown in Table 4.2.

In all cases, as shown in Figure 4.10, using manganese plates produced lower oxygen consumption. However, the oxygen consumption for some of the aggregates of low total sulphur was still higher than anticipated with respect to their low total sulphur content. Based on the obtained results, the test and the current limit of $4.0 \%$ (Annex P of CSA 23.1) work for carbonate aggregates. 
This is not the case for aggregates with silicate, where the limit still does not work for some. The high abrasion resistance of aggregates with silicate compared to that of the tested carbonate aggregates is anticipated to have a role in having more contamination in the aggregates with high silicate content. However, there is no direct relationship, within the aggregates with silicate, between abrasion resistance and oxygen consumption.

Table 4.2. Results of oxygen consumption test for aggregates crushed with cast iron and manganese plates

\section{$\mathrm{O}_{2}$ Consumption (\%)}

\begin{tabular}{cc}
\hline \hline Jaw crusher with & Jaw crusher with \\
cast iron plates & manganese plates
\end{tabular}

\begin{tabular}{|c|c|c|c|c|c|c|c|c|}
\hline Category & Aggregate & $\begin{array}{c}\text { Dominant } \\
\text { Composition }\end{array}$ & $\begin{array}{l}S_{t} \\
(\%)\end{array}$ & $\begin{array}{c}\text { Micro-devel } \\
\text { Abrasion } \\
(\%)\end{array}$ & $\begin{array}{l}\text { 3:00 } \\
\text { hrs }\end{array}$ & $\begin{array}{c}\text { 16:00 } \\
\text { hrs }\end{array}$ & $\begin{array}{l}\text { 3:00 } \\
\text { hrs }\end{array}$ & $\begin{array}{c}\text { 16:00 } \\
\text { hrs }\end{array}$ \\
\hline \multirow{2}{*}{1} & MSK & Quartz & 0.93 & 8.5 & 28.05 & 62.52 & 27.3 & 36.22 \\
\hline & 1052 & Silicate & 0.543 & 7.6 & 11.03 & 21.71 & 3.90 & 9.39 \\
\hline \multirow{2}{*}{$2 \mathrm{C}$} & $\mathrm{C} 1$ & Carbonate & 0.04 & 9.2 & 2.86 & 6.06 & 1.59 & 1.89 \\
\hline & 1029 & Carbonate & 0.303 & 10.9 & 5.60 & 11.11 & 2.04 & 3.69 \\
\hline \multirow{5}{*}{$2 \mathrm{~S}$} & 1044 & Silicate & 0.151 & 8.8 & 10.02 & 21.09 & 4.31 & 5.60 \\
\hline & 1046 & Silicate & 0.027 & 6.8 & 6.49 & 19.48 & 3.49 & 9.61 \\
\hline & 1047 & Silicate & 0.014 & 4.9 & 5.61 & 17.15 & 4.33 & 6.96 \\
\hline & 1048 & Silicate & 0.039 & 3.65 & 9.39 & 24.64 & 6.37 & 13.62 \\
\hline & 1049 & Silicate & 0.024 & 3.4 & 7.69 & 18.41 & 5.88 & 14.36 \\
\hline
\end{tabular}




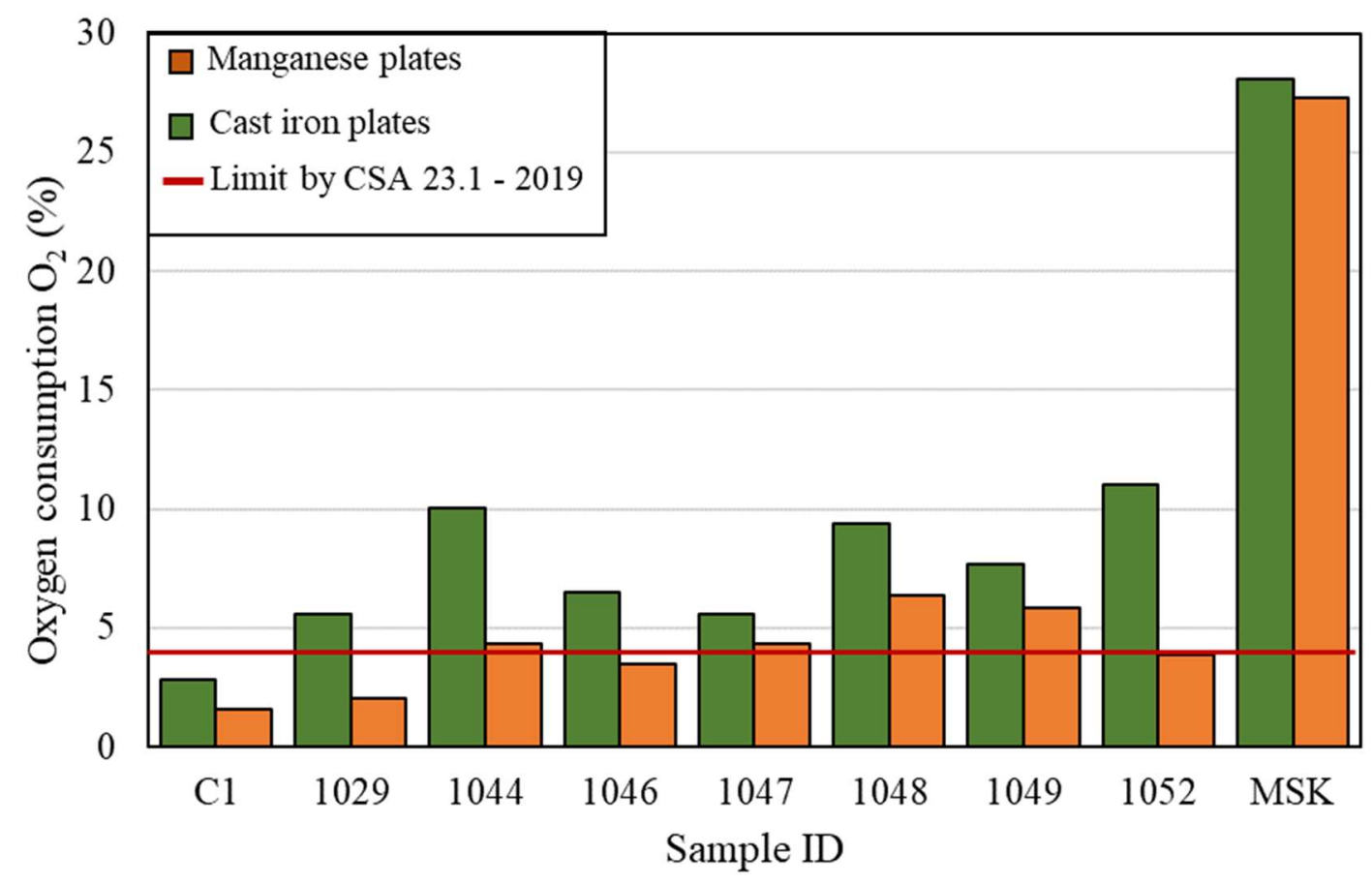

Figure 4.10. Oxygen consumption results for aggregates crushed with cast iron and manganese plates - after 3 hours

All aggregates with silicate showed high abrasion resistance and the range of values was too narrow to establish a relationship. It should be noted that while the manganese plates reduced the ironcontamination of the samples (which produced less consumption than that in case of iron plates), there is still a possibility of contamination. Some of the aggregates with silicate were not tested using the manganese-based jaw crusher due to lack of materials. Aggregate \#1029, the only carbonate aggregate with a consumption $>4.0 \%$ in Table 4.1 , showed a lower consumption of $2.04 \%$ when tested using the manganese plates.

Figure 4.11 and Figure 4.12 demonstrate the rate of consumption for some of the carbonate and silicate aggregates processed using the jaw crusher with cast iron plates and manganese plates. Testing aggregates processed with the jaw crusher with cast iron plates for a longer duration showed continued consumption even after 16 hours of testing. The consumption rate was low - in some 
aggregates - with the use of the jaw crusher with manganese plates, beyond the 3 hour-duration. It may be argued that consumption beyond the three hours is attributable to cast iron from abraded plates; however, the results in Figure $4.12 \mathrm{a}$ and $\mathrm{c}$ do not support the argument.

It is also essential to pay attention to the behaviour of the silicate aggregate 1052 (Figure 4.12d). Although this aggregate has a high total sulphur content of $0.543 \%$ and is known to have sulphide minerals (pyrrhotite and pyrite), it had a consumption $<4.0$ after 3 hours, with the use of the jaw crusher with the manganese plates. The reason for this is that the sulphide in this aggregate exists in the form of isolated particles rather than being distributed with the stone, as the case with MSK. There is a high possibility that the sample tested with the manganese plate did not contain enough or any of sulphide-rich particles. It should be noted that the sample tested using the manganese-plated jaw crusher was from a different bag than the one from which the first sample with cast iron plates was collected. This behaviour emphasizes the importance of proper sampling and sub-sampling before running a test.

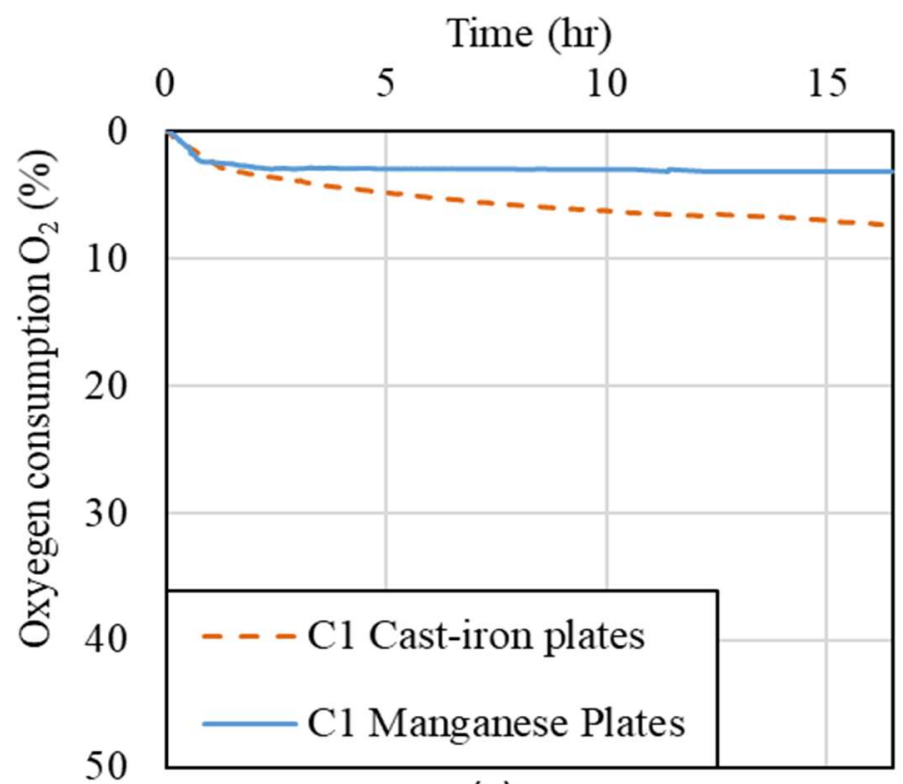

(a)

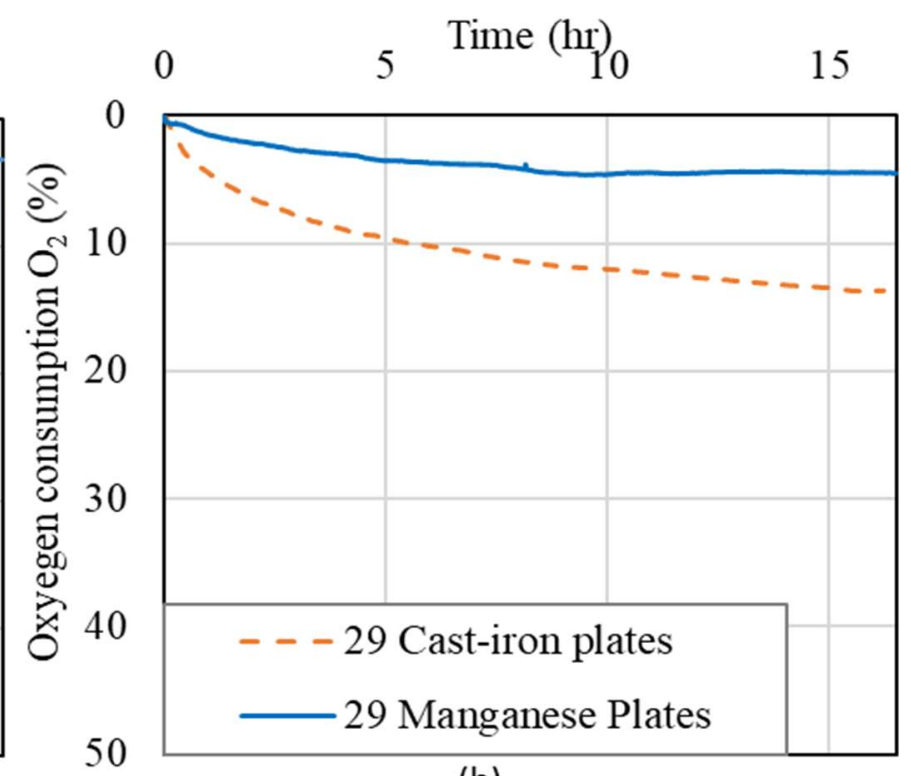

(b)

Figure 4.11. Oxygen consumption in carbonate aggregates processed with cast iron-plated and manganese-plated jaw crusher a.C1 b.1029 


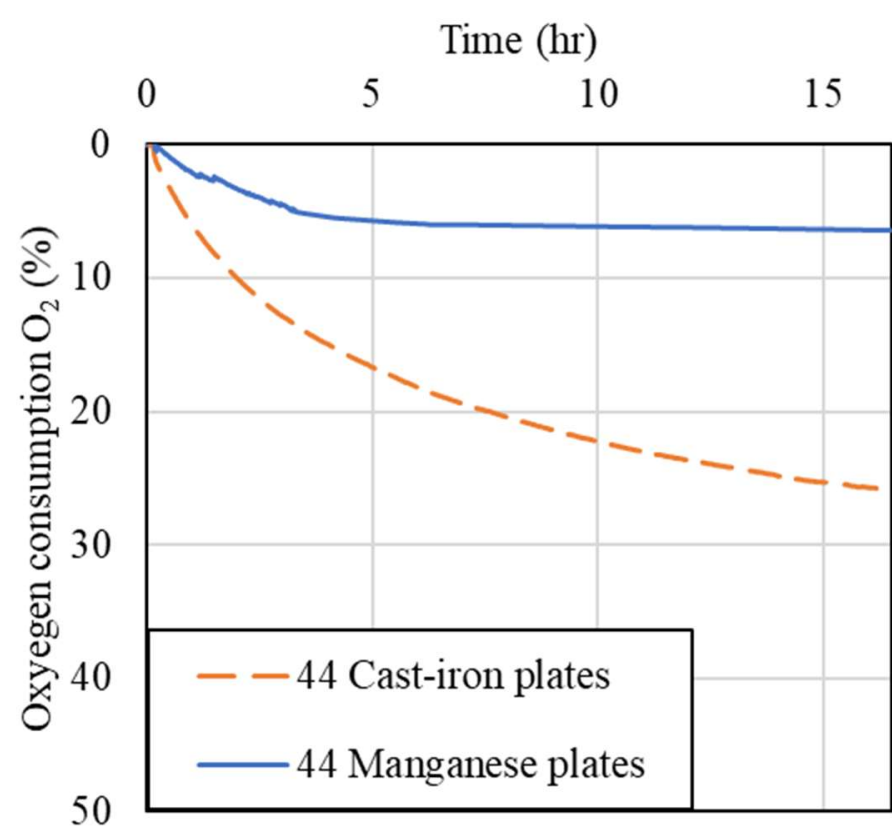

(a)

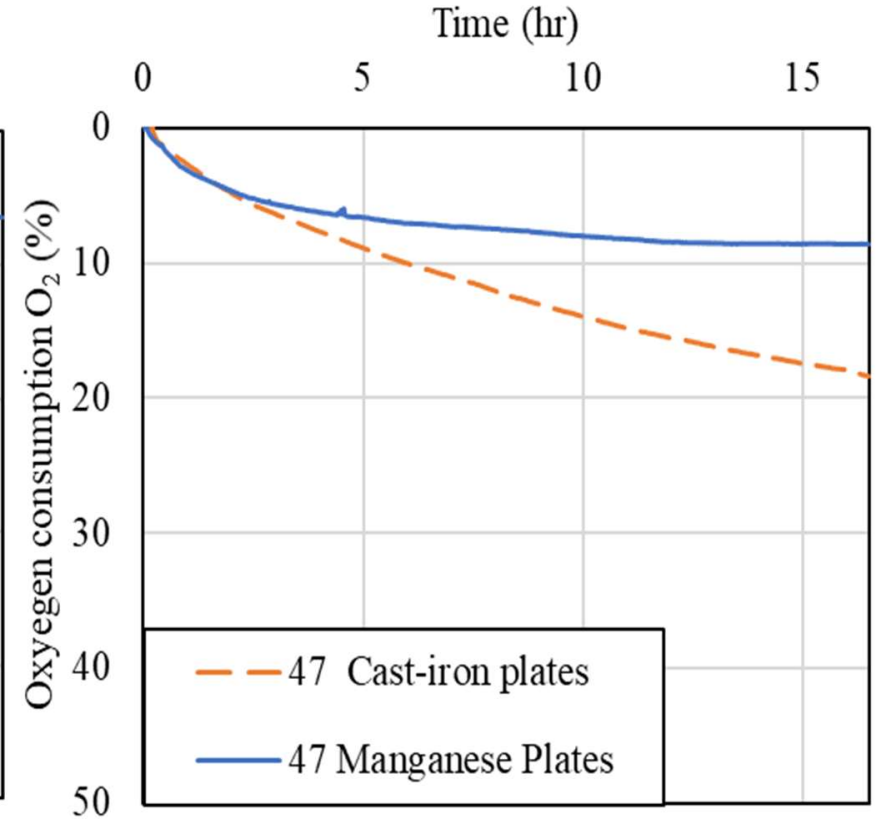

(b)

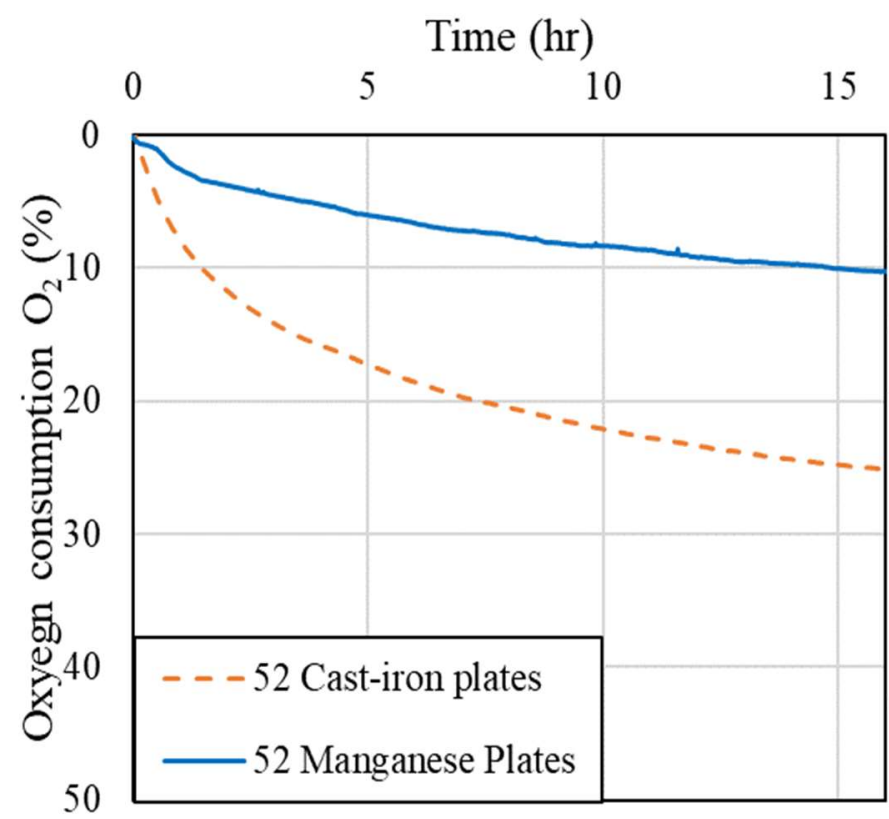

(c)
Time (hr)

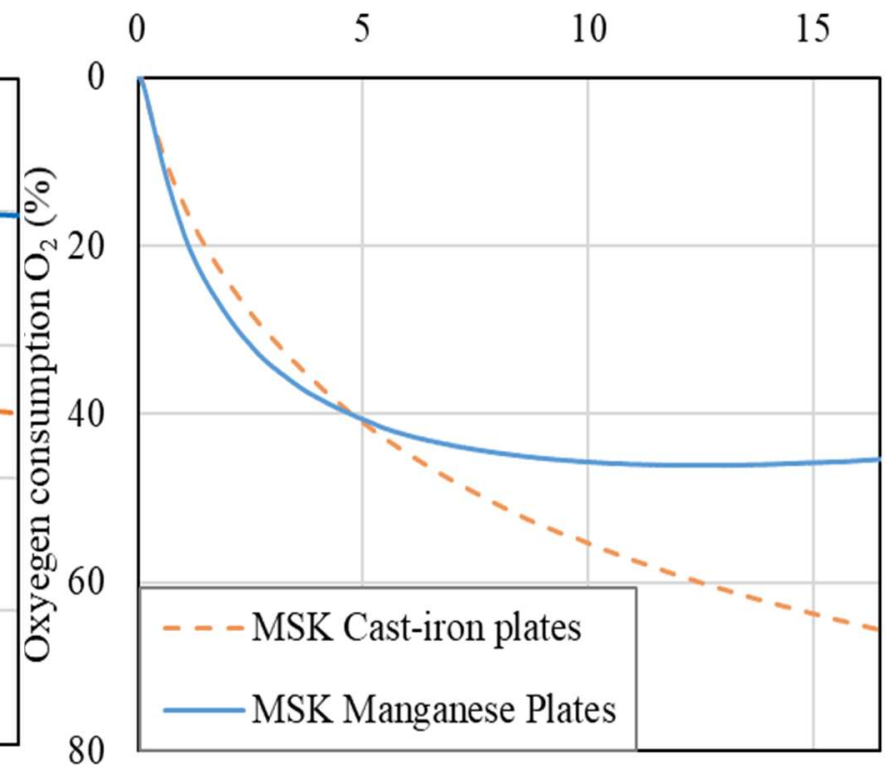

(d)

Figure 4.12. Oxygen consumption for non-carbonate aggregates prepared with cast iron-plated and manganese-plate jaw crusher a. 1044 b.1047 c. 1052 d. MSK 


\subsection{Applying OCT to Aggregates of Controlled Total Sulphur Content}

Since most of the tested aggregates had low total sulphur and sulphide content, the research team decided to test sulphide ore (Ore) blended with non-sulphide aggregate - at different ratios - to mimic aggregates with different levels sulphide minerals. This was carried out to examine the efficacy of the OCT in detecting the potentially deleterious effects of sulphide-bearing aggregates of different sulphide content.

Ore with total sulphur $14 \%$ was mixed at different ratios of 5,10 and $20 \%$ with the carbonate, which is the coarse aggregate $\mathrm{C} 1$ crushed to sand size. This carbonate aggregate was used to reduce any source of contamination from aggregate processing that can affect the results of the oxygen consumption as a result of the high abrasion resistance of the aggregates with silicates.

Table 4.3 shows the oxygen consumption for the samples after 3 hours. The consumption of the carbonate sample with 5\% Ore was 3.77\%, suggesting that this blend has a safe level of oxidizable sulphide. The sample with $10 \%$ had an OCT value of $8.27 \%$, suggesting that this blend has a considerable amount of oxidizable sulphide. The sample with $20 \%$ had a $14 \%$ consumption, which

is half the OCT of the MSK aggregate that caused severe damage in the concrete foundations in Trois-Rivières, Quebec; hence, this blend is anticipated to be detected by the mortar bar test as deleterious. This will be discussed in Chapter 5 . 
Table 4.3. Oxygen consumption after 3 hours in samples with controlled total sulphide content

\begin{tabular}{ccc}
\hline \hline Sample & $\begin{array}{c}\text { Total Sulphur* } \\
(\%)\end{array}$ & $\begin{array}{c}\mathrm{O}_{2} \\
\text { Consumption } \\
(\%)\end{array}$ \\
\hline \hline $100 \% \mathrm{C} 1$ & $\approx 0$ & 1.59 \\
\hline $\mathrm{C} 1+5 \%$ Ore & 0.7 & 3.77 \\
\hline $\mathrm{C} 1+10 \%$ Ore & 1.4 & 8.27 \\
\hline $\mathrm{C} 1+20 \%$ Ore & 2.8 & 13.99 \\
\hline *: Total sulphur is calculated as a $\%$ of Ore multiplied \\
by its total sulphur content.
\end{tabular}

\subsection{Summary and Discussion}

In this chapter, the oxygen consumption test was applied to aggregates with different total sulphur contents and different chemical and physical compositions. This was done in an attempt to evaluate the applicability of the test for the evaluation of susceptibility of sulphide-bearing aggregates to oxidation. The repeatability and sensitivity of the test were also evaluated.

Testing results revealed that contamination of aggregates can result in overestimation of the OCT value for aggregates. Aggregate processing equipment is a major source of aggregate contamination, especially for aggregates with high silicate content or high abrasion resistance. Hence, it is highly recommended to avoid the use of cast iron plates during sample processing. In this study, a jaw crusher with manganese plates (higher abrasion resistance than cast iron) and a disk pulverizer with ceramic plates was used and recommended. 
To investigate the test repeatability, MSK was tested with the same test method proposed by Rodrigues et al. (2016) (passing Sieve \#100 $(<150 \mu \mathrm{m})$ ). The obtained OCT consumption was $19.23 \%$ compared to $21.4 \%$ obtained at the University of Laval, suggesting good repeatability for this test.

Moreover, testing aggregates with different gradations revealed that testing controlled aggregates size ( $300 \mu \mathrm{m}$ to $75 \mu \mathrm{m})$ produces higher consumption than using the sample size that was proposed in the original test method by Rodrigues et al. (2016) (passing Sieve \#100 $(<150 \mu \mathrm{m})$ ). The MSK aggregate with size $<150 \mu \mathrm{m}$ showed consumption of $19.23 \%$ and the sample from $300 \mu \mathrm{m}$ to $75 \mu \mathrm{m}$ showed consumption of $28 \%$. Hence, the $4 \%$ limit proposed in CSA 23.1 Annex P can be relaxed to $5 \%$ for the size tested here. Based on this limit, all carbonate aggregate with known good performance would pass the test (Figure 4.13). It should be noted that the carbonate aggregates with OCT value just below $5.0 \%$ were tested in the jaw crusher with cast iron plates due to the lack of materials. Testing these aggregates after processing with the jaw crusher with manganese plates instead of the cast iron ones would bring these values even lower, similar to the behaviour of aggregate 1029.

In the case of aggregates with high silicate contents, some with negligible total sulphur content failed to meet the $5.0 \%$ limit even when the manganese-jaw crusher was used (Figure 4.13 ). This is likely due to some contamination caused by the highly abrasive nature of aggregates with silicate compared to carbonate aggregates. The presence of oxidizable phases other than sulphide in such aggregates is also a possibility. For examples, aggregates 1044, 1045, 1046, 1048 and 1051 are known to have traces of magnetite and biotite. The effect of these phases on oxygen consumption was not investigated in this study. However, the fact that manganese jaw crusher produced significantly lower consumption in all cases suggests that contamination is the main factor. Samples that do not meet this limit would be tested, according to the protocol, using the OMBT presented in the next chapter. 
It should be noted that the OCT test is relatively new and can benefit from more optimization in terms of sample size, moisture content, and level of compaction.

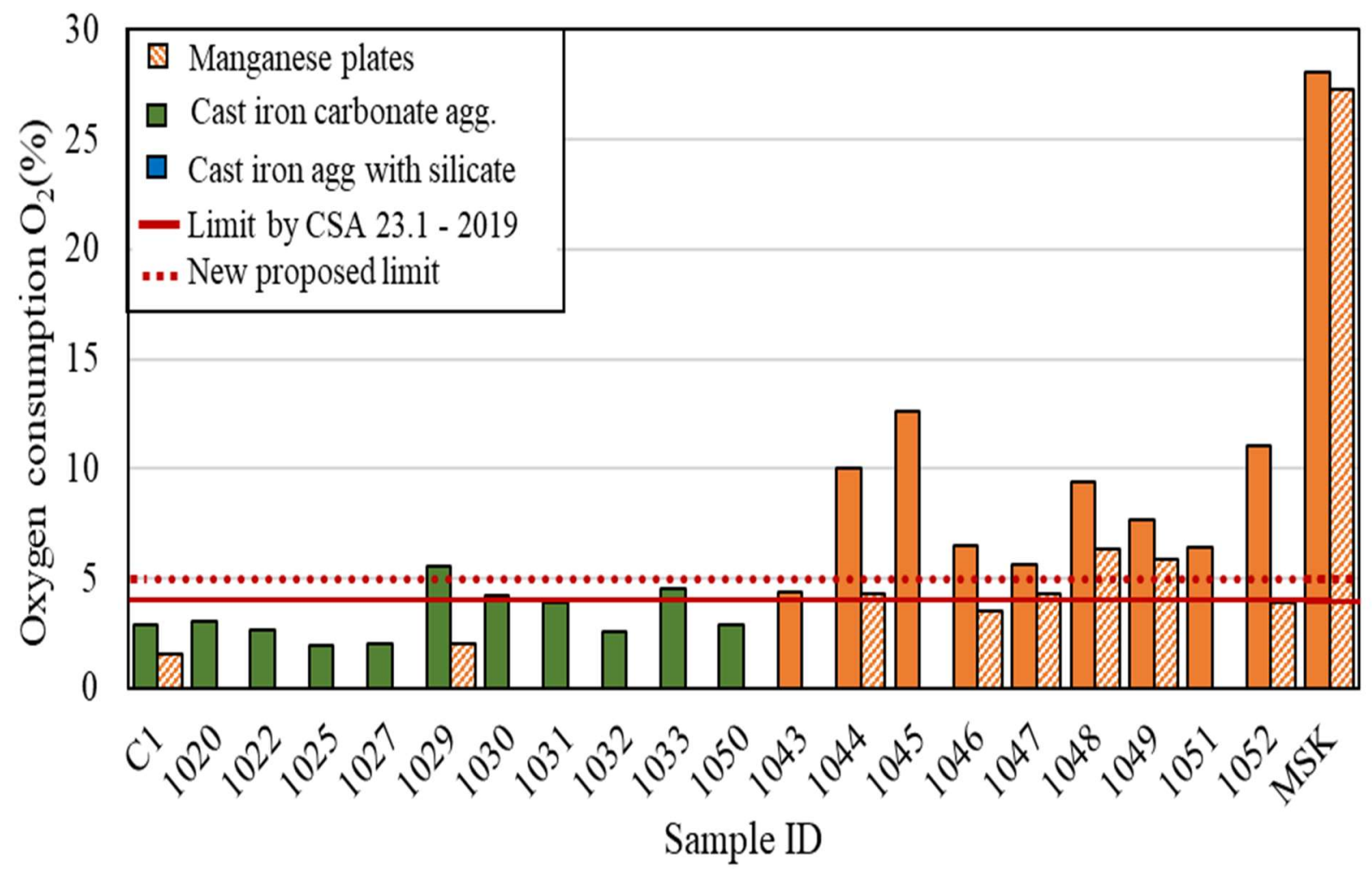

Figure 4.13 Oxygen consumption test results for aggregates crushed with cast iron and manganese jaw crusher plates 


\section{Chapter 5}

\section{Applicability of Oxidation Mortar Bar Test (OMBT)}

As explained in Chapter 3, the OMBT was carried out following the mortar bar test of the protocol proposed by Rodrigues et al. (2016). Mortar bar samples were tested to promote the oxidation of sulphide-bearing aggregates and subsequent internal sulphate attack.

Length measurements in both phases took place at room temperature in a saturated surface dry condition after the samples were soaked in bleach (sodium hypochlorite). The suggested maximum expansion limit as per Annex P of CSA A23.1-2019 is 0.10\% for Phase II, which lasted between 90 and 180 days.

The objective of this chapter is to investigate the ability of the adopted oxidation mortar bar test (OMBT) to detect potential oxidation and subsequent sulphate attacks in the mortar bar with aggregates of different mineralogical composition. This part of the study also investigates the limitations of the test and suggests ways to overcome them, including proposing new expansion criteria that will be presented in detail in Chapter 7 .

\subsection{Expansion Results}

In this part of the study, various aggregates from Ontario, along with the MSK aggregate from Quebec and the control concrete aggregate $\mathrm{C}$, were tested using the same procedure suggested by (Rodrigues et al., 2016). The testing procedure involved two phases. The first phase aimed to promote oxidation, with mortar bars being soaked in a sodium hypochlorite solution (household bleach) for 3 hours and stored in a conventional oven at $80^{\circ} \mathrm{C}$ and $80 \%$ humidity for 3.5 days. In the second phase, the same soaking conditions were applied, but the mortar bars were stored at 
$5^{\circ} \mathrm{C}$ and $100 \%$ humidity for 3.5 days in an attempt to promote Thaumasite formation, which favours low temperatures.

In the mortar bar test developed in the testing protocol developed by Rodrigues et al. (2016), mortar bars were placed in the fume hood for three hours after soaking for three hours in sodium hypochlorite. The three-hour time frame was assumed sufficient to help the bars reach $80 \%$ relative humidity in a shorter period. In Guirguis's study (2017), it was found that placing the mortar bars in the oven after soaking led to greater expansion. In order to confirm this behaviour and to decide which exposure to use in applying the test protocol, the mortar bar samples were tested with the same exposure condition with and without placing them in the fume hood for three hours post-soaking.

The test was also applied on mortar bars with a blend of the control carbonate aggregates $\mathrm{C}$ with $10 \%$ and $20 \%$ Ore. For Phase I, mortar bars was soaked for 3 hours in $6 \%$ sodium hypochlorite and stored in a conventional oven at $80^{\circ} \mathrm{C} / 80 \% \mathrm{RH}$ for 13 weeks. In Phase II, the same soaking conditions were used, with samples then being stored in the fridge at $5^{\circ} \mathrm{C} / 80 \% \mathrm{RH}$ for 13 weeks.

Figure 5.1 shows the expansions of the mortar bars. As can be seen, in both samples, the expansions are less in cases where the mortar bars were placed for three hours in the fume hood at $10 \%$ and $20 \%$ Ore. These results reaffirm the results obtained by Guirguis (2017), that longer storing periods under conditions of $80^{\circ} \mathrm{C} / 80 \% \mathrm{RH}$ increase expansion.

Guirguis (2017) also suggested washing aggregates prior to casting them to remove any fine particles or dust and to dry them in the oven at $80^{\circ} \mathrm{C}$ before using. To confirm the effect on the expansion of washing the aggregates, two sets of mortar bars with aggregate MSK were tested with and without washing the aggregate prior to casting. Figure 5.2 shows the expansion results, indicating that the mortar bars with unwashed aggregates expanded more. This shows that washing 
and drying the aggregates before casting may be causing oxidation of the aggregates before using them. Hence, the test was applied to different aggregates without washing and without placing the mortar bars in the fume hood after soaking.

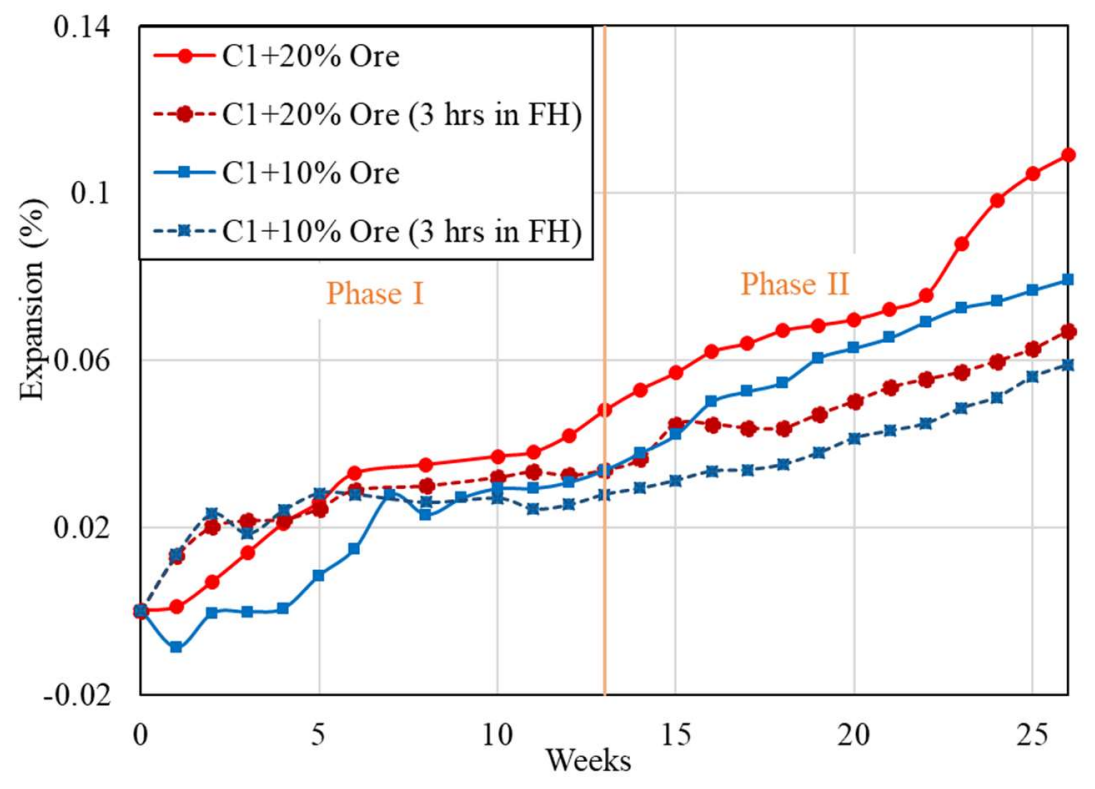

Figure 5.1. Expansion of mortar bars with blends of $\mathrm{C} 1$ and Ore with and without placing the samples for three hours in the fume hood $(\mathrm{FH})$ after soaking

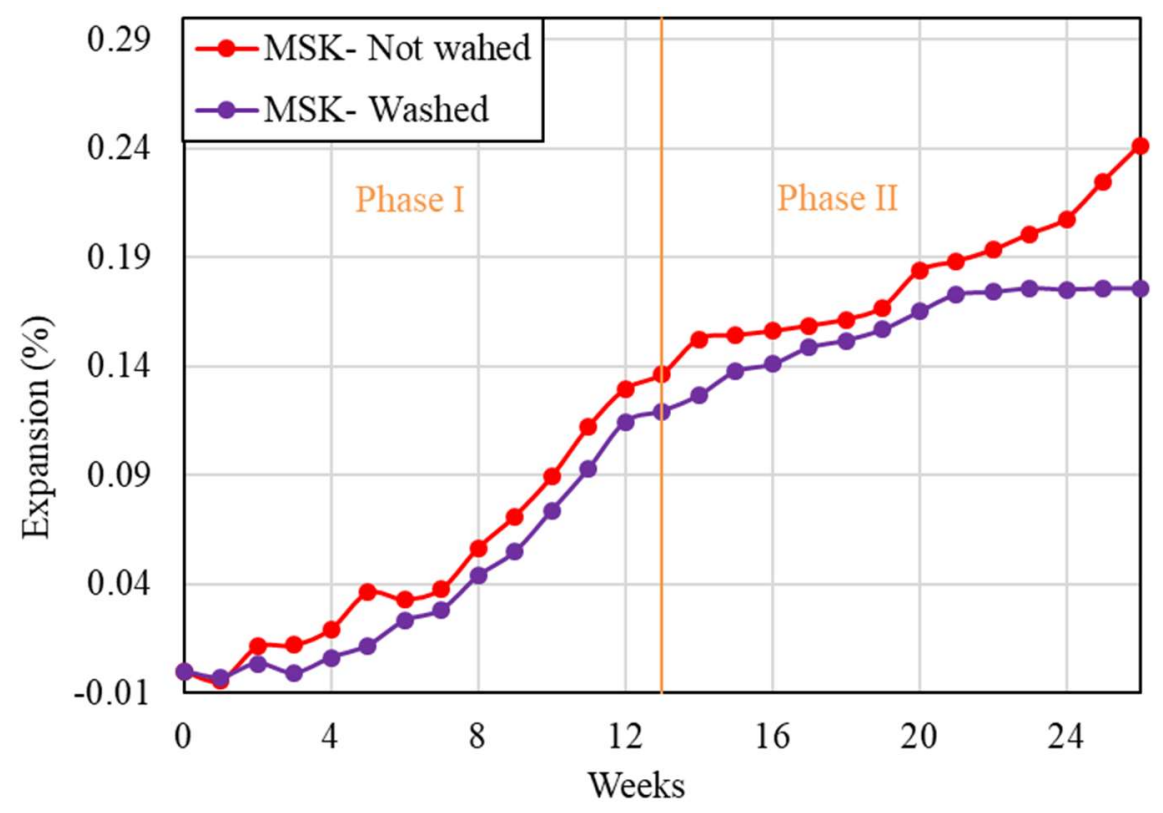

Figure 5.2. Expansion of mortar bars with washed and unwashed MSK 
Table 5.1 shows a summary of the mortar bar expansions at the end of each phase of testing and total expansion, along with some of the properties of the used aggregates.

Table 5.1. Results of mortar bars oxidation test

\section{Expansion (\%)}

\begin{tabular}{|c|c|c|c|c|c|c|c|}
\hline Category & $\begin{array}{c}\text { Aggre } \\
\text { gate }\end{array}$ & $\begin{array}{c}\text { Dominant } \\
\text { Composition }\end{array}$ & $S_{t}(\%)$ & $\begin{array}{l}\mathrm{SiO}_{2} \\
(\%)\end{array}$ & $\begin{array}{c}\text { Phase } \\
\text { I }\end{array}$ & $\begin{array}{c}\text { Phase } \\
\text { II }\end{array}$ & Total Expansion \\
\hline \multirow{2}{*}{1} & MSK & $\begin{array}{l}\text { Quartz- } \\
\text { feldspar }\end{array}$ & 0.93 & 50.58 & 0.136 & 0.105 & 0.241 \\
\hline & 1052 & Silicate & 0.543 & 66.51 & 0.079 & 0.110 & 0.189 \\
\hline \multirow{12}{*}{$2 \mathrm{C}$} & $\mathrm{C} 1$ & Carbonate & 0.04 & 0.54 & 0.035 & 0.008 & 0.043 \\
\hline & 1020 & Carbonate & 0.151 & 2.25 & 0.014 & 0.011 & 0.025 \\
\hline & 1022 & Carbonate & 0.038 & 2.11 & 0.011 & 0.016 & 0.028 \\
\hline & 1024 & Carbonate & 0.055 & 2.52 & 0.024 & 0.020 & 0.044 \\
\hline & 1025 & Carbonate & 0.046 & 1.73 & 0.012 & 0.015 & 0.027 \\
\hline & 1027 & Carbonate & 0.161 & 5.31 & 0.034 & -0.001 & 0.032 \\
\hline & 1029 & Carbonate & 0.303 & 14.05 & 0.117 & 0.078 & 0.194 \\
\hline & 1030 & Carbonate & 0.017 & 6.82 & 0.055 & 0.027 & 0.082 \\
\hline & 1031 & Carbonate & 0.059 & 3.53 & 0.023 & 0.021 & 0.045 \\
\hline & 1032 & Carbonate & 0.009 & 1.57 & 0.013 & 0.012 & 0.025 \\
\hline & 1033 & Carbonate & 0.025 & 2.03 & 0.014 & 0.018 & 0.032 \\
\hline & 1050 & Carbonate & 0.058 & 2.24 & 0.017 & 0.016 & 0.033 \\
\hline
\end{tabular}




\section{Expansion (\%)}

\begin{tabular}{|c|c|c|c|c|c|c|c|}
\hline Category & $\begin{array}{c}\text { Aggre } \\
\text { gate }\end{array}$ & $\begin{array}{c}\text { Dominant } \\
\text { Composition }\end{array}$ & $S_{t}(\%)$ & $\begin{array}{l}\mathrm{SiO}_{2} \\
(\%)\end{array}$ & $\begin{array}{c}\text { Phase } \\
\text { I }\end{array}$ & $\begin{array}{c}\text { Phase } \\
\text { II }\end{array}$ & Total Expansion \\
\hline \multirow{6}{*}{$2 \mathrm{~S}$} & 1043 & Silicate & 0.112 & 58.39 & 0.087 & 0.060 & 0.146 \\
\hline & 1044 & Silicate & 0.151 & 51.27 & 0.106 & 0.037 & 0.143 \\
\hline & 1045 & Silicate & 0.045 & 61.9 & 0.059 & 0.028 & 0.087 \\
\hline & 1046 & Silicate & 0.027 & 49.09 & 0.237 & 0.055 & 0.292 \\
\hline & 1047 & Silicate & 0.014 & 70.77 & 0.204 & 0.067 & 0.271 \\
\hline & 1048 & Silicate & 0.039 & 51.89 & 0.141 & 0.069 & 0.21 \\
\hline \multirow{4}{*}{$2 \mathrm{~S}$} & 1049 & Silicate & 0.024 & 93.57 & 0.293 & 0.142 & 0.435 \\
\hline & 1051 & Silicate & 0.009 & 73.88 & 0.176 & 0.086 & 0.262 \\
\hline & 1056 & Silicate & 0.01 & 68.91 & 0.178 & 0.070 & 0.248 \\
\hline & 1058 & Silicate & 0.025 & 67.07 & 0.093 & 0.062 & 0.155 \\
\hline
\end{tabular}




\subsection{Investigating the Ability of the (OMBT) to Evaluate the Oxidation Potential of Sulphide- Bearing Aggregates}

Figure 5.3 and Figure 5.5 show a demonstration of the level and shape of the expansions of the mortar bars during each phase of testing. According to the testing protocol adopted in Annex P in (CSA A23.1, 2019) and investigated here, an aggregate is considered to pass the test when the expansion between 90 and 180 days (Phase II) is $\leq 0.10 \%$. If Phase II expansion is $>0.10 \%$, the aggregate is considered susceptible to oxidation and may cause concrete deterioration.

As shown in Figure 5.3 for carbonate aggregate, the expansion of all the aggregates, except in 1029 , is very low in both phases. All the tested carbonate aggregates met the proposed limit of $<$ $0.10 \%$ in Phase II of the test. Most of these aggregates exhibit a total sulphur content of $<0.150 \%$, except for 1020 and 1027 , which show a $S_{t}$ of 0.15 and 0.16 , respectively. The $0.15 \%$ total sulphur below which aggregate is considered suitable for used in concrete as per Annex P of CSA 23.1. Moreover, all of the carbonate aggregates show a total expansion of $<0.10 \%$, except for aggregate 1029 , which has a total sulphur content of $0.303 \%$. In Phase II, the expansion was $0.078 \%$, which meets the $0.10 \%$ expansion limit in Phase II and can be used for concrete (Annex P of CSA 23.1). Aggregate 1029 has been used in concrete with no known aggregate-related issues. The relatively high $\mathrm{SiO}_{2}$ content (14.5\%) in this carbonate rock (Table 3.3 in Chapter 3 ) is mainly due to the presence of minor amounts of quartz present locally as sand-size grains. The sand-sized grains of quartz present within this carbonate-dominant rock may have led to another reaction similar to the case of silicate aggregates, which will be explained later in this subsection and in subsection 5.5. 

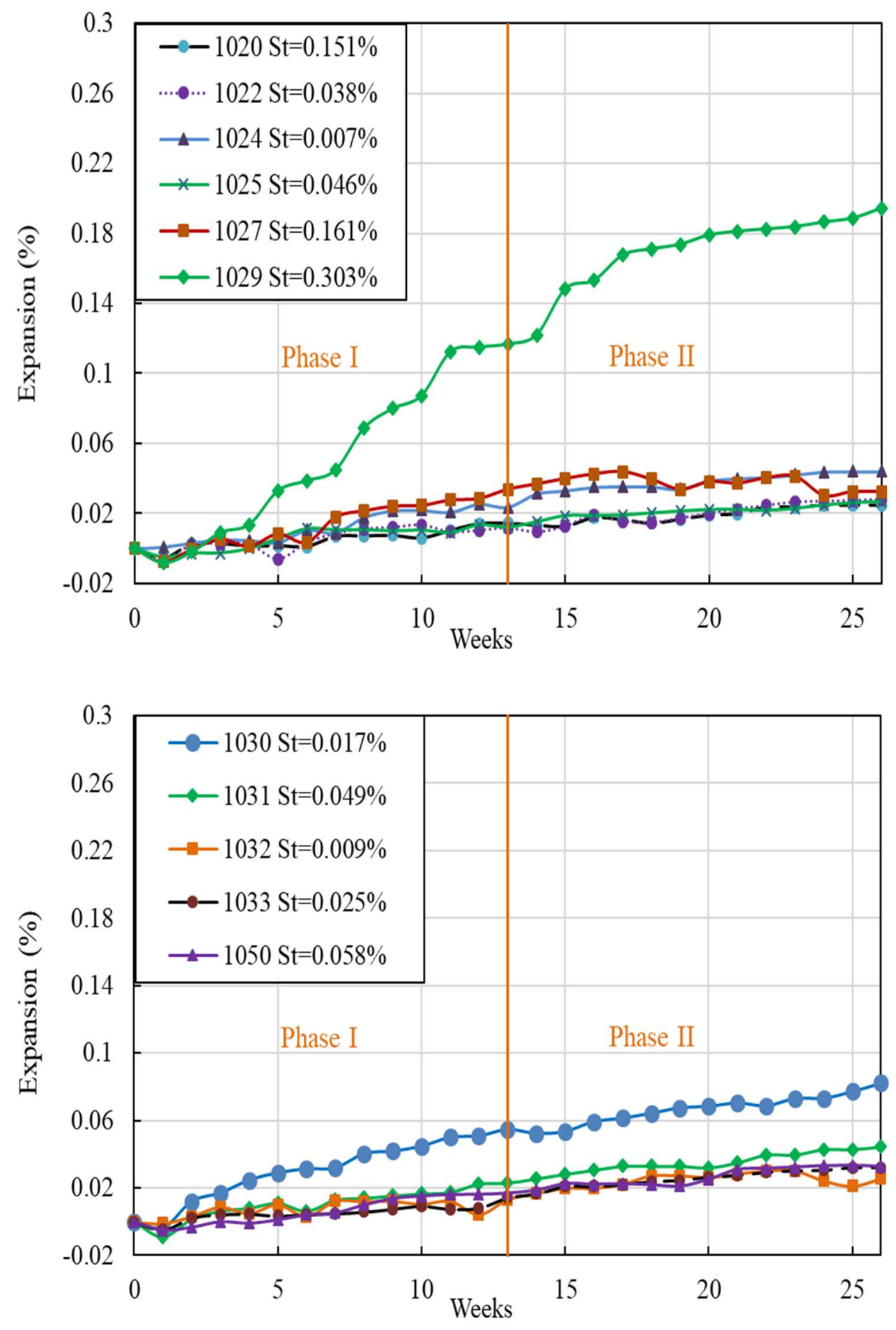

Figure 5.3. Expansion of mortar bars with carbonate aggregates, with the number in the legend box representing the total sulphur of the aggregate 
Figure 5.4 (a to c) shows some of the tested mortar bars after 26 weeks where, as expected, no evidence of damage to the bars appears in the form of cracks, rusting or pop-outs.

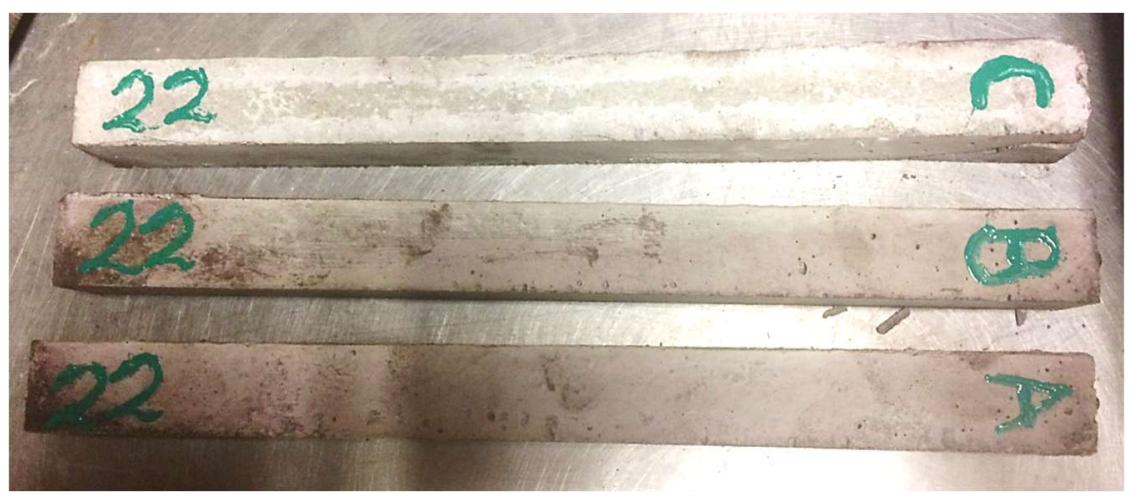

(a) 1022

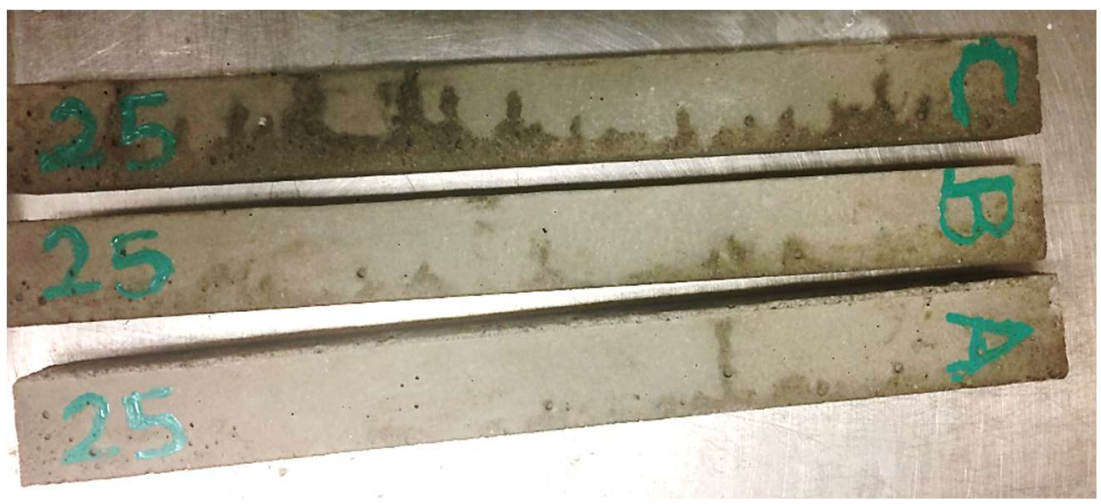

(b) 1025

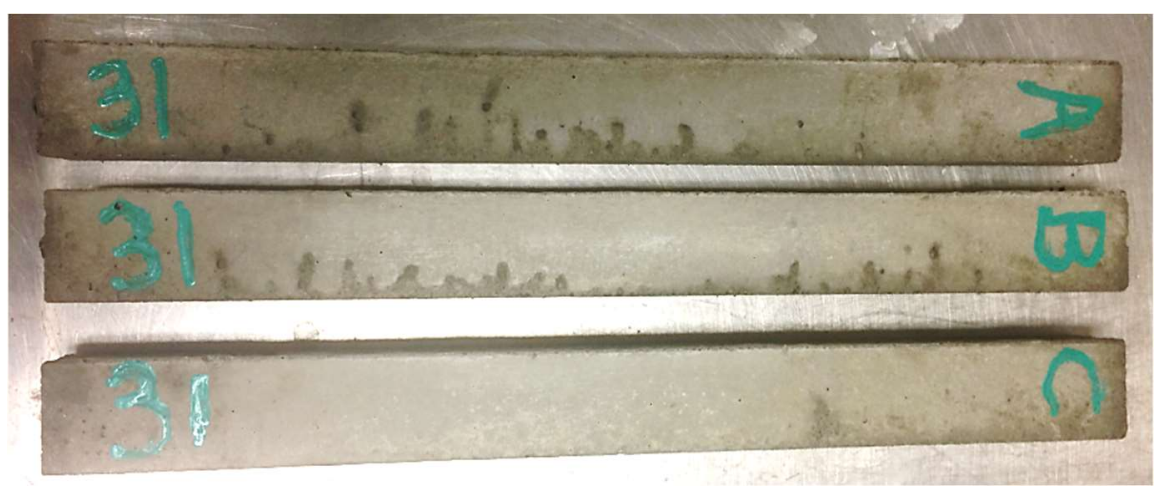

(c) 1031

Figure 5.4. Tested mortar bars with carbonate aggregates after 26 weeks of subjecting them to the exposure condition 
For non-carbonate aggregates (aggregates with high silicate content), the expansion of most of the mortar bars, as in Figure 5.5, exceeded $0.10 \%$ in the first 13 weeks (Phase I). The expansions in Phase II (the second 13 weeks) for these aggregates (except for aggregate 1049) were $<0.10 \%$, with a near-flat expansion curve. The expansion in Phase II for aggregate 1049 exceeded the $0.10 \%$ limit, with an expansion of $0.142 \%$.

In general, all aggregates, carbonates, or aggregates with silicate that belong to categories $2 \mathrm{C}$ and $2 \mathrm{~S}$ met the $0.10 \%$ expansion limit in Phase II, except for aggregate 1049. For the two sulphidebearing aggregates (MSK and 1052), the expansion in Phase II exceeded the $0.10 \%$ expansion limit, although the value was very close to the limit $(0.105 \%$ and $0.11 \%$, respectively). Testing on some of these aggregates was repeated (as will be explained later in section 5.3) for verification and examination of test repeatability. 

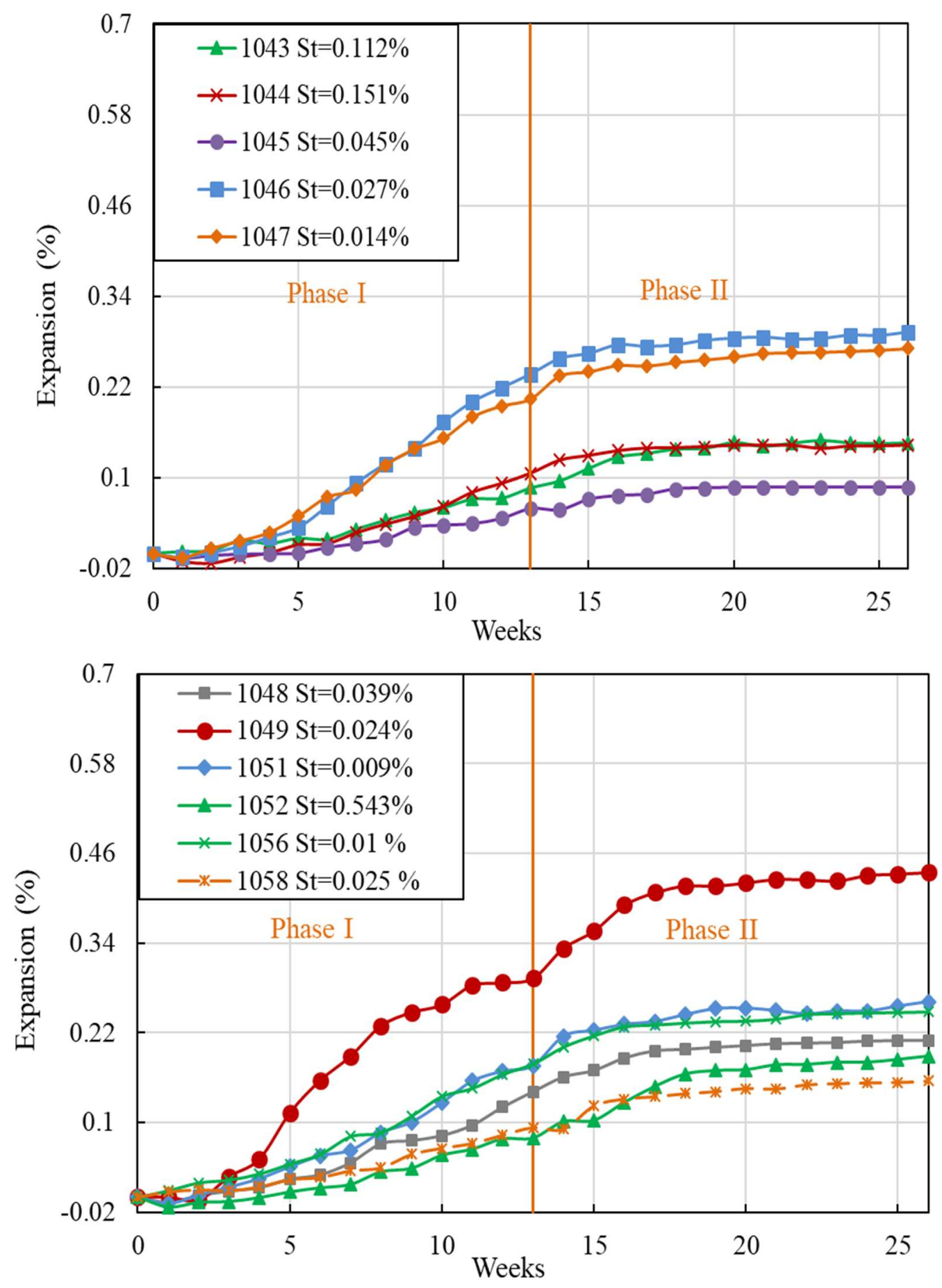

Figure 5.5. Expansion of mortar bars cast with non-carbonate aggregates

Figure 5.66 (a to d) shows some of the tested mortar bars with aggregates of high silicate content after 26 weeks. As shown in (a, b, c), some pop-outs took place because of the unexpected 
expansion. These samples only showed expansion in the first stage of the test with no subsequent expansion in the second 13 weeks. Also, rust appeared on some spots of the mortar bars with sulphide-bearing aggregate 1052, which indicates the occurrence of oxidation.

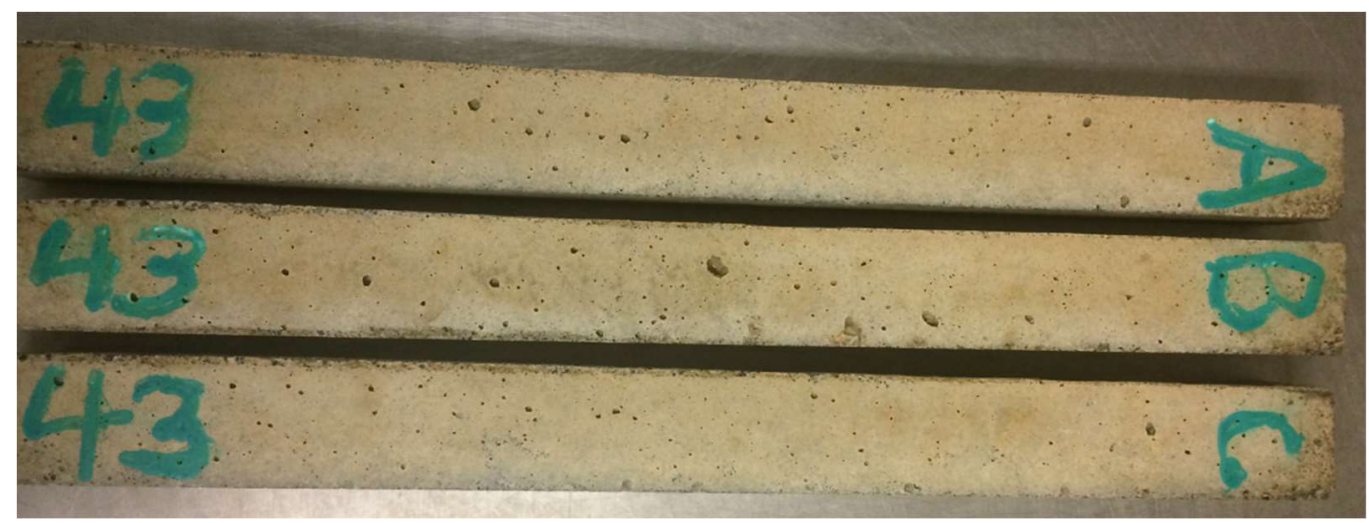

(a) 1043

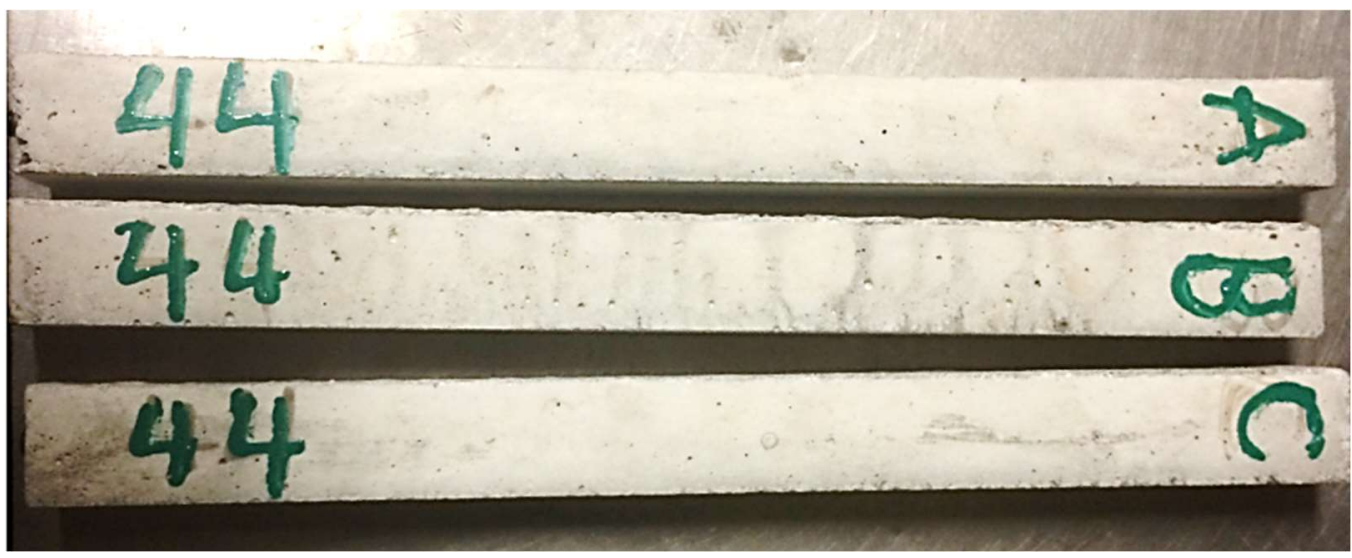

(b) 1044

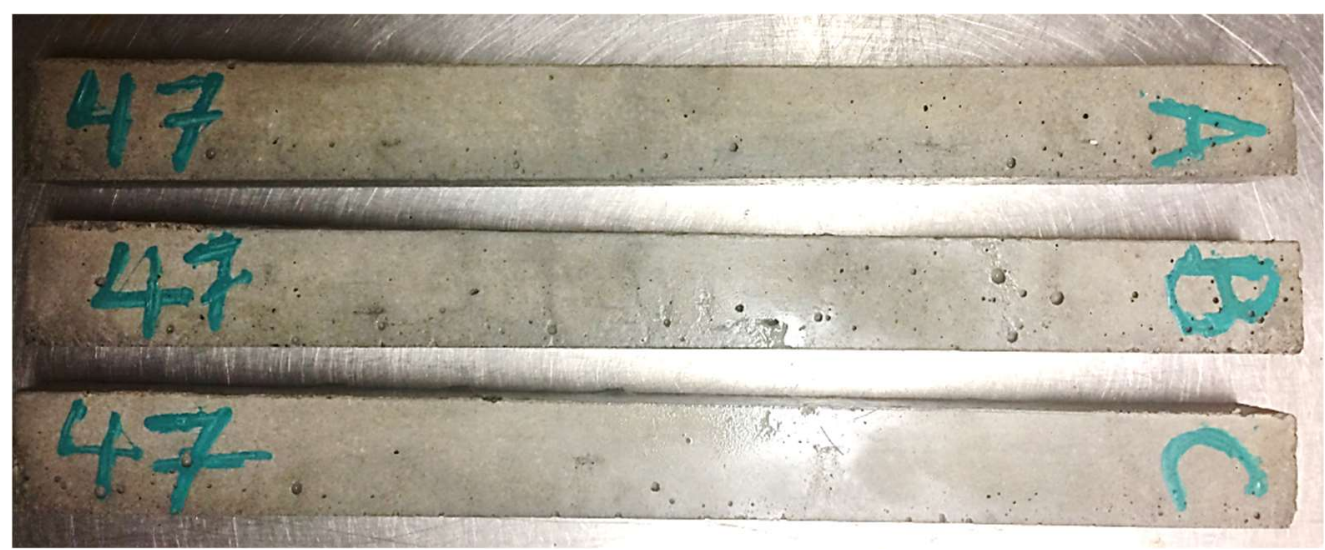

(c) 1047 


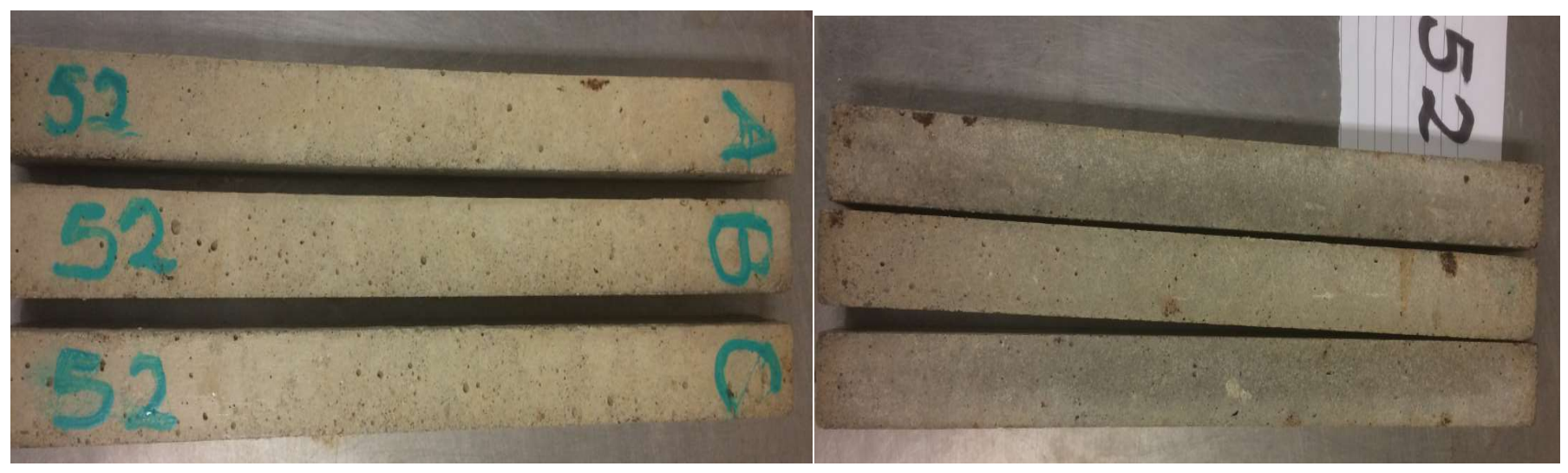

(d) 1052

Figure 5.6. Tested mortar bars with aggregates with high silicate content after 26 weeks of exposure

\subsection{Repeatability of OMBT}

In order to verify the repeatability of the OMBT, the test was repeated twice for eight of the aggregates. Seven of these aggregates are from Ontario, and the eighth is the MSK aggregate from the Trois-Rivieres region (Quebec, Canada). Figure 5.7 (a to h) shows the results of the repeatability analysis for the aggregates. As can be seen in the figure, the values of expansion for the same aggregates are quite close, with very low standard deviation. Table 5.2 shows the values of the expansions at the end of testing for the two samples and coefficient of variation (COV), where the maximum COV is $7.5 \%$. Moreover, t-test was done in order to determine if the samples' means are equal at a specific confidence level. In the null hypothesis, the samples means were assumed to be equal at 95\% confidence level. As shown in Table 5.2 all t-values were less than the critical values, which indicates that all samples' means are equal at the predefined confidence level of $95 \%$. The results are good indicators of the repeatability of the test. Also, as shown in Figure 5.7h, the expansions measured in this work using MSK aggregates were similar to the expansions obtained in the work of Guirguis (2017) for the same aggregate. 


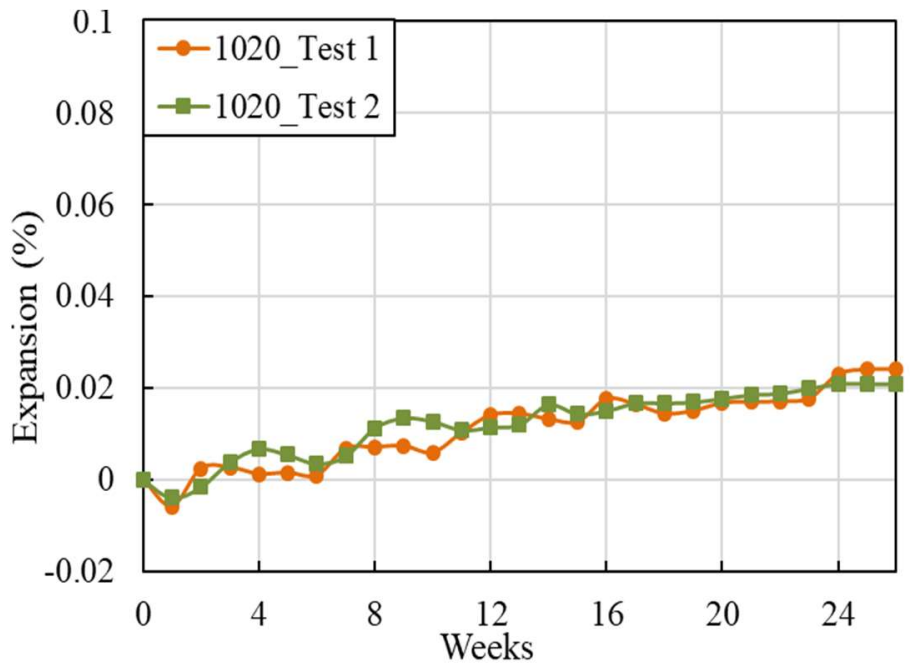

(a)

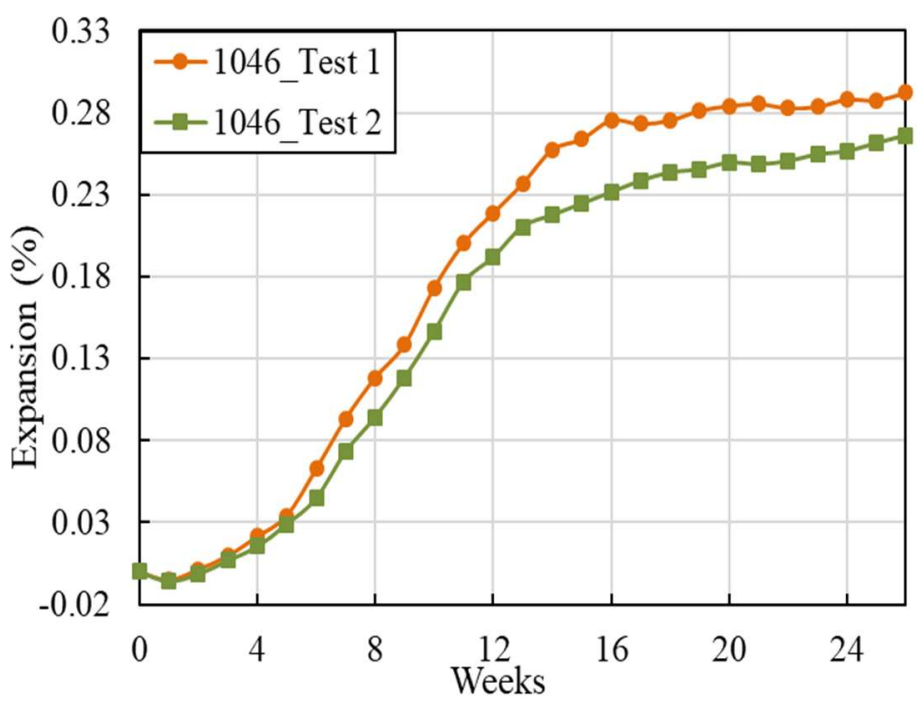

(c)

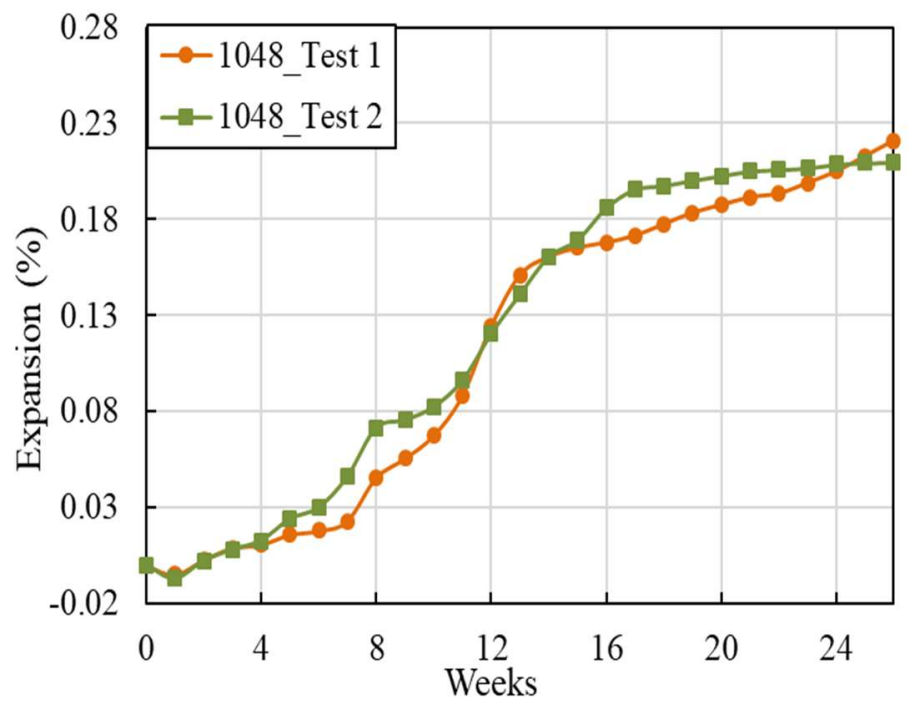

(e)

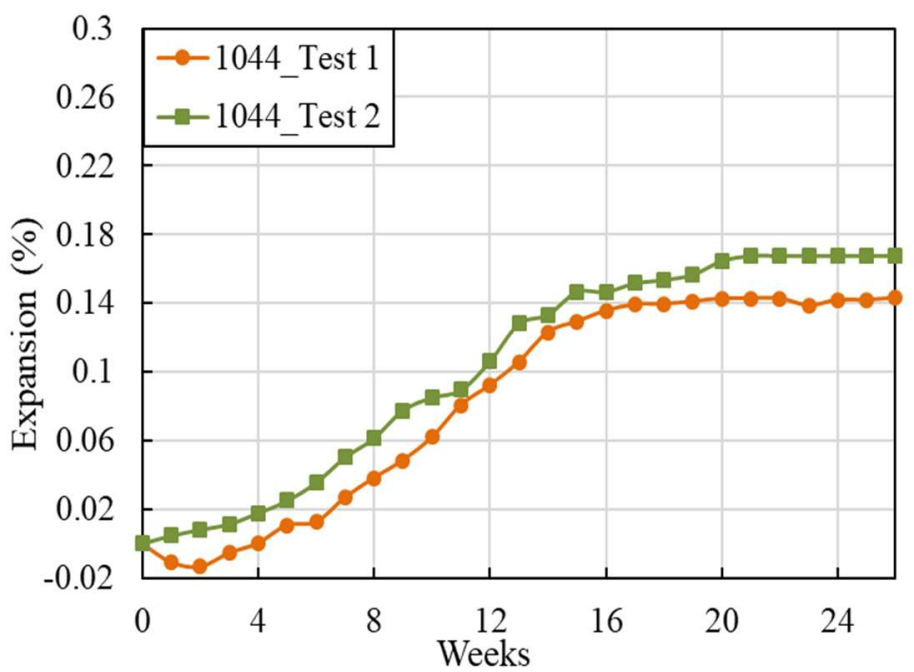

(b)

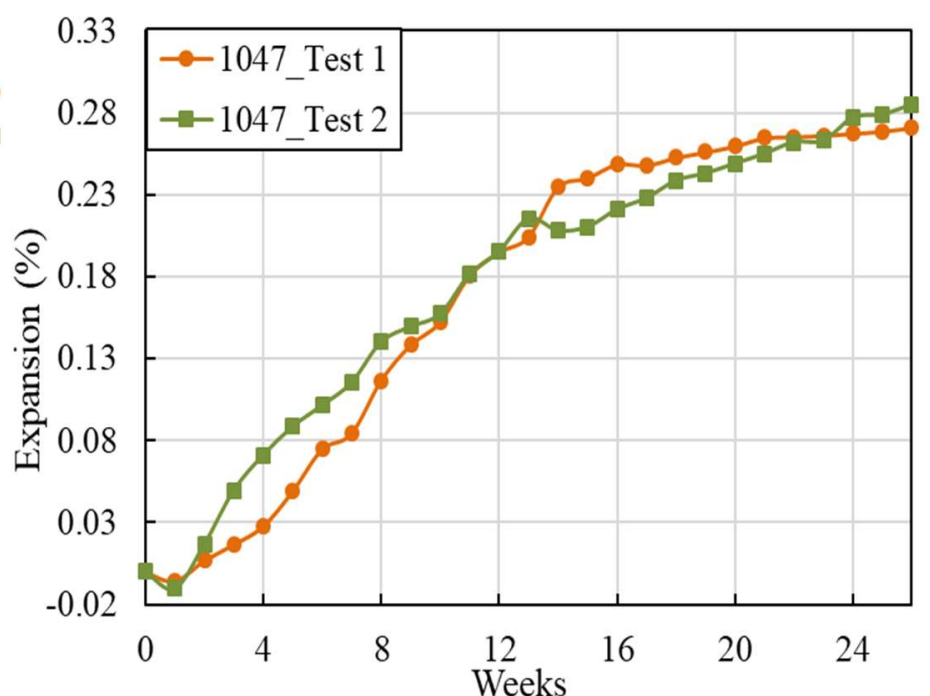

(d)

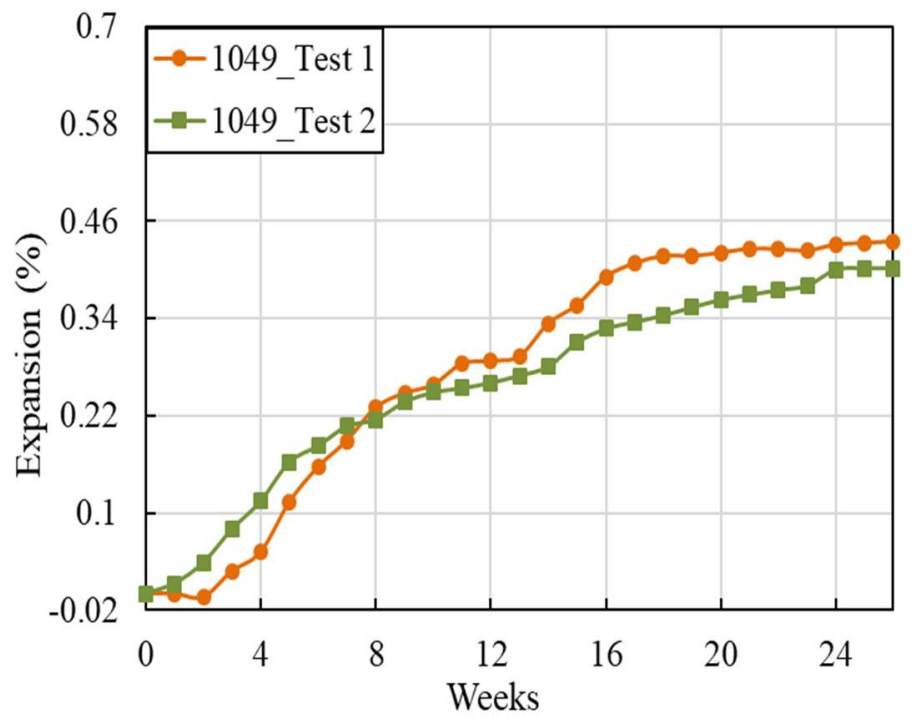

(f) 


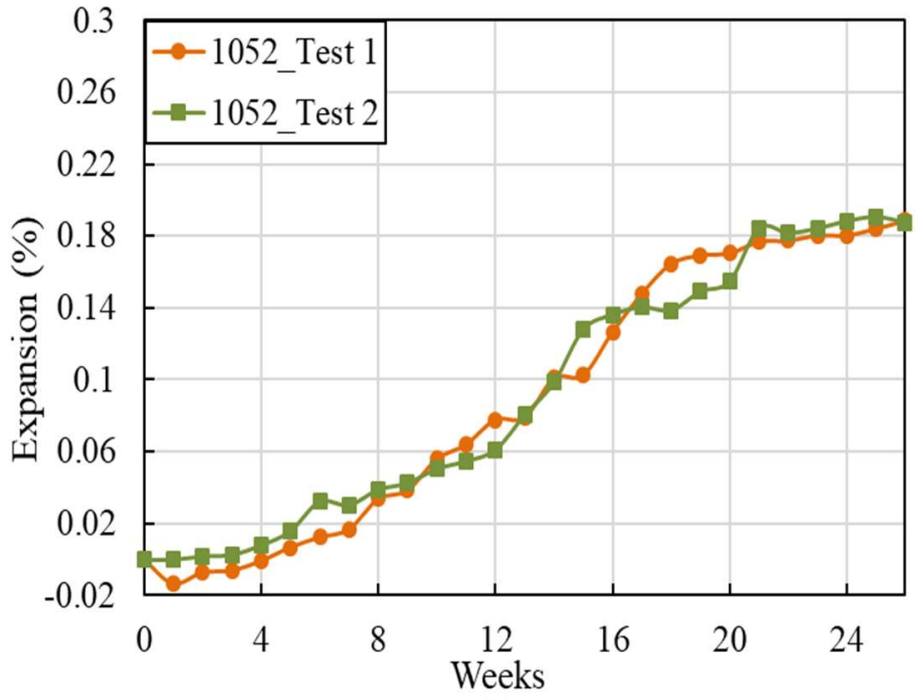

(g)

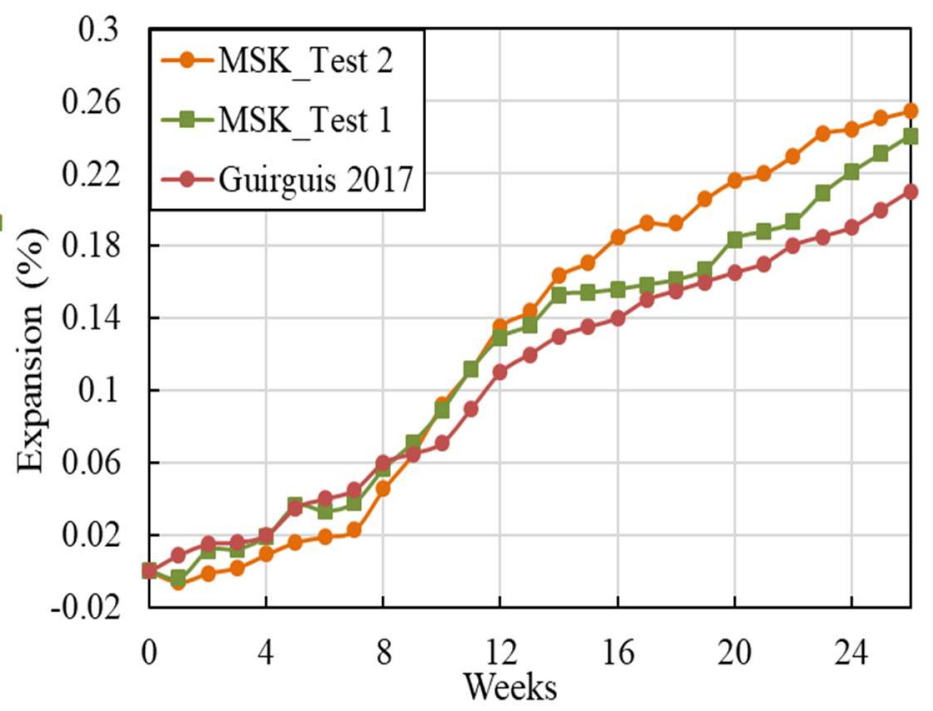

(h)

Figure 5.7. Repeatability of oxidation mortar bar test (OMBT) for aggregates with different composition subjected to the same exposure condition

Table 5.2. Statistical analysis for Phase II expansion for the repeated OMBT

\begin{tabular}{ccccccc}
\hline \hline \multirow{2}{*}{ Aggregate } & \multicolumn{2}{c}{ OMBT Test \# 1 } & \multicolumn{2}{c}{ OMBT Test \# 2 } & & \\
\cline { 2 - 4 } & Mean & $\begin{array}{c}\text { Coeff. of } \\
\text { variation } \\
(\%)\end{array}$ & Mean & $\begin{array}{c}\text { Coeff. of } \\
\text { variation } \\
(\%)\end{array}$ & t-value & t-critical \\
\hline \hline 1020 & 0.025 & 7.5 & 0.021 & 4.5 & 1.38 & 12.70 \\
1044 & 0.143 & 6.5 & 0.168 & 6.7 & -0.44 & -12.70 \\
1046 & 0.292 & 1.1 & 0.266 & 2.9 & 5.53 & 12.70 \\
1047 & 0.271 & 3.5 & 0.285 & 1.6 & -2.36 & -12.70 \\
1048 & 0.221 & 2.5 & 0.210 & 6.0 & 1.47 & 12.70 \\
1049 & 0.435 & 0.5 & 0.402 & 2.4 & 5.64 & 12.70 \\
1052 & 0.189 & 1.2 & 0.186 & 2.8 & 0.79 & 12.70 \\
MSK & 0.241 & 3.2 & 0.255 & 4.6 & -1.08 & -12.70 \\
\hline \hline
\end{tabular}




\subsection{Accelerated Mortar Bar Test (ASR)}

Some of the aggregates that had a high expansion in Phase I were tested in the ASR-accelerated mortar bar test (CSA A23.2-25A) for 28 days. As Figure 5.8 illustrates, the expansion of aggregate 1049 is $0.17 \%$ after 14 days, suggesting that this aggregate may be ASR-reactive. Other aggregates showed $<0.10$ at 14 days, except for sand $\mathrm{A}$, which shows an expansion that is just above 0.10 . Note that this sand is known to be non-reactive. Aggregate 1049 showed a very high expansion of almost $0.40 \%$ at 28 days, suggesting a severe reaction in an alkaline environment and high temperature. These conditions are available in the oxidation mortar bar test due to the soaking solution of sodium hypochlorite and testing at $80^{\circ} \mathrm{C}$. Similar behaviour was reported in the work of Guirguis et al. (2018). This is the reason for the high expansion of the aggregate in the oxidation mortar bar in both phases of the test, including Phase II $(0.142 \%)$, as will be reaffirmed later in section 5.5.

For the rest of the aggregate, there is no direct correlation between the expansion values in the ASR mortar bar and the OMBT. Despite the high expansions in Phase II of the OMBT for aggregates with high silicate content compared to carbonate aggregates, only aggregate 1049 showed an expansion $>0.10 \%$ in Phase II. 


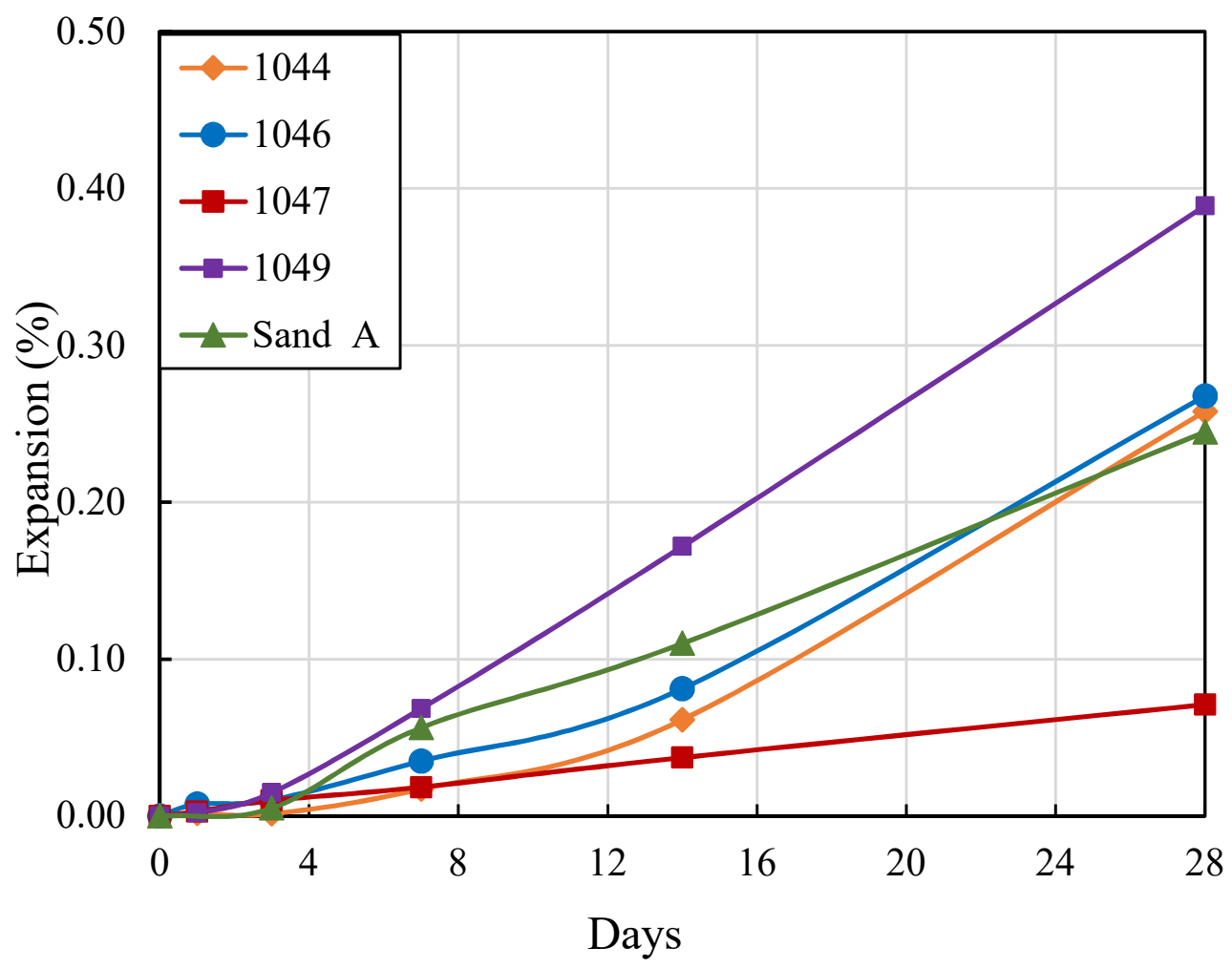

Figure 5.8. Expansion of ASR mortar bars tested for 28 days

\subsection{Microstructural Examination}

Most of the aggregates that are known to have no or minimal sulphide content passed the OMBT expansion limit $(<0.1 \%$ in Phase II), except for aggregate 1049. The sulphide-bearing aggregates 1052 and MSK had expansions just above $0.10 \%$ in Phase II; this is likely due to the thaumasite formation, which generally forms at temperatures of about $5^{\circ} \mathrm{C}$. However, the expansion for these two sets of mortar bars was not much higher than the limit $(0.105 \%$ and $0.11 \%$, respectively), despite their high total sulphur content. Also, for aggregate 1049, the OMBT results indicated a much higher expansion in Phase II (0.142\%.).

The behaviour of these samples warrants further investigation. Some of the tested mortar bars were examined using SEM and EDS to investigate the effect of the sodium hypochlorite and the storage temperature on the aggregates with different compositions and to investigate the 
mechanism that caused the expansion, especially aggregate 1049 . For comparison, the test was carried out on carbonate samples that did not show expansion. Figure 5.9 to Figure 5.18 show backscattered electron (BSE) images and the spectra obtained via scanning electron microscopyenergy dispersive X-ray analysis (SEM-EDS) on OMBT samples with carbonate and high silicate content aggregates.

Figure 5.9 presents the SEM-EDS images for aggregate 1030; this is a carbonate aggregate with low total sulphur content $(0.017 \%)$ and a total expansion of $0.082 \%$. The common feature observed in this aggregate is the presence of Friedel's salt and some sodium chloride crystals. This behaviour was observed in all the carbonate aggregates, as shown in Figure 5.10 for aggregate 1029. The Friedel's salt was also found in some of the aggregates with high silicate contents, as depicted in Figure 5.1111 for mortar bars with aggregate 1046.
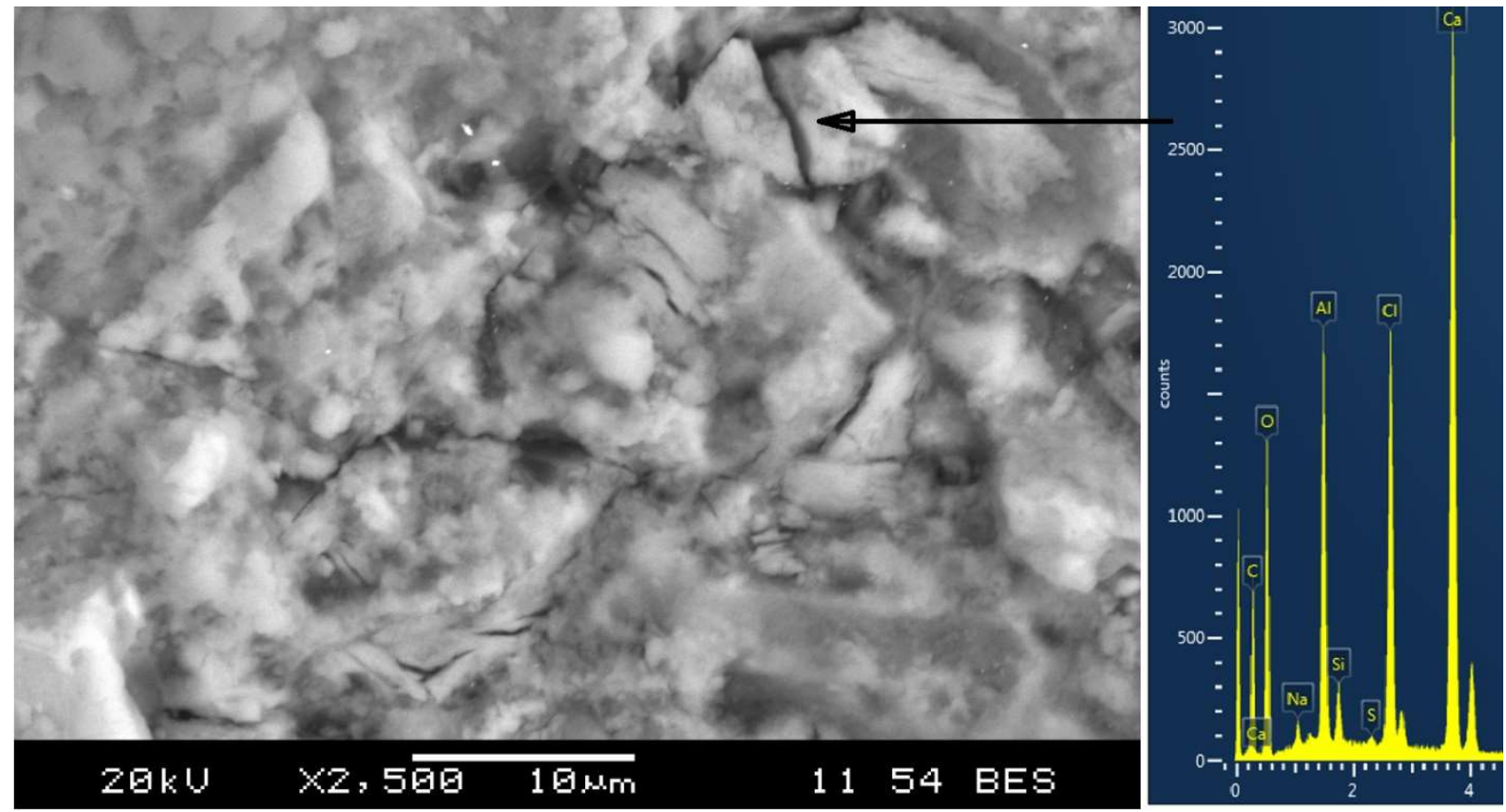

Figure 5.9. Friedel's salt with traces of silica appears in aggregate 1030. SEM-EDS obtained the BSE image and spectra, respectively 

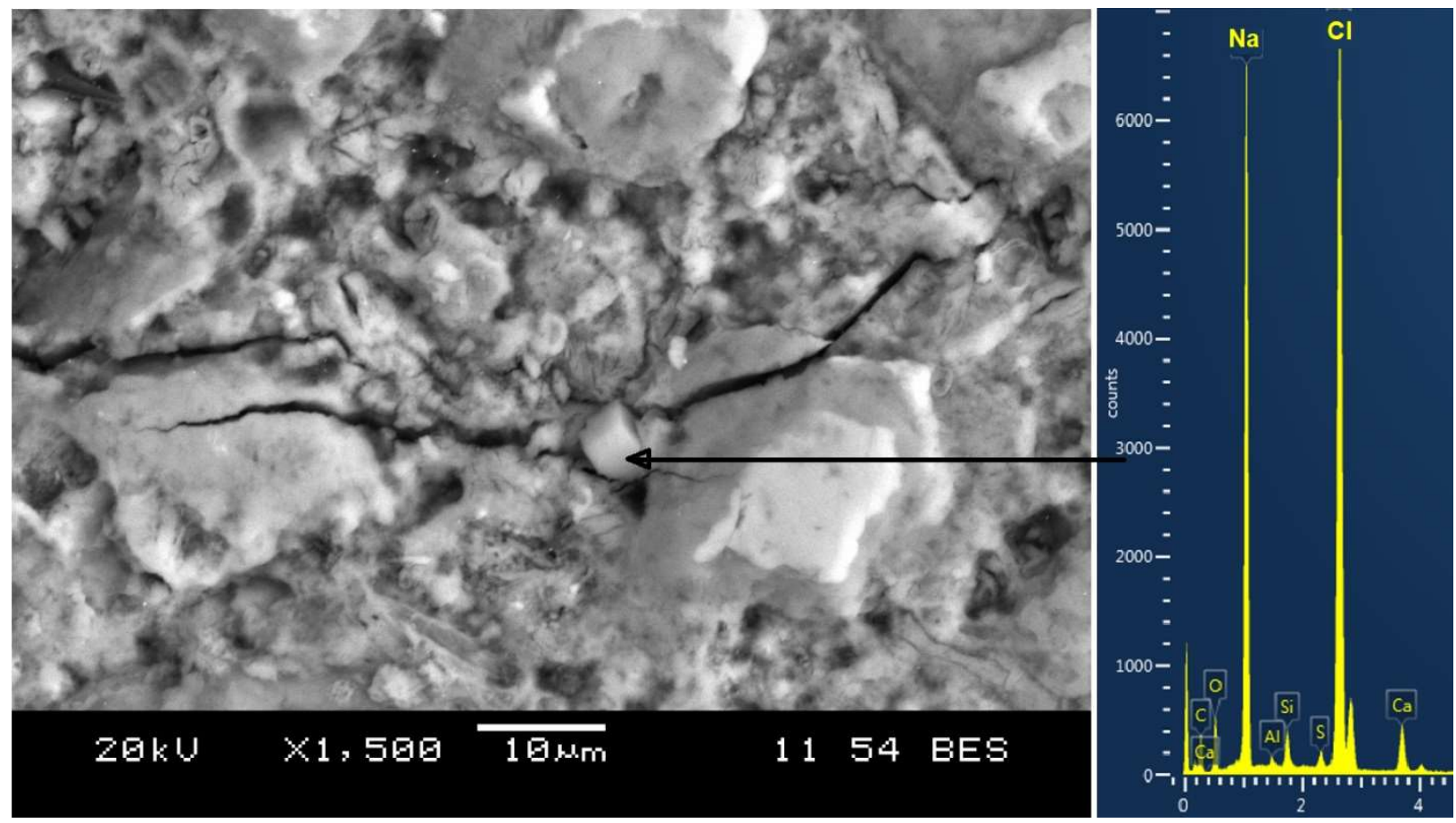

Figure 5.10. Sodium chloride appears in carbonate aggregate 1029
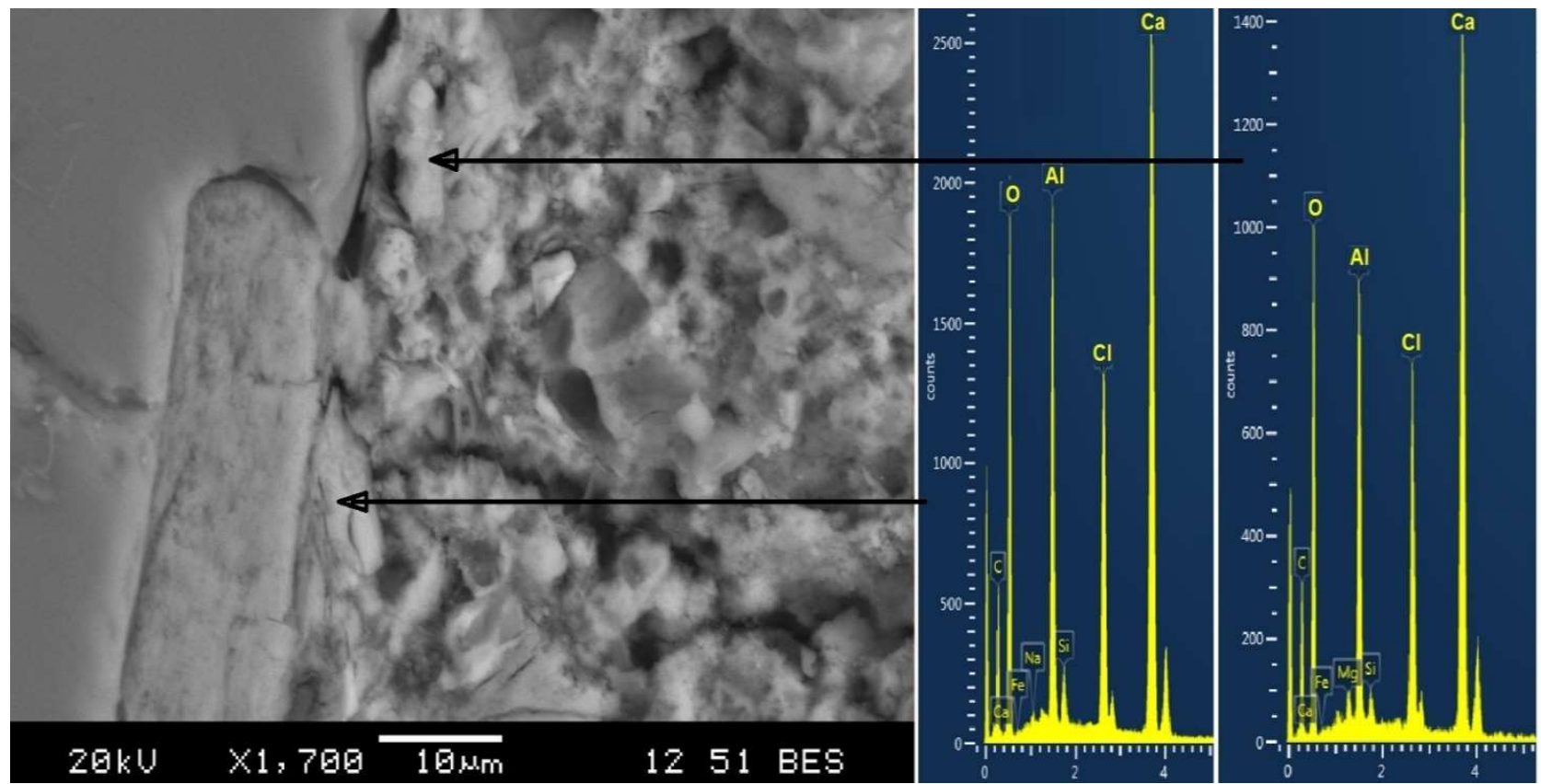

Figure 5.11. Friedel's salt appears in aggregate 1046 with high silicate content

The formation of Friedel's salt was identified in all samples, which may be attributed to the extended exposure of samples to chlorides from the sodium hypochlorite (bleach). The presence 
of Friedel's salt in the samples that did not show high expansion (mortar bars with carbonate aggregates) suggests that the formation of this salt does not cause severe expansion or cracking in mortars.

Similar behaviour was reported in the work of Guirguis et al. (2018), where the authors found that soaking the samples in sodium hypochlorite can produce Friedel's salt; however, soaking the mortar bars for three hours does not produce large enough amounts to cause expansions with limited alumina available from the cement.

The chloride becomes available from the following reactions, as explained in Guirguis et al. (2018). Initially, the reaction between sodium hypochlorite $(\mathrm{NaCl})$ and water produces hypochlorous acid $(\mathrm{HOCl})$ and sodium hydroxide $(\mathrm{NaOH})$, as expressed in Eq. (5.1). The hypochlorous acid transforms into hydrochloric acid $(\mathrm{HCl})$ and oxygen $\left(\mathrm{O}_{2}\right)$, as expressed in Eq. (5.2). Then the hydrochloric acid reacts with calcium hydroxide as one of the hydrated Portland cement products to form calcium chloride and water, as written in Eq. (5.3) below.

$$
\begin{array}{ll}
\mathrm{NaClO}+\mathrm{H}_{2} \mathrm{O} \rightarrow \mathrm{HOCl}+\mathrm{NaOH} & \text { Eq. (5.1) } \\
2 \mathrm{HOCl} \rightarrow 2 \mathrm{HCl}+\mathrm{O}_{2} & \text { Eq. (5.2) } \\
2 \mathrm{HCl}+\mathrm{CaOH} \rightarrow \mathrm{CaCl} 2+2 \mathrm{H} 2 \mathrm{O} & \text { Eq. (5.3) }
\end{array}
$$

Figure 5.12 shows SEM images for the carbonate aggregate 1029. As can be seen, evidence of inclusions of un-oxidized iron sulphides was found in the aggregates after 26 weeks of exposure to sodium hypochlorite (bleach) and storage in an oven at $80^{\circ} \mathrm{C}$ and $80 \%$ relative humidity. The petrographic analysis for this aggregate indicates that the iron sulphides are in the form of pyrrhotite and pyrite. The un-oxidized sulphide in the image may be from the pyrite that did not have a chance to oxidize, as it has less potential for oxidation than pyrrhotites. 
Also, aggregate 1029 is the only carbonate aggregate that had high expansion in Phase I (0.117\%). Although the expansion in Phase II was less than the limit proposed in Annex P of the CSA.23.1 (0.078), the expansion was more than expected for a carbonate aggregate. This aggregate has the highest total sulphur content $(0.303 \%)$ and silicate content among all the carbonate aggregates (14.0\%). Moreover, as Figure 5.13 illustrates, evidence alkali-silica gel was observed around the aggregate in some locations. The nature of this gel was different than the ASR products that were found in mortar bars of aggregates with high silicate content (1046 and 1049), as will be shown later. This behaviour highlights the - somehow - failed performance of the test on aggregates that have satisfactory performance as concrete aggregates.
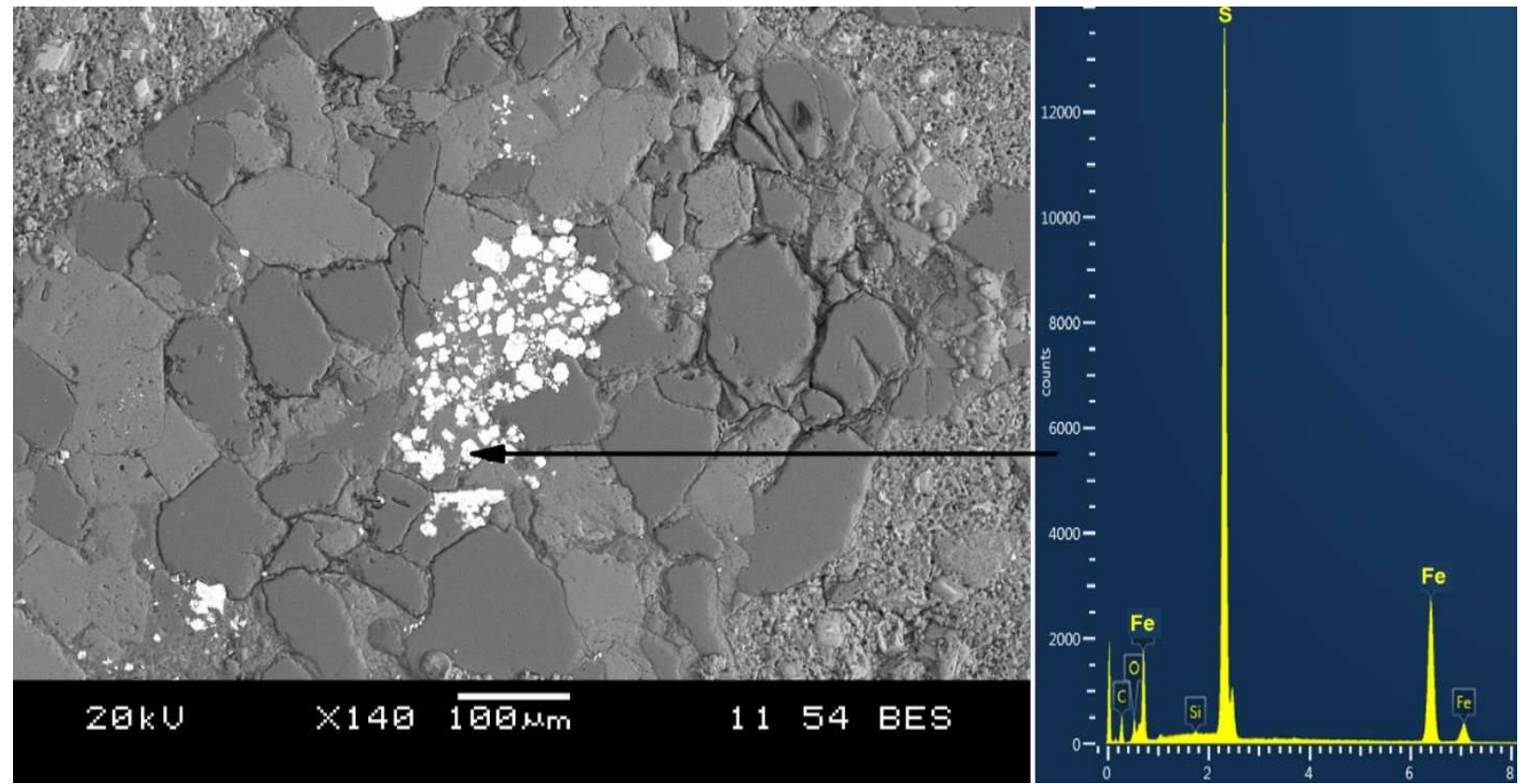

Figure 5.12. Un-oxidized iron sulphides in the carbonate aggregate 1029 


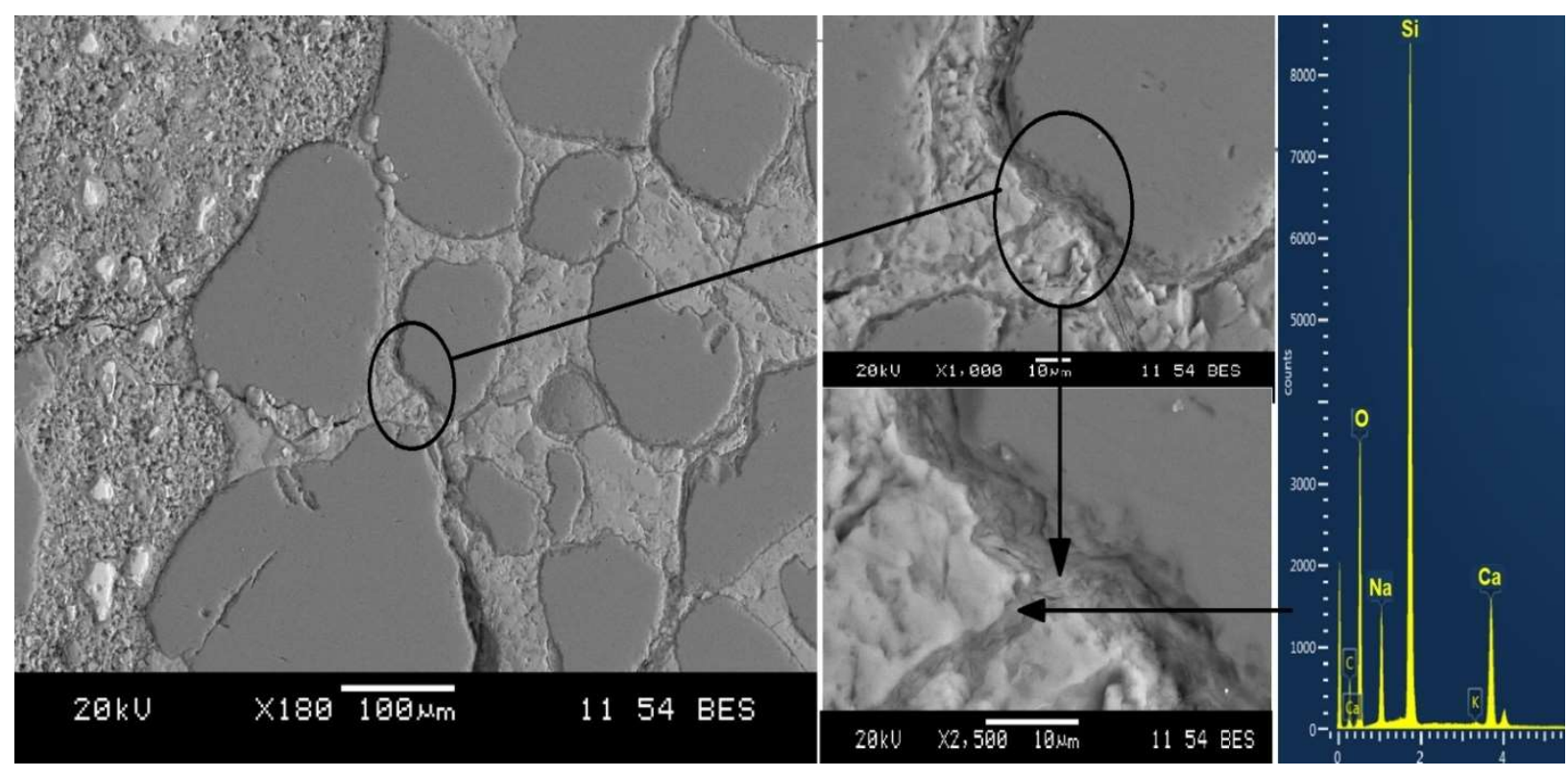

Figure 5.13. ASR gel around the aggregate in mortar bars with the carbonate aggregate 1029

Figure 5.14 and Figure 5.15 show SEM-EDS images for two locations in the sulphide bearingaggregate 1052. The images provide evidence of inclusions of un-oxidized iron sulphides in the aggregates after 26 weeks of exposure to sodium hypochlorite (bleach) and storage in an oven at $80^{\circ} \mathrm{C}$ and $80 \%$ relative humidity. The iron oxides in this aggregate are in the form of pyrite and pyrrhotite, which unlike pyrite, tends to oxidize, generating internal sulphate attack. The images indicate that some of the iron sulphides in these aggregates did not oxidize after testing. Figure 5.16 shows the image of another location in the mortar bar with unoxidized sulphide.

After inspecting various locations on the sample, evidence of mixture between Friedel's salt and traces of ettringite and possibly Thaumasite were observed, as shown in Figure 5.16. The marginal expansion value of this aggregate may be attributed to the nature of the occurrence of sulphide minerals in it. Unlike the MSK aggregate, where sulphide minerals occur in a disseminated state, the sulphide minerals present in aggregate 1052 occur as discrete, isolated particles or nuggets. 
The microstructural examination of this aggregate did not show pieces or particles with nuggets of sulphide minerals; instead, we only found some particles with un-oxidized sulphides. This indicates that the investigated piece of mortar bar might not have represented the nature of the aggregate.

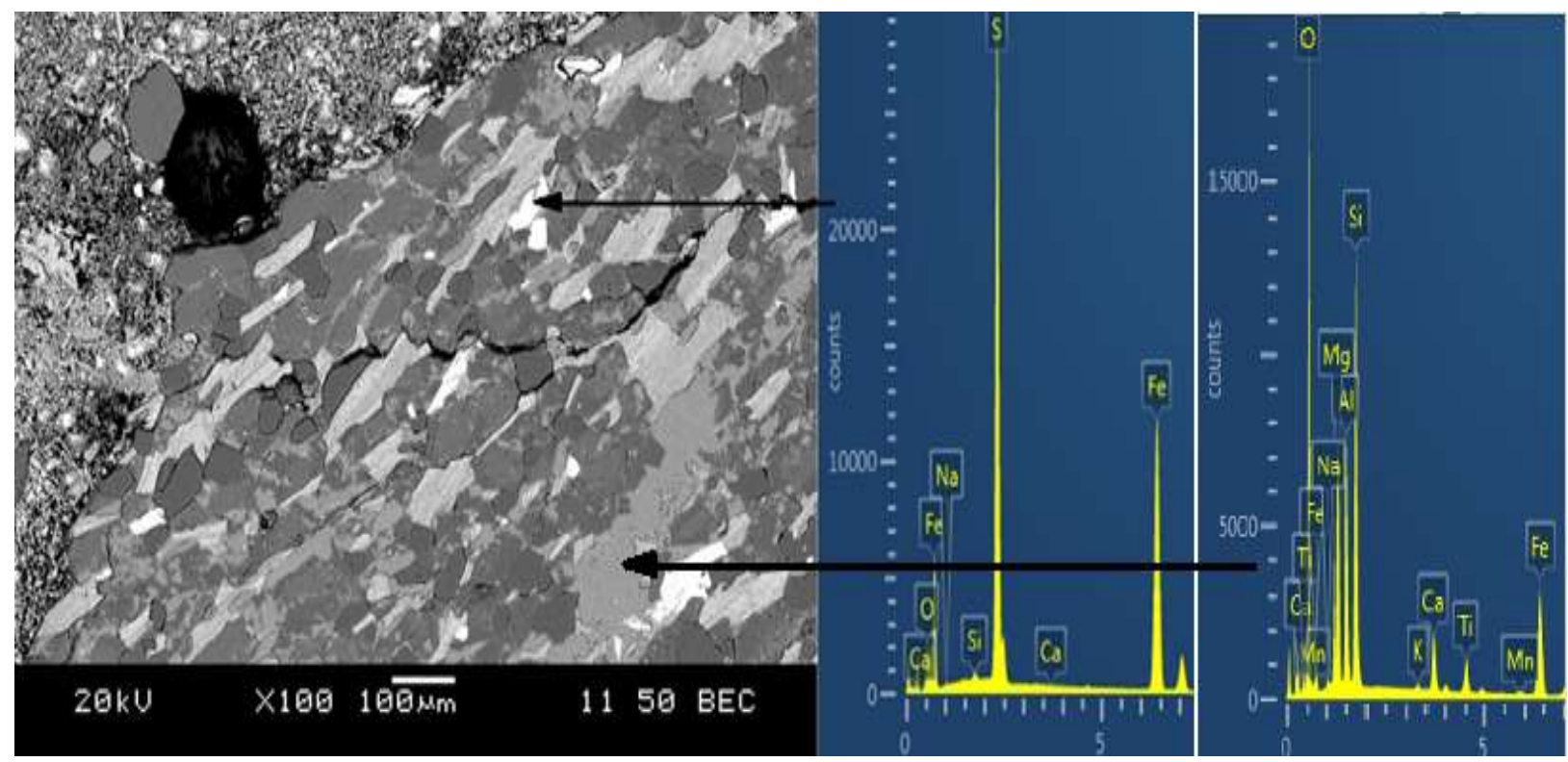

Figure 5.14. Un-oxidized iron sulphides in the sulphide-bearing aggregate 1052; the light grey areas show the composition of the aggregate

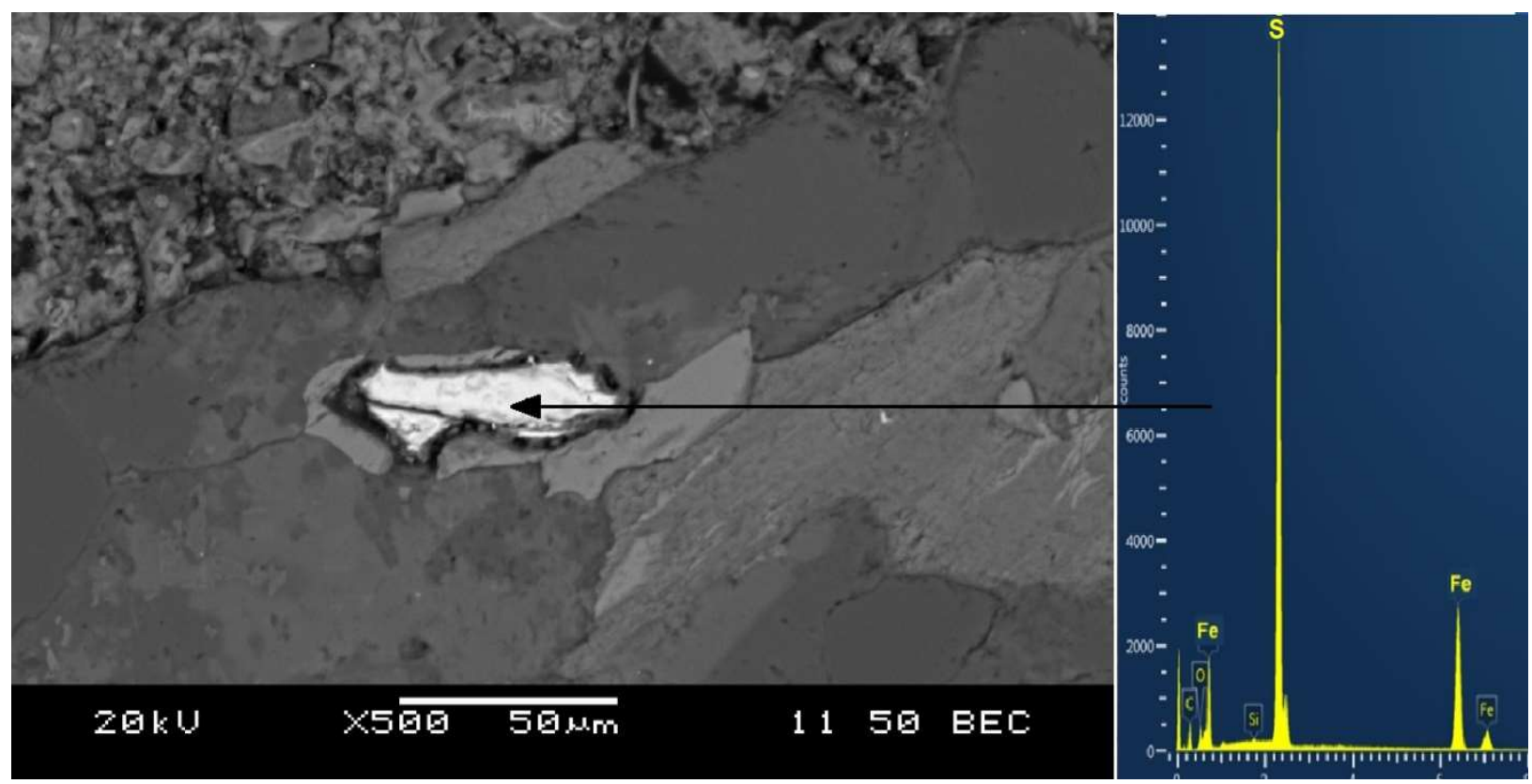

Figure 5.15. Un-oxidized iron sulphides in another site in the sulphide-bearing aggregate 1052 


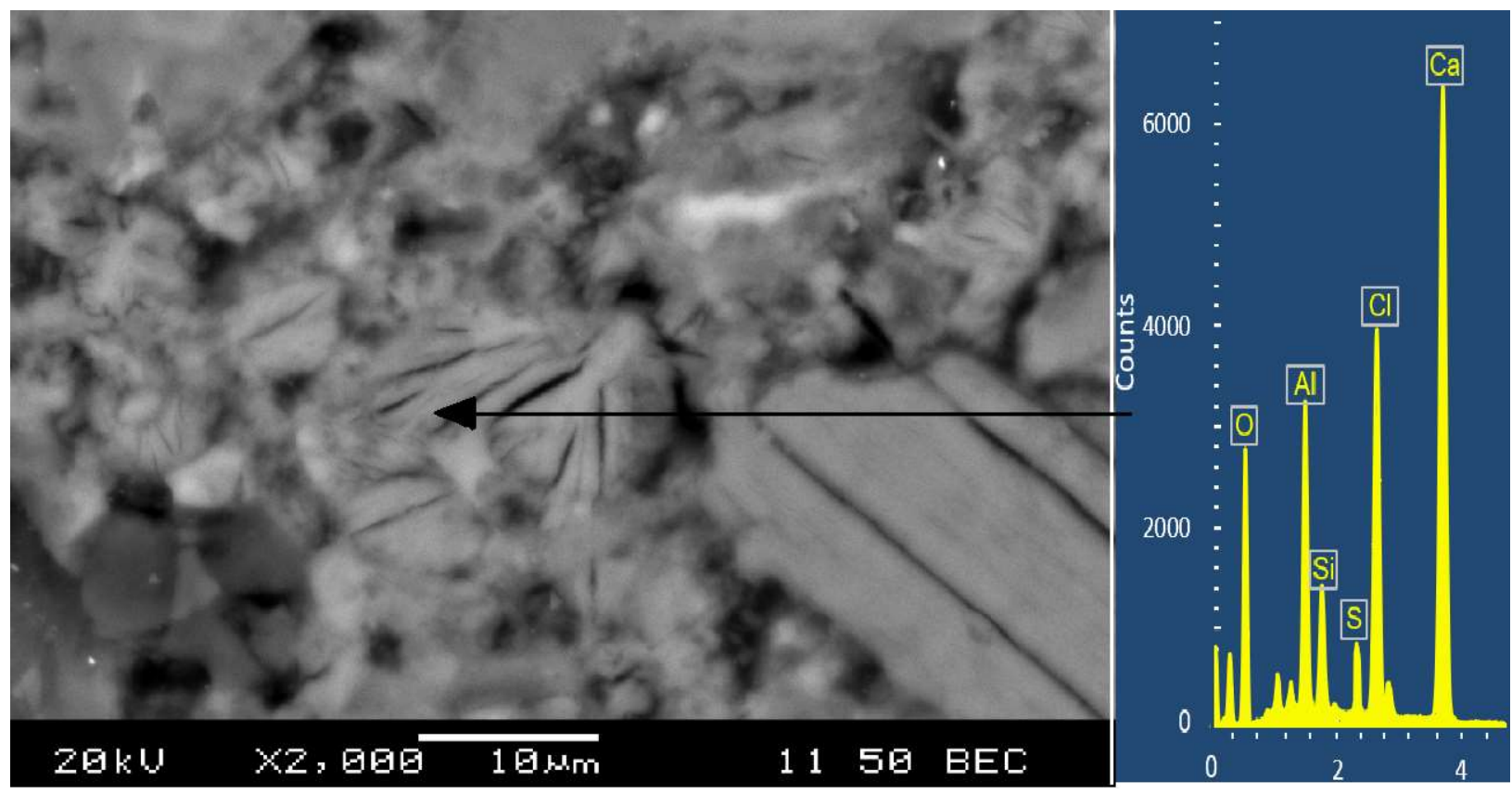

Figure 5.16. SEM and EDS images for mortar, with aggregate 1052 showing a mix of Friedel's salt with traces of ettringite

Figure 5.17 and Figure 5.18 show the formation of crystals composed mainly of silica and alkali at the cracks within the aggregate for mortar bars with aggregates 1046 and 1049, respectively. Fernández-Jiménez and Puertas (2002) and Yazıc1 (2012) reported the presence of similar crystals in an advanced stage of ASR when storing the mortar bars at $80^{\circ} \mathrm{C}$. Guirguis et al. (2018) also reported similar findings in the oxidation mortar bar test using aggregates with silicate.

This behaviour of non-alkali-silica-reactive aggregate may be attributed to the long exposure of the aggregate to heat $\left(80^{\circ} \mathrm{C}\right)$ and sodium hypochlorite, leading to the dissolution of silica and causing the formation of alkali-silica crystals. This would be similar to cases of ASR. The presence of these crystals could explain the expansion of some aggregates with silicate in the first phase of the oxidation mortar bar test. In severe cases, like in aggregate 1049, the expansion may continue in Phase II. Moreover, while there is no evidence of disintegration in the mortar bars prior to the preparation for SEM test, the images show that there is clear damage to the fabric. 


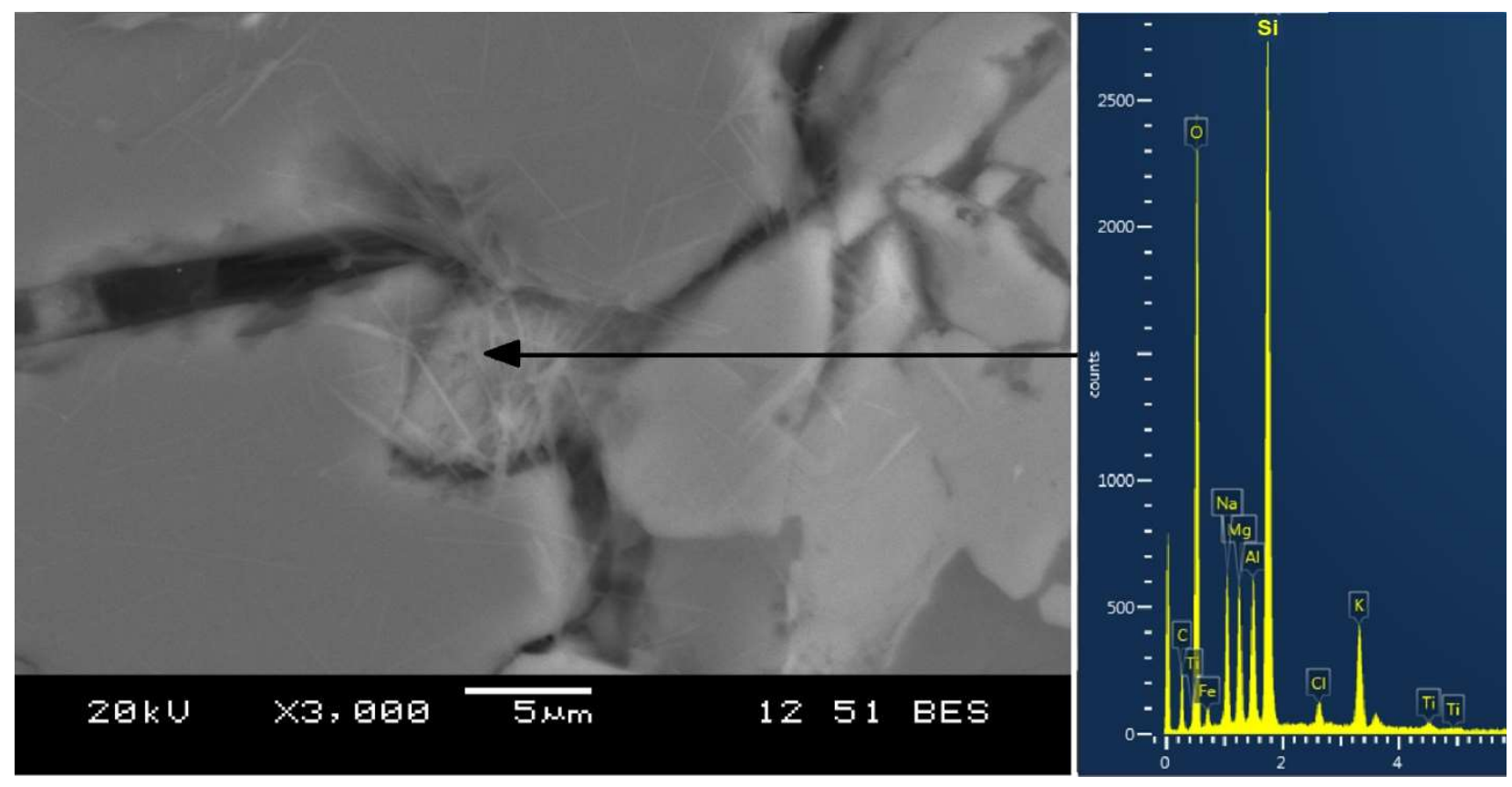

Figure 5.17. Deteriorated paste of mortar bar with aggregate 1046 showing the presence of ASR gel

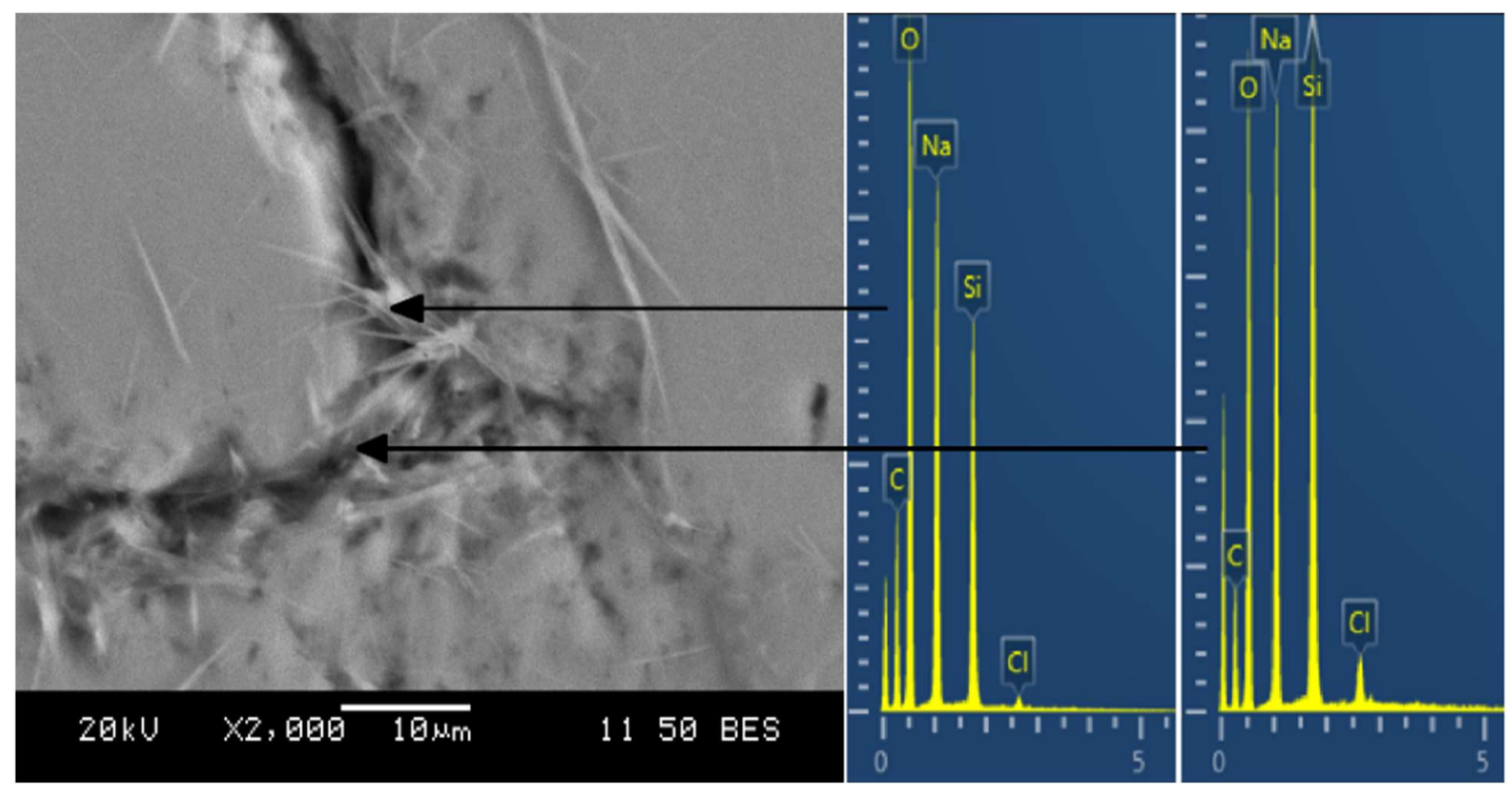

Figure 5.18. Deteriorated paste of mortar bar with aggregate 1049 showing the presence of ASR gel 


\subsection{Application of OMBT on Aggregates with Controlled Total Sulphur Content}

Since most of the tested natural aggregates had low total sulphur and sulphide content, sulphide ore (Ore) was blended with a non-sulphide aggregate and tested as aggregate with controlled sulphide levels., as explained under the experimental procedures.

Table 5.3 and Figure 5.19 show the expansion of the tested samples in both phases of the OMBT. The expansion values show that the expansion of samples with aggregates with silicates (as in the case of sand A, sand B, and mixtures of these aggregates with Ore) is much higher than that of carbonate aggregates $(\mathrm{C} 1)$ in both phases of the tests. This behaviour indicates that, with noncarbonate aggregates, the expansion in both phases (and in particular in Phase II) is not due solely to the presence of oxidizable sulphide phases. Part of this expansion is due to the presence of silicates in the aggregates.

It is also clear that the $0.10 \%$ limit in Phase II can give a false negative by showing a deleterious aggregate as safe, as is clear from the results of blends of (sand $\mathrm{B}+10 \%$ Ore), $(\mathrm{C} 1+10 \%$ Ore) and, more significantly, $(\mathrm{C} 1+20 \%$ Ore $)$. It is therefore obvious that a modified limit is needed for this test. This is presented in the coming subsection.

Table 5.3. Expansion of mortar bars with controlled total sulphide content

\begin{tabular}{cccc} 
& & \multicolumn{2}{c}{ Expansion (\%) } \\
\hline \hline Aggregate & Total Sulphur* $(\%)$ & Phase 1 & Phase II \\
\hline \hline Sand A & $\approx 0$ & 0.144 & 0.062 \\
\hline Sand A+5\% Ore & 0.7 & 0.109 & 0.073 \\
\hline Sand A+10\% Ore & 1.4 & 0.079 & 0.114 \\
\hline Sand B & $\approx 0$ & 0.176 & 0.061 \\
\hline
\end{tabular}




\section{Expansion (\%)}

\begin{tabular}{cccc}
\hline \hline Aggregate & Total Sulphur* $(\%)$ & Phase 1 & Phase II \\
\hline \hline Sand B+10\% Ore & 1.4 & 0.103 & 0.088 \\
\hline $\mathrm{C} 1$ & $\approx 0$ & 0.035 & 0.008 \\
\hline $\mathrm{C} 1+10 \%$ Ore & 1.4 & 0.034 & 0.046 \\
\hline $\mathrm{C} 1+20 \%$ Ore & 2.8 & 0.064 & 0.068 \\
\hline \hline
\end{tabular}

*: Total sulphur is calculated as \% of Ore multiplied by its total sulphur content

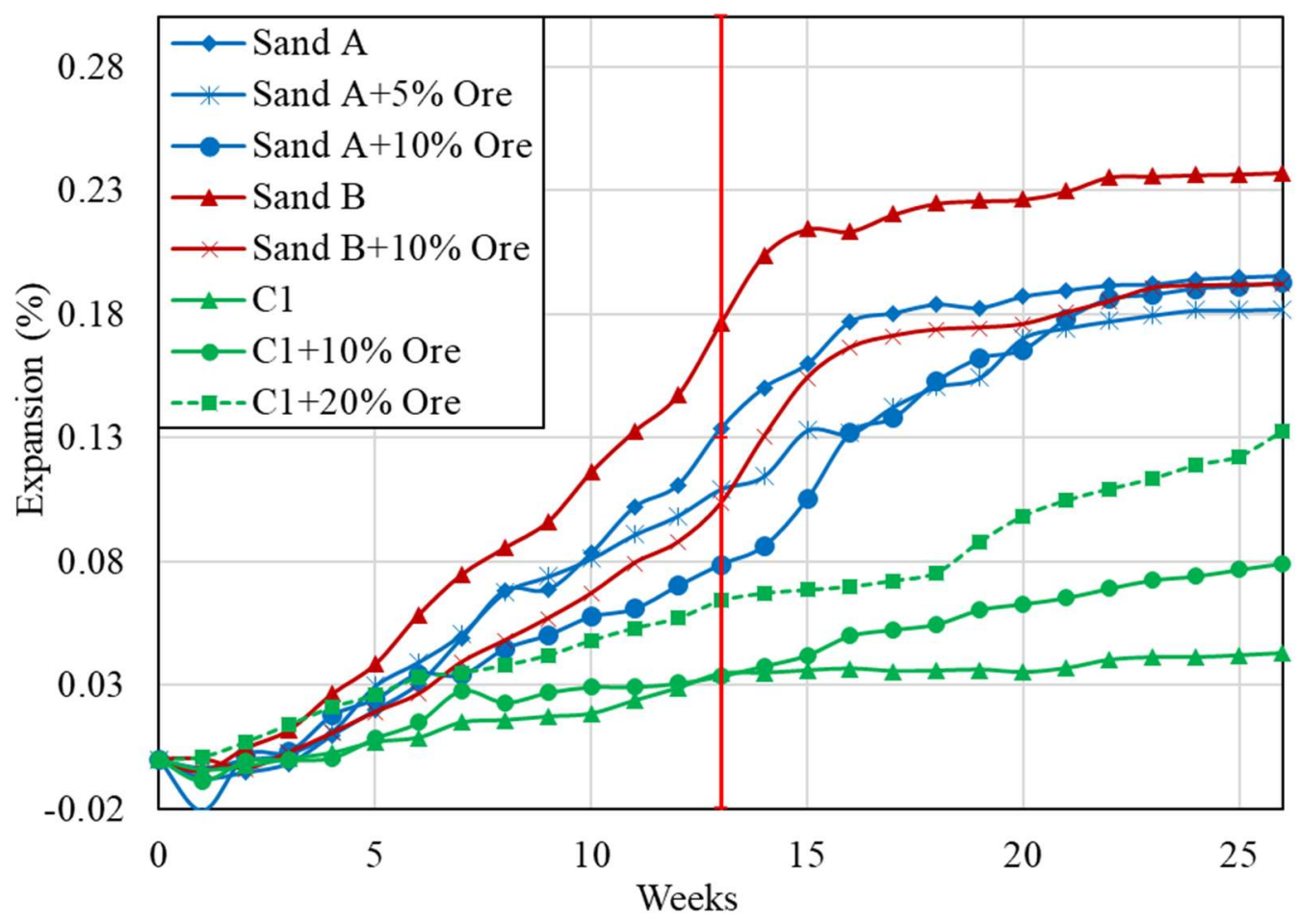

Figure 5.19. Expansion of mortar bars with controlled total sulphide content 


\subsection{Summary and Discussion}

In this chapter, the oxidation mortar bar test (OMBT) as developed by Rodrigues et al. (2016) was applied to aggregates with different total sulphur contents and various chemical and physical compositions to assess the ability of the test for the evaluation of susceptibility of sulphide-bearing aggregates to oxidation.

Testing all the aggregates in the oxidation mortar bar test in its set-up suggested by Rodrigues et al. (2016) raised two concerns that might be a barrier in the evaluation of the oxidation potential of aggregate. (i) The first concern is that aggregates with high silicate content and low total sulphur content have much higher expansion than carbonate aggregates in both phases of the test. This makes it difficult to establish one universal limit. In other words, using the 0.10 expansion limit for carbonate aggregate is highly likely to provide false negatives (show aggregates with high sulphide as safe). This was demonstrated when carbonate aggregate was tested with $10 \%$ and $20 \%$ Ore. (ii) The second concern is that samples with known high total sulphur content (category 1) have expansions just above the suggested expansion limit $(0.10 \%$ in Phase II), as in the case of MSK and 1052 expansion. This again indicates the risk of false negatives.

To provide better guidance and enhance the criteria for expansion limit, control aggregates with different levels of Ore were investigated to obtain more insight into the limitations of this test. As Figure 5.20 illustrates, if the expansion in Phase II is an indicator of the oxidation potential of the aggregates, mortar bars with the same total sulphur should have similar expansion. This was not the case, however, as $10 \%$ Ore did not cause the same expansion when blended with carbonate aggregate (C1) and silicate aggregates (sand A and sand B). The expansions in Phase II varied, with the different contents of the silicate in the aggregates measuring $1.88 \%, 56.44 \%$ and $69.5 \%$

for $\mathrm{C} 1$, sand $\mathrm{A}$ and sand $\mathrm{B}$, respectively. Moreover, the $10 \%$ Ore resulted in the failure of the 
sample when used with sand $\mathrm{A}$, whereas when it was blended with $\mathrm{C} 1$ or sand $\mathrm{B}$, the expansion was $<0.1 \%$.

Based on all these results, the following expansion criteria are suggested:

(i) The maximum expansion in Phase II is $0.03 \%$. Aggregates that exceed the $0.03 \%$ expansion limit should be investigated for the ratio of expansion in Phase II to expansion in Phase I (Phase II/Phase I).

(ii) A maximum ratio of expansion of 0.60 in Phase II to that in Phase I is suggested. This 0.60 ratio is suggested to take the effect of silicate into consideration. Aggregates with high silicate content would produce higher expansion in both phases, but less in Phase II. Normalizing the expansion in Phase II to that in Phase I would consider the effect of silicate.

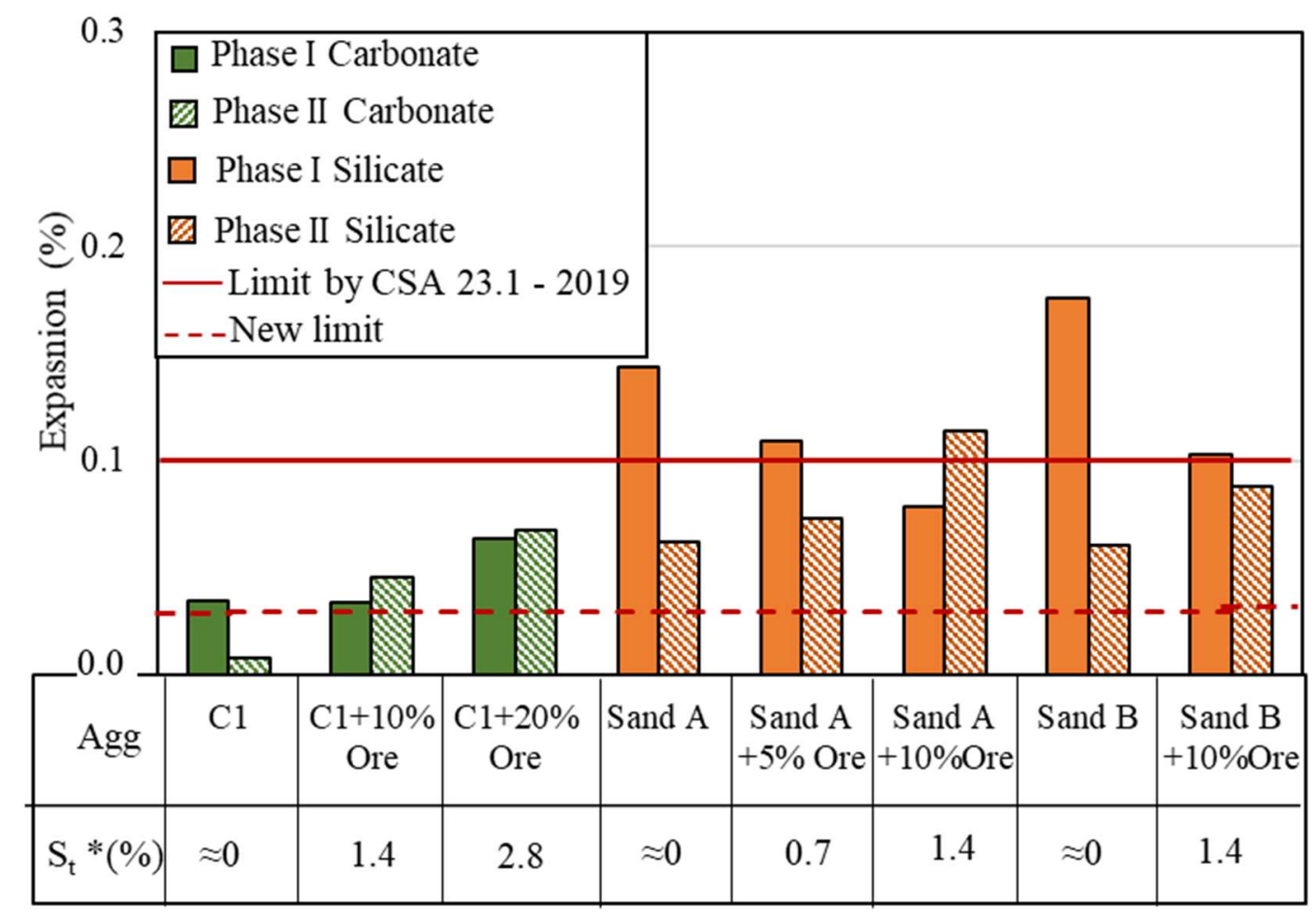

*calculated based on level of replacement of Ore

Figure 5.20. Expansion of mortar bars with controlled total sulphide content 
The applicability of this two-step criterion is investigated in Table 5.4, where the expansion criteria were applied to all the tested samples. As shown in the table, the ultimate benefit of this approach is best illustrated when looking at the values of aggregate 1049. The expansion of this aggregate is $0.142 \%$ in Phase II; however, the ratio of Phase II to Phase I is only 0.49 . Based on these criteria, aggregates with sulphides failed by a good margin, with four of the non-sulphide aggregates failing (1029, 1043, 1058 and sand $\mathrm{A}+5 \%$ Ore $)$.

It should be highlighted here that these criteria are conservative. For instance, using an expansion limit of $0.04 \%$ in Phase II and a 0.7 ratio of Phase II to Phase I can also be used. In this case, all aggregates with high sulphide content would fail and non-sulphide aggregates would pass. However, aggregate MSK has a ratio of 0.77 , which is not much higher than 0.70 . Testing more samples with sulphide-based aggregates from different geographic locations could provide more insights and improve the criteria. The next chapter presents the new mortar bar test methods that can overcome some of the current test limitations.

Table 5.4. The ratio between the expansion of Phase II and Phase II of mortar bars

\begin{tabular}{cccc||cccc}
\multicolumn{4}{c||}{ Expansion (\%) } & \multicolumn{4}{c}{ Expansion (\%) } \\
\hline \hline \multirow{2}{*}{ Aggregate } & $\begin{array}{c}\text { Phase } \\
\text { I Phase }\end{array}$ & Ratio & Aggregate & Phase & Phase & Ratio \\
& II & & & I & II & \\
\hline C1 & 0.035 & 0.008 & $* *$ & 1048 & 0.141 & 0.069 & 0.49 \\
\hline 1020 & 0.014 & 0.011 & $* *$ & 1049 & 0.293 & 0.142 & 0.48 \\
\hline 1022 & 0.011 & 0.016 & $* *$ & 1050 & 0.017 & 0.016 & $* *$ \\
\hline 1024 & 0.024 & 0.02 & $* *$ & 1051 & 0.176 & 0.086 & 0.49 \\
\hline 1025 & 0.012 & 0.015 & $* *$ & 1052 & 0.079 & 0.11 & 1.39 \\
\hline 1027 & 0.034 & -0.001 & $* *$ & 1056 & 0.178 & 0.07 & 0.39 \\
\hline 1029 & 0.117 & 0.078 & 0.67 & 1058 & 0.093 & 0.062 & 0.67 \\
\hline 1030 & 0.055 & 0.027 & $* *$ & MSK & 0.136 & 0.105 & 0.77 \\
\hline
\end{tabular}




\begin{tabular}{|c|c|c|c|c|c|c|c|}
\hline \multicolumn{4}{|c|}{ Expansion (\%) } & \multicolumn{4}{|c|}{ Expansion (\%) } \\
\hline Aggregate & $\begin{array}{c}\text { Phase } \\
\text { I } \\
\end{array}$ & $\begin{array}{c}\text { Phase } \\
\text { II } \\
\end{array}$ & Ratio & Aggregate & $\begin{array}{c}\text { Phase } \\
\text { I }\end{array}$ & $\begin{array}{c}\text { Phase } \\
\text { II }\end{array}$ & Ratio \\
\hline 1031 & 0.023 & 0.021 & $* *$ & Sand A & 0.144 & 0.062 & 0.43 \\
\hline 1032 & 0.013 & 0.012 & $* *$ & Sand $A+5 \%$ & 0.109 & 0.073 & 0.67 \\
\hline 1033 & 0.014 & 0.018 & $* *$ & Sand $A+10 \%$ & 0.079 & 0.114 & 1.44 \\
\hline 1043 & 0.087 & 0.06 & 0.69 & Sand B & 0.176 & 0.061 & 0.35 \\
\hline 1044 & 0.106 & 0.037 & 0.35 & Sand B $+10 \%$ & 0.103 & 0.088 & 0.85 \\
\hline 1045 & 0.059 & 0.028 & $* *$ & $\mathrm{C} 1$ & 0.035 & 0.008 & $* *$ \\
\hline 1046 & 0.237 & 0.055 & 0.23 & $\mathrm{C} 1+10 \%$ Ore & 0.034 & 0.046 & 1.35 \\
\hline 1047 & 0.204 & 0.067 & 0.33 & $\mathrm{C} 1+20 \%$ Ore & 0.064 & 0.068 & 1.06 \\
\hline
\end{tabular}

**: No ratio is needed, as Phase II expansion is $<\mathbf{0 . 0 3 \%}$. 


\section{Chapter 6}

\section{Development of New Expansion Test for Evaluation of Oxidation Potential of Sulphide- Bearing Aggregate}

The original expansion mortar bar test that was proposed and developed by (Rodrigues et al., 2016) has some limitations in the evaluation of susceptibility of aggregates to oxidation, especially in the case of aggregates with high silicate content, as explained earlier in Chapter 5. These limitations appeared from the long-duration exposure of mortar bars to heat and sodium hypochlorite, causing the dissolution of silica and generation of ASR products.

This chapter investigates the effects of exposing mortar bars and concrete prisms to various environmental conditions and soaking solutions to find the optimal conditions for maximizing the expansion of the samples due to the oxidation of the iron sulphides. In this part of the research, different sets of mortar bars and concrete prisms incorporating control silicate aggregates (sand B, 1046 and 1049), carbonate aggregates (C1) and sulphide-bearing aggregates (Ore, MSK and 1052) and cast with GU cement and different kind of SCMs were tested.

\subsection{Oxidation Mortar Bar Test}

\subsubsection{Using sodium hypochlorite $(\mathrm{NaClO})$ to promote oxidation}

In this part of the test program, sodium hypochlorite (household bleach 6\%) was used as the oxidizing agent with various environmental conditions. This approach was proposed in the work of Rodrigues et al. (2016) and Guirguis (2017).

As mentioned in Chapter 5, high storage temperature $\left(80^{\circ} \mathrm{C} / 80 \% \mathrm{RH}\right)$ caused expansions that were not attributed to the oxidation of iron sulphides. Hence, in the coming subsection, the same soaking solution ( $6 \%$ bleach) will be used, but the samples will be stored at room temperature $\left(21-23^{\circ} \mathrm{C} / 80 \% \mathrm{RH}\right)$ in Phase I. 


\subsubsection{Effect of lower storage temperature in Phase I $\left(21-23^{\circ} \mathrm{C} / 80 \% \mathrm{RH}\right)$ on the expansion of the mortar bars (Exposure B-1 in Table 3.5)}

Significant expansion was recorded in mortar bar samples with aggregates that have high silicate contents and limited total sulphur contents. The expansion was attributed to alkali-silica products. We assumed that reducing the storage temperature in Phase I may reduce the effect of silica dissolution and help identify aggregates with high sulphide content.

In the test, mortar bar samples were soaked for three hours in 6\% sodium hypochlorite and stored at room temperature $\left(21-23^{\circ} \mathrm{C} / 80 \% \mathrm{RH}\right)$ for 3.5 days for a period of 17 weeks in Phase I. During Phase II, the same soaking conditions were used, and samples were stored in a fridge at $5^{\circ} \mathrm{C} / 100 \% \mathrm{RH}$ for 3.5 days for another 17 weeks. The duration of each phase was extended to 17 weeks instead of the 13 weeks proposed by Rodrigues et al. (2016) to investigate if longer exposure would increase expansion. The test was applied to mortar bars that had silicate aggregates with high total sulphur content (MSK and 1052) and silicate aggregates with limited total sulphur (sand B+10\% Ore, 1046 and 1049).

Figure 6.1 presents a demonstration of the level and rate of the expansion of the mortar bars. As shown, during Phase I, the expansion of all the mortar bars was low. In Phase II, the rate of expansion for samples with high total sulphur content (i.e., MSK, sand B+10\% Ore and 1052) increased after moving the samples to $\left(5^{\circ} \mathrm{C} / 100 \% \mathrm{RH}\right)$. However, in the case of aggregates that had silicate with low total sulphur, 1046 and 1049, the expansion rate remained constant with low expansion values of $0.016 \%$ and $0.008 \%$, respectively.

This exposure reduced the effect of dissolution of silica and the development of ASR products in Phase I due to the long exposure of heat and sodium hypochlorite. However, as shown in Figure 6.2. SEM-EDS analysis of mortar bar with 1052 soaked in bleach in Phase IFigure 6.2, a 
microstructural examination of a mortar bar with aggregate 1052 that had high total sulphur content indicated the presence of un-oxidized iron sulphides after 34 weeks of testing. This exposure condition needs more investigation and application on a wider range of aggregates with different compositions.

The effect of increasing the storing temperature in Phase II on promoting expansion will be investigated in the following subsection.

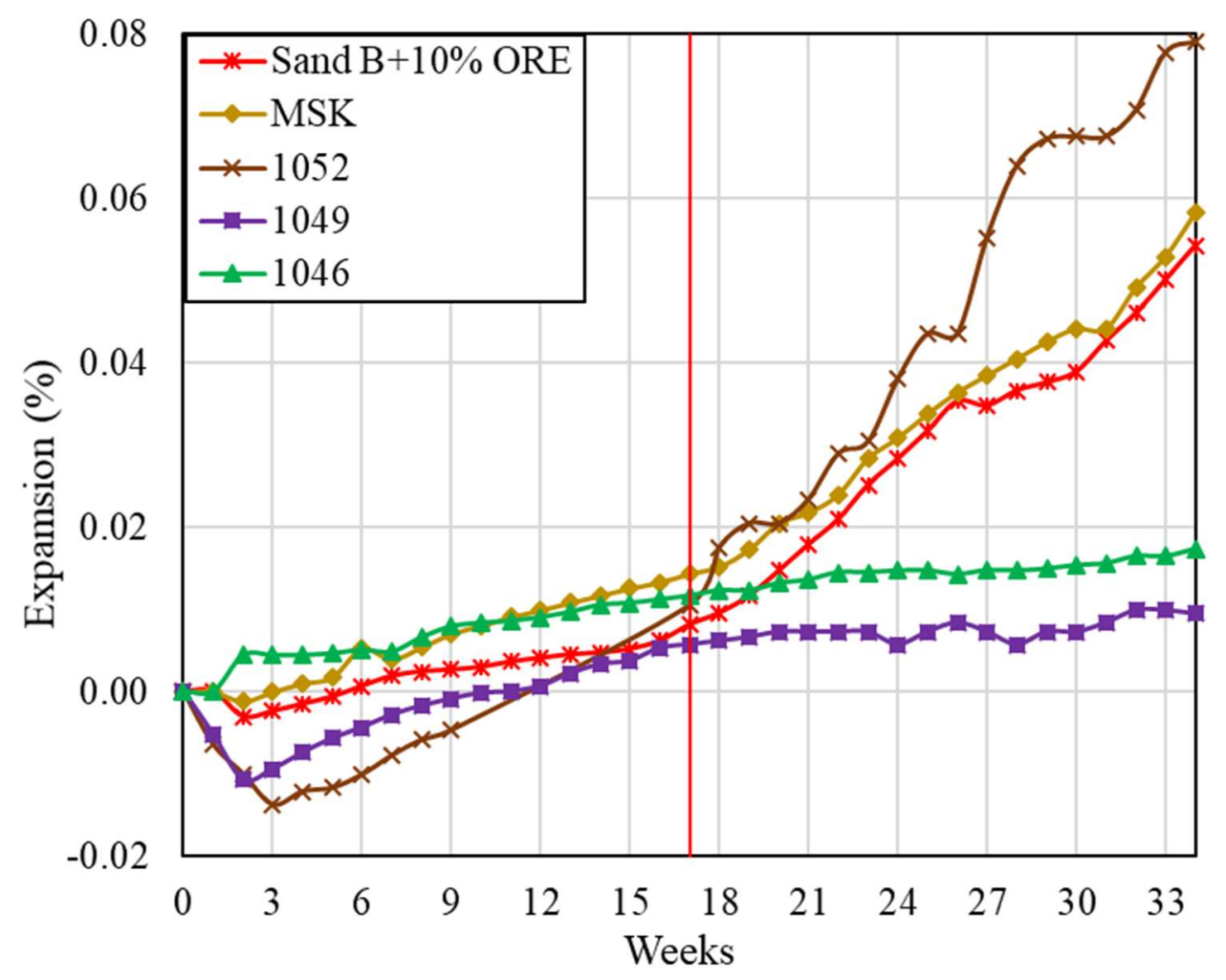

Figure 6.1. Expansion of mortar bars stored at room temperature $\left(21-23^{\circ} \mathrm{C} / 80 \% \mathrm{RH}\right)$ for 13 weeks in Phase I 


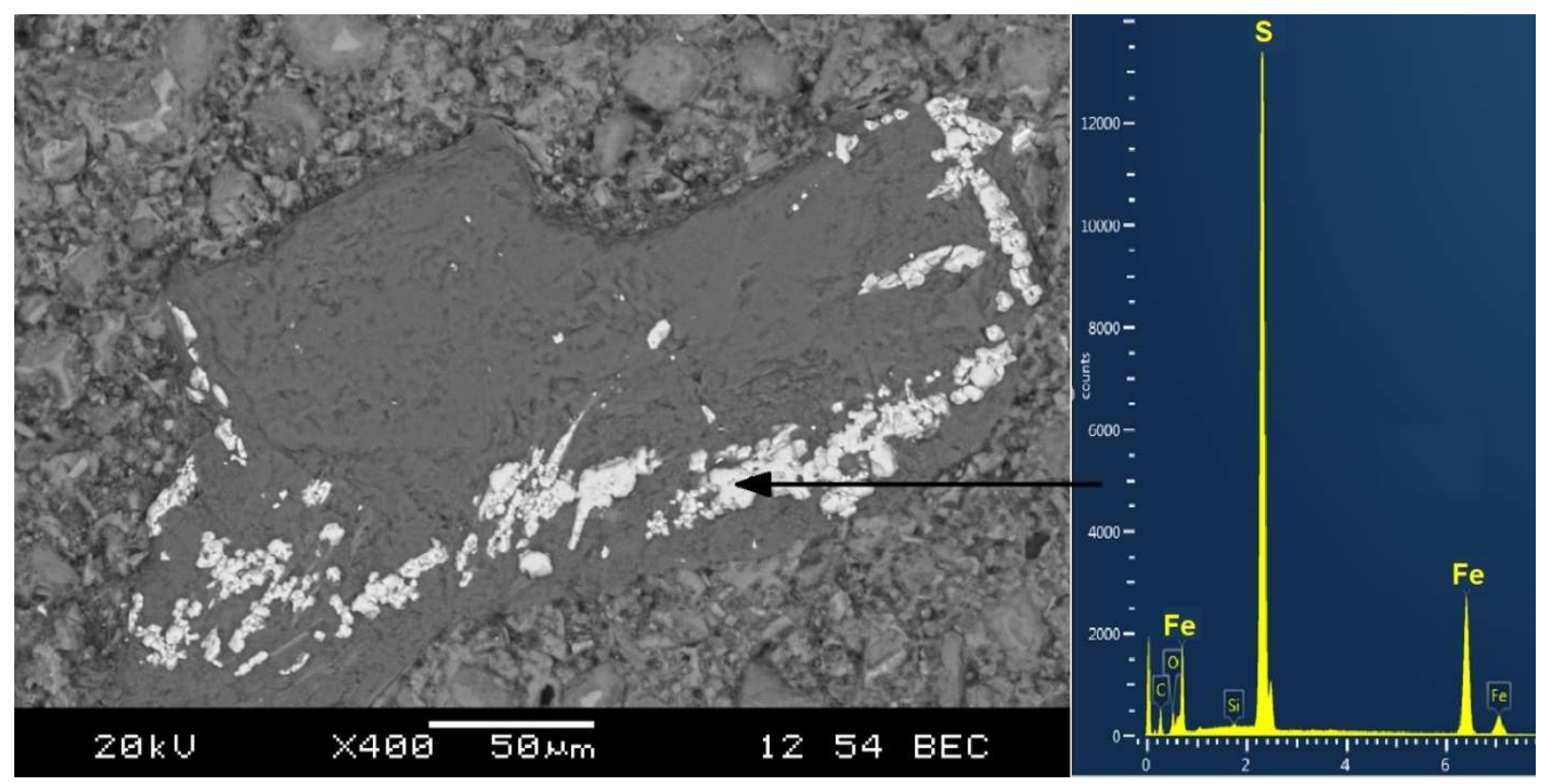

Figure 6.2. SEM-EDS analysis of mortar bar with 1052 soaked in bleach in Phase I

\subsubsection{Effect of higher storage temperature in Phase II $\left(21-23^{\circ} \mathrm{C} / 100 \% \mathrm{RH}\right)$ on the expansion of mortar bars (Exposure B-2 in Table 3.5)}

In this test, the effect of higher storage temperature in Phase II on the sulphate attack was investigated. The testing conditions in Phase I were similar to the exposure conditions that were used by Rodrigues et al. (2016) and Guirguis (2017). Specifically, mortar bars were soaked in bleach for three hours and then stored at $80^{\circ} \mathrm{C} / 80 \% \mathrm{RH}$ for 3.5 days. During Phase II, the mortar bars were stored at room temperature $\left(21-23^{\circ} \mathrm{C} / 80 \% \mathrm{RH}\right)$ for 3.5 days after three hours of soaking, instead of storing them in the fridge at $5^{\circ} \mathrm{C} / 80 \% \mathrm{RH}$.

Figure 6.3 demonstrates the rate and level of expansion for Phase I and Phase II, while Figure 6.4 shows a comparison between the expansion of these mortar bars and mortar bars stored at $5^{\circ} \mathrm{C} / 100 \% \mathrm{RH}$. As shown in the figures, the expansions were similar in Phase I, as the mortar bars have the same exposure. In Phase II, the mortar bars stored at $5^{\circ} \mathrm{C} / 100 \% \mathrm{RH}$ showed greater 
expansion. This behaviour indicates that lower temperatures $\left(5^{\circ} \mathrm{C}\right)$ promote greater expansion and possibly also lead to Thaumasite formation.

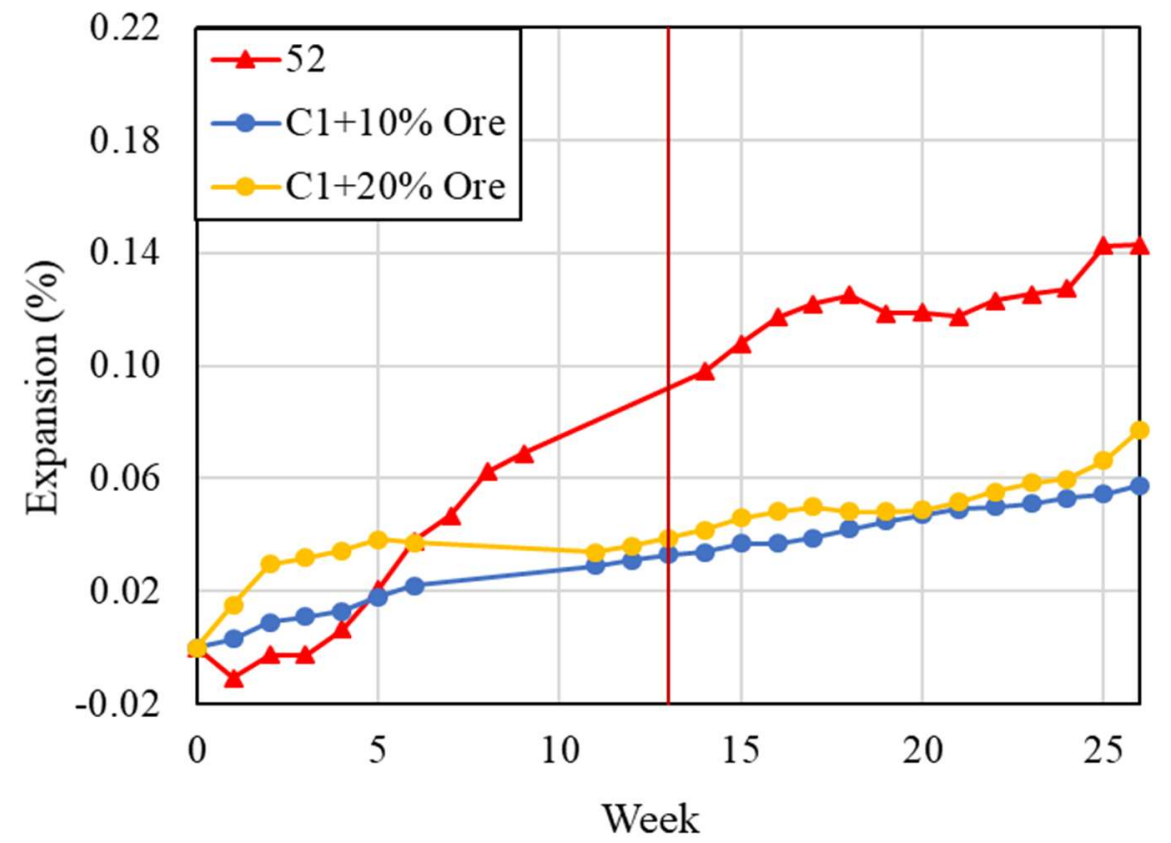

Figure 6.3. Expansion of mortar bars soaked in bleach and stored at $80^{\circ} \mathrm{C} / 80 \% \mathrm{RH}$ in Phase I and room temperature $\left(21-23^{\circ} \mathrm{C} / 100 \% \mathrm{RH}\right)$ in Phase II

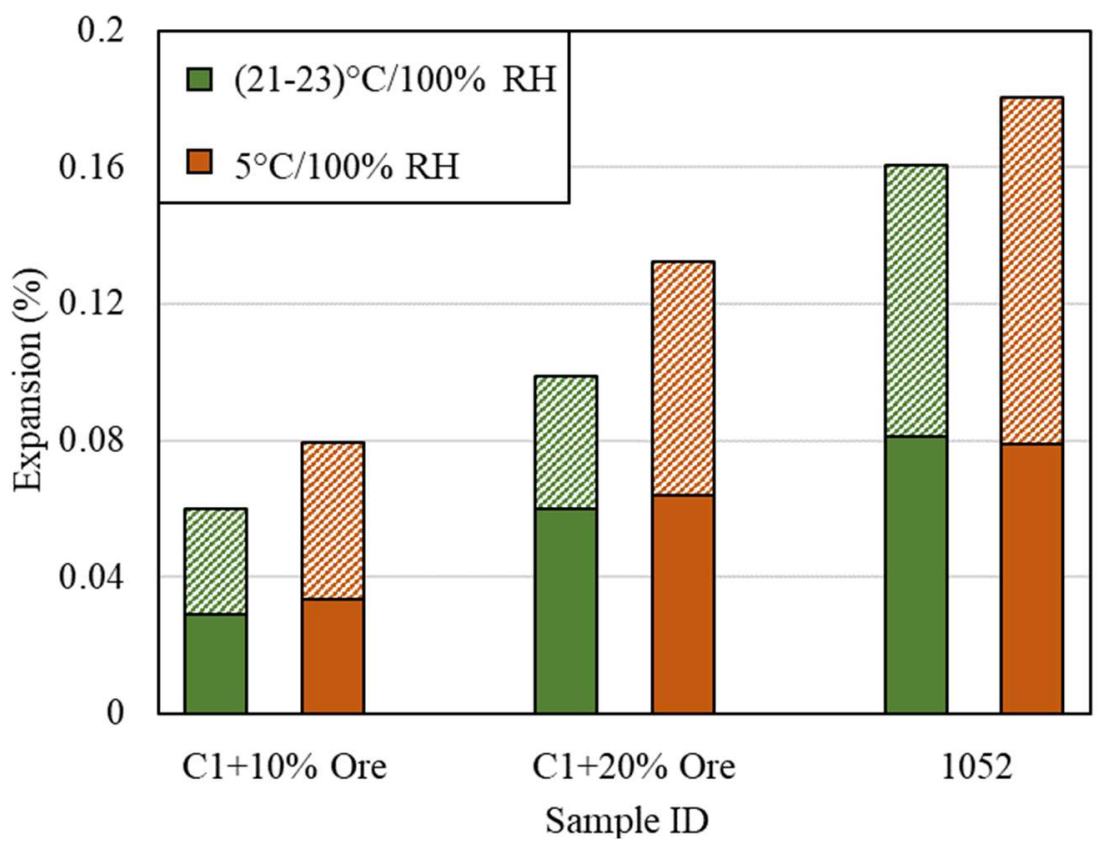

Figure 6.4. Comparison between the expansions of samples soaked in bleach and stored at 21$23{ }^{\circ} \mathrm{C} / 100 \% \mathrm{RH}$ and $5^{\circ} \mathrm{C} / 100 \% \mathrm{RH}$ in Phase II; the solid colour represents an expansion in Phase I, while the hatched area represents an expansion in Phase II 


\subsubsection{Using calcium hypochlorite ( $\mathrm{Ca}(\mathrm{ClO}) 2)$ as a soaking solution to promote oxidation (Exposure C-1 in Table 3.5)}

In this test, calcium hypochlorite $(6 \%)$ was used as the oxidizing agent with the same environmental conditions proposed by Rodrigues et al. (2016). Calcium hypochlorite was employed in an attempt to reduce the expansion caused by the effect of alkali-silica products due to a reaction between the sodium hypochlorite (bleach) and the silicates in the aggregates at high temperature, as explained in Chapter 5.

For Phase I, mortar bars were soaked for three hours in calcium hypochlorite and stored in a conventional oven at $80^{\circ} \mathrm{C} / 80 \% \mathrm{RH}$ for 3.5 days. In Phase II, mortar bar samples were soaked for three hours in calcium hypochlorite and stored in a fridge at $5^{\circ} \mathrm{C} / 80 \% \mathrm{RH}$ for 3.5 days. Each phase lasted for 13 weeks.

Figure 6.5 demonstrates the rate and level of the mortar bar expansions, while Figure 6.6 shows a comparison between the expansions from soaking in calcium hypochlorite and soaking in sodium hypochlorite or bleach. As the figures illustrate, the expansion behaviour of the carbonate aggregate with low total sulphur content $(\mathrm{C} 1)$ is similar to its behaviour in bleach, where the total expansion is $<0.05 \%$.

For aggregates with high silicate content and low total sulphur content (1046 and 1049), the expansion of the mortar bars that were soaked in calcium hypochlorite was less than the expansion of mortar bars with the same aggregates when soaked in bleach. This behaviour indicates that calcium hypochlorite is effective in reducing the creation of ASR products.

Moreover, mortar bars with MSK $\left(\mathrm{S}_{\mathrm{t}}=0.73-1.28 \%\right)$ and sand $\mathrm{B}+10 \%$ Ore $(\mathrm{St}=1.4 \%)$ had similar expansions after 26 weeks $(0.98 \%$ and $0.102 \%$, respectively). Also, while the expansion of MSK was similar to the expansions of 1046 and 1049 (aggregates with high silicates and limited total 
sulphur) in Phase I, the rate of expansion of these mortar bars decreased in Phase II but continued at a high rate in the case of MSK. This performance may indicate an expansion caused by the production of oxidation phases of iron sulphides (ettringite and thaumasite).

However, the difference in expansions between aggregates with minimal total sulphur content (1046 and 1049) and aggregates with high total sulphur content maybe not enough to establish a limitation criterion based on the limited tested aggregates. Moreover, a microstructural examination of mortar bars with aggregate 1049 soaked in calcium hypochlorite (Figure 6.7) and the differential thermal analysis (DTA) (Figure 6.8) shows the presence of Friedel's salt, which may be affecting the expansion. The endothermal peak at $590^{\circ} \mathrm{C}$ may be attributed to the thermal decomposition of calcium hydroxide phase at $570 \mathrm{C}$ (Morsy et al. (2012))

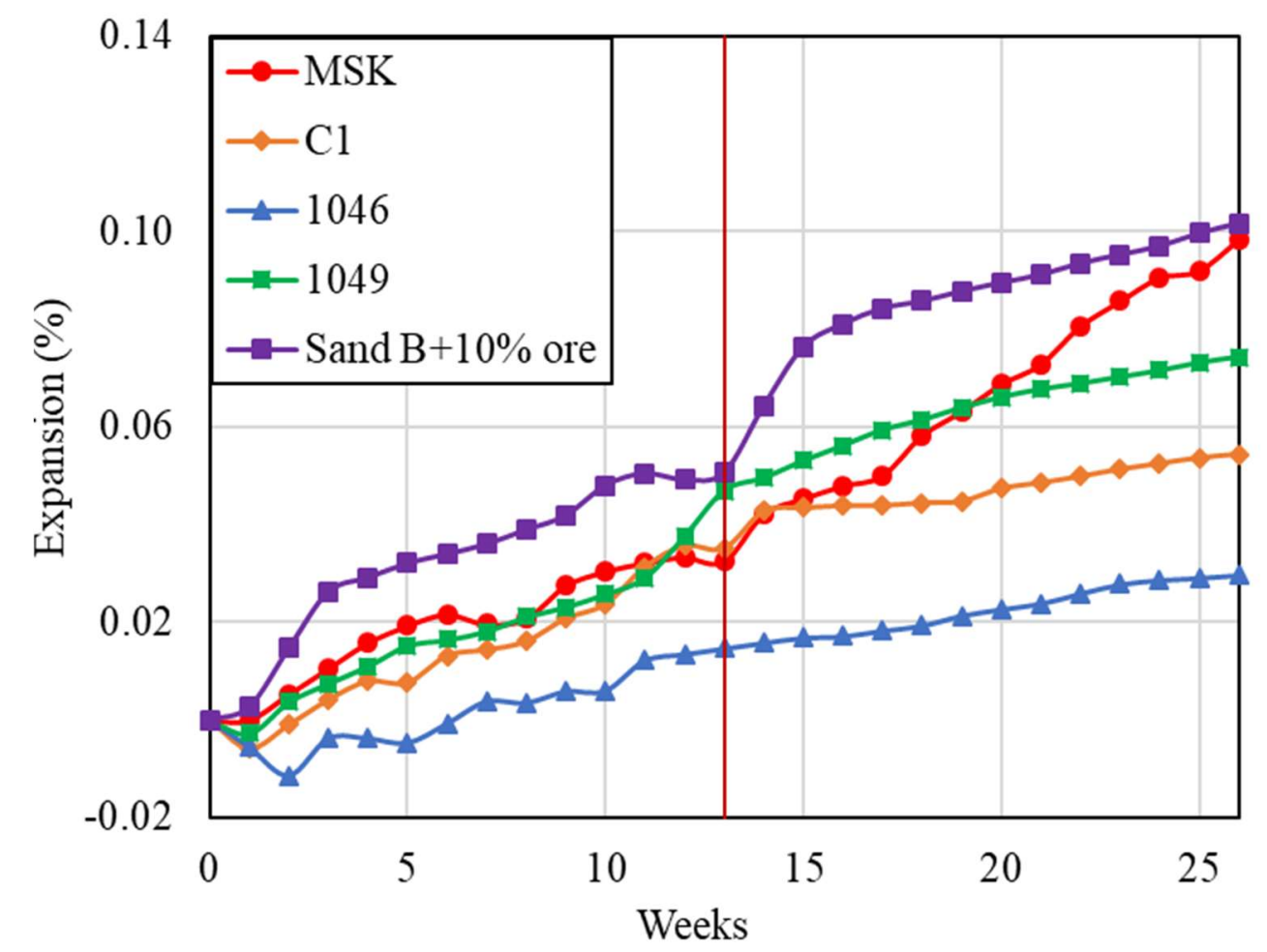

Figure 6.5. Expansion of mortar bars soaked in calcium hypochlorite and stored at $80^{\circ} \mathrm{C} / 80 \% \mathrm{RH}$ and $5^{\circ} \mathrm{C} / 100 \% \mathrm{RH}$ in Phase I and Phase II respectively 


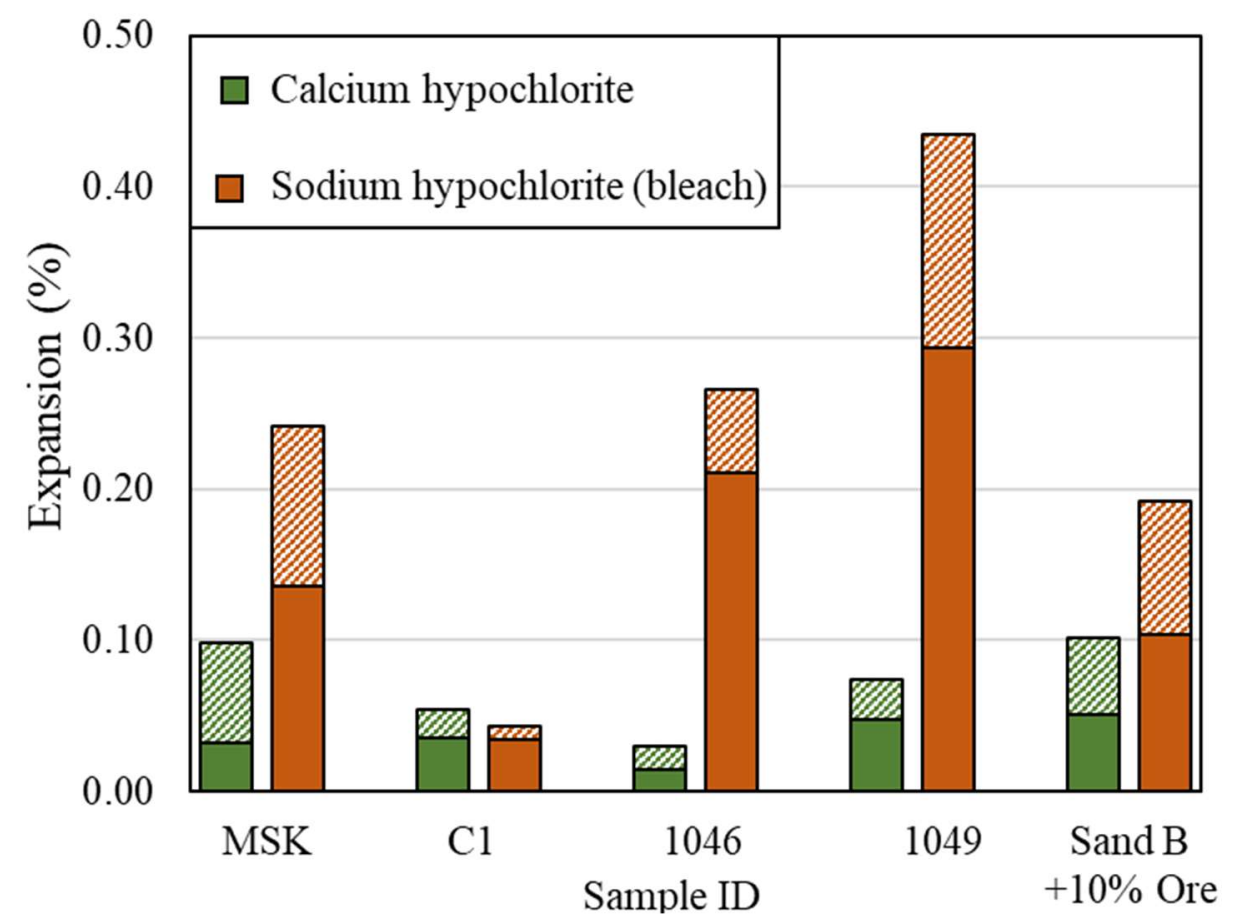

Figure 6.6. Comparison between the expansions of mortar bars soaked in calcium hypochlorite and those soaked in sodium hypochlorite and stored at $80^{\circ} \mathrm{C} / 80 \% \mathrm{RH}$ and $5^{\circ} \mathrm{C} / 100 \% \mathrm{RH}$ in Phase I and Phase II respectively. The solid colour representing expansions in Phase I and the hatched area representing expansions in Phase II
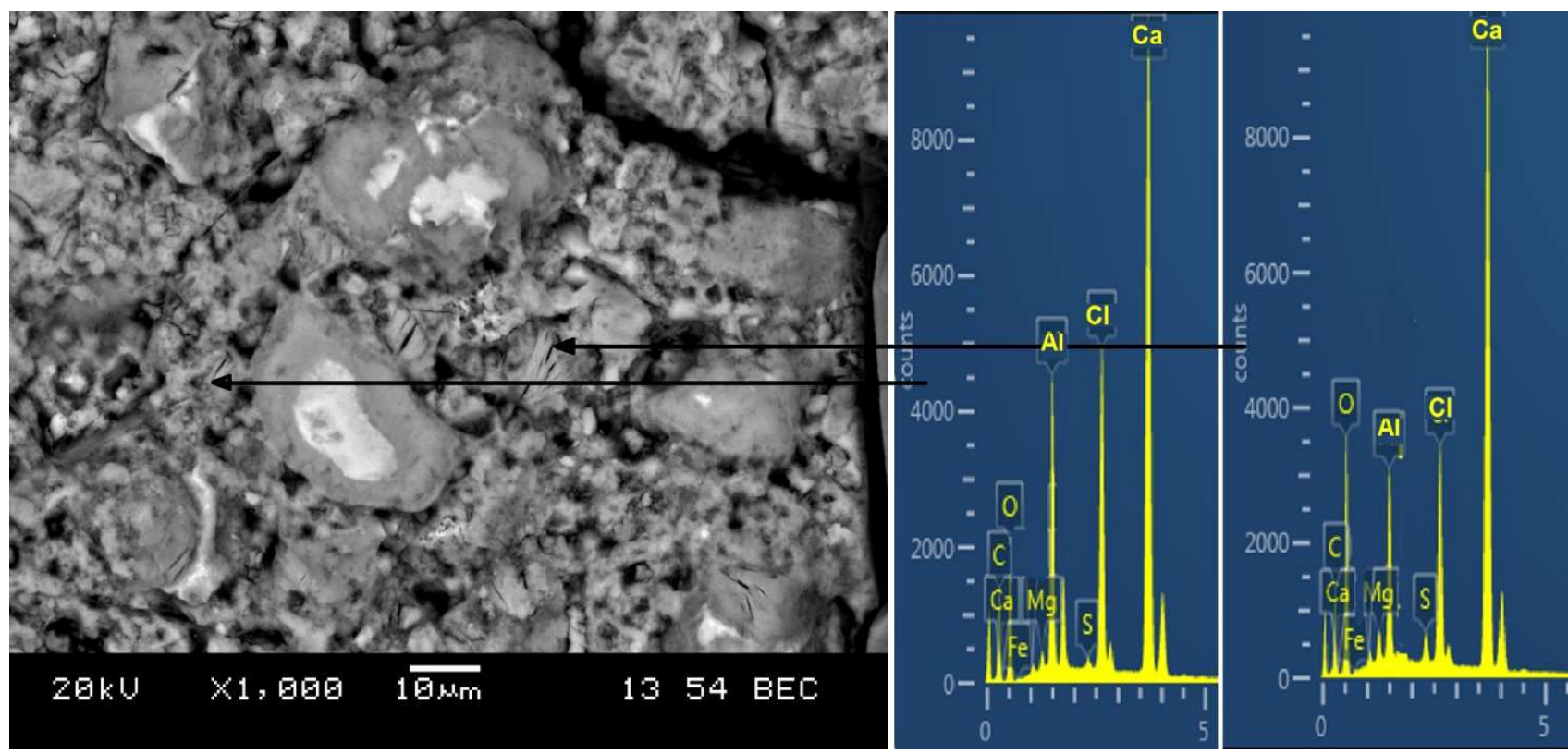

Figure 6.7. SEM-EDS analysis for mortar bar with aggregate 1049 and high silicate content soaked for three hours in calcium hypochlorite showing the presence of Friedel's salt 


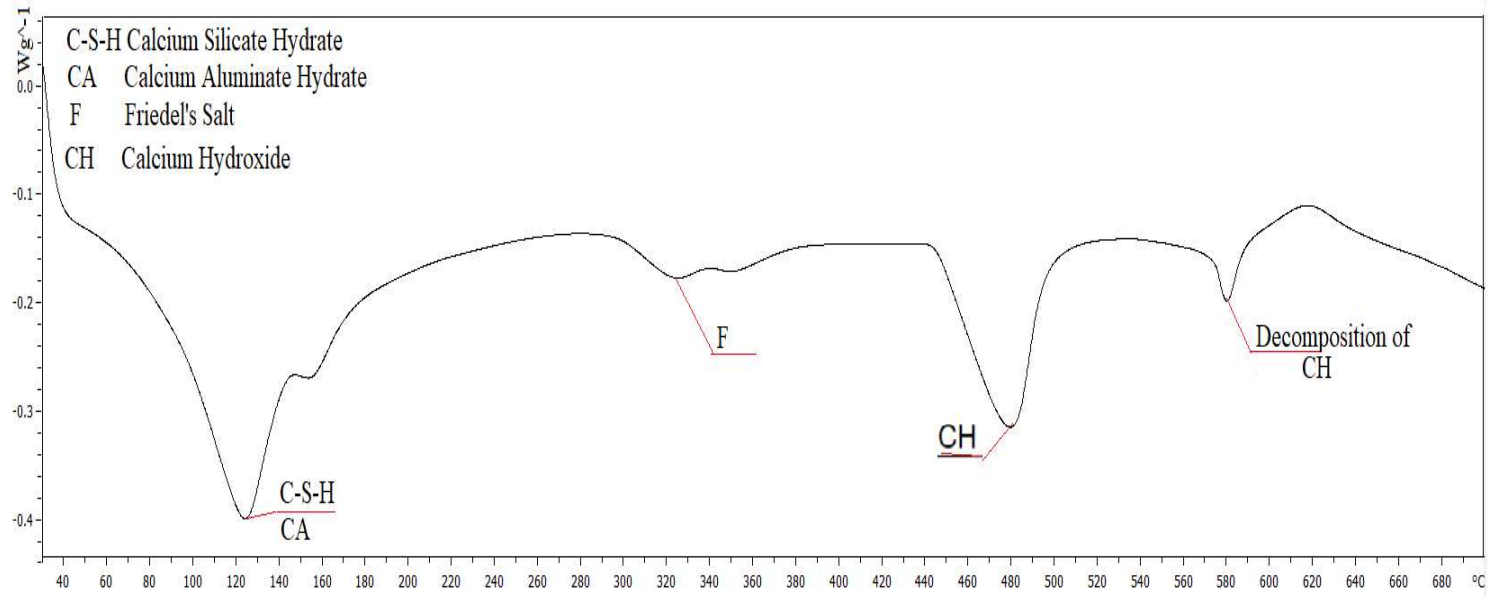

Figure 6.8. DTA analysis for mortar bar with high silicate content 1049 soaked in calcium hypochlorite

In the following subsections, a saturated lime solution will be used as a soaking solution to investigate its ability to promote the oxidation of iron sulphides in mortar bars with sulphidebearing aggregates and the subsequent internal sulphate attack. 


\subsubsection{Using the saturated lime soaking solution to promote oxidation}

As explained in Chapter 5 and earlier in this chapter, the use of sodium and calcium hypochlorite solution as oxidizing agents to promote oxidation of sulphide-bearing aggregates resulted in the production of other products rather than the oxidation products that affected the expansion of the tested mortar bars. Hence, in this section, a saturated lime solution (lime water) will be used as the oxidizing agent in an attempt to promote expansion caused by aggregate oxidation only.

In order to investigate the ability of the saturated lime solution to promote the oxidation of sulphide-bearing aggregates without the promotion of other reactions in aggregates with no or limited total sulphur contents, mortar bars will be tested under various environmental conditions and soaking durations. Specifically, mortar bars were tested with control carbonate (C1) and silicate (1046 and 1049) aggregates as well as aggregates with high total sulphur content (MSK and 1052).

In this test, two soaking durations were investigated. In the first one (Exposer L-1 to L-5), the samples were soaked for three hours in lime water, followed by 3.5 days in storage at different temperatures and relative humidity. This is covered under subsection 6.1.3.1. The second exposure involves a soaking period of two days followed by five-day storage at different temperatures and relative humidity. This is covered under subsection 6.1.3.2.

\subsubsection{Soaking mortar bars for three hours}

\section{a. Samples stored at $80^{\circ} \mathrm{C} / 80 \% \mathrm{RH}$ and $5^{\circ} \mathrm{C} / 100 \% \mathrm{RH}$ in Phase I and Phase II, respectively (Exposure L-1 in Table 3.5)}

The oxidation mortar bar test was applied with the same environmental conditions developed by Rodrigues et al. (2016). However, instead of soaking them in sodium hypochlorite (bleach), the bars were soaked in lime water for three hours. Figure 6.9 demonstrates the rate and level of 
expansion. The rate of expansion of mortar bars with $1046(\mathrm{St}=0.027 \%)$ decreased in Phase II but continued to expand in MSK ( $\mathrm{St}=0.73-1.28)$.

Moreover, as shown in Figure 6.10, a comparison of the expansions of mortar bars with MSK soaked in sodium hypochlorite and in lime water shows that the expansion was less in Phase II and greater in Phase II for samples soaked in lime water. In the case of mortar bars with 1052, the expansion was less when the samples were soaked in lime water for both phases. This behaviour indicates that soaking the mortar bars in lime water reduces the effect of expansion due to the production of alkali-silica products, especially in Phase I.

In the case of mortar bars containing aggregate 1046 with low total sulphur and high silicate content, there was less expansion when the mortar bars were soaked in lime water in both Phases I and II. Although the expansion of mortar bars with 1046 decreased with lime water, the expansion in Phase I was still relatively high. This behaviour led to investigating the effect of reducing the storage temperature and humidity, as will be presented in the following subsection.

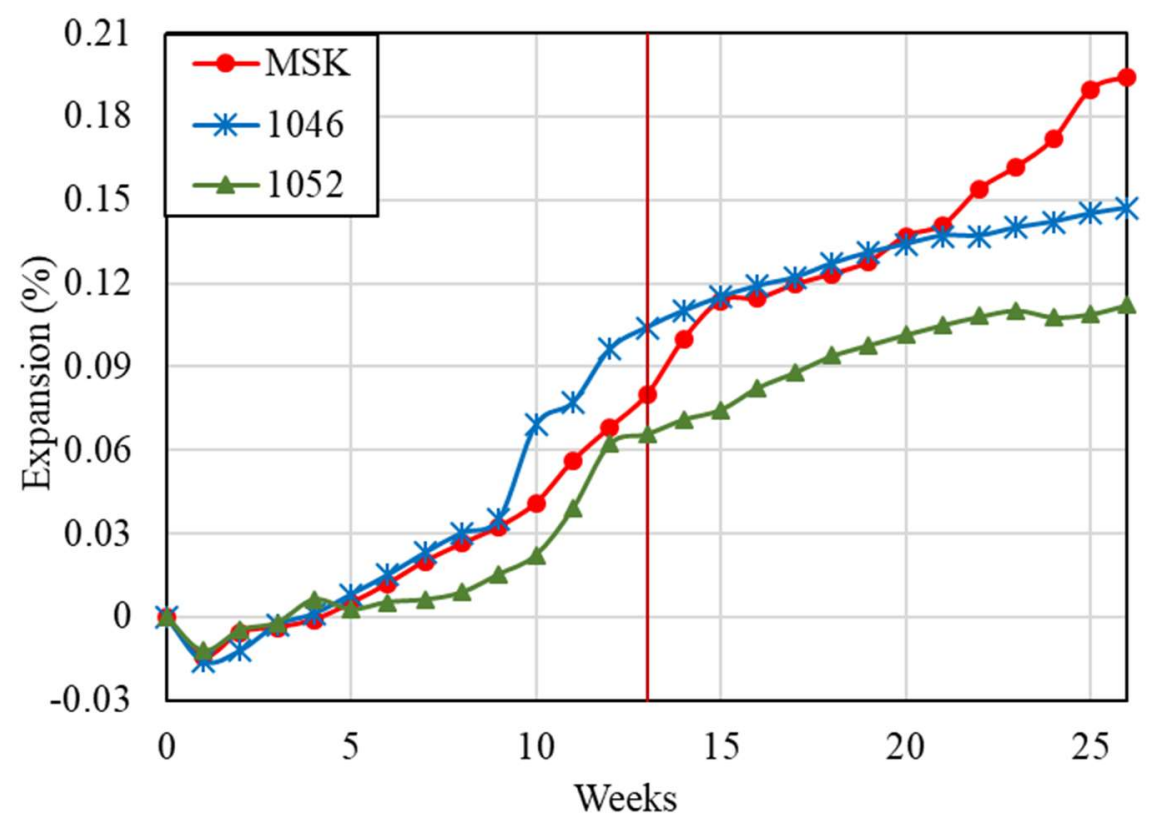

Figure 6.9. Expansion of mortar bars with MSK and 1046 soaked for three hours in lime water at $80^{\circ} \mathrm{C} / 80 \% \mathrm{RH}$ and $5^{\circ} \mathrm{C} / 100 \% \mathrm{RH}$ in Phase I and Phase II, respectively 


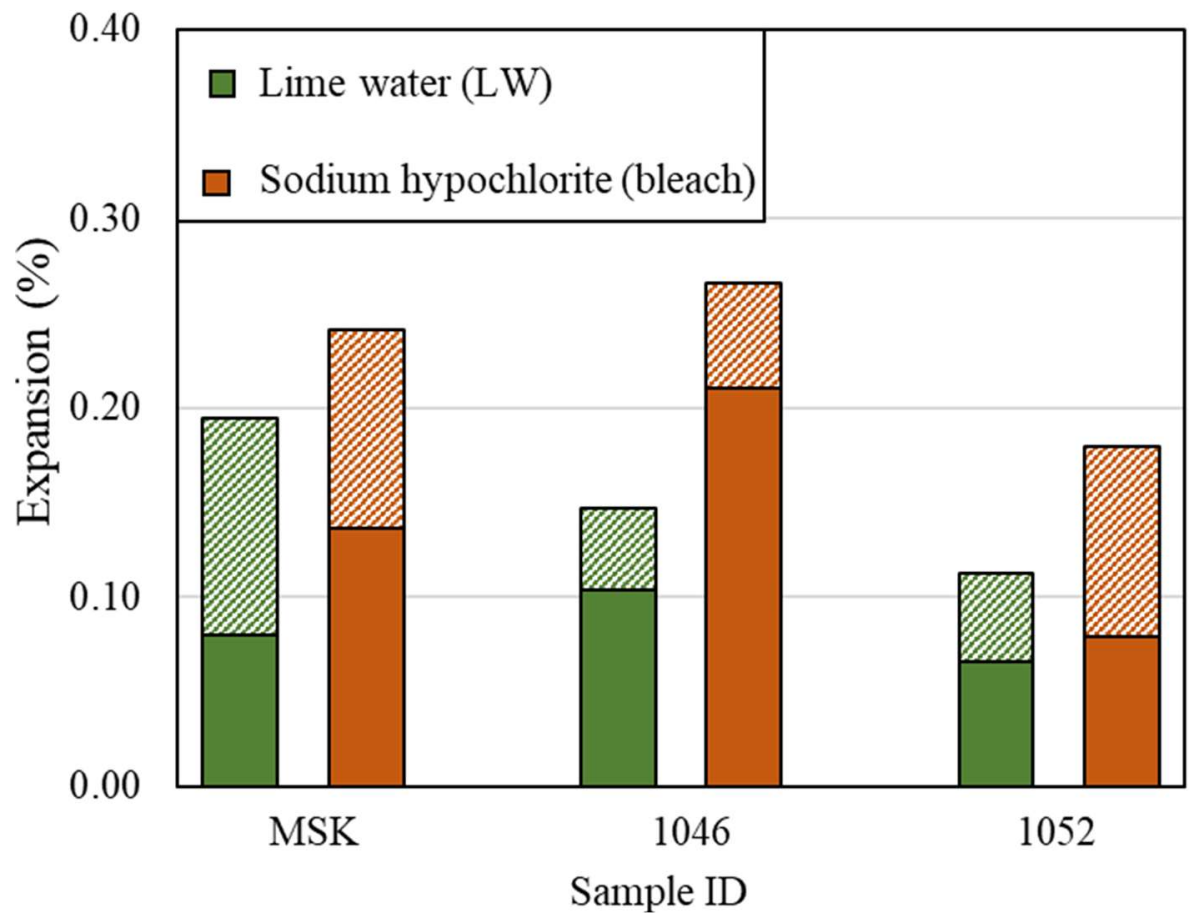

Figure 6.10.Comparison between the expansion of mortar bars soaked in lime-water and mortar bars soaked in bleach both stored at $80^{\circ} \mathrm{C} / 80 \% \mathrm{RH}$ in Phase I and $5^{\circ} \mathrm{C} / 100 \% \mathrm{RH}$ in Phase II.

The solid colour represents the expansion in Phase I while the hatched area represents the expansion in Phase II

\section{b. Samples stored at $40^{\circ} \mathrm{C} / 70 \% \mathrm{RH}$ and $5^{\circ} \mathrm{C} / 100 \% \mathrm{RH}$ in Phase I and Phase II, respectively (Exposure L-3 in Table 3.5)}

In order to reduce the effect of high storage temperature on inducing expansion due to the reaction of the dissolution of silica, mortar bars in Phase I were soaked for three hours in lime water and then stored at $40^{\circ} \mathrm{C} / 70 \% \mathrm{RH}$ for 3.5 days, over a period of 13 weeks. In Phase II, the samples were stored at $5^{\circ} \mathrm{C} / 100 \% \mathrm{RH}$ for 3.5 days after three hours of soaking for another period of 13 weeks.

Figure 6.11 shows a demonstration of the rate and level of the expansion of samples with different total sulphur content after 26 weeks. Mortar bars with aggregates with high total sulphur content (i.e. MSK, $\mathrm{C} 1+20 \%$ Ore and $\mathrm{C} 1+10 \%$ Ore) had expansions higher compared to mortar bars with control aggregates (carbonate or silicate) such as C1, 1046 and 1049. 


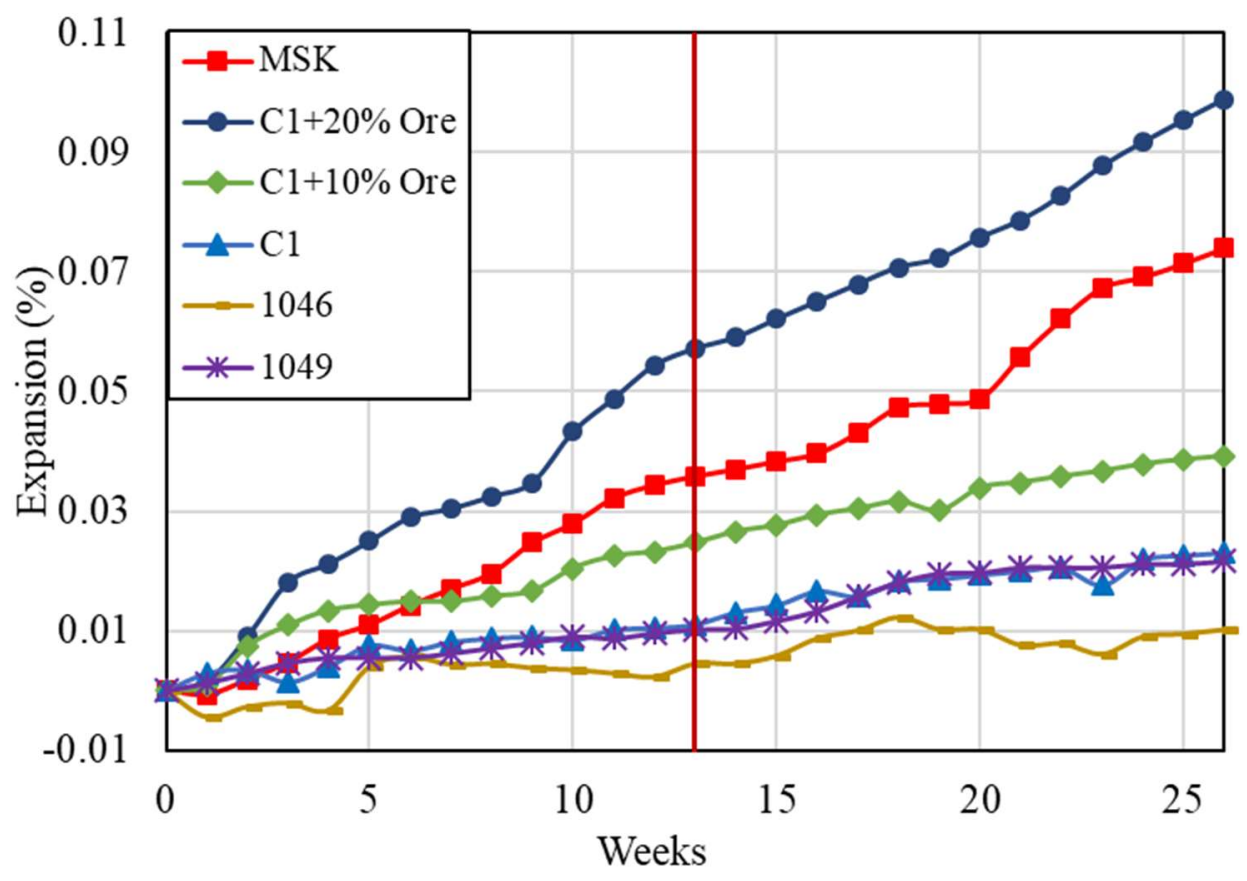

Figure 6.11. Expansion of mortar bars soaked in lime water for three hours and stored at $40^{\circ} \mathrm{C} / 70 \% \mathrm{RH}$ and $5^{\circ} \mathrm{C} / 100 \% \mathrm{RH}$ in Phase I and Phase II, respectively.

Figure 6.12 shows a comparison between the expansion of the mortar bar samples soaked in lime water and stored at $40^{\circ} \mathrm{C} / 70 \% \mathrm{RH}$ and the mortar bar samples soaked in bleach and stored at $80^{\circ} \mathrm{C} / 80 \% \mathrm{RH}$. As the figure illustrates, the expansions of the aggregates with high sulphide contents - MSK $(\mathrm{St}=0.7-1.28 \%), \mathrm{C} 1+10 \%$ Ore $(\mathrm{St} \approx 1.4 \%)$ and $\mathrm{C} 1+20 \%$ Ore $\left(\mathrm{S}_{\mathrm{t}} \approx 2.8 \%\right)-$ are less than the expansions when the samples were soaked in bleach. As well, this exposure condition - soaking in lime water - produced expansions in the control aggregates $(\mathrm{C} 1,1046$ and 1049) that are considerably less than those of mortar bars soaked in bleach.

Furthermore, when comparing the expansions of MSK and 1049 in Figure 6.9 of mortar bars stored at $80^{\circ} \mathrm{C} / 80 \% \mathrm{RH}$ and Figure 6.11 of mortar bars stored at $40^{\circ} \mathrm{C} / 70 \% \mathrm{RH}$ in Phase I, reducing the storage temperature to $40^{\circ} \mathrm{C}$ instead of $80^{\circ} \mathrm{C}$ resulted in reducing the expansion of aggregates with silicates that contained low total sulphur content (1046). At the same time, it 
maintained the ratio between the expansion of Phase I and Phase II in the case of aggregates with high total sulphur content (MSK).

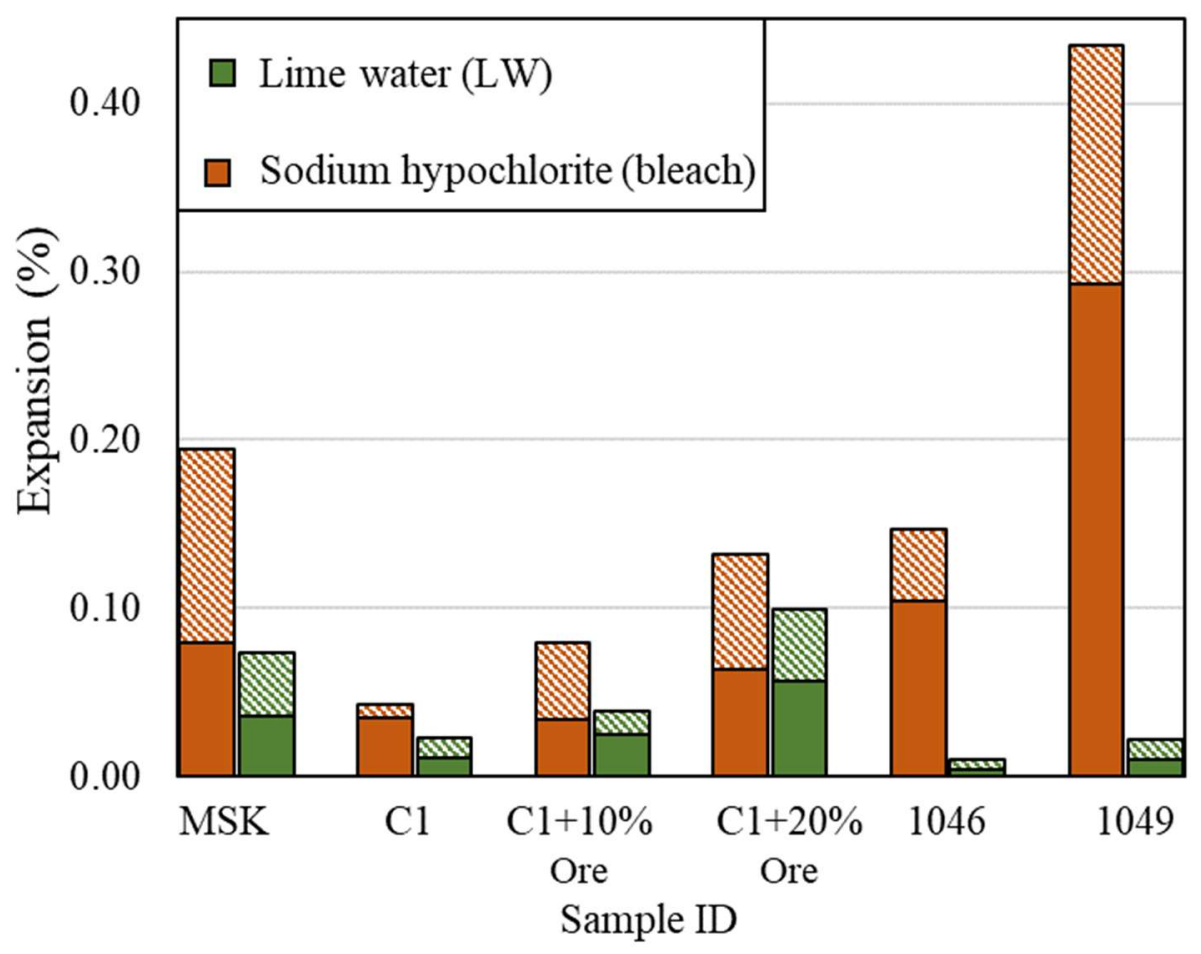

Figure 6.12. Comparison between expansions of mortar bars soaked in lime water and stored at $40^{\circ} \mathrm{C} / 70 \% \mathrm{RH}$ in Phase I and mortar bars soaked in bleach and stored at $80^{\circ} \mathrm{C} / 80 \% \mathrm{RH}$ in

Phase I, with the solid colour representing expansions in Phase I and the hatched area representing expansions in Phase II

\section{c. Samples stored at $40^{\circ} \mathrm{C} / 70 \% \mathrm{RH}$ in Phase $\mathrm{I}$ and $5^{\circ} \mathrm{C} / 100 \% \mathrm{RH}$ or $23^{\circ} \mathrm{C} / 100 \%$ or $4^{\circ} \mathrm{C} / 70 \%$ in Phase II (Exposure L-3, L-4 and L-5 in Table 3.5)}

In order to investigate the optimum storage temperature in Phase II that promotes the most critical type of sulphate attack, mortar bars incorporating control and sulphide-bearing aggregates were tested. The mortar bars had the same exposure condition in Phase I, while in Phase II the mortar bars were stored at $5^{\circ} \mathrm{C} / 100 \% \mathrm{RH}$ or $23^{\circ} \mathrm{C} / 100 \% \mathrm{RH}$ or $40^{\circ} \mathrm{C} / 70 \% \mathrm{RH}$.

Figure 6.13 and Figure 6.14 show expansions of mortar bars incorporating the sulphide-bearing aggregates Ore and MSK, respectively. The mortar bars were soaked in lime water and stored in 
the same environmental condition as in Phase $\mathrm{I}\left(40^{\circ} \mathrm{C} / 70 \%\right)$. In the case of mortar bars with Ore, a higher storage temperature in Phase II $\left(23^{\circ} \mathrm{C} / 100 \%\right.$ or $\left.40^{\circ} \mathrm{C} / 70 \%\right)$ promoted greater expansion compared to storing the mortar bars at $5^{\circ} \mathrm{C} / 100 \%$. For MSK, the highest expansion was recorded in mortar bars stored at $5^{\circ} \mathrm{C} / 100 \%$.

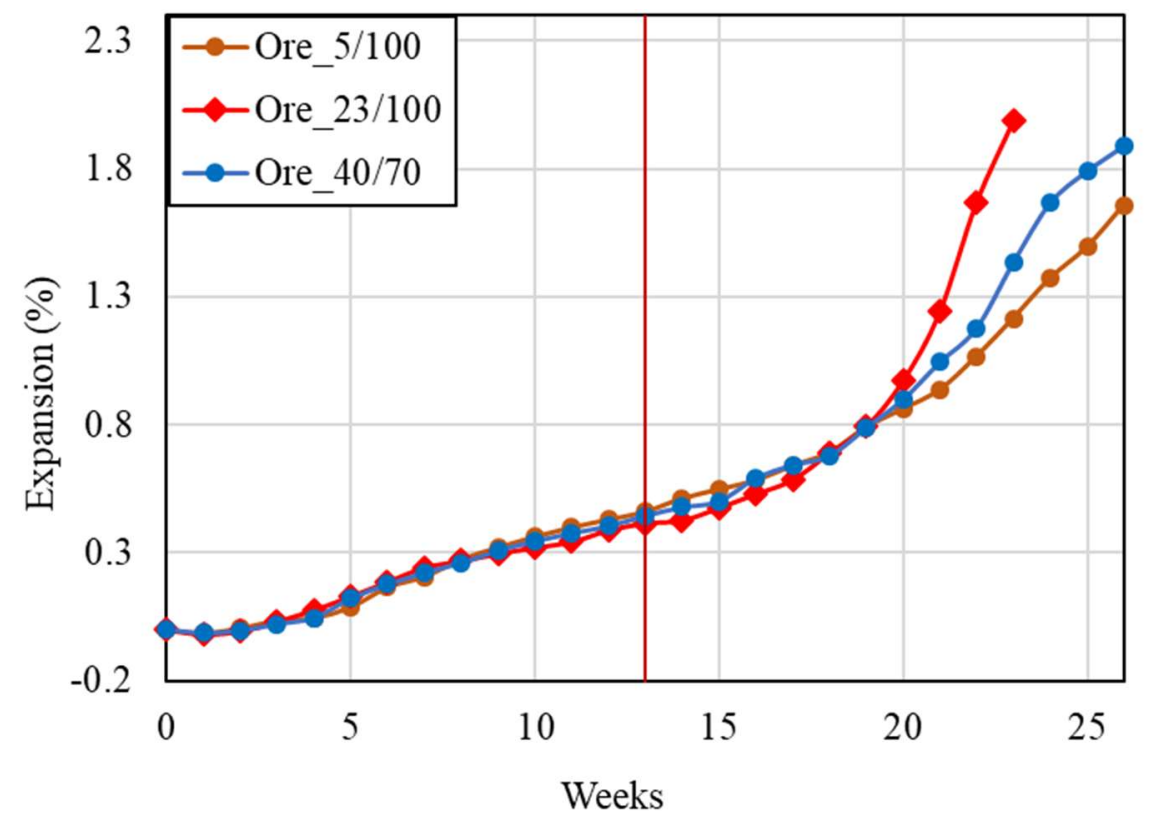

Figure 6.13. Expansion of mortar bars with 100\% Ore stored at different conditions in Phase II

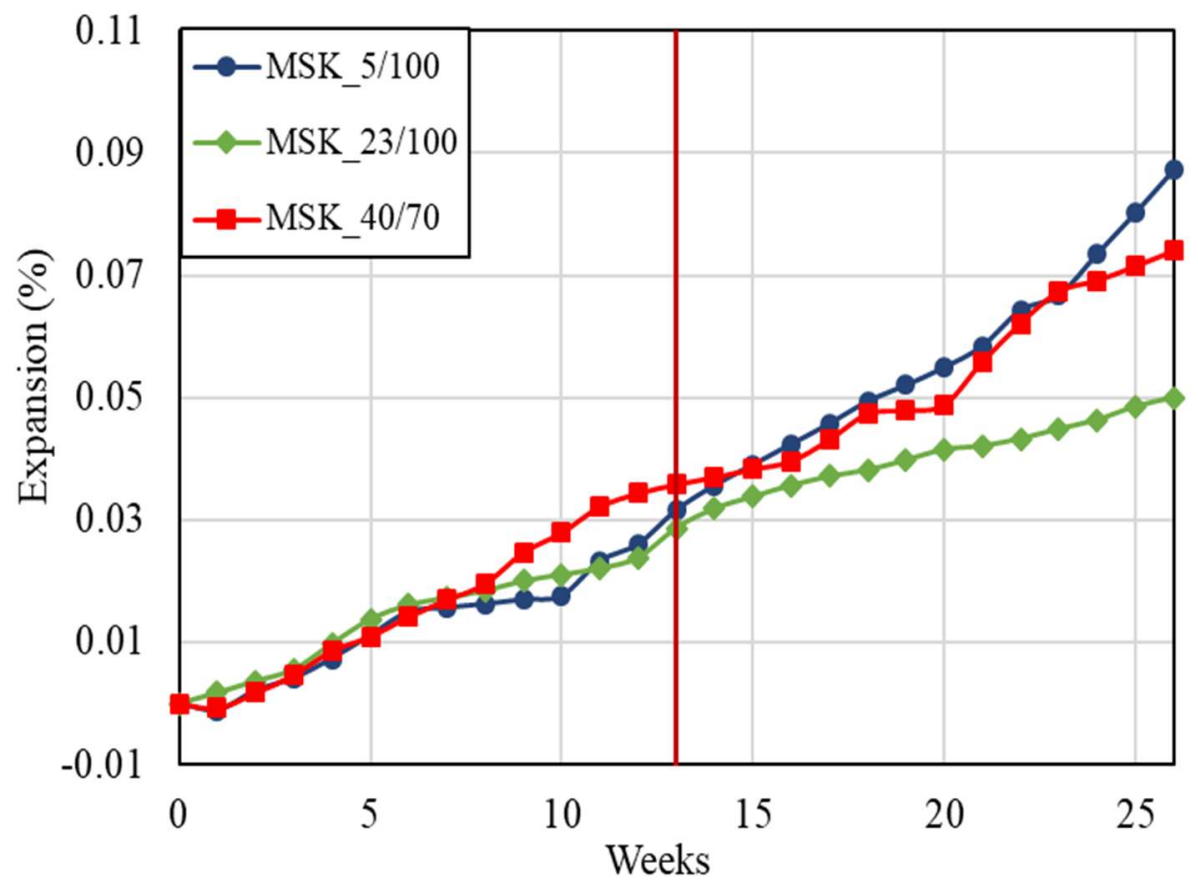

Figure 6.14. Expansion of mortar bars with MSK stored at different conditions in Phase II 
This behaviour indicates that the optimum temperature to promote the most damaging form of sulphate attack may not be the same for all aggregate types. It is well-known that Thaumasite formation favours lower temperatures, but some scholars still report the presence of this substance at higher temperatures, as mentioned earlier in Chapter 2. Ettringite formation may be faster at a higher temperature. Hence, it is recommended to test the aggregates at different storage temperatures in Phase II to determine the maximum expansion.

To investigate the products that caused the expansions in the mortar bars, SEM-EDS analysis was applied to mortar bars with 50\% Ore and MSK (Figure 6.15 and Figure 6.16). Also, mortar bars with MSK were tested in differential thermal analysis (DTA). As shown in the SEM-EDS photos, ettringite was identified in two locations in the shown photo and similar types were identified in other locations in both samples. The presence of silica in some of the peaks suggests that the phase is a mixture of Thaumasite and ettringite or the alumina in the ettringite is substituted by silica as reported by (Glasser, 2002). Moreover, the DTA analysis shown in Figure 6.17 revealed the presence of peaks at $130^{\circ} \mathrm{C}$ and $170-200^{\circ} \mathrm{C}$ that are attributed to ettringite or monosulphoaluminate, as they both have the same peaks (Bhatty, 1991; Guirguis et al., 2018). Formation of Friedel's salt was avoided with the use of lime water, with no peaks being observed between $310^{\circ} \mathrm{C}$ and $385^{\circ}$ as found in cases of testing with bleach (Guirguis et al., 2018). 


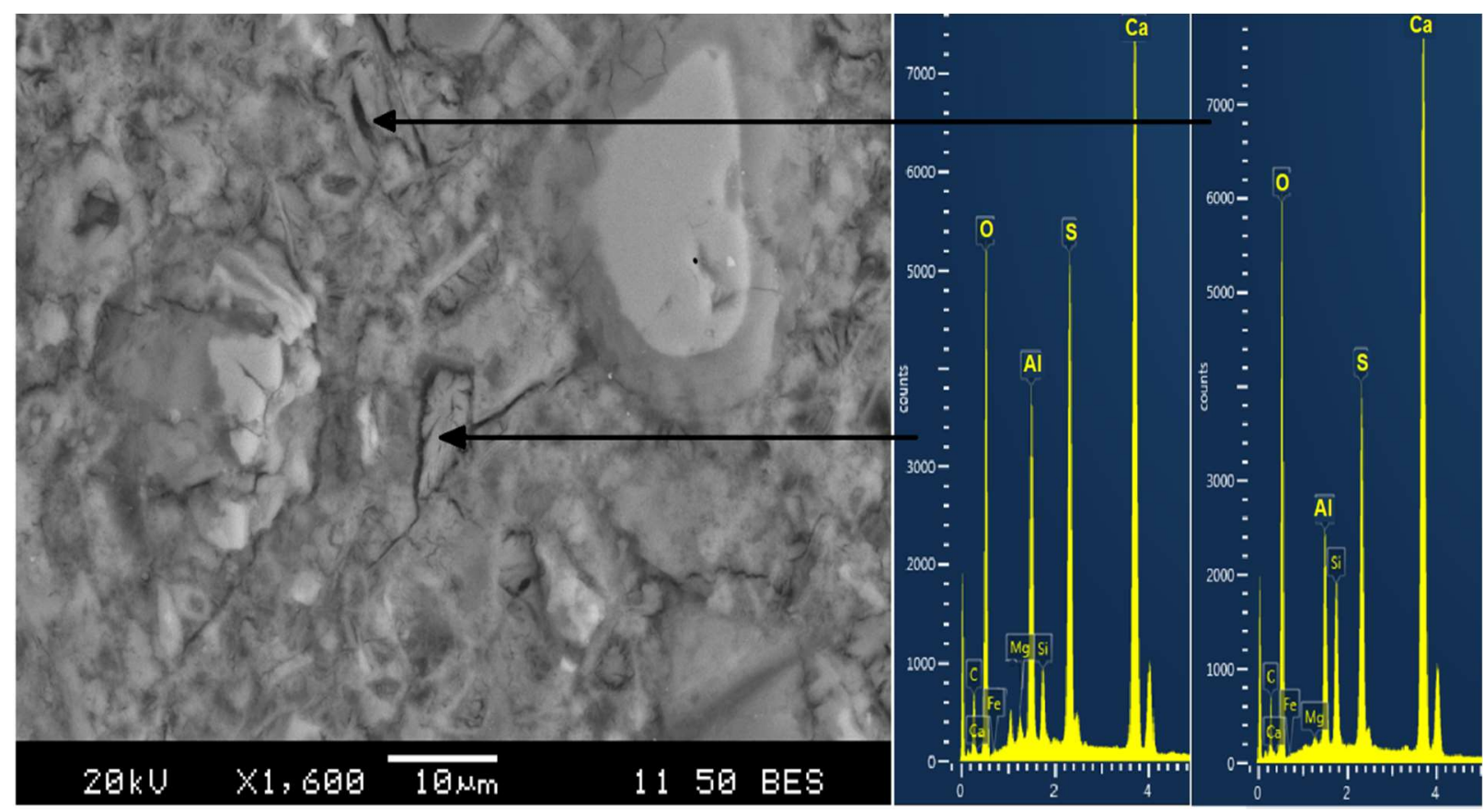

Figure 6. 15. SEM analysis showing the presence of ettringite or ettringite / Thaumasite mixture for mortar bar with 50\% Ore soaked in lime water for three hours and stored at $40^{\circ} \mathrm{C} / 70 \mathrm{RH}$ in Phase I and at $5^{\circ} \mathrm{C} / 100$ in Phase II
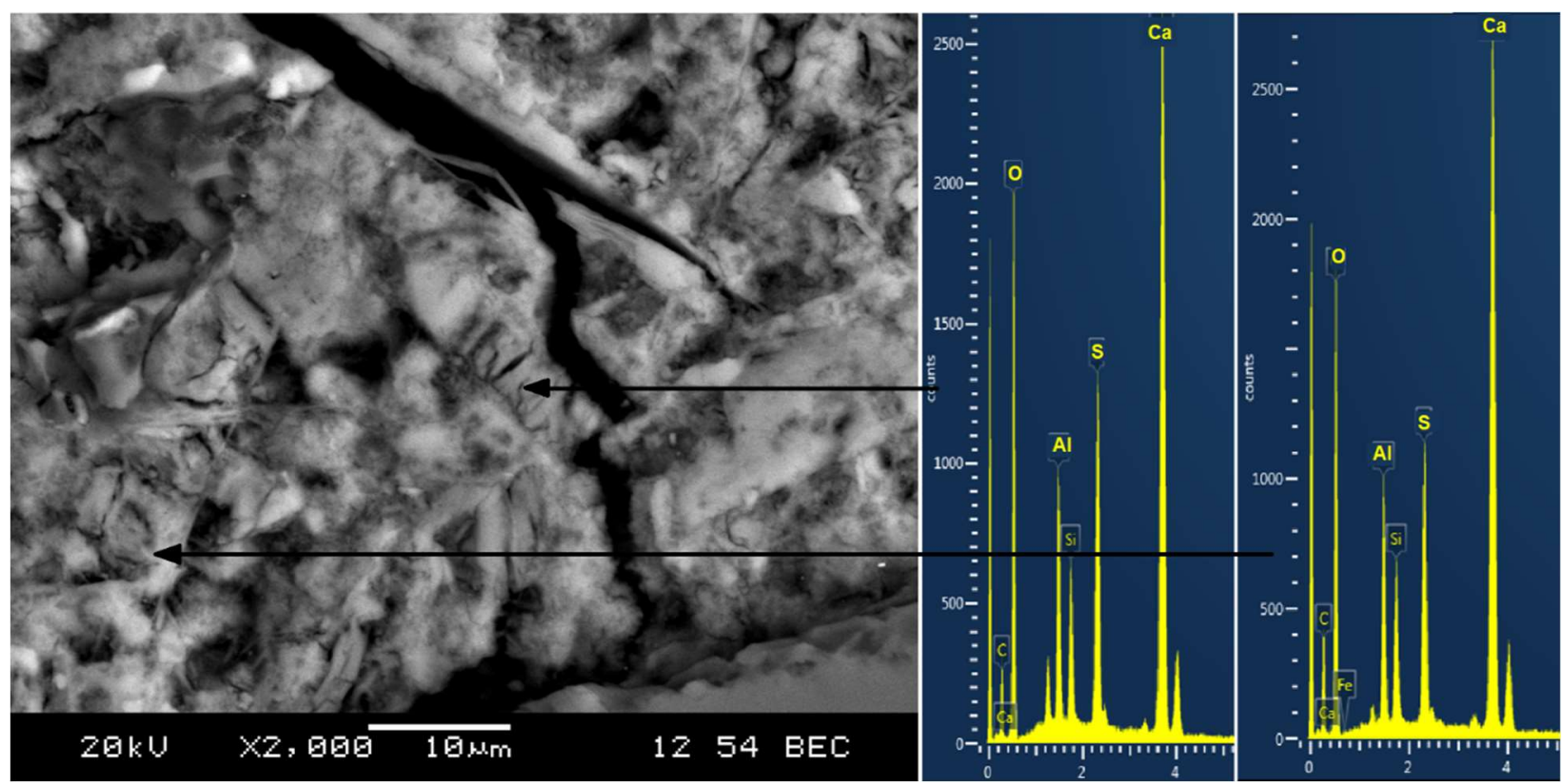

Figure 6.16. SEM analysis showing the presence of ettringite and Thaumasite mixture for mortar bar with MSK soaked in lime water for three hours and stored at $40^{\circ} \mathrm{C} / 70 \mathrm{RH}$ in Phase I and at $5^{\circ} \mathrm{C} / 100$ in Phase II 


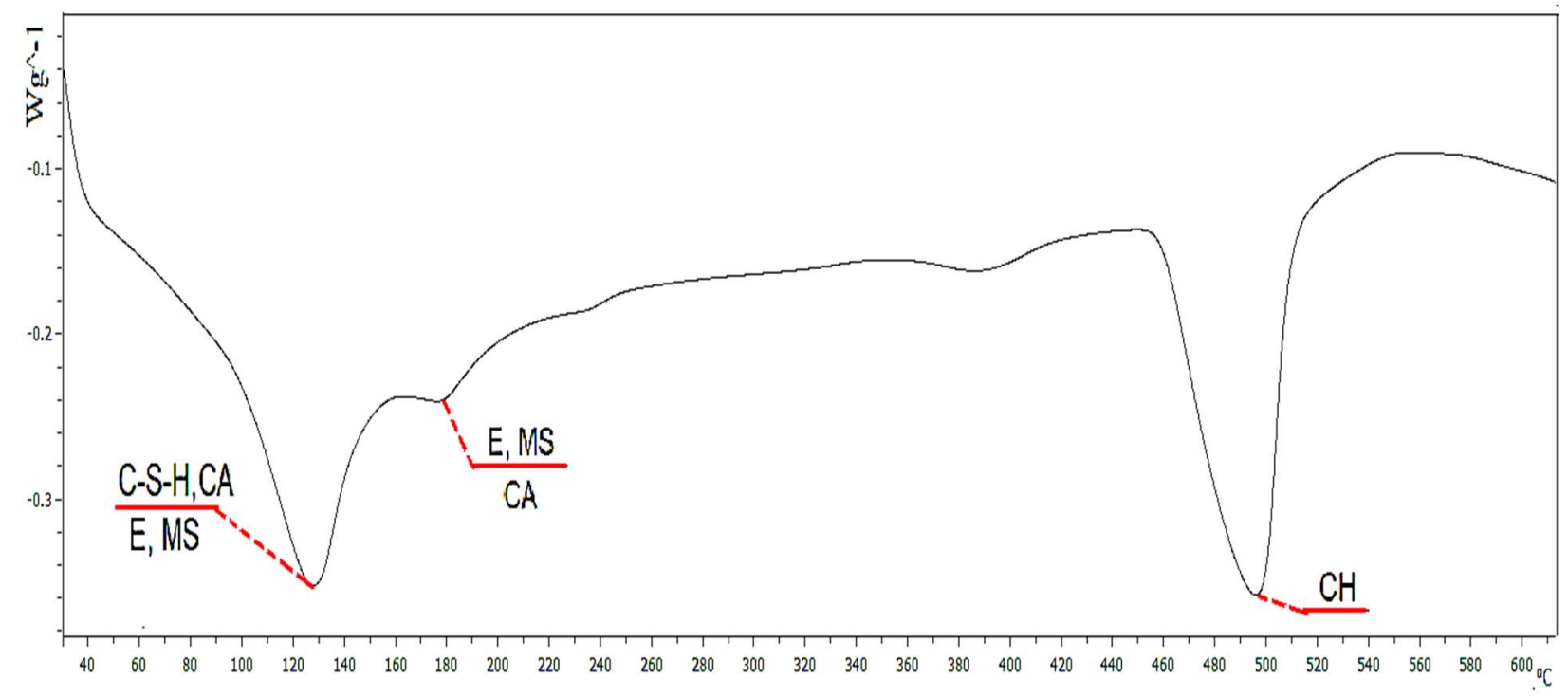

Figure 6.17. DTA for MSK soaked in lime water for three hours and stored at $40^{\circ} \mathrm{C} / 70 \mathrm{RH}$ in Phase I and at $5^{\circ} \mathrm{C} / 100$ in Phase II

\subsubsection{Soaking mortar bars for 48 hours (Exposure L-6, L-7 and L-8 in Table 3.5)}

In the next tests, mortar bars were soaked for 48 hours once per week. During the remaining time, the mortar bars were stored at $40^{\circ} \mathrm{C} / 70 \% \mathrm{RH}$ in Phase I, while different storage conditions were tested in Phase II $\left(5^{\circ} \mathrm{C} / 100 \% \mathrm{RH}, 23^{\circ} \mathrm{C} / 100 \% \mathrm{RH}\right.$, and $\left.40^{\circ} \mathrm{C} / 70 \% \mathrm{RH}\right)$. This longer soaking time period was used to examine whether a longer duration has an effect on increasing the damaging expansion due to the penetration of the oxidizing solution.

Figure 6.18 to 6.21 show the expansion of mortar bars incorporating different aggregates with control and sulphide-bearing aggregates. The sulphide-bearing aggregates were tested at various environmental conditions in Phase II. The expansion results confirmed the behaviour that was observed in 6.1.3.1(c), where the expansion of MSK was higher in the case of storing the mortar bars at $5^{\circ} \mathrm{C} / 100 \% \mathrm{RH}$ in Phase II. Greater expansion was recorded in mortar bars with 50\% Ore when the mortar bars were stored at $40^{\circ} \mathrm{C} / 70 \% \mathrm{RH}$ in Phase II, while mortar bars with control 
aggregates had low expansions in the case of carbonate or aggregates with high silicate content, as shown in Figure 6.20.

Figure 6.22 illustrates a comparison between the expansions of mortar bars soaked for two days and those soaked for three hours. Although the expansions were greater when the bars were soaked for three hours, the ratio of the expansion in Phase II to Phase I was nonetheless consistently greater when the mortar bars were soaked for two days. Moreover, considerably less expansion was recorded in the control carbonate aggregate $(\mathrm{C} 1)$ and silicate aggregate $(1046$ and 1049).

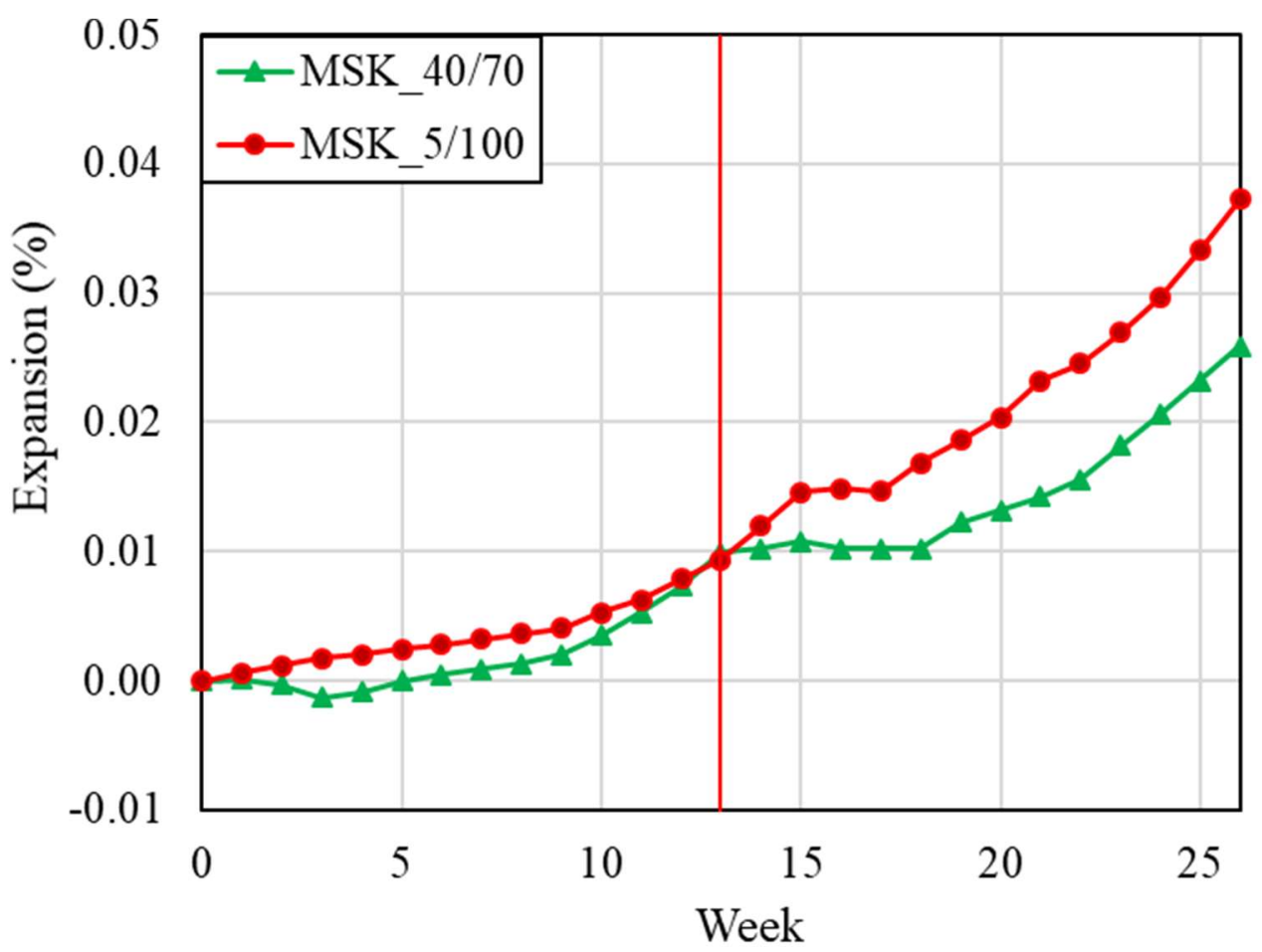

Figure 6.18. Expansion of MSK soaked 2-days in lime water and stored $40^{\circ} \mathrm{C} / 70 \% \mathrm{RH}$ and $5^{\circ} \mathrm{C} / 100 \% \mathrm{RH}$ in Phase I and Phase II, respectively 


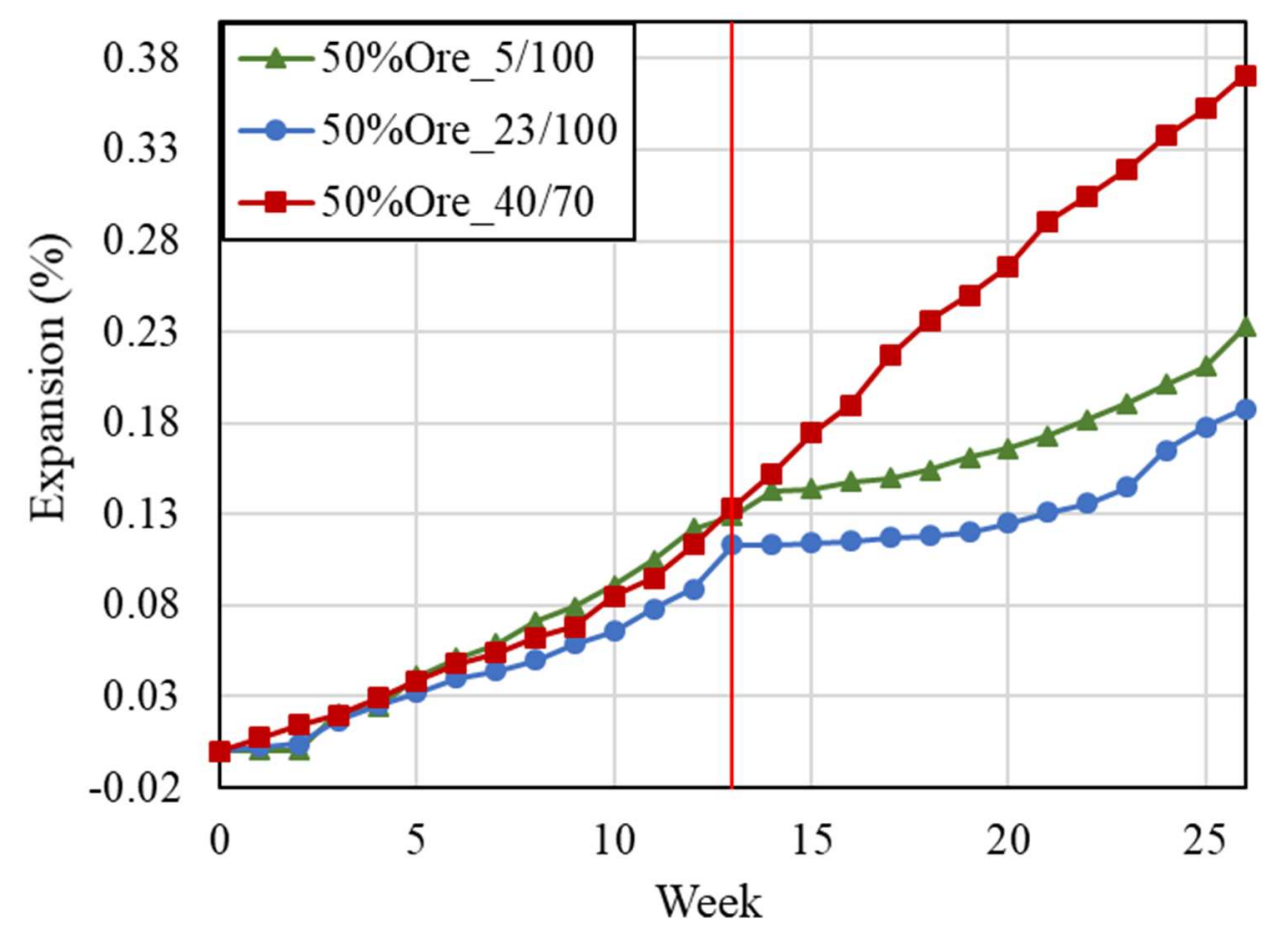

Figure 6.19. Expansion of mortar bars incorporating 50\% Ore soaked2-days in lime water and stored at $40^{\circ} \mathrm{C} / 70 \% \mathrm{RH}$ and $5^{\circ} \mathrm{C} / 100 \% \mathrm{RH}$ in Phase I and Phase II, respectively

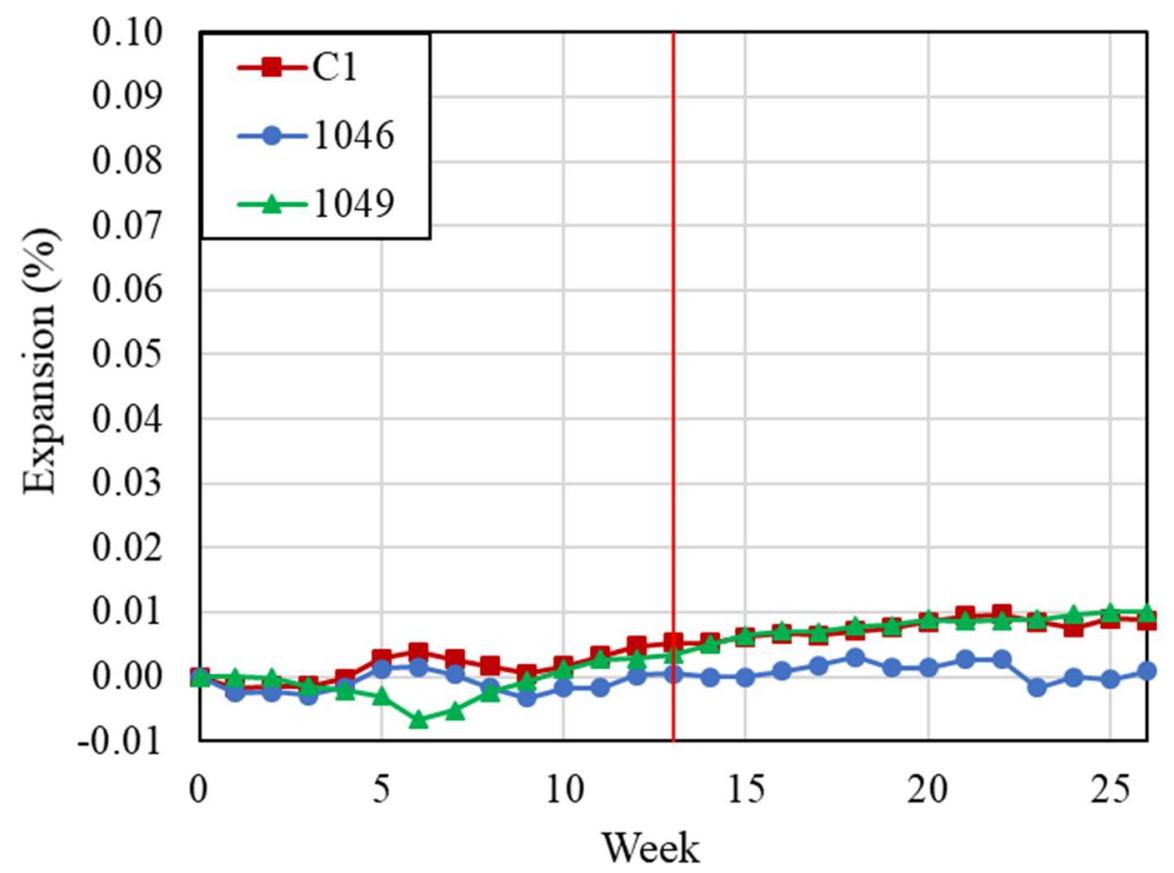

Figure 6.20. Expansion of mortar bars with control carbonate and silicate aggregates soaked for two days in lime water and stored at $40^{\circ} \mathrm{C} / 70 \% \mathrm{RH}$ and $5^{\circ} \mathrm{C} / 100 \% \mathrm{RH}$ in Phase I and Phase II, respectively 


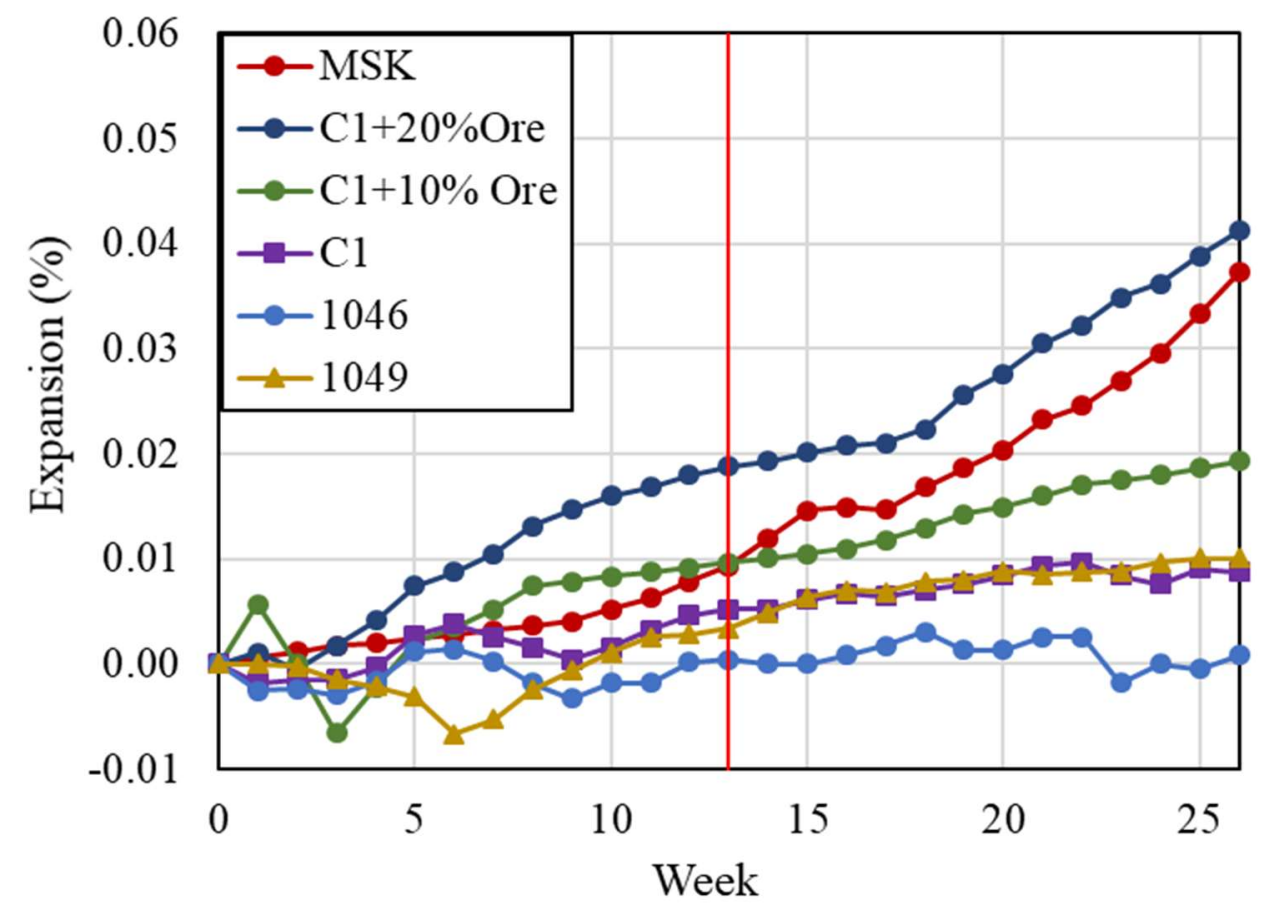

Figure 6.21. Expansion of mortar bars soaked in lime water for two days and stored at $40^{\circ} \mathrm{C} / 70 \% \mathrm{RH}$ and $5^{\circ} \mathrm{C} / 100 \% \mathrm{RH}$ in Phase I and Phase II, respectively

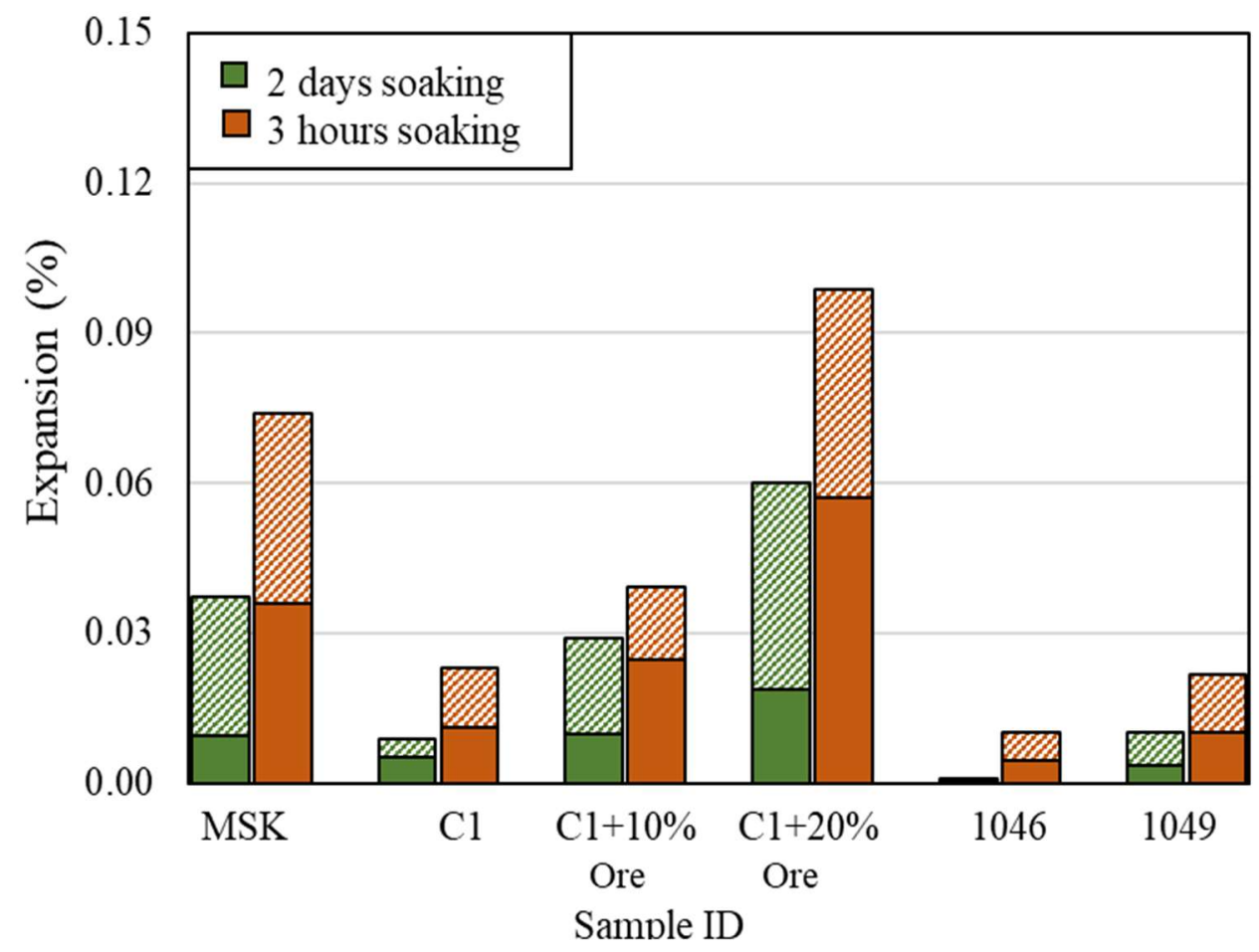

Figure 6.22. Expansion of mortar bars soaked in lime water for two days compared with those soaked for three hours, with the solid colour representing expansions in Phase I and the hatched area representing expansions in Phase II 


\subsubsection{Effect of supplementary cementing materials}

To investigate whether using SCMs has an effect on reducing the damaging expansion beyond that of reducing the penetration of the oxidizing solution, mortar bars incorporating different sulphide-bearing aggregates were tested. In all cases, mortar bars were soaked in lime water for three hours and then stored at $40^{\circ} \mathrm{C} / 70 \%$ for 3.5 days for a period of 13 weeks, followed by storage at $5^{\circ} \mathrm{C} / 100 \%$ for 3.5 days for another 13 weeks. The behaviour of mortar bars with general use (GU) Portland cement was compared with that of mortar bars with GU+25\% fly ash (FA), GU+30\% blast furnace slag (SG), and GU+10\% metakaolin (MK).

Figure 6.23 to 6.25 show the expansion of mortar bars incorporating $100 \%$ Ore, 50\% Ore and MSK aggregates. In all cases, fly ash (FA) and slag (SG) considerably reduced the expansion of mortar bars, whereas expansion was higher in metakaolin.

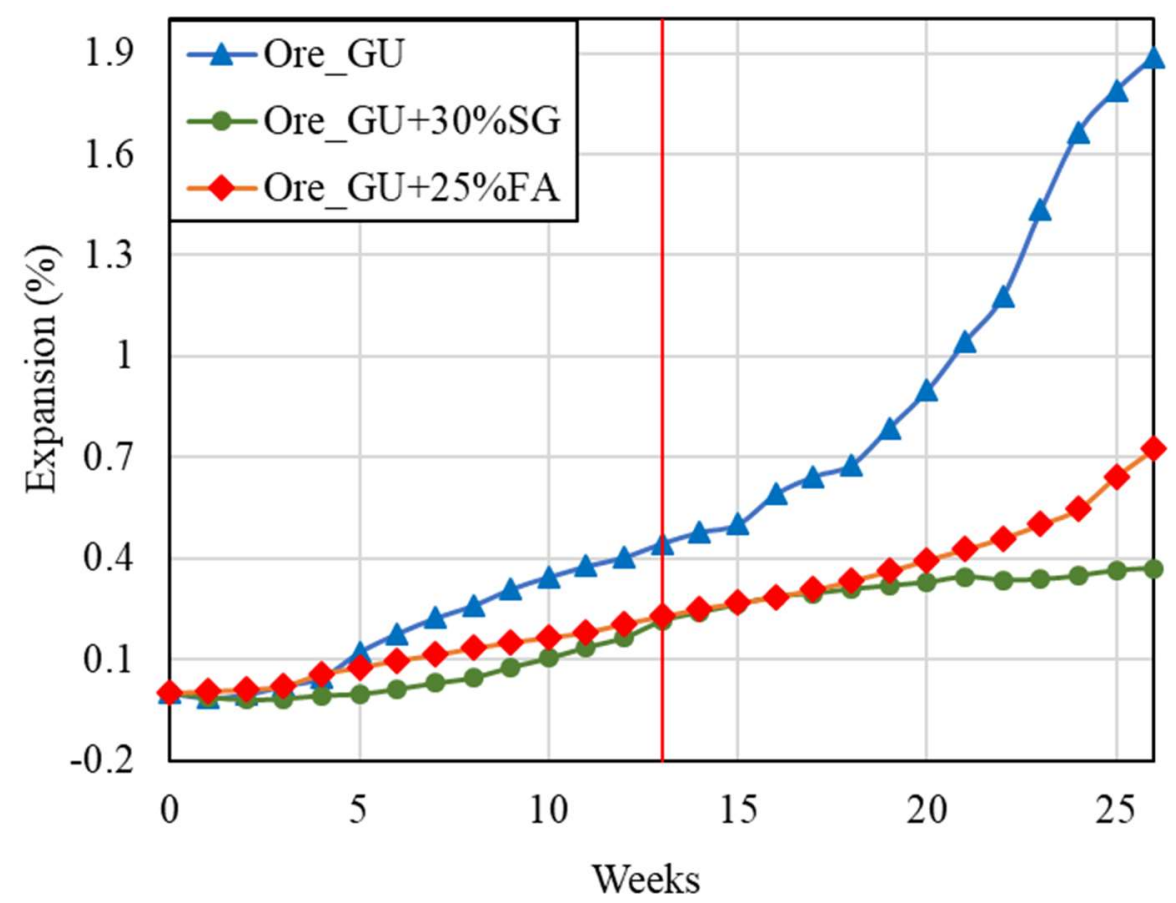

Figure 6.23. Effect of SCM on Ore sample soaked for three hours in lime water and stored at $40^{\circ} \mathrm{C} / 70 \%$ and at $5^{\circ} \mathrm{C} / 100 \%$ for 26 weeks 


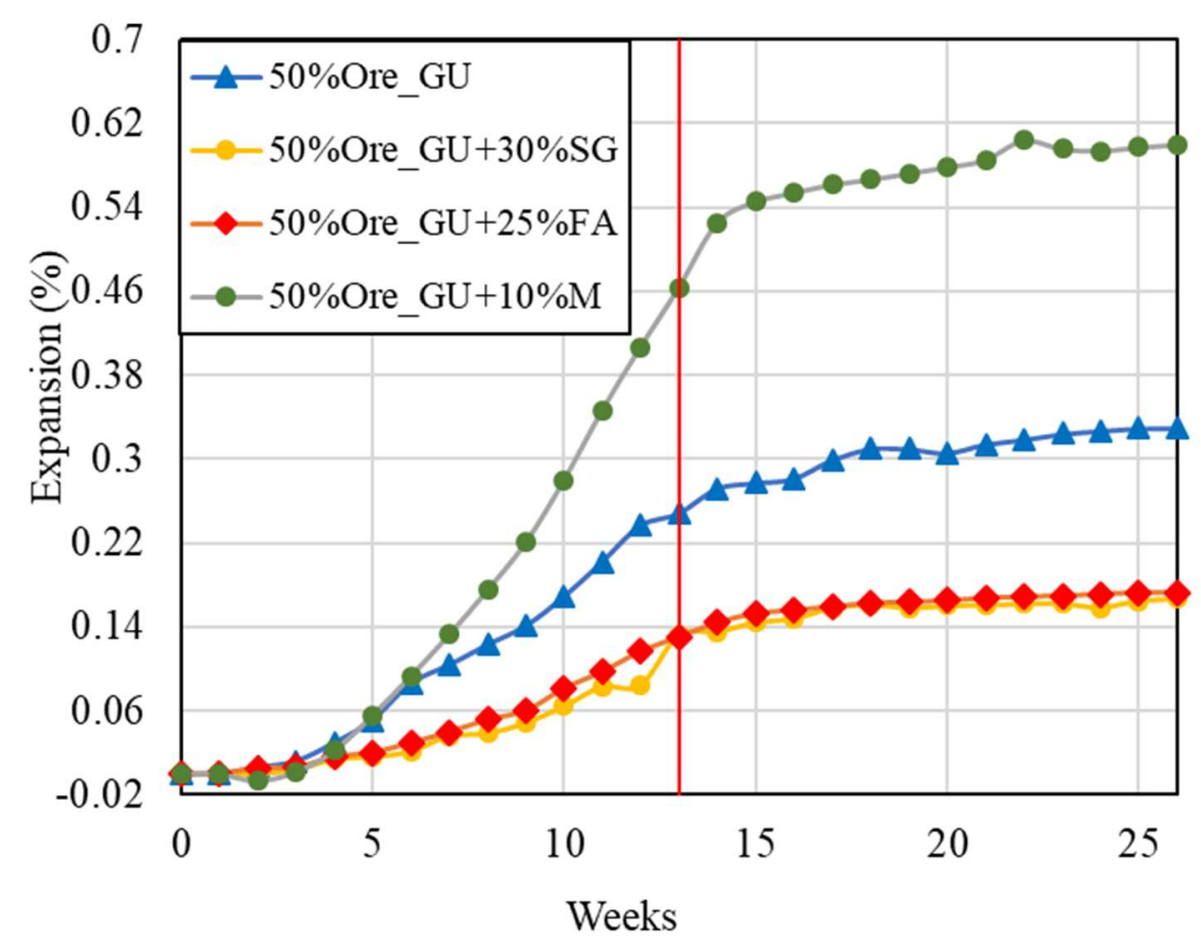

Figure 6.24. Effect of SCM on samples with 50\% Ore soaked for three hours in lime water and stored at $40^{\circ} \mathrm{C} / 70 \%$ and at $5^{\circ} \mathrm{C} / 100 \%$ for 26 weeks

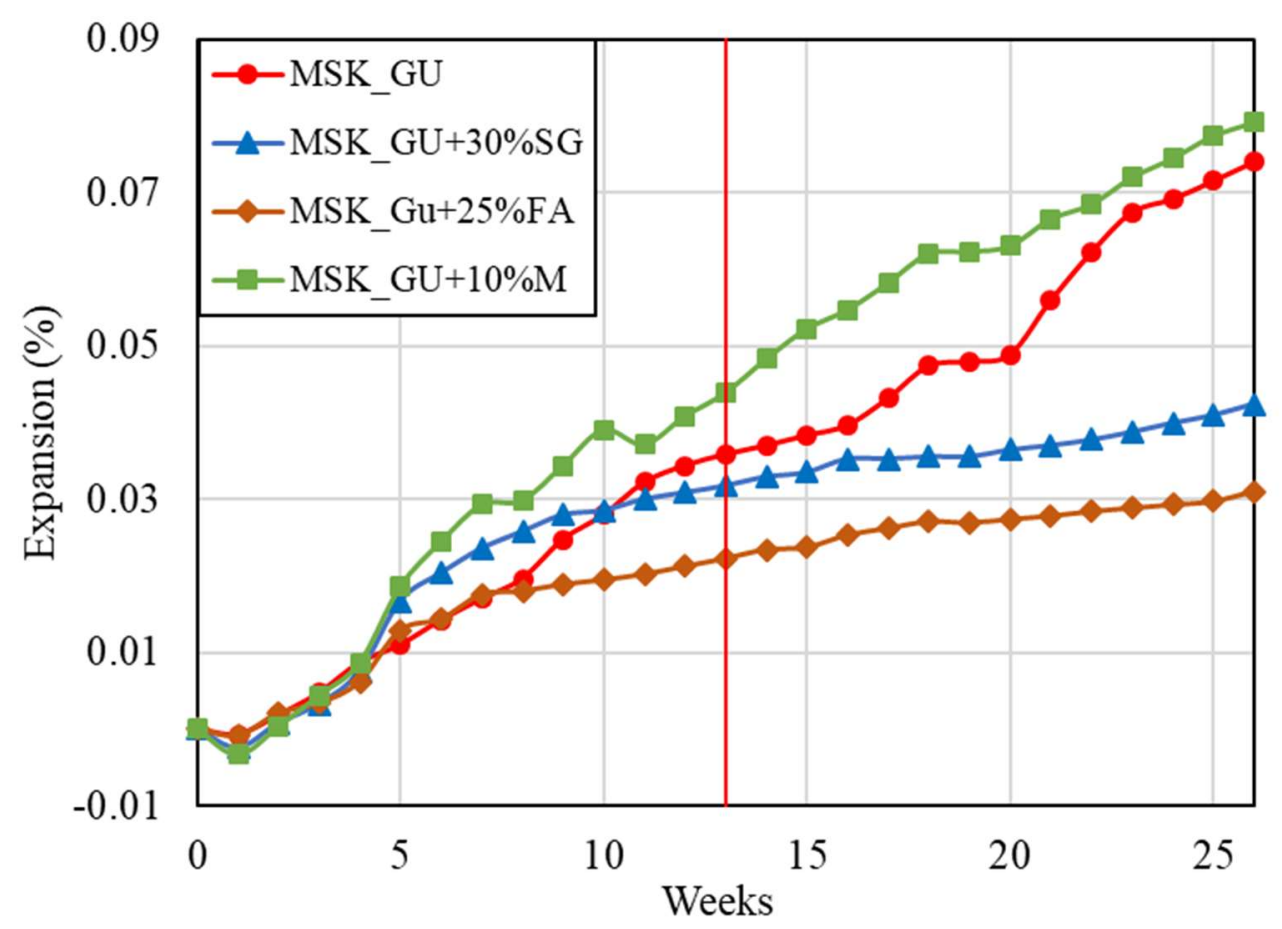

Figure 6.25. Effect of SCM on samples with MSK soaked for three hours in lime water and stored at $40^{\circ} \mathrm{C} / 70 \%$ and $5^{\circ} \mathrm{C} / 100 \%$ for 26 weeks 
To investigate whether the reduction in the expansion may be from the lower permeability due to the refined pore structure in mortar bars with SCM, soaking duration was extended to two days. As Figure 6.26 illustrates, less expansions were encountered in mortar bars with fly ash and slag.

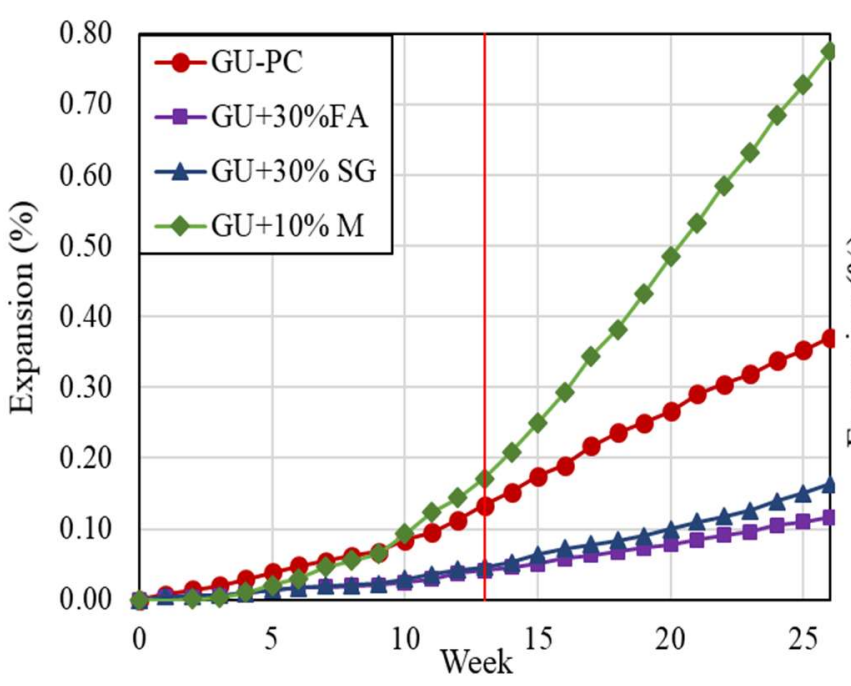

(a) $50 \%$ Ore

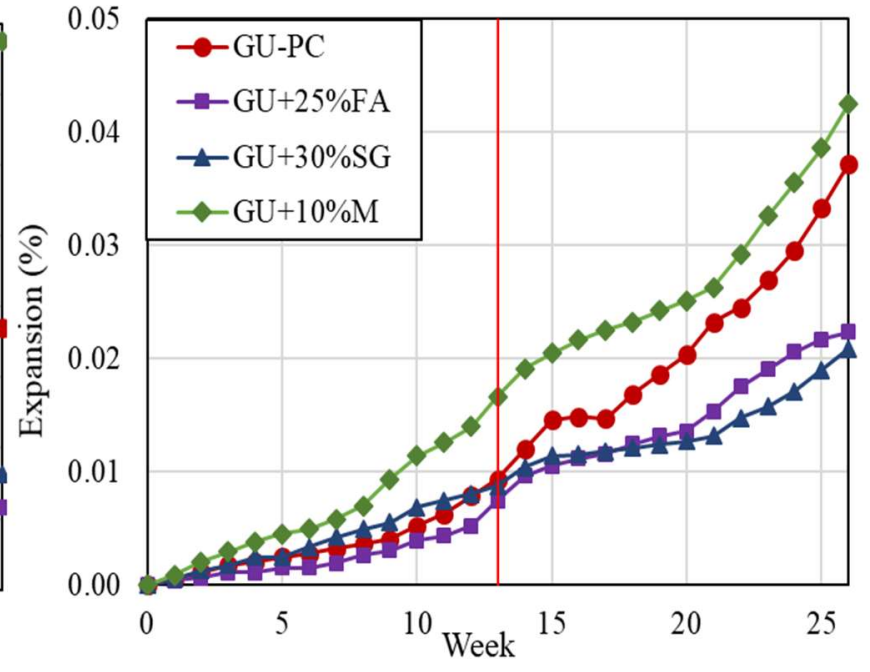

(b) MSK

Figure 6.26. Expansions of mortar bars soaked in lime water for 2days with aggregates a) $50 \%$ Ore and b) MSK and stored at $40^{\circ} \mathrm{C} / 70 \%$ for 5 days

To investigate the reason for less expansion in the case of fly ash and slag, the mortar bars were tested microstructurally. Figure 6.27 and Figure 6.28 show images for cement grain surrounded by inner hydrates a mortar bar with GU and another sample with GU+25\% FA, respectively. As the figures illustrate, the inner hydrates in the case of the mortar bar with fly ash contain some sulphate, whereas this behaviour was not observed in the case of GU-PC. The presence of aluminum and magnesium in the EDS image occurred with a very low atomic number ( 0.5 to $0.7 \%$ ), which could have resulted from inaccuracies in the reading. The presence of sulphate in inner hydrates is not confirmed whether it is chemically bound or physically adsorbed on the 
surface. This observation - binding of sulphate by hydration products of PC-FA system needs further detailed studies for validation.

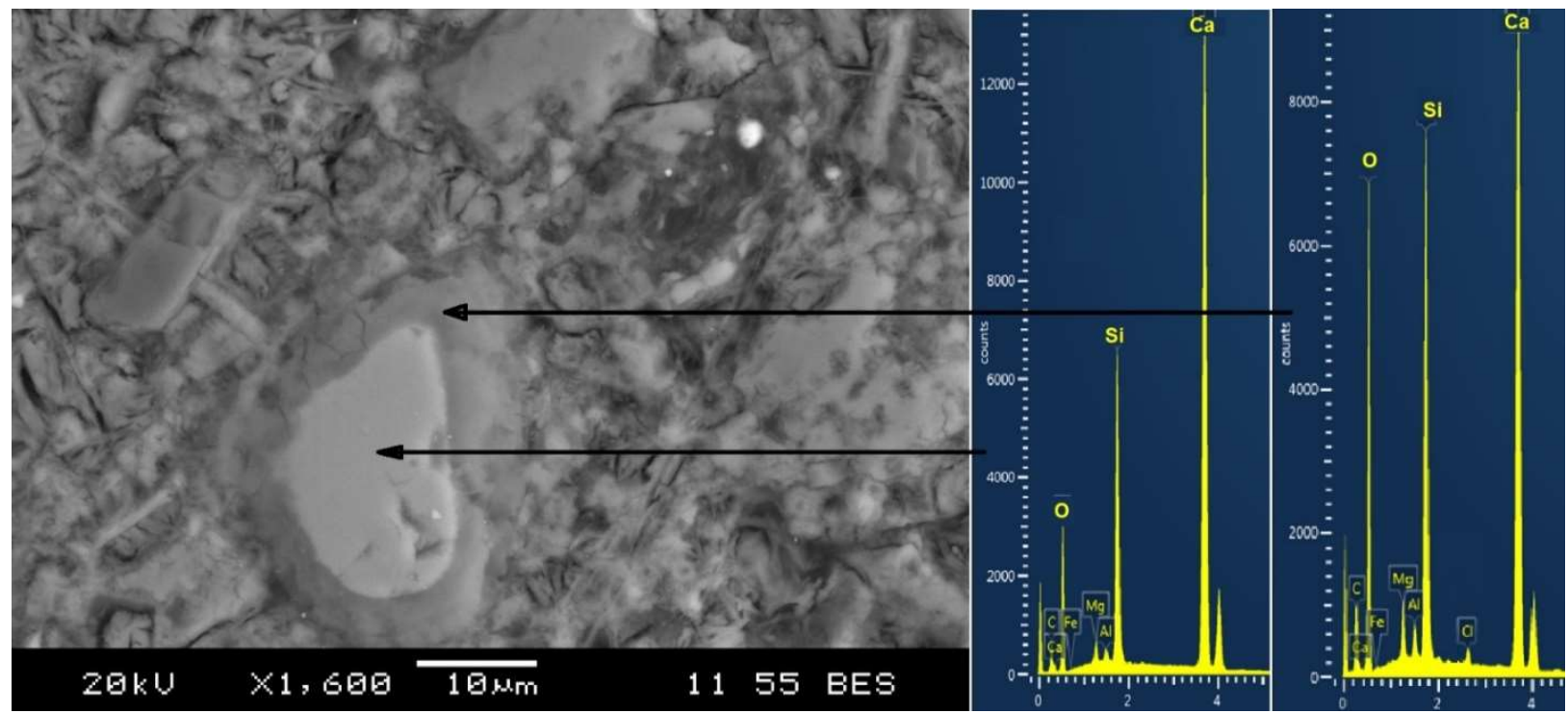

Figure 6.27. SEM analysis of mortar bar with 50\% Ore and GU-PC soaked in lime water for three hours and stored at $40^{\circ} \mathrm{C} / 70 \% \mathrm{RH}$ for 26 weeks showing the hydrated and un-hydrated cement
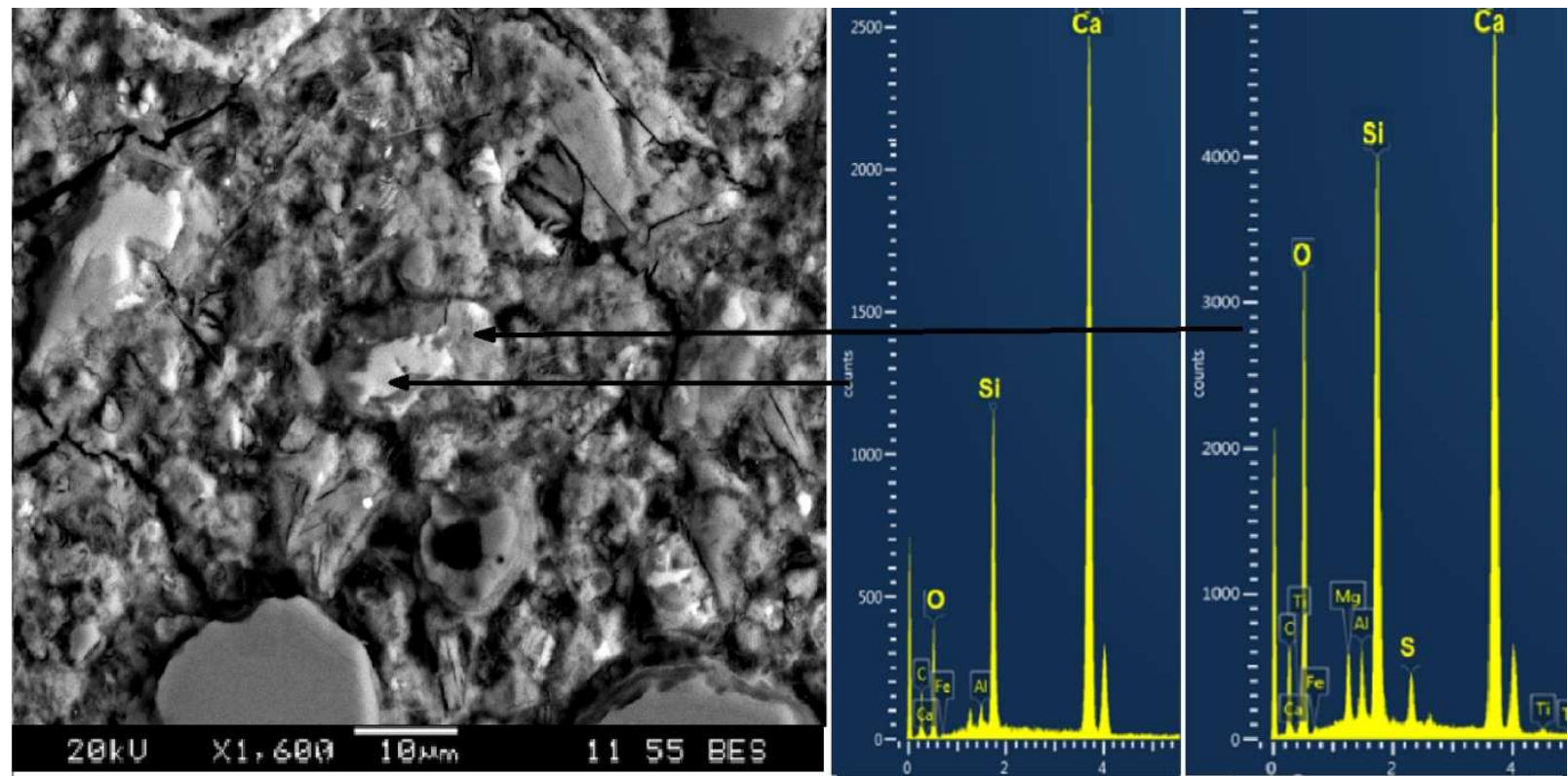

Figure 6.28. SEM analysis for mortar bar with 50\% Ore and GU+25\% FA soaked for three hours in lime water and stored at $40^{\circ} \mathrm{C} / 70 \% \mathrm{RH}$ for 26 weeks showing the hydrated and unhydrated cement 
To investigate the reason for the higher expansion recorded when $10 \%$ metakaolin was used in the mortar bars, mortar bars incorporating MSK with GU+10\% MK were tested in the SEMEDS for microstructural examination, as shown in Figure 6.29. As the figure illustrates, ettringite and monosulphoaluminate were detected with large amounts in the paste. The monosulphoaluminate is characterized by a lower content of sulphur. The atomic ratio in $\mathrm{S}$ to $\mathrm{Ca}$ in case of ettringite is 0.5 while in case of monosulphoaluminate is 0.25 .

Figure 6.30 depicts differential thermal analysis for mortar bars incorporating MSK aggregates with GU-PC, GU+25\% FA and GU+10\% MK. As the figure illustrates, the peak recorded at about $130^{\circ} \mathrm{C}$ could be due to the presence of C-S-H, Ettringite, C-A-H or monosulphoaluminate, as these phases have the same peaks (Bhatty, 1991; Guirguis et al., 2018). This peak is much higher in the case of GU-PC. Moreover, the calcium hydroxide phase at $480-500^{\circ} \mathrm{C}$ was much higher in the case of GU-PC, whereas the aluminate phase (calcium aluminate hydrate) was higher in the case of GU+10\% MK.

However, at the $170-200^{\circ} \mathrm{C}$ range, another two peaks which may be associated with Ettringite or monosulphoaluminate (Guirguis et al., 2018) were recorded. These peaks were much higher in the case of $\mathrm{GU}+10 \% \mathrm{MK}$ and can explain the greater expansion in the case of metakaolin and the high amount of monosulphoaluminate that was observed in the microstructural examination of the mortar bars. The presence of large amounts of monosulphoaluminate in these samples may be attributed to the decomposition of ettringite caused by the availability of more aluminate from the metakaolin. 


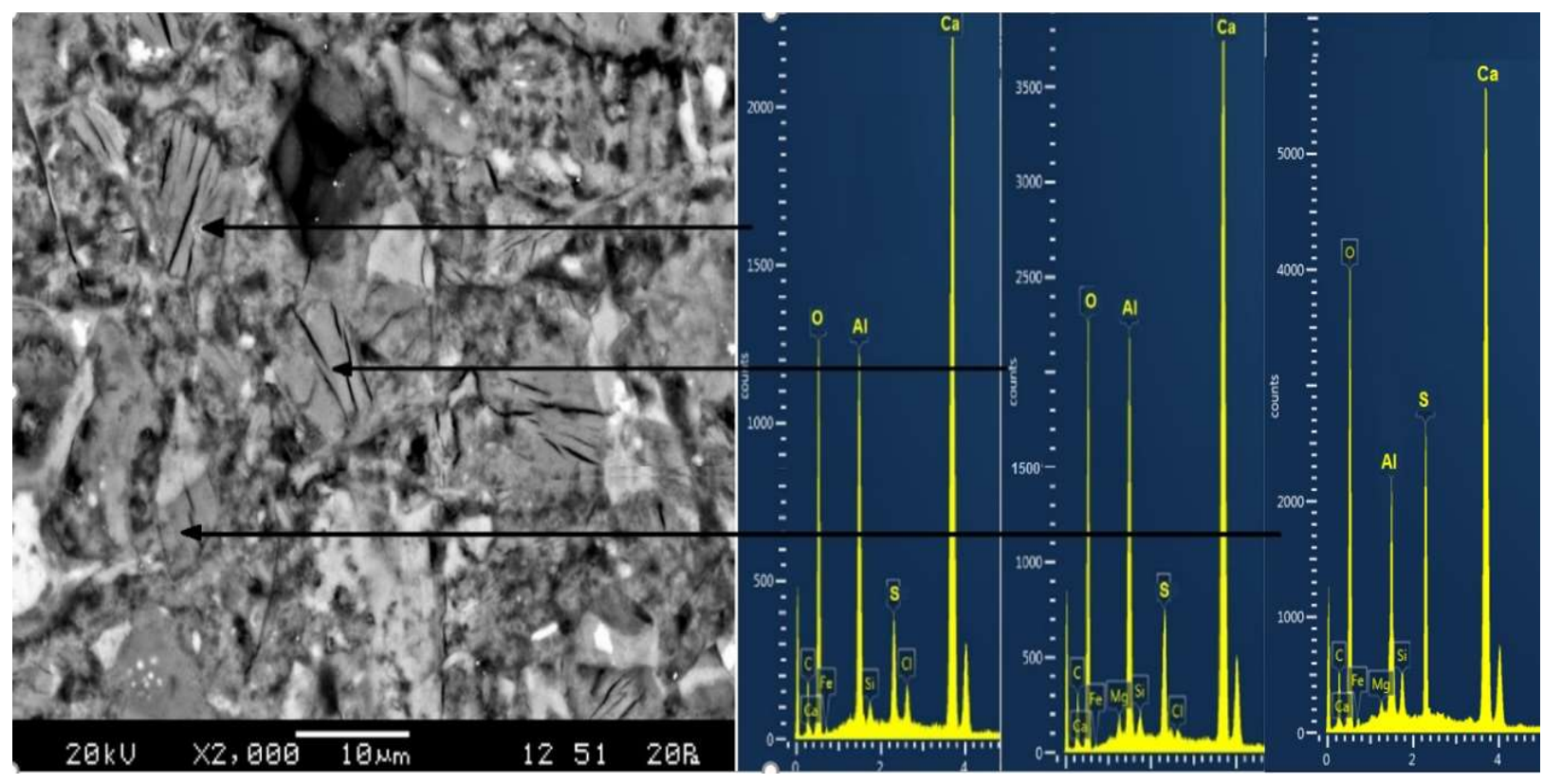

Figure 6. 29. SEM for MSK incorporating GU-PC+10\% MK soaked for three hours in lime water and stored at $40^{\circ} \mathrm{C} / 70 \% \mathrm{RH}$, showing the presence of monosulphoaluminate and ettringite

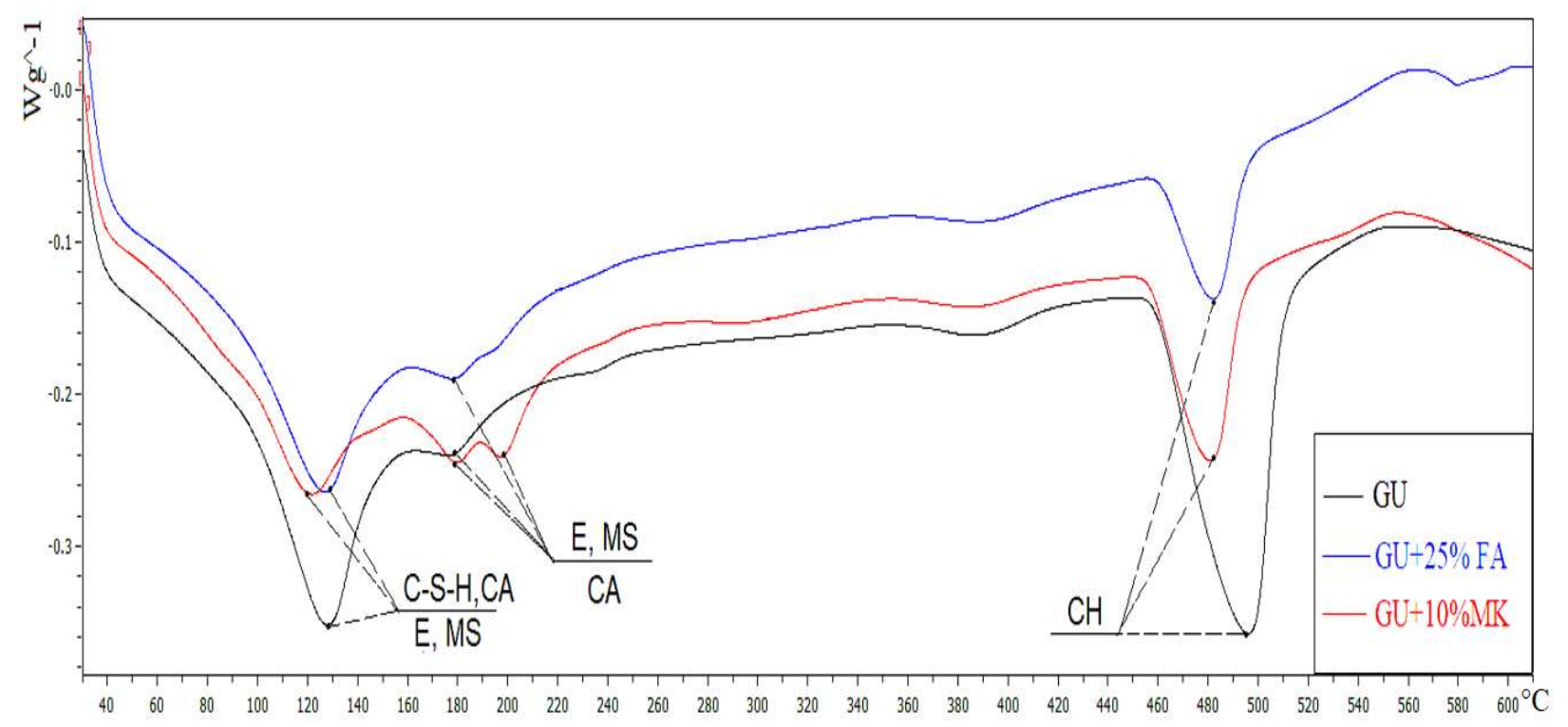

Figure 6.30. DTA for mortar bars incorporating MSK aggregate with GU-PC, GU+25\% FA and $\mathrm{GU}+10 \% \mathrm{MK}$ soaked for three hours in lime water and stored at $40^{\circ} \mathrm{C} / 70 \% \mathrm{RH}$ 


\subsection{Concrete Prism Oxidation Test}

In order to investigate the possibility of concrete samples to detect the expansion potential of sulphide-bearing aggregates, concrete prisms were tested with different regimes that were designed to include a range of exposure conditions. Testing of concrete prisms is thought to be more representative of real-life conditions, as it incorporates coarse aggregates without any crushing. Testing details for the different exposure are shown in Table 3.6 in Chapter 3.

\subsubsection{Samples soaked in bleach (sodium hypochlorite 6\%)}

\subsubsection{Samples stored at $80^{\circ} \mathrm{C} / 80 \% \mathrm{RH}$ and $5^{\circ} \mathrm{C} / 100 \% \mathrm{RH}$ in Phase I and Phase II, respectively (Exposure PB-1 in Table 3.6)}

In this part of the testing program, during Phase I, concrete prisms were soaked for eight hours in a sodium hypochlorite solution and then stored for 3.5 days at $80^{\circ} \mathrm{C} / 80 \% \mathrm{RH}$ for 17 weeks. In Phase II, the prisms were soaked for the same duration but stored at $5^{\circ} \mathrm{C} / 100 \% \mathrm{RH}$ for another 25 weeks. The eight hours are used here as concrete has a larger cross-section than bars so longer soaking time is needed for the oxidizing solution to penetrate the samples.

In the original testing plan, Phase II was supposed to last for 17 weeks, similar to Phase I. However, as shown in Figure 6.31, the prisms did not have a considerable expansion, so the period was extended to 25 weeks. As no noticeable increase in the expansion was recorded, the samples were soaked in bleach for eight weeks in an attempt to induce the oxidation, but this resulted in only very minor expansion. Although these prisms did not have considerable expansions, some rust spots and deteriorations appeared in the sulphide-bearing aggregate, as shown in Figure 6.32. Also, as shown in Figure 6.33, some pop-outs were observed in the concrete prisms with the silicate aggregate 1046, which may be indicative of behaviour similar to the mortar bars, where some ASR products were observed. 
The samples were then moved to a building rooftop for 15 weeks during winter to investigate if the cold weather might increase the expansion rate, but no noticeable expansions were recorded during this period. It should be noted that measurements were taken after 2 years and no further expansion was recorded.

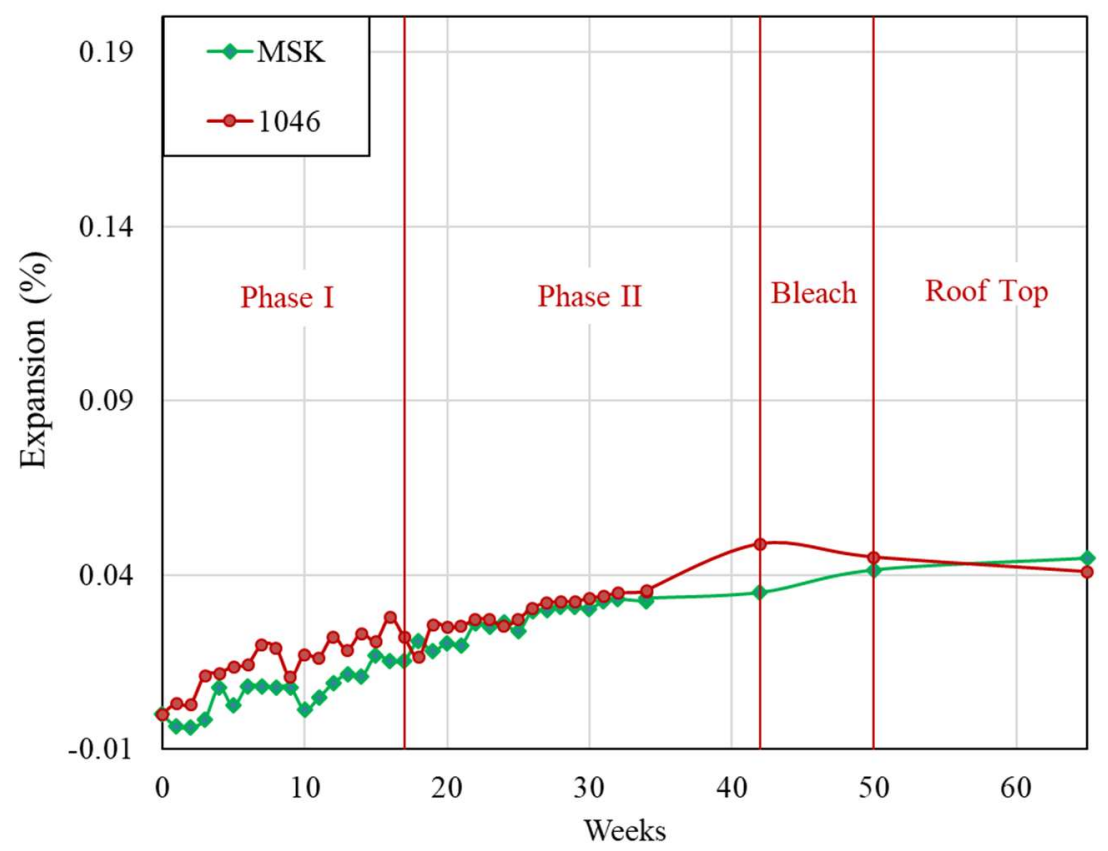

Figure 6.31. Expansion of concrete prisms soaked in bleach for eight hours and stored at $80^{\circ} \mathrm{C} / 80 \% \mathrm{RH}$ and $5^{\circ} \mathrm{C} / 100 \% \mathrm{RH}$ in Phase I and Phase II, respectively
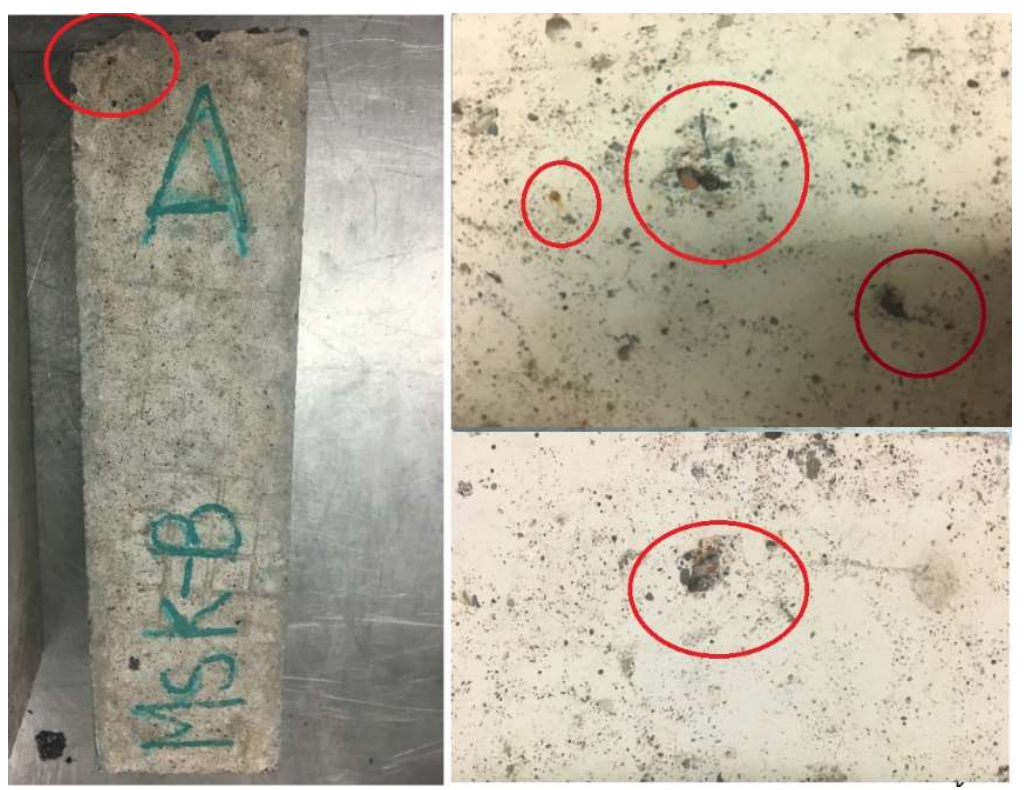

Figure 6.32. Deterioration and rust in concrete prisms with MSK 


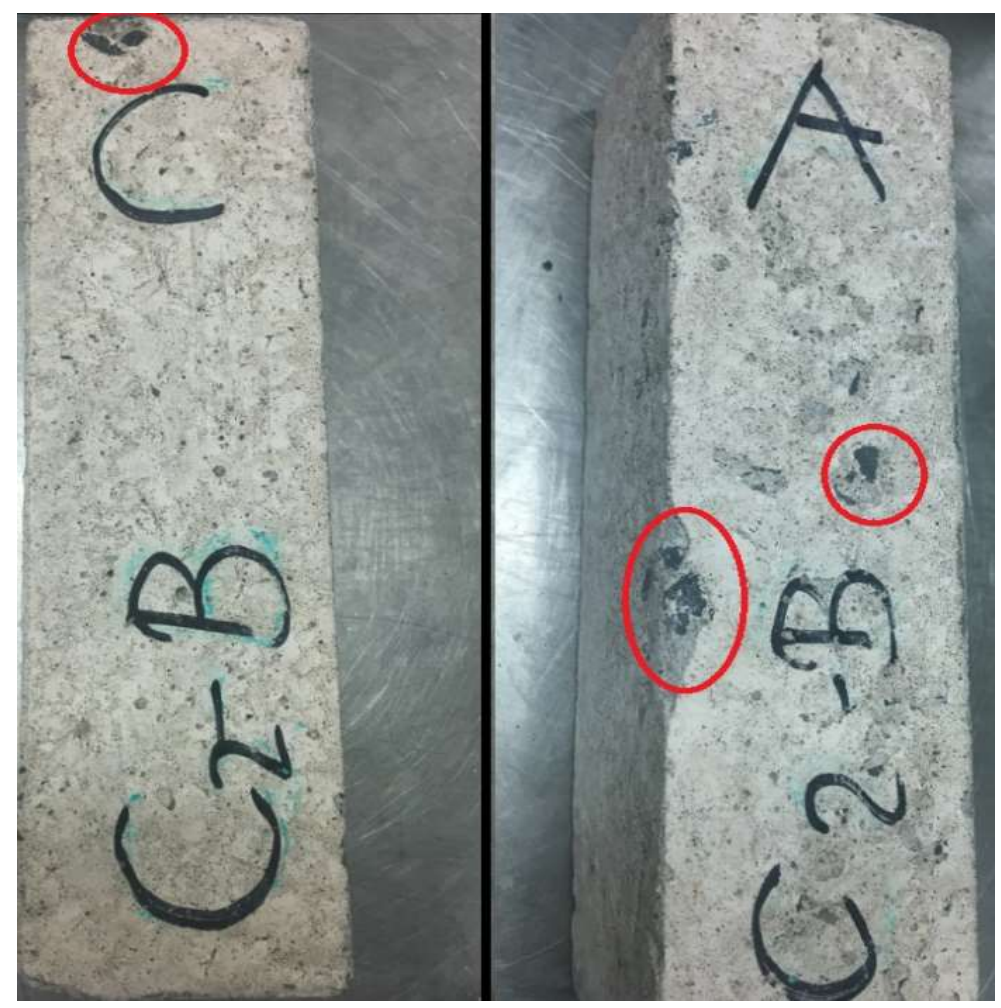

Figure 6.33. Deterioration and pop-outs in concrete prisms with aggregate 1046

\subsubsection{Samples stored at $60^{\circ} \mathrm{C} / 80 \% \mathrm{RH}$, then $23^{\circ} \mathrm{C} / 50 \% \mathrm{RH}$, and then $5^{\circ} \mathrm{C} / 100 \% \mathrm{RH}$ in} Phase I, Phase II and Phase III, respectively (Exposure PB-2 in Table 3.6)

In this experiment, for eight weeks during Phase I, concrete prisms were soaked in lime water for one day and then stored at $60^{\circ} \mathrm{C} / 80 \% \mathrm{RH}$ for four days. For the remaining part of the week (two days), the samples were stored at $23^{\circ} \mathrm{C} / 50 \% \mathrm{RH}$. After this phase, the samples were stored at $23^{\circ} \mathrm{C} / 50 \% \mathrm{RH}$ for another eight weeks (Phase II). The samples were then moved to Phase III, which includes soaking the concrete prisms for one day and storing them at $5^{\circ} \mathrm{C} / 100 \%$ humidity for six days over a period of 20 weeks.

The expansions of these concrete prisms are shown in Figure 6.34 As can be seen, the expansion of the sulphide-bearing aggregate (MSK) after the three phases of exposure was less than $0.01 \%$. Also, the expansion rate increased during Phase I. 


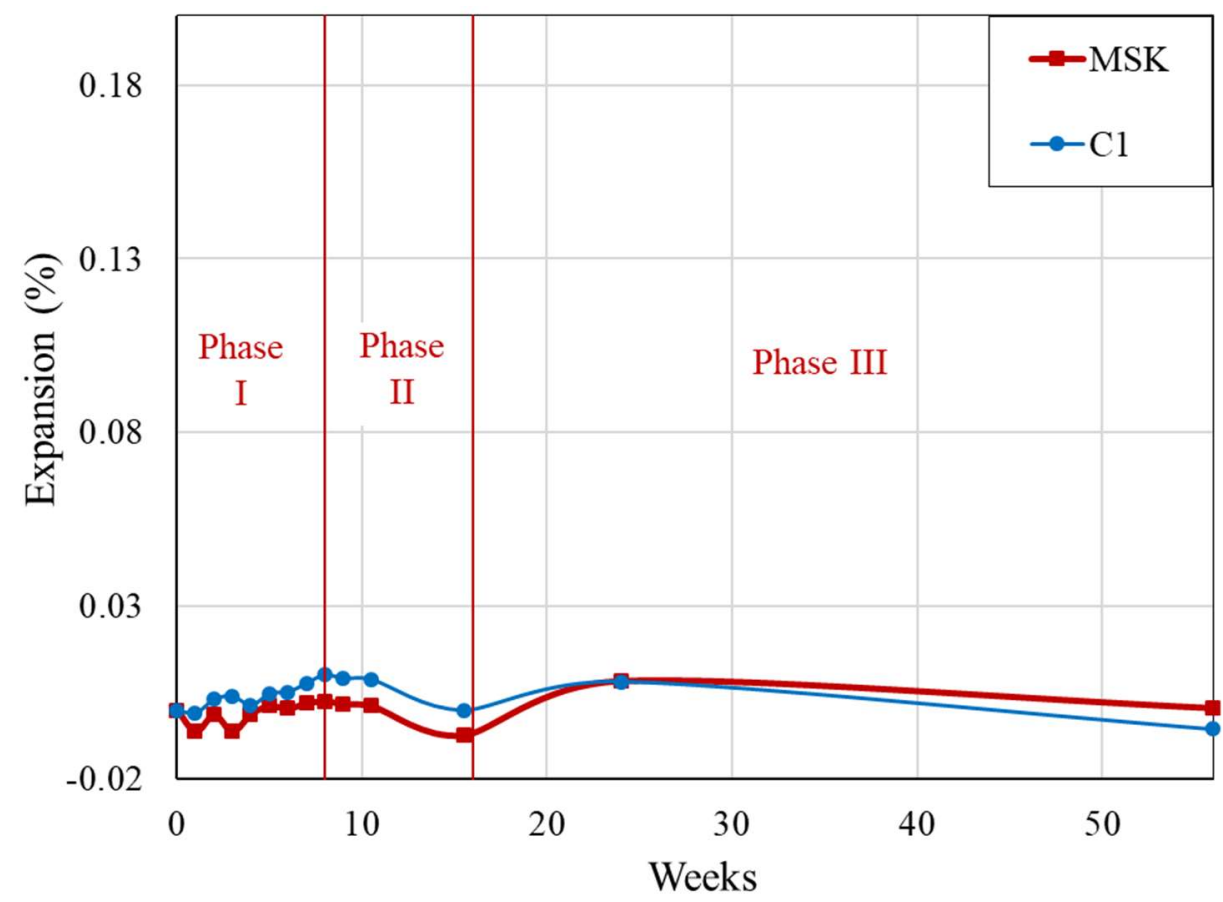

Figure 6.34. Expansion of concrete prisms soaked in bleach for two days and stored at $60^{\circ} \mathrm{C} / 80 \% \mathrm{RH}$, then $23^{\circ} \mathrm{C} / 50 \% \mathrm{RH}$, and then $5^{\circ} \mathrm{C} / 100 \% \mathrm{RH}$ in Phase I, Phase II and Phase III, respectively.

\subsubsection{Samples stored at $60^{\circ} \mathrm{C} / 80 \% \mathrm{RH}$, then $23^{\circ} \mathrm{C} / 50 \% \mathrm{RH}$, and then $23^{\circ} \mathrm{C} / 100 \% \mathrm{RH}$ in Phase I, Phase II and Phase III, respectively (Exposure PB-3 in Table 3.6)}

In this eight-week test during Phase I, concrete prisms were soaked in lime water for one day and then stored at $60^{\circ} \mathrm{C} / 80 \% \mathrm{RH}$ for four days. For the remaining two days of each week, the samples were stored at $23^{\circ} \mathrm{C} / 50 \% \mathrm{RH}$. After this phase, the samples were stored at $23^{\circ} \mathrm{C} / 50 \%$ $\mathrm{RH}$ for another eight weeks (Phase II) and then moved to Phase II, which includes soaking the concrete prisms for one day and storing them at $23^{\circ} \mathrm{C} / 100 \%$ humidity for six days over a 20 week time period.

The expansions of the concrete prisms with this exposure are shown in Figure 6.35. As the figure illustrates, during Phase I and Phase II, the expansion behaviour was similar to concrete prisms tested in the previous section, as the exposure is the same. During Phase II, where the prisms 
were stored at $23^{\circ} \mathrm{C}$ instead of $5^{\circ} \mathrm{C}$, the expansion remained constant. However, it decreased when the prisms were stored at $5^{\circ} \mathrm{C}$, as shown earlier in Figure 6.34.

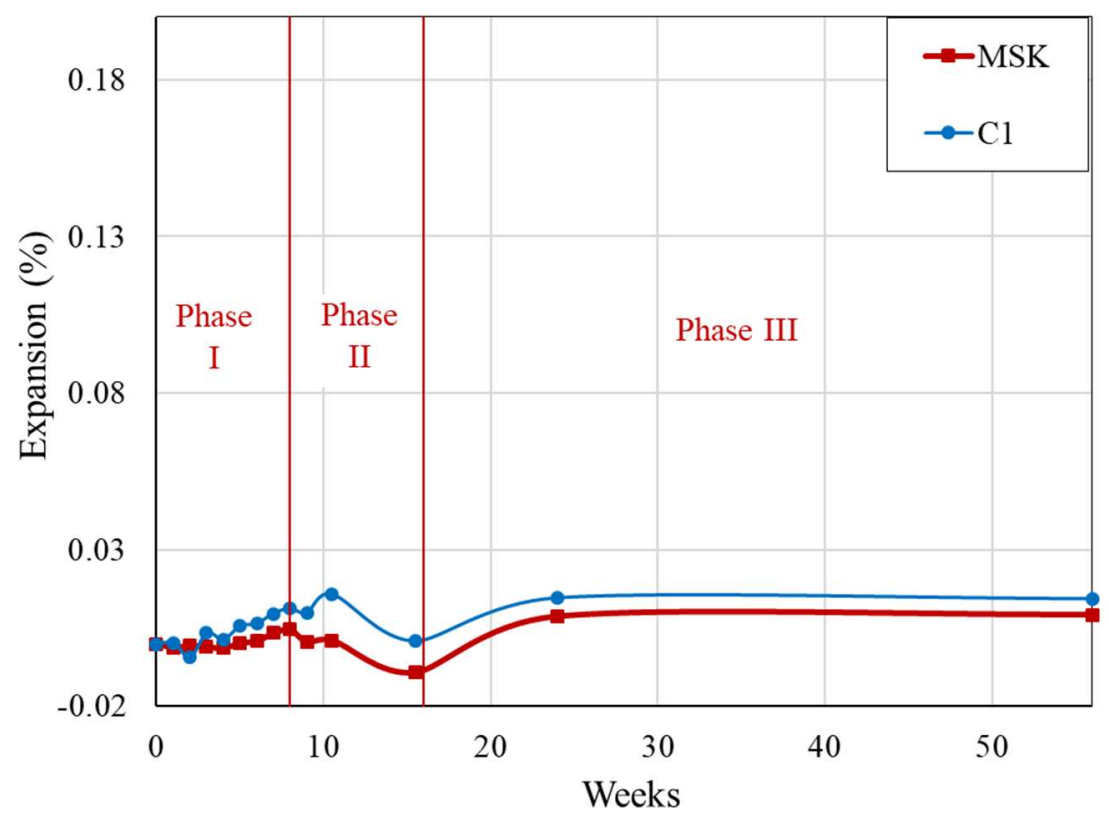

Figure 6.35. Expansion of concrete prisms soaked in bleach for two days and stored at $60^{\circ} \mathrm{C} / 80 \% \mathrm{RH}$, then $23^{\circ} \mathrm{C} / 50 \% \mathrm{RH}$, and then $5^{\circ} \mathrm{C} / 100 \% \mathrm{RH}$ in Phase I, Phase II and Phase III, respectively

\subsubsection{Samples soaked in saturated lime solution (LW), (Exposure PL-1 in Table 3.6)}

In this part of the testing program, in Phase I, concrete prisms were soaked for eight hours in lime water solution and then stored for 3.5 days at $80^{\circ} \mathrm{C} / 80 \%$ RH for 17 weeks. In Phase II, the prisms were soaked for the same duration but stored at $5^{\circ} \mathrm{C} / 100 \% \mathrm{RH}$ for another 25 weeks.

In the original testing plan, Phase II was supposed to last for 17 weeks, similar to Phase I. However, the prisms did not have a considerable expansion, so the period was extended to 25 weeks. This is illustrated in Figure 6.36. Even with this extended period, no noticeable increase in expansion was recorded, so the samples were soaked in lime water for eight weeks in an attempt to induce the oxidation. The final result was a very small expansion. 
The samples were then moved to a building rooftop for 15 weeks during winter to investigate whether the cold weather would increase the expansion rate, but no noticeable expansions were recorded during this period, either. It should be noted that the samples were left on the roof for another 2 years and no further expansion was recorded.

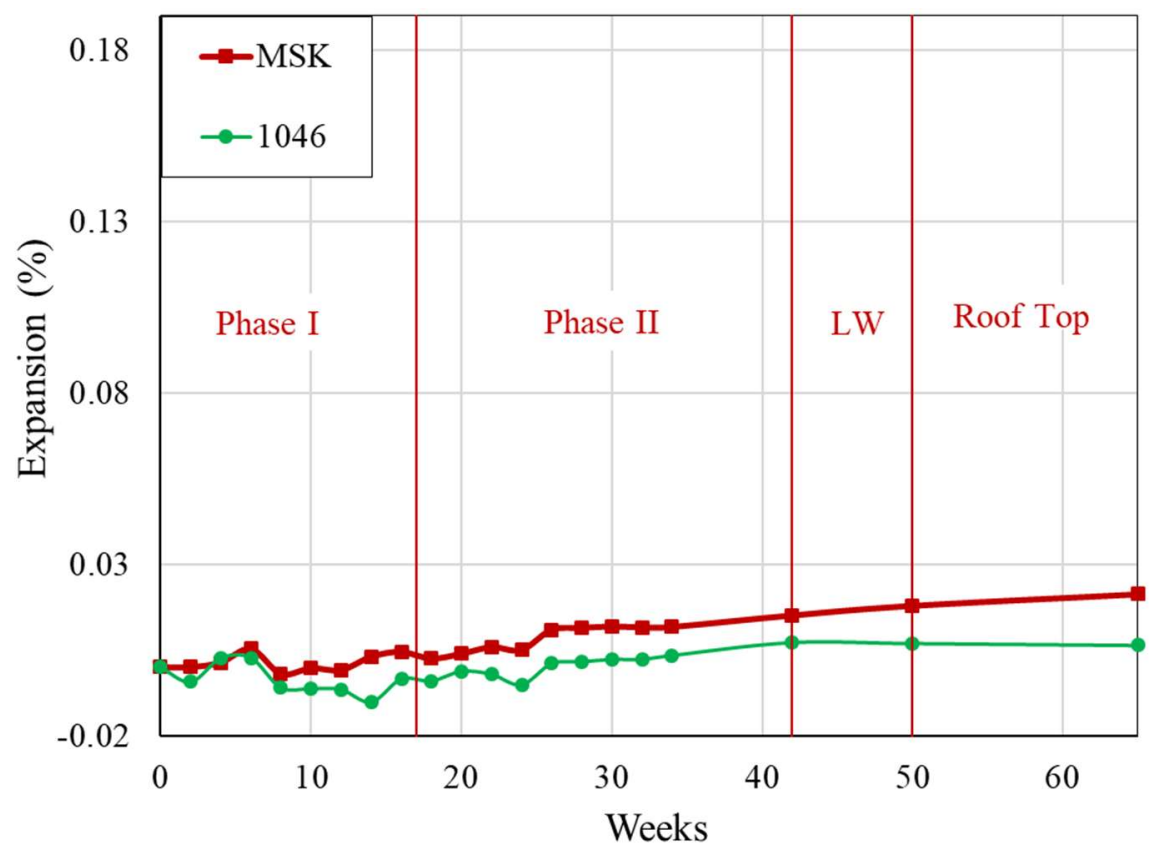

Figure 6.36. Expansion of concrete prisms soaked in lime water for eight hours and stored at $80^{\circ} \mathrm{C} / 80 \% \mathrm{RH}$ and $5^{\circ} \mathrm{C} / 100 \% \mathrm{RH}$ in Phase I and Phase II, respectively

\subsubsection{Samples stored on the rooftop (Exposure $R$ in Table 3.6)}

In an attempt to simulate the environmental conditions that promoted the oxidation of the sulphide-bearing aggregate MSK, concrete prisms with MSK and carbonate aggregate were placed on a building roof after casting and curing. The samples were exposed for a duration of about 92 weeks. Figure 6.37 shows the level and rate of expansion. As can be seen in the figure, no noticeable expansions were observed for the sulphide-bearing aggregate MSK after 92 weeks. 


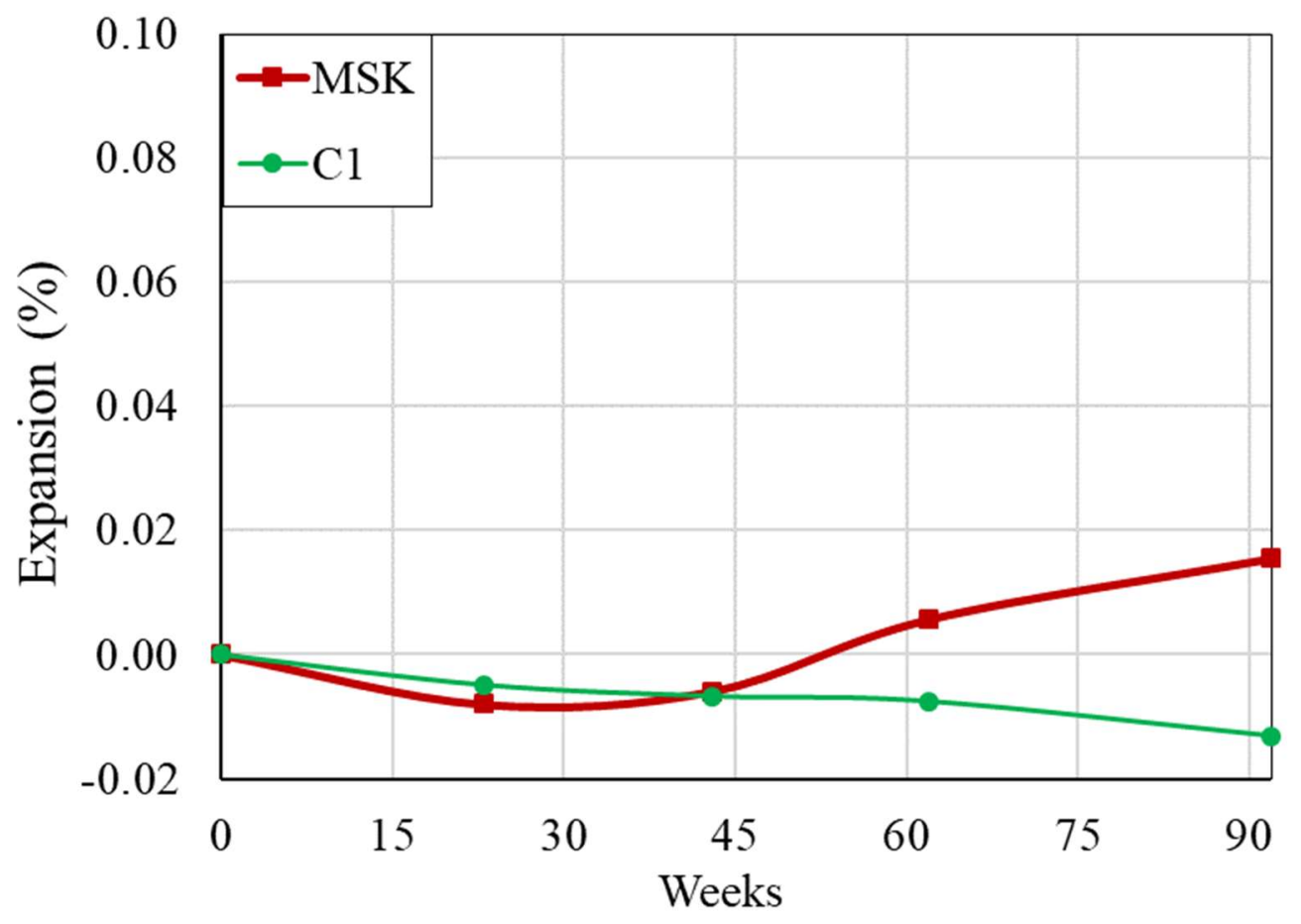

Figure 6.37. Expansion of concrete prisms placed on the roof

The previous results indicate that testing of concrete prisms did not produce enough expansion to provide sufficient data to establish an expansion criterion or testing program for concrete prisms. Further investigation is required with other exposure conditions. 


\subsection{Summary and Discussion}

This chapter has two main objectives. The first is to develop a new oxidation mortar bar test that can avoid the limitations that appeared in the original oxidation mortar bar test with respect to high storage temperature and the use of bleach as an oxidizing agent. The second objective is to develop a new concrete prism test. In the case of concrete prism testing, no considerable expansion was observed in our tests. This may be the result of aggregate oxidation which occurred prior to testing. Another concrete testing is now being investigated at Ryerson University in Toronto.

In the tests conducted in this part of the study, mortar bars were investigated under a range of testing regimes. Different solutions were used as oxidizing agents under various storage temperature and humidity conditions. The ultimate goal here was to determine optimum testing conditions that can be used to evaluate the susceptibility of sulphide-bearing aggregates to oxidation, without promoting other reactions (e.g., ASR products, Friedel's salt or sodium chloride crystals) that can affect the expansion.

In the beginning, sodium hypochlorite was used at a lower storage temperature to investigate if low temperatures will produce expansion by oxidation only. As well, calcium hypochlorite was used to investigate if avoiding sodium hypochlorite will eliminate ASR products. Both testing regimes produced more Phase II expansion in mortar bars with sulphide-bearing aggregates compared to aggregates with negligible total sulphur content.

Although the expansion of the mortar bars with aggregates that have low total sulphur was considerably less compared to mortar bars soaked in bleach and stored at high temperature, the presence of Friedel's salt and sodium and calcium chloride, as the microstructural examination and thermal analysis showed, may be evidence of some reaction with silicates in the aggregate. 
The expansion results along with the ratio of expansion of Phase II to Phase I are shown in Table 6.1. Applying the expansion criteria that was suggested in Chapter 5 on mortar bars soaked in calcium hypochlorite helped in identification of sulphide bearing aggregates and aggregates with low sulphides. The expansions of mortar bars with aggregates with negligible sulphides were $<0.03 \%$ and the expansion ratios of Phase II to Phase I were $>0.6 \%$ for sulphide bearing aggregates. Normalizing the expansion in Phase II to that in Phase I helped in considering the effect of silicate. In the case of using sodium hypochlorite as an oxidizing agent, where the mortar bars were stored at room temperature in Phase I, the expansions of all mortar bars- whether sulphide bearing or not- was low $(<0.3)$ mostly because higher temperature promotes more expansions. However, applying the expansion ratio of Phase II to Phase I only gave considerably high ratios in sulphide-bearing aggregates compared to control aggregates. Moreover, although testing is still in progress for mortar bars with MSK, Sand B+10\% Ore, 1046 and 1049, but the expansion ratios of the sulphide bearing aggregates are very high. Therefore, the expansion criteria in case of mortar bars stored at room temperature are suggested to include the expansion ration of Phase II to Phase I only. These tests need deeper investigation and broader application on a wider range of aggregates in order to assess their ability to evaluate the aggregates.

Table 6.1. The ratio between the expansion of Phase II and Phase II of mortar bars

\begin{tabular}{cccccc}
\hline \hline Solution & Aggregate & $\mathrm{S}_{\mathrm{t}}(\%)$ & Phase I & Phase II & Ratio \\
\hline \hline $\begin{array}{c}\text { Calcium } \\
\text { hypochlorite } \\
\text { stored at } \\
80^{\circ} \mathrm{C} / 80 \mathrm{RH}\end{array}$ & MSK & $0.73-1.28$ & 0.032 & 0.066 & 2.02 \\
\cline { 2 - 6 } & $\mathrm{C} 1$ & 0.04 & 0.019 & 0.054 & 0.55 \\
\cline { 2 - 6 } & 1046 & 0.027 & 0.015 & 0.015 & $* *$ \\
\hline \hline
\end{tabular}




\begin{tabular}{|c|c|c|c|c|c|}
\hline Solution & Aggregate & $\mathrm{S}_{\mathrm{t}}(\%)$ & Phase I & Phase II & Ratio \\
\hline \multirow{5}{*}{$\begin{array}{c}\text { Bleach } \\
\text { stored at } \\
23^{\circ} \mathrm{C} / 100 \mathrm{RH}\end{array}$} & MSK & $0.73-1.28$ & 0.014 & $0.03 *$ & 2.08 \\
\hline & Sand B $+10 \%$ Ore & $\approx 1.4$ & 0.008 & $0.035^{*}$ & 4.37 \\
\hline & 1046 & 0.027 & 0.012 & $0.004 *$ & 0.34 \\
\hline & 1049 & 0.024 & 0.006 & $0.003 *$ & 0.362 \\
\hline & 1052 & 0.535 & 0.011 & 0.079 & 7.02 \\
\hline \multicolumn{6}{|c|}{$*$ Test is still in progress } \\
\hline \multicolumn{6}{|c|}{$* *$ No ratio is needed as expansion in Phase $\mathrm{II}<0.03 \%$} \\
\hline
\end{tabular}

As mentioned in subsection 6.1.3, to avoid the production of other reactions rather than the oxidation products, lime water was used as the oxidizing agent for mortar bars. Two different soaking durations were applied - three hours and two days. The longer soaking duration was aimed at investigating whether longer durations will result in more oxidation. When high storage temperature $\left(80^{\circ} \mathrm{C} / 80 \% \mathrm{RH}\right)$ was used, as illustrated in Figure 6.9, the expansion was significant in the case of the non-sulphide aggregate 1046. Hence, the storage temperature was reduced to $\left(40^{\circ} \mathrm{C} / 70 \% \mathrm{RH}\right)$ in Phase I. In Phase II, different conditions were investigated (i.e., $40^{\circ} \mathrm{C} / 70 \% \mathrm{RH}$, $23^{\circ} \mathrm{C} / 100 \% \mathrm{RH}$, and $\left.5^{\circ} \mathrm{C} / 100 \% \mathrm{RH}\right)$ to find the optimum one.

Although the total expansion values of mortar bars soaked in lime water and stored at $40^{\circ} \mathrm{C} / 70 \% \mathrm{RH}$ were less than those of mortar bars soaked in bleach and placed in high storage temperatures $\left(80^{\circ} \mathrm{C} / 80 \% \mathrm{RH}\right)$, the test outcomes still indicated that reducing the temperature produced more representative results. The expansion decreased noticeably with less total sulphur in the aggregate and microstructural examinations of the mortar bars showed the presence of signs of sulphate attack (i.e., ettringite and Thaumasite). Perhaps using a lower expansion limit 
will solve the matter of having lower expansion in the case of using lime water as an oxidizing agent compared to bleach.

Investigating the optimum storage temperature in Phase II resulted in interesting observation. The storage temperature that can result in greater expansion differs depending on the type of aggregate used. For instance, expansion was greater when MSK samples were stored at $5^{\circ} \mathrm{C} / 100 \% \mathrm{RH}$, while in the case of $50 \%$ Ore, expansion was greater when the samples were stored at $40{ }^{\circ} \mathrm{C} / 70 \% \mathrm{RH}$. The greater expansion in the case of mortar bars with $50 \%$ Ore may be explained by the extensive oxidizable sulphides in this blend. Storing the mortar bars at $40^{\circ} \mathrm{C} / 70 \% \mathrm{RH}$ is better, as oxidation continues with the formation of ettringite, whereas in the case of $5^{\circ} \mathrm{C} / 100 \% \mathrm{RH}$, oxidation - likely - stops and thaumasite begins to form.

Moreover, investigating the effect of longer soaking duration (i.e., two days/week vs. three hours/twice per week) indicated that three hours of soaking can produce similar expansion to that of the mortar bars soaked for two days at shorter times. As Figure 6.38 for expansion of mortar bars with $50 \%$ Ore illustrates, more soaking cycles (e.g., three hours) accelerates expansion, which may be beneficial in accelerating the testing, especially for aggregates with fewer sulphides. In the case of mortar bars with MSK, different expansion behaviour was observed as shown in Figure 6.39. The expansion of mortar bars soaked for 3 hours (two times per week) was much higher than the expansion of mortar bars soaked for 2 days per week. Samples were tested with 2 days of soaking are being tested until reaching the same number of cycles as that of the samples soaked for three hours. The results will then be compared to see if there is any benefit of extending the test duration, in case of a 2-day soaking period. 
No. of cycles for 3 hours saoking

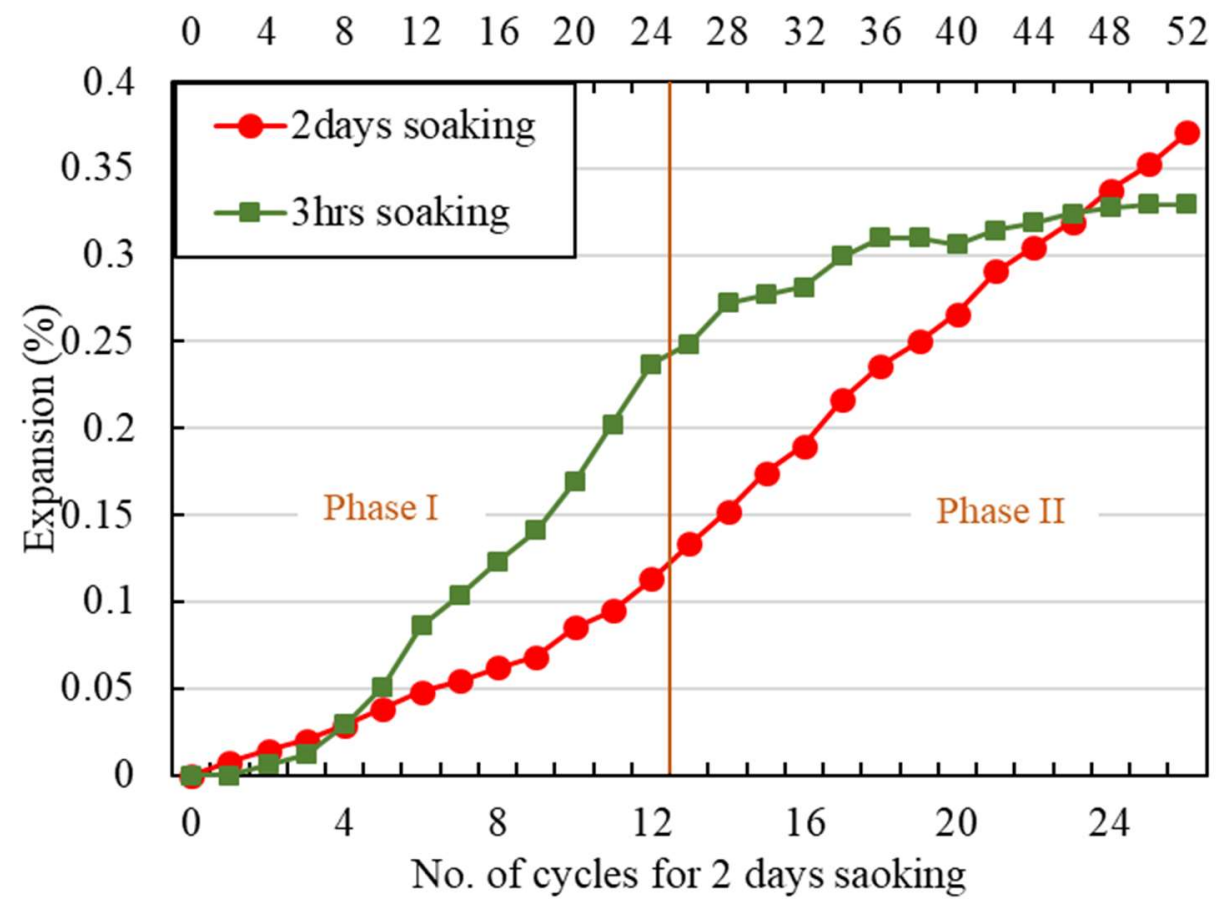

Figure 6.38. Expansion of mortar bars with 50\% Ore soaked in lime water for three hours or two days

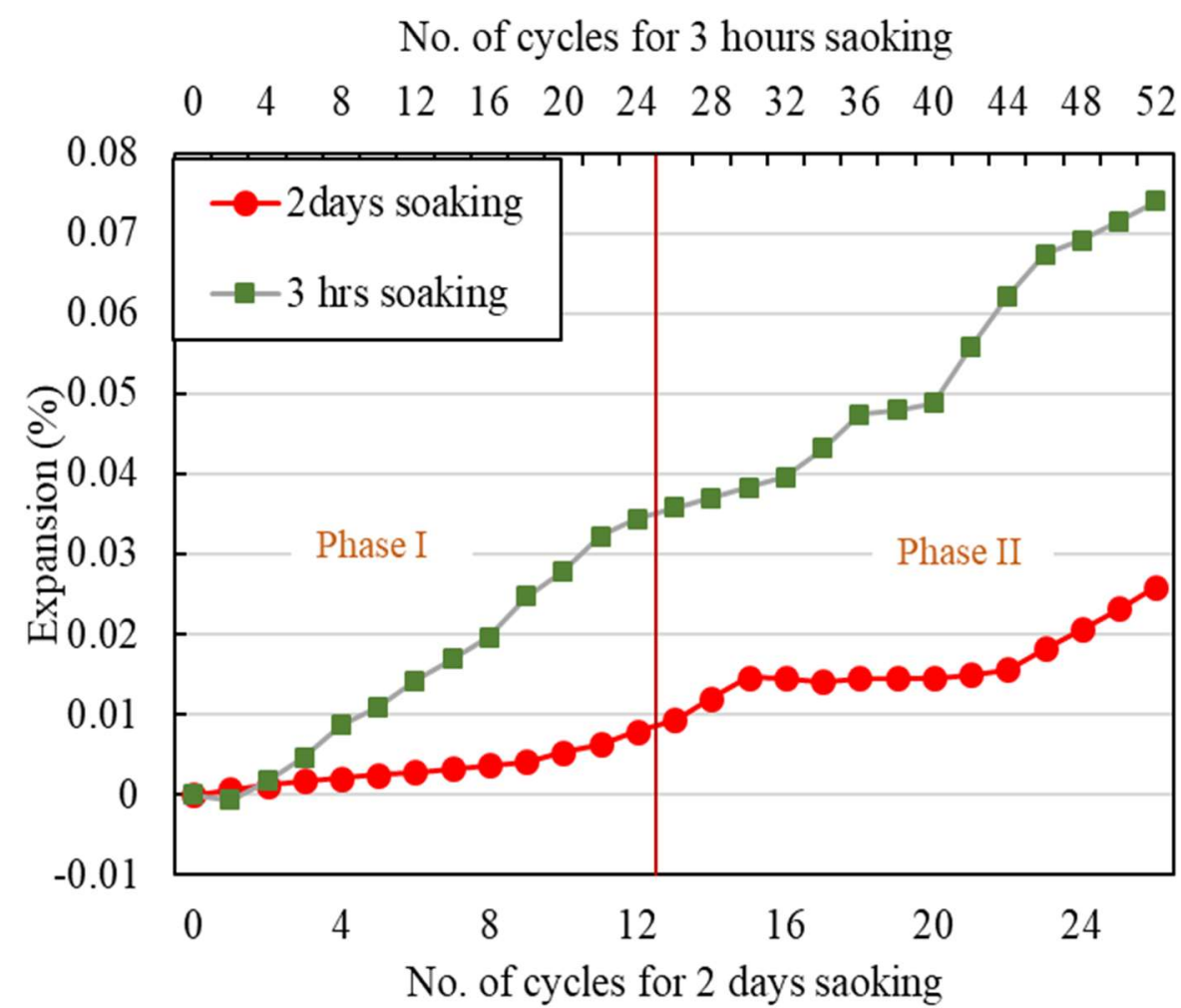

Figure 6.39. Expansion of mortar bars with MSK soaked in lime water for three hours or two days 
Based on the results, the approach of using lime water as the oxidizing agent and a soaking duration of three hours twice per week, with storing the samples at $40^{\circ} \mathrm{C} / 70 \% \mathrm{RH}$ in Phase I, is suggested. Figure 6.40 illustrates the total expansions of the mortar with this exposure, with the expansion decreasing with lower total sulphur content. Moreover, mortar bars with aggregates that featured high silicate content, such as 1046 and 1049, and showed significant expansions when exposed to sodium hypochlorite and high heat $\left(80^{\circ} \mathrm{C}\right)$, produced only low expansions. Based on the expansions presented in the figure, a total expansion limit of $0.04 \%$ is suggested. This limit is based on the tested samples only. An application of the test to more aggregates with other total sulphur contents is required.

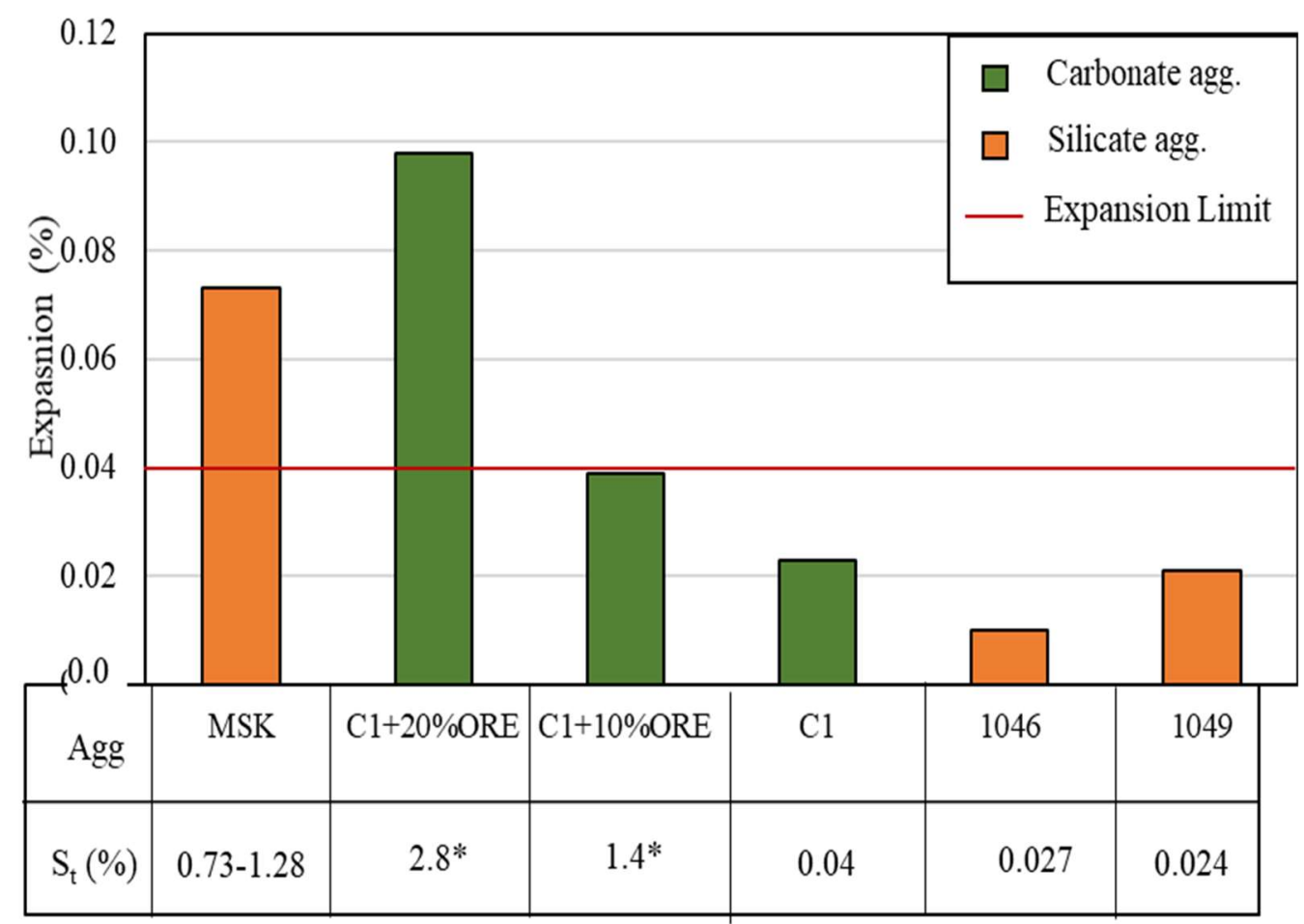

* calculated based on level of replacement of Ore

Figure 6.40. Total expansion of mortar bars soaked in lime water for three hours and stored at $40^{\circ} \mathrm{C} / 70 \% \mathrm{RH}$ and $5^{\circ} \mathrm{C} / 100 \% \mathrm{RH}$ in Phase I and Phase II, respectively 


\section{Chapter 7}

\section{Summary and Conclusions}

\subsection{Summary}

The originally suggested protocol (Annex P of CSA 23.1-19) investigated and optimized in this dissertation consists of three stages or tests:

- Stage 1: Chemical quantitative testing, where the total sulphur content in the aggregate should not exceed $0.15 \%$

- Stage 2: Oxygen consumption test (OCT) run on aggregates with total sulphur $>0.15 \%$, where the consumption should not exceed $4 \%$, and

- Stage 3: Oxidation mortar bar test, run on aggregates with OCT $>4.0 \%$, where the expansion in Phase II of the test should not exceed $0.10 \%$.

The investigated aggregates used here are all of known total sulphur contents. They include two aggregates known to have oxidizable sulphide content that can cause damage to concrete (MSK and 1052) and twenty-four aggregates are known to have no issues related to sulphide mineral oxidation. The last material is sulphide ore (Ore) with a total sulphur content of $14 \%$, which is used in this study as a source of sulphide minerals.

Although following the protocol will result in some aggregates passing the first two stages and not tested for all tests or stages, the three tests were applied to all the aggregates to check their applicability to a wide range of aggregate composition. The aim of the thesis was to evaluate the capacity of the tests to evaluate oxidation potential of the aggregates, suggest modifications to the current test methods and acceptance limits, and to develop a new OMBT based on the obtained results. Note that the first stage of the protocol (total sulphur testing) was not investigated here, as the chemical properties and total sulphur content of the aggregates were tested in an external lab.

The results of the oxygen consumption test indicated that contamination of the aggregates from 
the processing equipment can result in higher consumption values that are not related to aggregate oxidation. This contamination can be reduced by eliminating cast iron plates and using a jaw crusher with manganese plates (as these have higher abrasion resistance) and a disc pulverizer with ceramic plates. Moreover, aggregate size optimization indicated that processing the aggregate to a controlled size of $300 \mu \mathrm{m}$ to $75 \mu \mathrm{m}$ produced higher consumption than the size suggested in the original protocol, where all the samples passed size $150 \mu \mathrm{m}$ without controlling the minimum aggregate size. Hence, the oxygen consumption limit is suggested to be relaxed to $5 \%$ instead of $4 \%$, with the use of aggregate size from $300 \mu \mathrm{m}$ to $75 \mu \mathrm{m}$. It should be noted that the $5.0 \%$ limit was originally suggested by Rodrigues et al. (2016) Prior to adopting the protocol by Annex P of CSA 23.1-19.

Testing mortar bars with aggregates that have different physical and chemical compositions raised several concerns. The first major concern is the significant expansion in mortar bars with aggregates that have high silicate content but negligible total sulphur content that in some cases exceeds the $0.10 \%$ expansion limit in Phase II. A case in point is aggregate 1049 , due to the development of ASR products. A second concern is the marginal expansion of the sulphidebearing aggregates MSK and 1052 in Phase II, where they produced expansions of $0.105 \%$ and $0.11 \%$, respectively. To take into consideration the effect of silica and enhance the failure criteria of the sulphide-bearing aggregate, a new expansion limit criterion was suggested in this work. The first step was to investigate the expansions in Phase II, where mortar bars with expansions < $0.03 \%$ are considered safe for use in concrete. Aggregates with expansions greater than $0.03 \%$ are investigated for the ratio of the expansion in Phase II to Phase I, with a maximum ratio of $0.60 \%$ being suggested here. Aggregates with higher ratios are deemed not suitable for concrete or should be further investigated by other techniques including detailed petrography. Normalizing the 
expansions in Phase II to those in Phase I is to consider the effect of silicate. Figure 7.1 illustrates the testing protocol with the proposed modifications to the oxygen consumption test (OCT) limits and the suggested expansion criteria for the oxidation mortar bar test (OMBT). The OCT criteria used here is for the modified OCT with the aggregate size and processing procedures proposed and used in this thesis.

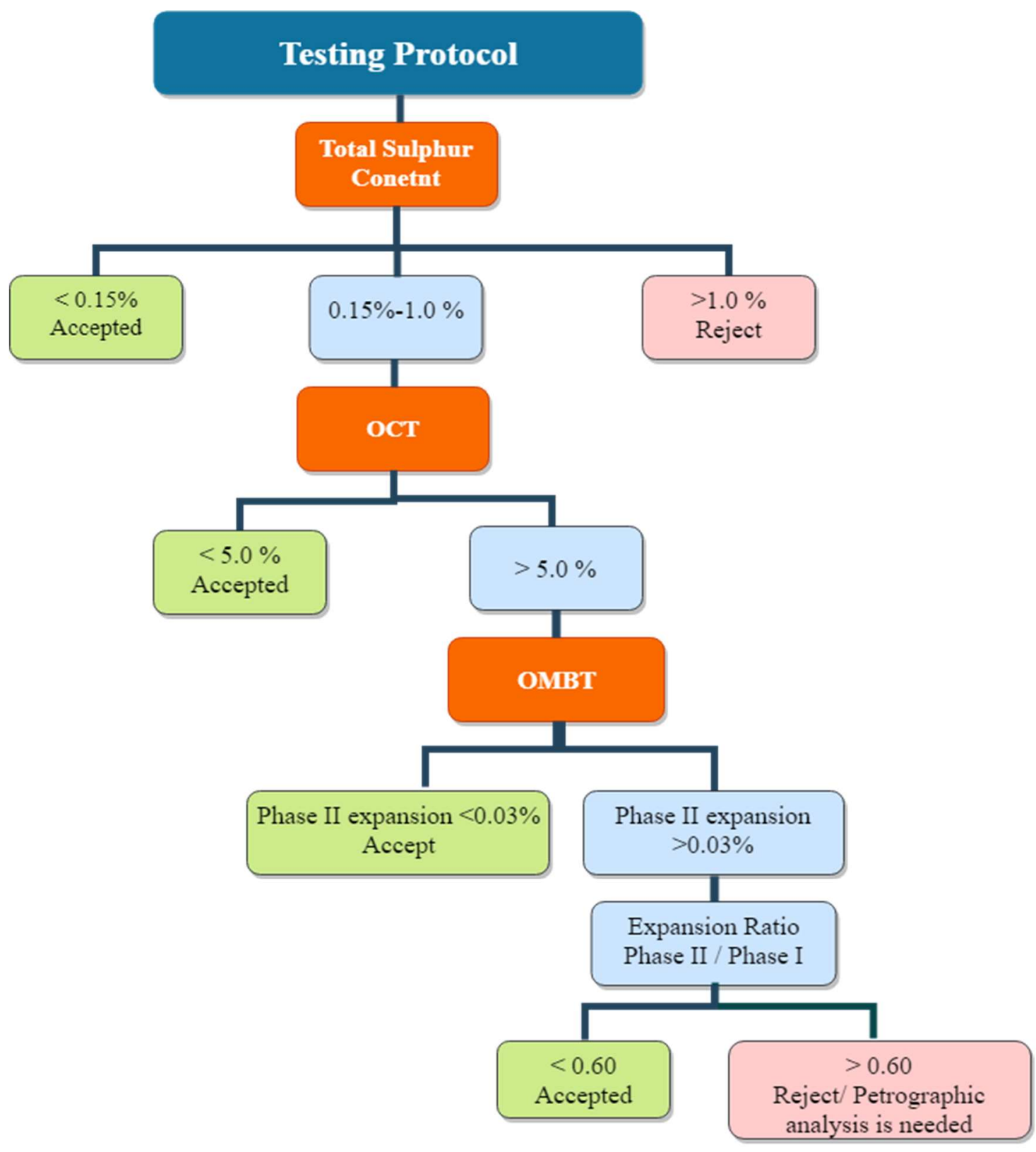

Figure 7.1. A modified protocol for evaluation of sulphide-bearing aggregate 
In order to avoid the limitations of the OMBT with siliceous aggregates, different testing regimes were investigated to find an exposure condition that can promote expansion due to sulphate attack and reduce the promotion of other products that may cause expansion (e.g. ASR products). Two of the tested exposure showed promising results that can help to identify sulphide-bearing aggregates.

Using sodium hypochlorite (household bleach) as the oxidizing agent was proposed in the original protocol to promote the oxidation of sulphide bearing aggregates. However, as mentioned earlier, some limitations appeared from the high storage temperature that promoted other products and affected the evaluation of the aggregates. Reducing the storage temperature in Phase I to be (21$23^{\circ} \mathrm{C}$ ) instead of $80^{\circ} \mathrm{C}$ produced better results (sub-section 6.1.1.1). During Phase I, the expansions were low for all the aggregates where oxidation took place in sulphide-bearing aggregates. Storage at $5^{\circ} \mathrm{C} / 100 \% \mathrm{RH}$ in Phase II promoted the expansions due to sulphate attack where only mortar bars with sulphide-bearing aggregates continued to expand as illustrated in Figure 6.1. As such, the first step in the proposed expansion limit criteria suggested for mortar bars soaked in bleach and stored at high temperature $80^{\circ} \mathrm{C}$ can be eliminated here, and only the ratio of expansions in Phase II/Phase I can be considered.

Using lime water as an oxidizing agent to avoid developing ASR products from the use of sodium hypochlorite at high storage temperature showed that, even without using bleach, high storage temperatures can still produce greater than expected expansions in silicate aggregates (Figure 6.9). Hence, the storage temperature was reduced to $40^{\circ} \mathrm{C} / 70 \% \mathrm{RH}$ in Phase I. Two exposures were investigated with these environmental conditions. In the first exposure, mortar bars were soaked for 3 hours, two times per week, and stored in the suggested conditions for 3.5 days (Figure 6. 11). In the second exposure, the mortar bars were soaked for 2-days and stored in the suggested 
conditions for 5 days, to investigate if longer soaking can promote more oxidation (Figure 6.18). Both soaking durations resulted in expansion behaviour that decreased with less total sulphur, and mortar bars with negligible total sulphur had low expansions. However, the more soaking cycles (two cycles of 3 hours per week) resulted in higher and accelerated expansion. Based on this analysis, the following testing procedure is suggested which involves testing three sets of mortar bars (three bars each):

(a) Phase I to week 13 (or 90 days) involves soaking the sample in lime water for three hours at room temperature, followed by placing the samples for 3.5 days in the oven at $40^{\circ} \mathrm{C}$ and $70 \%$ relative humidity.

(b) Phase II from week 14 to week 26 (another 90 days) involves placing mortar bar samples in lime water for three hours followed by 3.5 days in storage. Each set will be placed at different storage temperatures: i) in a fridge at $4^{\circ} \mathrm{C} / 100 \% \mathrm{RH}$, ii) at room temperature at $23^{\circ} \mathrm{C} / 100 \% \mathrm{RH}$, and iii) in an oven at $40^{\circ} \mathrm{C} / 70 \% \mathrm{RH}$. The different environmental conditions in Phase II are geared for optimum expansion.

From the interpretation of the results of the aggregate expansions, a total expansion limit of $0.04 \%$ is suggested. Aggregates that cause expansions beyond the limit are deemed not suitable for concrete. Further investigations and applications of the test on a wider range of aggregates with different chemical compositions are required.

Based on the results of mortar bars soaked in bleach and stored at room temperature in Phase I and mortar bars soaked in lime water and stored at $40^{\circ} \mathrm{C} / 70 \% \mathrm{RH}$ in Phase $\mathrm{I}$, the following testing regimes and expansion criteria are suggested: 
Table 7. 1. Expansion criteria for the developed new tests

\section{Exposure}

\begin{tabular}{|c|c|c|c|c|}
\hline \multirow{2}{*}{$\begin{array}{l}\text { Soaking } \\
\text { solution }\end{array}$} & \multirow[t]{2}{*}{ Duration } & \multicolumn{2}{|c|}{ Storage conditions } & \multirow{2}{*}{$\begin{array}{l}\text { Evaluation } \\
\text { criterion }\end{array}$} \\
\hline & & Phase I & Phase II & \\
\hline Bleach & 3 hours & $21-23^{\circ} \mathrm{C} / 70 \% \mathrm{RH}$ & $5^{\circ} \mathrm{C} / 100 \% \mathrm{RH}$ & $\begin{array}{l}\text { The ratio of } \\
\text { expansion in Phase } \\
\text { II/Phase I }<0.6\end{array}$ \\
\hline $\begin{array}{l}\text { Lime } \\
\text { water }\end{array}$ & 3 hours & $40^{\circ} \mathrm{C} / 70 \% \mathrm{RH}$ & $\begin{array}{l}\text { Three sets: } \\
\text { 1) } 5^{\circ} \mathrm{C} / 100 \% \mathrm{RH} \\
\text { 2) } 21-23^{\circ} \mathrm{C} / 100 \% \mathrm{RH} \\
\text { 3) } 40^{\circ} \mathrm{C} / 70 \% \mathrm{RH}\end{array}$ & $\begin{array}{l}\text { Total maximum } \\
\text { expansion }<0.04 \%\end{array}$ \\
\hline
\end{tabular}

Applying both tests on aggregates may be beneficial where aggregates that pass both tests are considered safe, aggregates that failed both tests are deemed not suitable for concrete. In the case of aggregates that pass one of the tests and fail the other, further petrographic analysis is needed. It should also be highlighted that the OMBT is the last stage of the three-stage protocol. Samples with negligible sulphides and total sulphur are likely to pass one of the two first tests $\left(\mathrm{S}_{\mathrm{t}}\right.$ and OCT) and may not need to be tested in the oxidation mortar bar test. Samples failing all the three protocol stages are recommended to go through further investigation, including a detailed petrographic examination to assess the form of sulphide. 


\subsection{Conclusions}

From the materials investigated in this study, the following conclusions are drawn:

1. The oxygen consumption test (OCT) is highly sensitive to contamination. Careful sample preparation and avoidance of the use of cast iron equipment is essential. Using a jaw crusher with manganese plates and a disc pulverizer with ceramic plates is recommended to reduce contamination.

2. Using a sample size of $300 \mu \mathrm{m}$ to $150 \mu \mathrm{m}$ (Sieve $\# 50$ to \#100) and $150 \mu \mathrm{m}$ to $75 \mu \mathrm{m}$ (Sieve $\# 100$ to \#200) at a ratio of 1:1 was found to produce higher oxygen consumption than finer samples passing $150 \mu \mathrm{m}$ (Sieve \#100). For this aggregate size - recommended in this dissertation - a maximum consumption limit is $5 \%$.

3. For the oxidization mortar bar test, the expansion is significantly affected by aggregate composition, not only its sulphide content. Aggregates with silicate are found to have greater expansion in both phases of the test, suggesting that having one absolute expansion limit for carbonate aggregates and aggregates with silicate is not possible. Aggregates that are known to be sulphide-bearing aggregates had a marginal expansion.

4. A two-step expansion criterion is suggested here in this study for the OMBT. The first step is to look at the absolute expansion in Phase II; if the maximum limit of $0.03 \%$ is not met, the second stage is to evaluate the ratio of expansion in Phase II to that in Phase I, with a 0.60 maximum limit. An expansion in Phase II of $0.04 \%$ and a ratio of Phase II to Phase I of 0.70 can also be used, but some of the sulphide-bearing aggregates will fail with marginal expansion just above the limits.

5. Using sodium hypochlorite as the oxidizing agent, but with storage temperature in Phase I 
lower than the conditions proposed in the original protocol $\left(23^{\circ} \mathrm{C} / 80 \% \mathrm{RH}\right)$, reduced the effect of the production of ASR products. With this test a ratio of expansion in Phase II to Phase I of 0.60 can be used as the limit.

6. Using a saturated lime solution as the oxidizing agent with lower storage temperatures produced greater expansion with silicate aggregates. Storing mortar bars at $40^{\circ} \mathrm{C} / 70 \% \mathrm{RH}$ in Phase I produced better results, with expansions increasing with more total sulphur and internal sulphate attack products being present.

7. For testing mortar with saturated lime solution, soaking mortar bars for a duration of three hours for two cycles per week produced accelerated expansion compared to one single cycle per week of two-day soaking duration.

8. For testing mortar with saturated lime solution, optimum storage environmental conditions in Phase II vary according to aggregate types, as aggregates with carbonates may require low temperature for the formation of Thaumasite, while aggregates with limited carbonate may require room or higher temperature to produce excessive ettringite. This requires testing different aggregates at different temperatures in Stage II of the test.

9. Two oxidation mortar bar tests are suggested from this work to distinguish between sulphidebearing aggregates and aggregates with no oxidation potential. The tests are suggested to replace Stage III of the testing protocol listed in Figure 7.1:

a) Using sodium hypochlorite as the soaking solution for 3 hours at room temperature followed by storing them at $21-23^{\circ} \mathrm{C}$ above water for 3.5 days in Phase I. In Phase II, the samples are soaked in sodium hypochlorite for 3 hours followed by storing them above water at $5^{\circ} \mathrm{C}$ for 3.5 days. The aggregate is deemed suitable for concrete if the ratio of Phase 
II to Phase I expansion is $\leq 0.60$.

b) Testing three sets of mortar bars ( 3 bars each) with 3 hours soaking in lime water and storing at $40^{\circ} \mathrm{C} / 70 \% \mathrm{RH}$ in Phase I for 3.5 days. In Phase II, each set of mortar bars should be placed in different condition $\left(5^{\circ} \mathrm{C} / 100 \% \mathrm{RH}\right.$ or $21-23^{\circ} \mathrm{C} / 100 \% \mathrm{RH}$ or $\left.40^{\circ} \mathrm{C} / 70 \% \mathrm{RH}\right)$. The aggregate is deemed suitable for use in concrete if the maximum total expansion is $\leq 0.04 \%$.

10. No appreciable expansions were recorded from the concrete prism testing regimes. However, some rust and pop-outs were observed. Further investigation is required with other exposure conditions. Additional concrete testing is currently underway at Ryerson University.

11. The results produced in this research are based on aggregates, mainly from Ontario. The main objective of the dissertation was to investigate the limitations of the testing protocol and to develop a new oxidation mortar bar test. More testing on aggregates from different locations are recommended to confirm the applicability of the test recommended here. 


\subsection{Recommendations for Future Work}

1. Quantitative analysis of sulphide sulphur should be investigated as the first step in the testing protocol as it is important for the determination of sulphides that are susceptible to oxidation.

2. For the OCT, although crushing the aggregates using the jaw crusher to a size of $1.18 \mathrm{~mm}$ can be achieved, it may be introducing some contamination to the aggregates. Crushing the aggregate to a size of $4.75 \mathrm{~mm}$ may reduce the contamination.

3. For the OCT, although using jaw crusher with manganese plates reduced the contamination from the abraded iron, it is recommended to avoid them as contamination from the manganese plates is still a possibility. In this case, non-metallic tools are recommended.

4. For the OMBT, the repeatability and the reproducibility of the new oxidation mortar bar test on more aggregates in different laboratory is important to establish precision statement and proposed limits.

5. For the OMBT, partial soaking of the bar may be helpful in the promotion of oxidation of sulphide bearing aggregates. In these cases, the bottom half of the bars can be soaked while the top bar not.

6. For OMBT, it is recommended to use calcium hypochlorite as oxidizing agent but with storing the mortar bars at room temperature in Phase I. 
7. It is recommended to conduct further investigation on the behaviour of SCM in reducing the expansion due to oxidation of sulphide minerals.

8. Testing aggregates with different geological formations and various ranges of total sulphur content is very important to confirm the proposed limits for both OCT and OMBT.

9. While testing of concrete prisms did not produce appreciable expansion, it is recommended to continue working on developing a test method for concrete. 


\section{References}

Al-Akhras, N. M., "Durability of metakaolin concrete to sulfate attack," Cement and Concrete Research, Vol. 36, No. 9, 2006, 1727-1734.

ASTM C150-18, "Standard specification for Portland Cement," 2018.

ASTM C192-10, "Standard practice for making and curing concrete test specimens in the laboratory," West Conshohocken (PA): ASTM International, 2010.

ASTM C490/C490M-17, "Standard Practice for Use of Apparatus for the Determination of Length Change of Hardened," Cement Paste, Mortar, and Concrete, 2017.

ASTM C641, "Test Method for Iron Staining Materials in Lightweight Concrete Aggregates," 2017

Bhatty, J. I., "A review of the application of thermal analysis to cement-admixture systems," Thermochemical Acta, Vol. 189, No. 2, 1991, pp. 313-350.

Belgeri J.J. and Siegel T.C., "Design and Performance of Foundations in Expansive Shale," Ohio River Valley Soils Seminar XXIV, Louisville, KY, Vol. 2, No. 6, 1998, pp. 2.

Belzile, N., Chen, Y.-W., Cai, M.-F., \& Li, Y., "A review on pyrrhotite oxidation," Journal of Geochemical Exploration, Vol. 84, No. 2, 2014, pp. 65-76.

Bensted, J., "Thaumasite-direct, woodfordite and other possible formation routes," Cement and Concrete Composites, Vol. 25, No. 8, 2003, pp. 873-877.

Binici, H., \& Aksoğan, O., "Sulfate resistance of plain and blended cement," Cement and Concrete Composites, Vol. 28, No. 1, 2006, pp. 39-46.

Bonen, D., \& Cohen, M. D., "Magnesium sulfate attack on portland cement paste-I. Microstructural analysis," Cement and Concrete Research, Vol. 22, No. 1, 1992, pp. 169-180. 
Brown, P. W., "Thaumasite formation and other forms of sulfate attack," Cement and Concrete Composites, Vol. 3, No. 24, 2002, pp. 301-303.

Bryant L., "Geotechnical Problems with Pyritic Rock and Soil," Doctoral dissertation, Virginia Tech, 2003.

Byerly, D. W., "Guidelines for handling excavated acid-producing materials," US Department of Transportation, Federal Highway Administration, 1990.

Casanova, I., Aguado, A., \& Agullo, L., "Aggregate expansivity due to sulfide oxidation-II. Physico-chemical modeling of sulfate attack," Cement and Concrete Research, Vol. 27, No. 11, 1997a, pp. 1627-1632.

Casanova, I., Aguado, A., \& Agullo, L., "Aggregate expansivity due to sulfide oxidation-II. Physico-chemical modeling of sulfate attack," Cement and Concrete Research, Vol. 27, No. 11, 1997b, pp. 1627-1632.

Chinchon J.S.; Ayora C.; Aguado A. and Guirado F., "Influence of Weathering of Iron Sulfides Contained in Aggregates on Concrete Durability," Cement and Concrete Research, Vol. 25, No. 6, 1995, pp.1264-1272.

Chinchón-Payá, S., Aguado, A., \& Chinchón, S., "A comparative investigation of the degradation of pyrite and pyrrhotite under simulated laboratory conditions," Engineering Geology, Vol. 127, 2012, pp. 75-80.

Cohen, M. D., \& Mather, B., "Sulfate attack on concrete: research needs," Materials Journal, Vol. 88 , No. 1, 1991, pp. 62-69.

Collepardi, M., "Thaumasite formation and deterioration in historic buildings," Cement and Concrete Composites, Vol. 21, No. 2, 1999, pp. 147-154.

Craig, J. R., \& Vokes, F. M., "The metamorphism of pyrite and pyritic ores: an overview," Mineralogical Magazine, Vol. 57, No. 386, 1993, pp. 3-18. 
Crammond, N. J., "The thaumasite form of sulfate attack in the UK," Cement and Concrete Composites, Vol. 25, No. 8, 2003, pp. 809-818.

CSA A23.1-19, "Concrete materials and methods of concrete construction/Test methods and standard practices for concrete," 2019.

CSA A23.2-25A-14, "Test Method for Detection of Alkali-Silica Reactive Aggregate by Accelerated Expansion of Mortar Bars," 2014.

Diamond, S., and Lachowski, E. E., "Investigation of the composition and morphology of individual particles of portland cement paste: 2. Calcium sulfoaluminates," Cement and Concrete Research, Vol. 13, No. 3, 1983, pp. 335-340.

Dougherty M. and Barsotti N., "Structural Damage and Potentially Expansive Sulfide Minerals," Bulletin of the Association of Engineering Geologists, Vol. 9, 1972, pp. 105-125.

Duchesne J. and Fournier B., "Deterioration of Concrete by the Oxidation of Sulphide Minerals in the Aggregate," Journal of Civil Engineering and Architecture, Vol. 7, No. 8, 2013, pp.922.

Elberling, B., Nicholson, R. V., Reardon, E. J., \& Tibble, R., "Evaluation of sulphide oxidation rates: A laboratory study comparing oxygen fluxes and rates of oxidation product release," Canadian Geotechnical Journal, Vol. 31, No. 3, 1994, pp. 375-383.

Fernández-Jiménez A. and Puertas F., "The Alkali-Silica Reaction in Alkali-Activated Granulated Slag Mortars with Reactive Aggregate," Cement and Concrete Research, Vol. 32, No. 7, 2002, pp.1019-1024.

Freeman, R. B., \& Carrasquillo, R. L., "Adjustments in Gypsum Content for Production of Sulphate-Resistant Blended Cements Containing High-Calcium Fly Ash," ACI Materials Journal, Vol. 92, No. 4, 1995, pp. 411-418.

Fu, Y., Ding, J., \& Beaudoin, J. J., "Expansion of portland cement mortar due to internal sulfate attack," Cement and Concrete Research, Vol. 27, No. 9, 1997, pp. 1299-1306. 
Glasser, F. P.,"The Stability of Ettringite. International RILEM TC 186-ISA Workshop on Internal Sulfate Attack and Delayed Ettringite Formation," 22. Villars, Switzerland, 2002

Grabowski, E., Czarnecki, B., Gillott, J. E., Duggan, C. R., \& Scott, J. F., "Rapid Test of Concrete Expansivity Due to Internal Sulfate Attack," ACI Materials Journal, Vol. 89, No. 5, 1992.

Grattan-Bellew, P. E., Beaudoin, J. J., \& Vallée, V.-G., "Effect of aggregate particle size and composition on expansion of mortar bars due to delayed ettringite formation," Cement and Concrete Research, Vol. 28, No. 8, 1998, pp. 1147-1156.

Guirguis B. and Shehata M.H., "A New Screening Test to Evaluate the Presence of Oxidizable Sulphide Minerals in Coarse Aggregates," Construction and Building Materials. Vol. 154, 2017, pp.1096-1104.

Guirguis B.; Shehata M.H.; Duchesne J.; Fournier B.; Durand B. and Rivard P., "The Application of a New Oxidation Mortar Bar Test to Mixtures Containing Different Cementing Systems," Construction and Building Material. Vol. 173, 2018, pp.775-785.

Guirguis B., "Test Methods for Evaluating the Oxidization Potential of Sulphide -Bearing Aggregates and its Effects on Concrete Durability," Ph.D. dissertation, Ryerson University, Toronto, Canada, 2017:241.

Hansen, W. C., "Crystal growth as a source of expansion in Portland cement concrete," Proc. ASTM, 63, 1963, pp. 932-945.

Hansen, W. C. "Attack on Portland Cement Concrete by Alkali Soils and Waters-A Critical Review," Highway Research Record, 1966, 113.

Hawkins A.B. and Pinches G.M., "Understanding Sulphate Generated Heave Resulting from Pyrite Degradation," Ground Chemistry Implications for Construction. Rotterdam, Netherlands; 1997, pp. 51-75.

Heinz, D., \& Ludwig, U., "Mechanism of secondary ettringite formation in mortars and concretes subjected to heat treatment," Special Publication, 100, 1987, pp. 2059-2072. 
Herrero, J., Artieda, O., \& Hudnall, W. H., "Gypsum, a Tricky Material," Soil Science Society of America Journal, Vol. 73, No. 6, 2009, pp.1757.

Hooton, R. D., Nokken, M., \& Thomas, M. D., Portland-limestone cement: state-of-the-art report and gap analysis for CSA A 3000," Report prepared for St. Lawrence Cement, 2007.

Irassar, F., \& Batic, O., Effects of low calcium fly ash on sulfate resistance of OPC cement," Cement and Concrete Research, Vol. 19, No. 2, 1989, pp.194-202.

Jones, C. F., LeCount, S., Smart, R. S., \& White, T. J., Compositional and structural alteration of pyrrhotite surfaces in solution: XPS and XRD studies," Applied Surface Science, Vol. 55, No. 1, 1992, pp. 65-85.

Jones, F. E., The calcium aluminate complex salts," Proceeding of the Symposium on the Chemistry of Cements, 231. Stockholm, 1938

Kakali, G., Tsivilis, S., Skaropoulou, A., Sharp, J. H., \& Swamy, R. N., Parameters affecting thaumasite formation in limestone cement mortar," Cement and Concrete Composites, Vol. 25, No. 8, 2003, pp. 977-981.

Köhler, S., Heinz, D., \& Urbonas, L., Effect of ettringite on thaumasite formation," Cement and Concrete Research, Vol. 36, No. 4, 2006, pp. 697-706.

Kosmatka, S. H., Kerkhoff, B., \& Panarese, W. C., "Design and Control of Concrete Mixtures. Portland Cement Association, 2002

Kuzel, H. J., "Initial hydration reactions and mechanisms of delayed ettringite formation in Portland cements", Cement and Concrete Composites, Vol. 18, No. 3, 1996, pp.195-203.

Lawrence, C. D., "Long-term expansion of mortars and concretes", Special Publication, Vol. 177, 1999, pp.105-124.

Lukas, W., "Substitution of Si in the lattice of ettringite," Cement and Concrete Research, Vol. 6, No. 2, 1976, pp. 225-233. 
Macphee, D., \& Diamond, S., "Thaumasite in cementitious materials, " Cement and Concrete Composites, Vol. 8, No. 25, 2003, pp. 805-807.

Mather, B., "Discussion of "The Process of Sulfate Attack on Cement Mortars" by Shen Yang, Xu Zhongzi, and Tang Mingshu," Advanced Cement Based Materials, Vol. 5, No. 3-4, 1997, pp. 109110.

Mehta, P., "Sulfate attack on concrete-a critical review, " Materials Science of Concrete III, 1992, pp. 105 .

Mehta, P. K., "Effect of Fly Ash Composition on Sulfate Resistance of Cement, " ACI Journal Proceedings, Vol. 83, No. 6, 1986.

Midgley, H. G., "The staining of concrete by pyrite, " Magazine of Concrete Research, Vol. 10, No. 29, 1958, pp. 75-78.

Monteny J.; Vincke E. and Beeldens A., "Chemical, Microbiological, and in Situ Test Methods for Biogenic Sulfuric Acid Corrosion of Concrete," Cement and Concrete Research, Vol. 30, No. 4, 2000, pp. 623-634.

Morsy, M. S., Al-Salloum, Y. A., Abbas, H., \& Alsayed, S. H., "Behavior of blended cement mortars containing nano-metakaolin at elevated temperatures," Construction and Building Materials, Vol. 35, 2012, pp. 900-905.

Neville, A. "The confused world of sulfate attack on concrete," Cement and Concrete Research, Vol. 34, No. 8, 2004, pp. 1275-1296.

Neville, A. M., "Properties of concrete," Pearson Education India, 1963.

Nielsen, J., "Investigation of resistance of cement paste to sulfate attack," Highway Research Record, Vol. 113, 1966, pp. 114-117.

Nordstorm D.K. and Alpers C.N., "Geochemistry of Acid Mine Waters," The environmental geochemistry of mineral deposits, Vol. 6, 1999, pp.133-160. 
Orndorff Z.W., "Evaluation of Sulfidic Materials in Virginia Highway Corridors," Doctoral dissertation, Virginia Polytechnic Institute and State University, Blacksburg, Virginia. 2002.

Penner, E., Eden, W. J., \& Grattan-Bellew, "P. E., Expansion of pyritic shales, " Canadian Building Digest, Vol. 152, 1972, pp.1-4.

Ramlochan, T., "The effect of pozzolans and slag on the expansion of mortars and concrete cured at elevated temperature", (Doctoral dissertation). University of Toronto, 2003.

Ramos, V., Rodrigues, A., Fournier, B., \& Duchesne, J., "Development of a quick screening staining test for detecting the oxidation potential of iron sulfide-bearing aggregates for use in concrete, " Cement and Concrete Research, Vol. 81, 2016, pp. 49-58.

Rodrigues A.; Duchesne J. and Fournier B., "A New Accelerated Mortar Bar Test to Assess the Potential Deleterious Effect of Sulfide-Bearing Aggregate in Concrete," Cement and Concrete Research. Vol. 73, 2015, pp. 96-110.

Rodrigues A.; Duchesne J. and Fournier B., "Quantitative Assessment of the Oxidation Potential of Sulfide-Bearing Aggregates in Concrete Using an Oxygen Consumption Test," Cement and Concrete Composite, Vol. 67, 2016, pp. 93-100.

Rodrigues A.; Duchesne J.; Fournier B.; Durand B.; Rivard P. and Shehata M., "Mineralogical and Chemical Assessment of Concrete Damaged by the Oxidation of Sulfide-Bearing Aggregates: Importance of Thaumasite Formation on Reaction Mechanisms," Cement and Concrete Research, Vol. 42, No. 10, 2012, pp. 1336-1347.

Rodrigues A.; Duchesne J.; Fournier B.; Durand B.; Shehata M.H. and Rivard P., "Evaluation Protocol for Concrete Aggregates Containing Iron Sulfide Minerals," ACI Material Journal Vol.113, No. 3, 2016, pp.349

Schmidt, T., Leemann, A., Gallucci, E., \& Scrivener, K., "Physical and microstructural aspects of iron sulfide degradation in concrete, " Cement and Concrete Research, Vol. 41, No. 3, 2011, pp. 263-269. 
Seaton S.G., "Study of Causes and Prevention of Staining and Pop-Outs in Cinder Concrete," In Journal Proceedings, Vol. 44, No. 1, 1948, pp. 361-378.

Shehata, M. H., Adhikari, G., \& Radomski, S., "Long-Term Durability of Blended Cement Against Sulfate Attack, " ACI Materials Journal, Vol. 105, No. 6, 2008.

Shi, C., Wang, D., \& Behnood, A., "Review of Thaumasite Sulfate Attack on Cement Mortar and Concrete,". Journal of Materials in Civil Engineering, Vol. 24, No. 12, 1450-1460.

Simonds K. and Epstein I., "Sulfate Attack on Concrete"; 2002.

Skalny, J., "Internal sulfate attack - points of agreement and disagreement, " International RILEM Workshop on Internal Sulfate Attack and Delayed Ettringite Formation, 2004, pp.265-276.

Skalny, J., Marchand, J., \& Odler, I., "Sulfate attack on concrete, " London; New York: Spon Press. 2003.

Skousen, J. G., Sexstone, A., \& Ziemkiewicz, P. F., "Acid mine drainage control and treatment. Reclamation of drastically disturbed lands", American Society of Agronomy and American Society for Surface Mining and Reclamation., 2000, pp. 1-42.

Smallwood, I., Wild, S., \& Morgan, E., "The resistance of metakaolin (MK)-Portland cement (PC) concrete to the thaumasite-type of sulfate attack (TSA) - Programme of research and preliminary results, " Cement and Concrete Composites, Vol. 25, No. 8, 2003, pp. 931-938.

Stark, J., \& Bollmann, K., "Delayed Ettringite Formation in Concrete", Nordic Concrete ResearchPublications, Vol. 23, 2000, pp. 4-28.

Sylla, H. M., "Reactions in cement stone due to heat treatment", Benton, Vol. 38, No. 11, 1988, pp. $449-454$.

Thomas, M. D. A., Shehata, M. H., Shashiprakash, S. G., Hopkins, D. S., \& Cail, K., "Use of ternary cementitious systems containing silica fume and fly ash in concrete, "Cement and Concrete Research, Vol. 29, No. 8, 1999, pp. 1207-1214. 
Tian, B., \& Cohen, M. D., "Does gypsum formation during sulfate attack on concrete lead to expansion?", Cement and Concrete Research, Vol. 30(1), 2000, pp.117-123.

Tikalsky, P. J., "Influence of Fly Ash on the Sulphate Resistance of Concrete", ACI Material Journal, Vol. 89, No. 1, 1992, pp. 69-75.

Tikalsky, P. J., "Fly Ash Evaluation and Selection for Use in Sulfate-Resistant Concrete, " $A C I$ Materials Journal, Vol. 90, No. 6, 1993, pp. 545-551.

Topçu, İ. B., \& Bilir, T., "Effects of slag fineness on durability of mortars, " Journal of Zhejiang University-SCIENCE A, Vol. 8, No. 11, 2007, pp. 1725-1730.

Wedding, P., \& Dunstan, E., "A Possible Method for Identifying Fly Ashes That Will Improve the Sulfate Resistance of Concretes, " Cement, Concrete and Aggregates, Vol. 2, No. 1, 1980, pp. 2031.

Xu, L., Wang, P., \& Zhang, G., "Formation of ettringite in Portland cement/calcium aluminate cement/calcium sulfate ternary system hydrates at lower temperatures, "Construction and Building Materials, Vol. 31, 2012, pp. 347-352.

Yazıc1 H., "The Effect of Steel Micro-Fibers on ASR Expansion and Mechanical Properties of Mortars," Construction and Building Material, Vol. 30, 2012, pp. 607-615. 